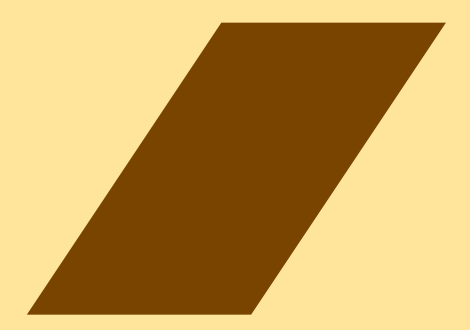

\title{
피:|R|P|TEIAN
}

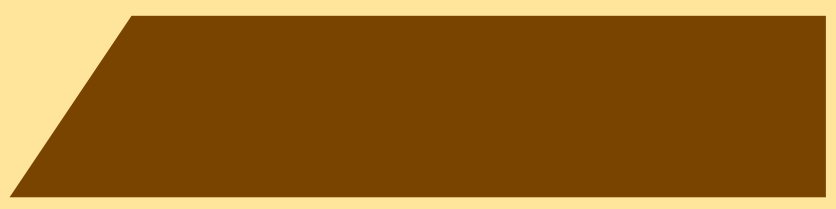

9 LOS SERVICIOS SOCIALES FRENTE A LA EXCLUSIÓN 27 ESTRATEGIA EUROPA 2020 E INCLUSIÓN SOCIAL: DISTANCIAMIENTO CRECIENTE ENTRE OBJETIVOS, POLITICAS E INSTRUMENTOS 49 AKTIBAZIOA ETA GIZARTERATZEKO ESKUBIDEA, EAE-KO ENPLEGUKO ETA DIRU-SARRERAK BERMATZEKO POLITIKEN ESPARRUAN 67 LAS EMPRESAS DE INSERCIÓN SOCIAL EN UN CONTEXTO DE CAMBIOS SOCIOLABORALES. UN ANÁLISIS CRÍTICO DE SU REGULACIÓN DESDE LA NORMATIVA VASCA Y ESTATAL 83 LA MEDIDA DE LA EMPLEABILIDAD EN LAS EMPRESAS DE INSERCIÓN EN EL PAIIS VASCO: DE LA EXCLUSIÓN A LA INSERCIÓN SOCIOLABORAL 95 LA IDENTIDAD PROFESIONAL DE LOS TRABAJADORES SOCIALES COMO ELEMENTO CLAVE EN EL ACCESO A LOS PROGRAMAS DE RENTAS MÍNIMAS: EL CASO DE CATALUNYA 107 REVISIÓN DE ESTUDIOS DE COSTEEFECTIVIDAD EN SERVICIOS DE ATENCIÓN COMUNITARIA Y ATENCIÓN CENTRADA EN LA PERSONA 119 ENVEJECIMIENTO Y DETERIORO DE LAS PERSONAS CON DISCAPACIDAD INTELECTUAL DE LANTEGI BATUAK EN EL ÁMBITO OCUPACIONAL Y DEL EMPLEO EN BIZKAIA 137 TENDENCIAS, INNOVACIONES Y BUENAS PRÁCTICAS INTERNACIONALES EN EL ÁMBITO DEL VOLUNTARIADO 

social. Se dirige a todos los agentes involucrados en este ámbito -profesionales, responsables institucionales, investigadores/as, voluntariado y usuarios/as- y tiene como objetivo contribuir al debate sobre la mejora de las políticas y los servicios sociales. Su periodicidad es semestral y se edita tanto en papel como en formato electrónico.

\begin{abstract}
Las colaboraciones publicadas en esta revista con la firma de sus autores expresan la opinión de éstos y no necesariamente la de Zerbitzuan o la del SIIS.
\end{abstract}

PRODUCE

SIIS Centro de Documentación y Estudios

SIIS Dokumentazio eta lkerketa Zentroa

Fundación Eguía Careaga Fundazioa

General Etxague 10 bajo

20003 Donostia

Tel. 943423656

Fax 943293007

www.siis.net

publicaciones@siis.net

CONSEJO DE REDACCIÓN

Edorta Azpiazu

Maite Etxabe

Iñaki Heras

Elena Martín Zurimendi

Jesus Otaño

Arantxa Rodríguez Berrio

Luis Sanzo

Ramón Saizarbitoria

Helena Sotelo

Joseba Zalakain

EDITA

Eusko Jaurlaritzaren Argitalpen

Zerbitzu Nagusia

Servicio Central de Publicaciones del

Gobierno Vasco

Donostia-San Sebastián, 1

01010 Vitoria-Gasteiz

(c) Administración de la Comunidad Autónoma del País Vasco

Departamento de Empleo

y Asuntos Sociales

DISEÑO

Estudio Lanzagorta

MAQUETACIÓN

Concetta Probanza

IMPRESIÓN

Depósito Legal: SS-101/86

ISSN: 1134-7147

http://dx.doi.org/10.5569/1134-7147/51

(B) SIIS Centro de Documentación

y Estudios de la Fundación

Eguía-Careaga

Está permitida la reproducción total o parcial por cualquier medio de los artículos contenidos en esta revista, siempre que se cite la fuente y el autor o autores de los mismos.

Aldizkaria honako datu-baseetan

zerrendatuta dago:

Esta revista está incluida en las

siguientes bases de datos:

- Dialnet, DOAJ, IN-RECS, ISOC, Latindex,

MIAR, Inguma. 


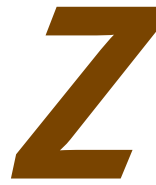

erbitzuan aldizkariaren ale hau osatzen duten bederatzi artikuluen artean, funtsezko zatia hartzen dute gizarteratzearen alorreko erronkek, eta, bereziki, aktibazioaren aldeko politika eta, gaur eguneko ekonomia-krisialdi betean eta langabezia hazten ari den testuinguruan, lan-merkaturatzea eta gizarteratzea aldezten duten politikek. Horietako bi artikuluetan -Aguilar, Llobet eta Pérez Eransus; eta Cortinas Muñoz-, berariaz aztertzen da gizartezerbitzuen betebeharreko rola eta gaur egun betetzen duten rola, eta xeheki aztertu dituzte gizarte-bazterketari aurre hartzeko oinarrizko gizartezerbitzuak. Beste bi artikuluetan -Llinares, Córdoba y Zácares; eta Martínez Morales, Bernad eta Navas-, gizarteratzeko enpresen kudeaketa eta erregulazioaren gaia aztertzen da; eta gizarteratzeko Europako 2020 estrategia aztertzen da Fresno, Renes eta Tsolakis egileen artikuluan.

Maila teorikoago batean, gizarte-bazterketa xede hartzen da SIIS Dokumentazio eta Ikerketa Zentroak diru-sarrerak bermatzeko errenta eta enpleguaren esparruko gizarteratze aktiboko paradigmaren ezartzeaz idatzitako artikuluan. Bertan laburtzen da aurretik Eusko Jaurlaritzaren Enplegu eta Gizarte Gaietako Sailaren aginduz SIISek eginiko azterlan zabalago bat. Txosten horren xedea izan da gizarteratzeko diru-sarrerak bermatu eta enplegurako kudeaketaren aktibazioaren kontzeptua ezartzean eman beharreko gogoeta teorikoari ildoak proposatzea, betiere baliabide gerta daitezen Lanbideren esku-hartzeko ereduaren esparru kontzeptual eta filosofikoa aberasteko. Txosten horrek testuinguruan kokatu nahi du EAEn aktibazioaren paradigmaren teoria-esparruan garatzen ari den aldaketa-prozesua, eta, gogoeta hori oinarri harturik, herritar guztien eskubideak errespetuz hartuko dituen esku-hartzeko eredu bat proposatu nahi da diru-sarrerak bermatzeko prestazioak jasotzen dituzten pertsonak aktibatzeko politiken alorrean.

Hori guztia lortzeko, txostenak eskaintzen du gure inguruneko herrialdeetako aktibaziorako politiken osoko ikuspegi bat, gutxienez 1980. hamarkadatik, eta bertan jasotzen da egile askoren esanean Ongizate Estatuaren eredu tradizionalarekiko gertatutako paradigma-aldaketaren berri. Aktibazioaren

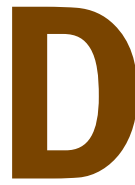
e los nueve artículos que conforman esta entrega de Zerbitzuan, una parte muy sustancial de ellos está relacionada con los retos que plantea la inclusión social y, muy particularmente, con las políticas de activación y de inclusión sociolaboral, en un momento de profunda crisis económica y de incremento del desempleo. Dos de esos artículos -el de Aguilar, Llobet y Pérez Eransus; y el de Cortinas Muñozhacen referencia específica al papel que deberían jugar, y al que juegan en la actualidad, los servicios sociales y, más concretamente, los servicios sociales de base, en la lucha contra la exclusión. Otros dos artículos -el de Llinares, Córdoba y Zácares, y el de Martínez Morales, Bernad y Navas- se centran, por su parte, en la gestión y la regulación de las empresas de inserción, mientras que el artículo de Fresno, Renes y Tsolakis analiza, con una mirada crítica, la estrategia europea 2020 para la inclusión social.

Desde una perspectiva algo más teórica, también se centra en el ámbito de la exclusión el artículo elaborado por el SIIS Centro de Documentación y Estudios en torno a la aplicación del paradigma de la inclusión activa en el marco de las políticas de garantía de ingresos y de empleo en Euskadi. El artículo resume un trabajo más amplio desarrollado por el SIIS, a instancias del Departamento de Empleo y Asuntos Sociales del Gobierno Vasco. El objetivo de ese informe era el de proponer una serie de líneas de reflexión, de carácter teórico, sobre la aplicación del concepto de activación a la gestión de las políticas de garantía de ingresos y de empleo, que sirva de marco conceptual y filosófico al modelo de intervención de Lanbide. El informe pretende contextualizar el proceso de cambio que se está desarrollando en la CAPV en el marco teórico desarrollado en torno al paradigma de la activación y, a partir de esa reflexión, proponer un modelo de intervención, en el ámbito de la activación de las personas perceptoras de prestaciones de garantía de ingresos, respetuoso con los derechos de toda la ciudadanía.

Para ello, el informe ofrece una descripción global de las políticas de activación introducidas en los países de nuestro entorno desde, al menos, la década de 1980 , y consideradas por numerosos autores como un cambio de paradigma en relación al modelo 
paradigmari egozten zaizkion ezaugarri, gure inguruneko herrialdeetan ezarritako modu eta haustura edota jarraipena gertatu ote denaz azalpenak bildu ostean, txostenak nahiko xeheki aztertzen ditu eredu horren aurka egindako kritika nagusiak; betiere, ebaluatu ahal izateko gure ingurunean ezartzean zein modutan eginbeharraz eta ikuspegi filosofiko egoki batetik ezartzeko egokitasunaz.

Gogoeta horiek guztiak oinarri, SIISek eginiko lan horretan biltzen dira EAEko testuinguruan aktibazioaren politiken maila teorikoari eginbeharreko ekarpenak, eta proposatzen dira EAEko gizarteratze aktiboaren ereduak beharreko lituzkeen ezaugarriak.

Zeintzuk dira oinarri teoriko horiek? Txostenak aldezten du lehenik, egungo araudia kontuan hartuz (EAEn pobreziari aurre egiteko politiken hastapenetatik egin bezala), enpleguaren erdiz erdiko garrantzia aitortzea gizarteratzean lehenetsitako mekanismo gisara. Enplegu ezegonkorraren hedatzeak enpleguaren gizarteratzeko ahalmena urritzean izandako benetako eragina eta betiere gizarteratzea lanaren bidez ez dela gertatzen aitortu arren, bertan aldezten den ereduak gaur eguneko gizarteratzeko oinarrizko mekanismo gisara hartzen du enplegua, banakoaren nahiak landu eta pobreziari aurre egitean babes gertarazteko. Bertan aldezten den ereduaren bigarren oinarriko osagaia da eskubide bikoitzaren printzipioa modu eraginkor batean gauzatzea, izan ere, gizarte-bazterketa pairatu edota pairatzeko arriskuan dagoenari aitortu behar zaio eskubidea kalitatezko laguntza jasotzeko eta bai laneratze, gizarteratze edota enplegagarritasunean hobetzearren, adibidez, baliabide propioak urriak gertatzen direnean oinarrizko errenta jasotzeko eskubidea. Ereduak oinarri hartzen du modu eraginkorrean herritarrentzat bi eskubide horiek aitortu eta eskubide biak ere betetzeko beharrezko gerta daitezkeen baliabide horiek guztiak egokitzea.

Proposamen horretan eguneratzen da, baita ere, baldintzazkotasunaren kontzeptua, eta, behin eta berriz, herritarren eskubide eta betekizunen garrantzia aipatzen duen kontzeptu horren irakurketa progresista batetik hartzen da kontzeptu hori. Horrela, bertan aldezten den ereduaren arabera, ikuspegi etiko batetik norbanakoaren autonomia oinarri hartzen da diru-sarrerak bermatzeko eskubidean, eta horren ondorioz, herritar batzuek ezin dute beste herritarrentzat zama izan, ahal duten heinean, behintzat; eta, arrazoi horiengatik guztiengatik, ahal izanez gero, ezin dute saihestu besteek egiten duten komunitatearen iraunkortasunaren aldeko ahalegina, eta arrazoizko ekarpenak egin behar dituzte, ahal den heinean, guztien ongia hobetzeko bai eskubide bai betebeharrak ezarritako sistema baten esparruan. Aldi berean, kontuan hartzen da arrazoizko ahaleginak egin behar dituztela prestazio ekonomikoak jasotzen dituztenek, prestazio horiek jasotzea justifikatzen duten behar-egoera horietatik aldentzeko. Lan-eremuko betebeharren arloan, baldintzazkotasun-printzipioaren bidezkotasuna oinarritzen da banaketa-justiziari loturiko elkarrekikotasunaren tradicional de Estado del bienestar. Una vez presentadas las principales características que se le atribuyen al paradigma de la activación, la forma en la que sido introducido en los países de nuestro entorno y lo que representa de ruptura, o de continuidad, con los enfoques tradicionalmente aplicados en la CAPV, el informe repasa con cierto detalle las principales críticas que se le han hecho, al objeto de evaluar en qué medida se trata de un modelo aplicable a nuestro entorno y/o en qué condiciones debería aplicarse para resultar adecuado desde un punto de vista filosófico o conceptual.

A partir de esas reflexiones, el trabajo realizado por el SIIS plantea las bases teóricas en las que deberían sustentarse las políticas de activación en el contexto de la CAPV, y propone las características que debería tener un modelo inclusivo de activación en la CAPV.

¿Cuáles son esas bases teóricas? El informe apuesta en primer lugar, y de acuerdo con la normativa actual (y con la que desde el inicio de las políticas de lucha contra la pobreza se ha establecido en la (APV) por reconocer la centralidad del empleo como mecanismo prioritario de inclusión social. Efectivamente, aun reconociendo la erosión que la extensión del empleo precario ha provocado en la capacidad inclusiva del empleo, y el hecho de que no siempre la inclusión social pasa necesariamente por la inclusión laboral, el modelo que se propugna parte de la base de que el empleo constituye en nuestros días un mecanismo esencial de inclusión social, de realización personal y de protección contra la pobreza. Un segundo elemento básico del modelo que se propugna es la materialización efectiva del principio de doble derecho, en el sentido de que debe reconocerse a las personas en situación o riesgo de exclusión social tanto el derecho a recibir apoyos de calidad para la inserción social y laboral y para la mejora de la empleabilidad, como el derecho a la percepción de una renta mínima adecuada en caso de insuficiencia de recursos propios. El modelo parte de la necesidad de reconocer de forma efectiva ambos derechos y de poner los medios necesarios para que ambos, y no sólo uno de ellos, puedan ser ejercidos por la ciudadanía.

La propuesta actualiza, por otra parte, el concepto de condicionalidad a partir de una lectura progresista, que insiste tanto en los derechos como en los deberes de la ciudadanía. Así, en el modelo que se propugna, el derecho a la garantía de ingresos se basa en una interpretación en clave ética de la autonomía individual, en virtud de la cual todas las personas deben contribuir razonablemente, en la medida de sus posibilidades, a la construcción del bien común en el marco de un sistema que establece tanto derechos como deberes a toda la ciudadanía. Al mismo tiempo, se considera que las personas perceptoras de prestaciones económicas asistenciales deben realizar los esfuerzos razonablemente posibles para salir de la situación de necesidad que justifica la percepción de esas prestaciones. La legitimidad del principio de condicionalidad aplicado a las obligaciones laborales parte de una noción de la 
ideian, hau da, gizarte-produktuaren onura nahitara jasotzen duen orok hartzen du komunitatearentzako ordezko produkzio-ekarpen baten betekizuna, betiere arrazoizko neurrian eta proportzionalki.

Guztien ongiari ekarpena egiteko betekizuna bidezko elkarrekikotasunaren azpian dagoen arren, ezin da, ordea, ezartzen den testuinguru sozioekonomikotik aldendu, hau da, konkretuki gauzatzen den ondasun eta aukeren banaketaren esparrua kontuan hartu beharra. Beraz, kolektibitateak begirunez hartzen dituen berdintasuna, birbanaketa eta gizartejustiziaren irizpide batzuen mende dago aktibazioaren atzetik dagoen kontratu-mekanismoaren legezkotasun-maila. Ikuspegi horretatik, elkarrekikotasunaren kontzeptua nabarmentzen du administrazio publikoak eta, oro har, gizarteak aukeraberdintasunaren, birbanaketa eta enpleguaren kalitatearen inguruan oinarriko gutxiengo batzuek errespetatzea.

Horrek guztiak konpromiso bikoitza eskatzen du, hau da, batetik, pertsonek berauek hartzen dute langabetu edota bazterketa egoeratik hobetzeko konpromisoa eta, ahal den heinean, guztion ongiari ekarpen produktiboa egitea; eta, bestetik, gizartea arduratzen da beharra duenari diru-sarrerak bermatzeko errenta eman eta gizarteratzerako eskaintza eginez, eta arrazoizko testuinguru sozioekonomiko bat bermatuz.

Bestetik, aipatutako printzipioekin bat eginez, bertan aldezten den gizarteratze aktiborako eredua interpretatzeko enplegagarritasunaren kontzeptu zabala oinarri hartzen da bai norbanakoen trebezia eta ezaugarriak lan-merkaturatzeko egokitzen bai enpleguaren eskari agregatua eta lan-merkatuko baldintzak nabarmentzen. Modu berean, bertan aldezten den ereduan azpimarratzen da making work pay edota enpleguaren errentagarritasunaren aldeko politiken garapenaren beharra, betiere, lan-merkaturatzeari eraginez eta, gehienbat, dirusari apalak jasotzen dituztenei diru-sarrerak haztaraziz, eta horrelako enpleguen gizarteratzeko gaitasuna indartuz. Horrelako neurriak ezartzeko aldatu egin behar da logika bai kontzeptualki bai diru-sarrerak bermatzeko politiken diseinuan, ordezkatze-logika baten beharrean osagarri diren errenta batzuen sistema ezartzeko.

Dokumentuan garatu den ereduak gizarte-bazterketa kausa anitzekotzat hartzen du azalpenerako, eta aurre egiteko soilik dimentsio anitzetako gizarteratzearen kontzepzio bat hartu behar da, ez soilik lan-merkatuan zentratua (nahiz eta, aurretik aipatu den moduan, lana izan gizarteratzeko eta pobreziari kontra egiteko oinarriko mekanismoa). Hori dela-eta, egokia litzateke gizarteratze-prozesuetan enplegagarritasuna edota lanaren kontzepzio zabalago bat izateko aukeraz jardutea, ohiko ordaindutako enpleguaren ereduaz gain, bestelako ekarpenak ere aintzat hartzea, adibidez, ekintza boluntarioa edota etxekoen zaintza. Gizarteratzearen kontzeptua aplikatzean, ezgaitasunaren eredu sozialaren ildo beretik, bestelako inplikazio bat gertatzen da, izan ere, pertsonak lan-merkatuaren beharretara egoki- justicia distributiva basado en la idea de la reciprocidad: todo aquel que voluntariamente se beneficie del producto social asume el correspondiente deber de realizar a cambio una contribución productiva, razonable y proporcional, a la comunidad.

La obligación de realizar alguna aportación al bien común que subyace al principio de reciprocidad no puede, sin embargo, establecerse al margen del contexto socioeconómico en el que se aplica, del marco concreto de distribución de los bienes y las oportunidades en el que se materializa. La legitimidad del mecanismo contractual que subyace a la activación depende, por tanto, de la medida en la que colectividad respeta unos criterios básicos de igualdad, redistribución y justicia social. Desde ese punto de vista, el concepto de reciprocidad justa subraya la necesidad de que, para poder aplicar legítimamente el principio de condicionalidad antes señalado, desde las administraciones públicas y desde el conjunto de la sociedad, se respeten unos mínimos básicos en términos de igualdad de oportunidades, redistribución y calidad en el empleo.

Todo ello exige un doble compromiso: el que asumen las personas en situación de desempleo o exclusión para la mejora de su situación y para la realización, en la medida de sus posibilidades, de una aportación productiva al bien común; y el que asume la sociedad al proveer a las personas en situación de necesidad de una renta de garantía de ingresos adecuada y de unos apoyos para la inclusión, y al garantizar un contexto socioeconómico razonablemente justo.

El modelo parte, por otro lado, de una interpretación amplia del concepto de empleabilidad, basado tanto en la adecuación de las habilidades y características individuales a las necesidades del mercado de trabajo, como en la necesidad de incidir en factores estructurales, como la demanda de empleo o las condiciones del mercado de trabajo. Igualmente, el modelo se basa en la necesidad de desarrollar las llamadas políticas de rentabilización del empleo, o making work pay, con el objeto de incentivar el acceso al empleo y, sobre todo, de incrementar los ingresos de los trabajadores de bajos salarios, reforzando la capacidad insertadora de este tipo de empleos. Este tipo de medidas requieren un cambio en la concepción y en el diseño de las prestaciones económicas de garantía de ingresos, que ha de pasar de una lógica de sustitución de rentas a otra de complementación.

Se aboga también por incorporar en toda su extensión el concepto de inclusión social al paradigma de la activación. En ese sentido, es preciso recordar que la multicausalidad de la exclusión sólo puede abordarse desde una concepción multidimensional de la inclusión, no exclusivamente centrada en la inserción laboral (por más que, como antes se ha dicho, ésta se considere el mecanismo básico de inclusión social y protección frente a la pobreza). Ello abre la puerta a la conveniencia de abordar en los procesos de inclusión cuestiones distintas a la de la empleabilidad y/o de trabajar a partir de una concepción más amplia 
tzeaz gain, pertsonen beharretara egokitu behar da lan-merkatu hori bera.

Bertan aldezten den gizarteratze aktiborako eredua oinarritzen da, baita ere, esku-hartzeen indibidualizazioan, bai pertsonen eta faseen arabera behar zehatzetarako zerbitzuak egokitzeko bai helburuak eta esku-hartzeen osagaiak definitzean erabiltzaileen partaidetza sustatzeko. Ikuspegi horretatik, baina langabetuen testuinguruarekiko faktoreei garrantzia emanaz, norbanakoaren ezaugarriak nabarmentzen ditu gizarteratzeko aktibazio-eredu horrek langabezia eta gizarte-bazterketa egoera horiek aztertzean. del trabajo, que no se limite al empleo remunerado y reconozca otras aportaciones posibles, como el trabajo voluntario o los cuidados familiares. La aplicación del concepto de inclusión social, en la línea del modelo social de la discapacidad, implica también la idea de que, más allá de adaptar las personas a las necesidades del mercado de trabajo, es necesario adaptar el mercado de trabajo a las necesidades de las personas.

El modelo de inclusión activa que se propugna se basa igualmente en la individualización de las intervenciones, tanto en lo que se refiere a la adecuación de los servicios prestados a las necesidades específicas de las personas y a la fase del proceso de inserción en la que se encuentran, como a la participación de las personas afectadas en la definición de los objetivos y los contenidos de las intervenciones.

ZERBITZUAN 


\section{Aurkibidea Índice}

9

Los servicios sociales frente

a la exclusión

Manuel Aguilar Hendrickson

Marta Llobet Estany

Begoña Pérez Eransus

27

Estrategia Europa 2020 e inclusión social: distanciamiento creciente entre objetivos, políticas e instrumentos José Manuel Fresno

Víctor Renes Ayala

Andreas Tsolakis

\section{9}

Aktibazioa eta gizarteratzeko eskubidea, EAE-ko enpleguko eta diru-sarrerak bermatzeko politiken esparruan SIIS Dokumentazio eta Ikerketa Zentroa

\section{7}

Las empresas de inserción social en un contexto de cambios sociolaborales. Un análisis crítico de su regulación desde la normativa vasca y estatal Ignacio Martínez Morales Joan Carles Bernad i Garcia Almudena Navas Saurín

\section{3}

La medida de la empleabilidad en las empresas de inserción en el País Vasco: de la exclusión a la inserción sociolaboral Lucía I. Llinares Insa

Ana I. Córdoba Iñesta

Juan José Zacarés González

\section{5}

La identidad profesional de los trabajadores sociales como elemento clave en el acceso a los programas de rentas mínimas: el caso de Catalunya Joan Cortinas Muñoz

\section{7}

Revisión de estudios de coste-efectividad en servicios de atención comunitaria y atención centrada en la persona

Madalen Saizarbitoria

\section{9}

Envejecimiento y deterioro de las personas con discapacidad intelectual de Lantegi Batuak en el ámbito ocupacional y del empleo en Bizkaia

Edurne Elorriaga Zugazaga

William Restrepo

Víctor Bayarri

Yolanda Fillat

\section{7}

Tendencias, innovaciones y buenas

prácticas internacionales en el ámbito del voluntariado

SIIS Centro de Documentación y Estudios 



\section{Los servicios sociales frente a la exclusión.}

\author{
Manuel Aguilar Hendrickson \\ Universitat de Barcelona \\ <manuel.aguilar.hendrickson@ub.edu>
}

Marta Llobet Estany

Universitat de Barcelona

\section{Begoña Pérez Eransus}

Universidad Pública de Navarra
Gainkarga gertatzen ari dira gizarte-zerbitzuen alorrean krisialdiak sortarazi dituen ekonomiamailako herritarren zailtasunak. Arazo horietako batzuek orain horren larriki azaldu arren, krisialdiaren aurreko arazoen ondorio dira. Arazo horiek zerikusia dute Espainian nahi izandako Estatu sozial modernoaren gizarte-zerbitzuak ezartzean gertatutako hutsegitearekin, eta geldiaraztearen erantzule da, baita ere, ongintzan indartutako eredua eta laguntza jasotzeko sarbide izateko arautu gabeko babes ekonomikoaren kudeaketa. Egoera hobetzearren aurkezten dira zenbait proposamen, adibidez, gizarte-zerbitzuen eta laguntza sozialaren funtzio propioak bereizten, edo gertutasuneko laguntzearen aldeko espazioa eta ekintza komunitarioa indartuz.

\section{HITZ-GAKOAK:}

gizarte-zerbitzuak, bazterketa, gizarteratzea, pobrezia, laguntzea.
Las dificultades económicas de muchas personas ocasionadas por la crisis están suponiendo una sobrecarga para los servicios sociales. Parte de los problemas que se presentan de forma especialmente aguda en estos momentos, sin embargo, derivan de problemas anteriores a la crisis. Dichos problemas tienen que ver con el encaje insatisfactorio de los modernos servicios sociales en el Estado social en España, con el peso del modelo tutelar de la beneficencia y con el colapso del espacio de la incorporación y el acompañamiento bajo el peso de la gestión de una protección económica discrecional. Se proponen vías de salida de la situación, como la diferenciación de las funciones propias de los servicios sociales de las de asistencia social, y la apertura de espacios para el acompañamiento desde la proximidad y la acción comunitaria.

\section{PALABRAS ClaVe:}

servicios sociales, exclusión, incorporación social, pobreza, acompañamiento. 


\section{Crisis: pobreza, exclusión social y servicios sociales}

Una parte significativa de la población española está sufriendo dificultades económicas graves como consecuencia de la fuerte destrucción de empleo de los últimos tres años. El número de hogares que, según la Encuesta de Población Activa, no tienen ningún perceptor de ingresos salariales, ni gozan de la protección social general (pensiones ni prestaciones por desempleo) pasó de 333.000 a fines de 2005 a 461.000 a finales de 2009, y alcanza los 584.000 a principios de 2012. En número de personas, el salto fue de 620.000 en 2005 a 962.000 en 2009 , y a 1,24 millones a principios de 2012.

Gráfico 1. Hogares con todos sus miembros activos parados y hogares sin ingresos. España, 2005-2012

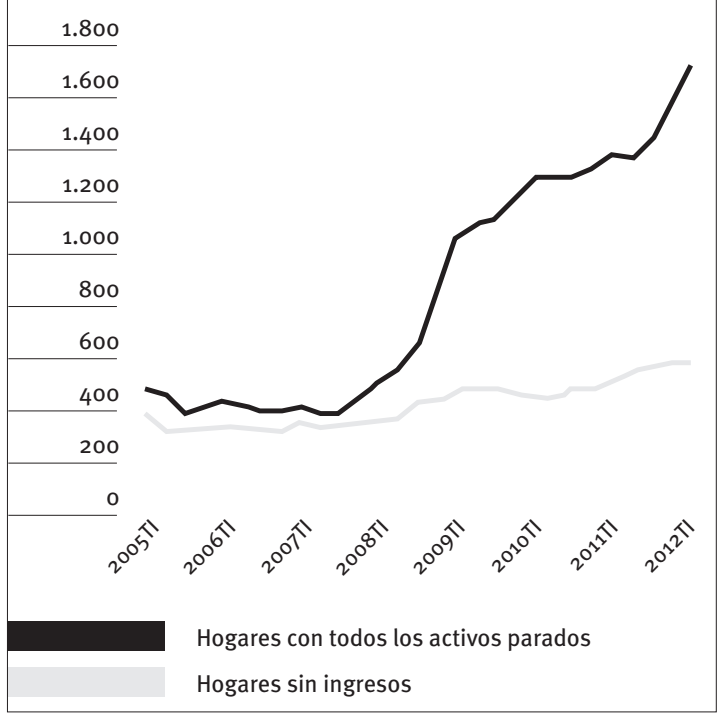

Fuente: Encuesta de Población Activa.

Estas cifras son un indicador claro de la tendencia, pero no es el único. El número de hogares con todos sus activos en paro ha crecido a un ritmo aún mayor, acercándose a 1,8 millones a principios de 2012. Muchos de estos hogares perciben alguna prestación por desempleo, en muchas ocasiones de cuantía bastante reducida, lo que los coloca en una situación de dificultad económica extrema. Además, la destrucción de empleo de estos últimos años se ha producido en un contexto de elevados costes de la vivienda y de un importante sobreendeudamiento de los hogares, que añade a las dificultades de quienes carecen de ingresos las de quienes manteniendo algunos ingresos (uno de los dos salarios, prestaciones por desempleo) se ven en la imposibilidad de hacer frente a los gastos de mantenimiento mensuales.

El empeoramiento de la situación económica de numerosos hogares ha tenido un efecto apreciable en los servicios sociales, en especial en los de atención primaria. Aún no disponemos de estadísticas generales que permitan medirlo en términos de incremento de la demanda, pero hay datos procedentes de fuentes diversas (noticias en los medios, declaraciones de responsables institucionales) que indican que dicho incremento ha sido importante. Las consejerías responsables de servicios sociales de diversas comunidades han anunciado que el número de solicitudes de prestaciones de renta mínima y de ayudas de emergencia social (que, en la gran mayoría de los casos, se tramitan a través de los servicios sociales locales) se ha incrementado de forma notable durante los dos últimos años. Por su parte, Cáritas Española ha informado de un incremento continuo del número de personas atendidas en sus servicios de acogida y atención primaria, que se duplicó entre 2007 y 2009, pasando de 370.000 a casi 790.000 (Cáritas Española, 2010).

Este incremento de la demanda se ha producido en un momento en el que los servicios sociales de atención primaria de muchas comunidades autónomas estaban absorbiendo la demanda suscitada por la implantación del Sistema de Autonomía y Atención a la Dependencia (SAAD), demanda no sólo importante en términos cuantitativos, sino también exigente en términos de cambios en los modos de actuación. Ha llegado tras una etapa relativamente larga de crecimiento del empleo, que había dejado atrás las tensiones de un largo periodo de alto desempleo en los años ochenta y primeros noventa. El anterior crecimiento del empleo había permitido, en algunos territorios, empezar a abordar con mayor tranquilidad procesos de acompañamiento de la inserción social y sociolaboral de personas en dificultad social.

Cuando se habla con responsables y trabajadores de los servicios sociales locales, se percibe un malestar que no parece explicable sólo por el exceso de carga trabajo que supone esta situación. Son frecuentes las opiniones acerca de la imposibilidad de dar respuesta adecuada a las situaciones que se presentan, y hay datos que parecen confirmar dicha percepción. Este malestar se expresa con frecuencia poniendo en duda que los servicios sociales deban gestionar las rentas mínimas, o aludiendo a la aparición de demandantes de renta mínima 'no excluidos', para los que no se dispone de una oferta adecuada y que, con frecuencia, tampoco se sienten muy cómodos en los servicios sociales. También es síntoma de dicha inadecuación el hecho de que una mayoría de las personas atendidas por Cáritas en 2009 (cerca de seis de cada diez) habían acudido con anterioridad a los servicios sociales públicos. La incapacidad para ofrecer una respuesta suficiente parece el motivo principal, y es frecuente que los propios servicios sociales públicos envíen a las personas atendidas a Cáritas.

\subsection{Los servicios sociales, (atrapados) entre la pobreza y la exclusión}

Un elemento característico del desarrollo moderno de los servicios sociales desde los años setenta y ochenta ha sido intentar escapar de su concepción de 'servicios para los pobres'. La beneficencia pública y su sucesora modernizada, la asistencia social, se 
definían por la población de la que se ocupaban (los pobres, o las personas de ingresos bajos), y no por el tipo de acción que realizaban (educativa, de alojamiento y manutención, de apoyo personal, sanitaria). Los servicios sociales modernos quieren ser 'otra cosa' diferente (aunque, como veremos más adelante, esa 'otra cosa' no acaba de estar bien definida), pero heredan en parte el espacio de la beneficencia y la asistencia social en el espacio institucional, en el 'mandato' que reciben y en el imaginario de los ciudadanos. Nuestra hipótesis es que el problema debería abordarse definiendo la especificidad de los servicios sociales en relación con los demás sistemas de política social, más que intentando borrar de su imaginario a pobres, marginales y excluidos.

Esta inquietud se ha traducido en una afirmación doble de los servicios como 'universales' y prioritariamente 'generalistas'. La universalidad afirmada no ha tenido en muchas ocasiones efectos reales, ya que, al disponer de pocos medios, se ha acabado por dar prioridad de acceso a las personas de renta baja, opción legítima, pero contraria a la universalidad. La prioridad de lo generalista, de lo inespecífico, en especial en el nivel local o primario, derivaba tanto de corrientes favorables a lo generalista procedentes del Reino Unido y de Estados Unidos (aunque en contextos y con significados muy diferentes), como de la preocupación por evitar la pervivencia de la imagen de servicios encargados de atender a los pobres y marginados.

Un elemento central de los nuevos servicios sociales ha sido el desarrollo de servicios locales, de carácter generalista ${ }^{2}$. En los últimos decenios, se ha producido un progresivo desarrollo de una red que ha llegado a casi todo el territorio. Esta red se ha ido extendiendo, proporcionando un acceso universal (o muy amplio) a servicios de información y orientación a la ciudadanía, así como el acceso (más limitado y no siempre bien orientado) a algunos programas específicos de atención a domicilio, prestaciones de mínimos o recursos de alojamiento.

Sin embargo, atender estas actividades de información y orientación ha condicionado la intervención diaria de estos servicios, que se ha centrado, sobre todo, en responder a las demandas planteadas. La gestión de la información y la tramitación de las prestaciones concentran la mayor parte del esfuerzo profesional, lo que deja escaso espacio para diseñar acciones de atención específica, o procesos de intervención profesional de mayor profundidad y continuados en el tiempo.

Por ello la acción en materia de incorporación social con colectivos excluidos ha quedado, en muchos casos, reducida a favorecer su acceso a las prestaciones de garantía de ingresos (rentas mínimas y otros) y su orientación o derivación hacia recursos de for-

${ }^{2}$ La denominación de tales servicios es múltiple: servicios sociales de base, unidades de base, atención social primaria, servicios sociales generales o comunitarios, entre otras. mación, empleo o incorporación social gestionados, en su mayoría, por entidades sociales. Los procesos de intervención intensos con población excluida impulsados directamente desde la red de servicios sociales de atención primaria son limitados.

A partir de la Encuesta de Condiciones de Vida de la Población Española, especialmente realizada para elaborar el VI Informe FOESSA (Renes, 2008), hemos podido aproximarnos a la relación entre acceso a los servicios sociales y grado de integración social. De acuerdo con esta encuesta, el colectivo más numeroso dentro de la población usuaria es el de aquellos hogares que se encuentran en situación de integración precaria, que suponen casi la mitad de la demanda. Se entiende por 'integración precaria' la vulnerabilidad causada por determinados factores de índole sobre todo económica (déficit de acceso al empleo o a los sistemas de protección social), pero en situaciones en las que existen vínculos de integración relacionados con las redes familiares o sociales, y la propiedad de la vivienda.

Tabla 1. Personas que han acudido alguna vez a los servicios sociales. España, 2007 (\%)

\begin{tabular}{|l|c|}
\cline { 2 - 2 } \multicolumn{1}{c|}{} & $\%$ \\
\hline Integrado & 29,9 \\
\hline Integración precaria & 44,8 \\
\hline Exclusión compensada & 16,2 \\
\hline Exclusión severa & 9,0 \\
\hline Total & $\mathbf{1 0 0 , 0}$ \\
\hline
\end{tabular}

Fuente: Encuesta FOESSA (2007).

El segundo grupo más numeroso de personas que hacen uso de la red es el que se encuentra en situaciones de 'integración'. Sin embargo, las personas con problemas de exclusión no llegan a la cuarta parte de la población atendida por los servicios sociales. Las situaciones de exclusión más grave o severa (que acumulan problemas en diversos ámbitos) no llegan al $9 \%$ de los usuarios. Este dato nos indica cuánto suponen los excluidos sobre el conjunto de usuarios. Sin embargo, el dato que verdaderamente alerta sobre la limitada utilización de los servicios por parte de la población más excluida es la proporción de ésta que llega a los servicios sociales: tres cuartas partes de la población en situación de exclusión no tienen contacto con los servicios sociales.

Tabla 2. Personas que han acudido alguna vez a los servicios sociales, por grupos. España, 2007 (\%)

\begin{tabular}{|l|c|c|c|c|c|}
\cline { 2 - 6 } \multicolumn{1}{c|}{} & Integrado & $\begin{array}{c}\text { Integración } \\
\text { precaria }\end{array}$ & $\begin{array}{c}\text { Exclusión } \\
\text { compensada }\end{array}$ & $\begin{array}{c}\text { Exclusión } \\
\text { severa }\end{array}$ & Total \\
\hline Sí & 9,3 & 18,7 & $\mathbf{2 0 , 1}$ & 25,3 & $\mathbf{1 4 , 8}$ \\
\hline No & 90,7 & 81,3 & 79,9 & 74,7 & $\mathbf{8 5 , 2}$ \\
\hline Total & $\mathbf{1 0 0 , 0}$ & $\mathbf{1 0 0 , 0}$ & $\mathbf{1 0 0 , 0}$ & $\mathbf{1 0 0 , 0}$ & $\mathbf{1 0 0 , 0}$ \\
\hline
\end{tabular}

Fuente: Encuesta FOESSA (2007). 
Es difícil identificar las barreras que dificultan el acceso de la población excluida a los servicios sociales. Cuando se pregunta a la población en situación de exclusión severa los motivos por los cuales nunca ha tenido contacto con el sistema de servicios sociales públicos, casi dos tercios $(63,2 \%)$ dicen no conocerlos, proporción que duplica a la del colectivo de personas que se encuentra en situación de exclusión compensada (33\%). En este grupo, precisamente, el acceso a los servicios sociales y sus prestaciones, junto con la existencia de redes sociales de apoyo, pueden ser uno de los factores claros de compensación de esas situaciones. Las amistades, los contactos y la capacidad para resolver trámites constituyen factores de integración que favorecen el acceso a los servicios y cuya ausencia caracteriza las situaciones de exclusión más severa.

Un segundo grupo de factores lo integran aquellos relacionados con la capacidad de captación del propio sistema respecto a la población excluida. La limitada capacidad de detección más allá de las demandas planteadas, la rigidez de las formas de acceso (atención en horario de oficina, cita previa) y las escasas respuestas efectivas para las situaciones de exclusión pueden influir en que las personas excluidas no recurran a dichos servicios.

También resulta significativo que el grado de satisfacción respecto al sistema de servicios sociales está estrechamente relacionado con el nivel de exclusión social de la población. Las personas en situación de exclusión severa son las más insatisfechas con los servicios sociales. Casi dos tercios (más del 63\%) se muestran poco o nada satisfechas con el sistema, mientras que el grado de satisfacción en el resto de colectivos es mucho más elevado. Las causas, a juicio de los encuestados, de este grado de insatisfacción de los más excluidos son la lentitud y burocracia a la hora de resolver los trámites, la falta de respuestas adecuadas a su situación, la falta de información y las listas de espera.

Tabla 3. Grado de satisfacción con los servicios sociales. España, 2007 (\%)

\begin{tabular}{|l|c|c|c|c|c|}
\cline { 2 - 6 } \multicolumn{1}{l|}{} & Integrado & $\begin{array}{c}\text { Integración } \\
\text { precaria }\end{array}$ & $\begin{array}{c}\text { Exclusión } \\
\text { compensada }\end{array}$ & $\begin{array}{c}\text { Exclusión } \\
\text { severa }\end{array}$ & Total \\
\hline $\begin{array}{l}\text { Muy } \\
\text { satisfecho }\end{array}$ & 36,6 & 15,9 & 32,6 & 8,5 & $\mathbf{2 3 , 6}$ \\
\hline $\begin{array}{l}\text { Bastante } \\
\text { satisfecho }\end{array}$ & 40,5 & 45,3 & 32,6 & 29,8 & $\mathbf{4 0 , 3}$ \\
\hline $\begin{array}{l}\text { Poco } \\
\text { satisfecho }\end{array}$ & 19,8 & 27,6 & 23,3 & 44,7 & $\mathbf{2 6 , 4}$ \\
\hline $\begin{array}{l}\text { Nada } \\
\text { satisfecho }\end{array}$ & 3,1 & 11,2 & 11,6 & 17,0 & $\mathbf{9 , 7}$ \\
\hline Total & $\mathbf{1 0 0 , 0}$ & $\mathbf{1 0 0 , 0}$ & $\mathbf{1 0 0 , 0}$ & $\mathbf{1 0 0 , 0}$ & $\mathbf{1 0 0 , 0}$ \\
\hline
\end{tabular}

Fuente: Encuesta FOESSA (2007).
Sería injusto no reconocer aquí la importancia que han tenido los servicios sociales de atención primaria en favorecer el acceso de (una parte de) los sectores excluidos a las rentas mínimas y otros recursos, así como la labor de seguimiento que han desarrollado aprovechando el contexto de tramitación y adjudicación de las prestaciones. Sin embargo, desde el propio sector se reconocen las limitaciones de recursos humanos y materiales para llevar a cabo procesos de incorporación social más intensos.

La percepción de responsables y profesionales a los que hemos entrevistado es que, a lo largo del tiempo y coincidiendo con la expansión de los servicios sociales, el conjunto de la población ha tenido un mayor conocimiento de su existencia y se ha producido un mayor acceso de personas 'integradas' vinculadas a la demanda de información y acceso a los servicios, en especial en relación con las personas mayores y con discapacidad. La sobrecarga de tareas de información y gestión de prestaciones se muestra como una de las principales barreras para desarrollar trabajo social de incorporación con colectivos excluidos. Algunos vislumbran en los años más recientes un incremento de esta tendencia de desplazamiento de los más excluidos, debido a la asunción de la responsabilidad de gestión del SAAD.

Los síntomas que hemos descrito hasta aquí hacen pensar que el problema es algo más profundo que el derivado de un incremento puntual de la demanda. Es evidente que cualquier sistema de servicios que experimente un crecimiento en un breve periodo de tiempo de su demanda se ve sometido a tensiones, como sucede en estos mismos años con el aumento de las solicitudes de admisión en las universidades y los centros de formación profesional, como consecuencia de la crisis de empleo, o como sucedió con la renovada demanda de plazas escolares en los años noventa, cuando el sistema educativo empezaba a hacerse a la idea de que no volvería a tener muchos alumnos. Sin embargo, en el caso que nos ocupa, el grado de tensión y de dificultad para responder a la situación es mucho mayor y remite, en nuestra opinión, a problemas más de fondo.

Los problemas derivados de la implantación del SAAD tenían que ver, sobre todo, con el volumen de población que había de atender (y la oferta de servicios necesaria para hacerlo) y con la introducción de una lógica de derecho subjetivo en un sistema acostumbrado a racionar la atención de forma discrecional. Pero nadie pone en duda que atender a las personas que han perdido autonomía mediante residencias, centros de día, atención a domicilio y otros servicios similares era tarea propia de los servicios sociales. Era algo que venían haciendo, y que debían seguir haciendo, adecuándose al nuevo marco.

En el caso de la pobreza derivada de la crisis del empleo, sin embargo, la cuestión no está tan clara. ¿Es responsabilidad de los servicios sociales asegurar que las personas que han perdido sus ingresos 
del trabajo puedan hacer frente a sus necesidades de subsistencia? En principio, parece que tal responsabilidad corresponde, en nuestro sistema de protección social, al ámbito de la garantía de rentas, y de forma más precisa, a la protección por desempleo. Ni las leyes generales ni las de servicios sociales atribuyen una función de garantía de renta a los servicios sociales. A pesar de ello, los servicios sociales han intervenido en este terreno desde hace años, por medio de ayudas económicas puntuales y discrecionales y, en algunas comunidades y desde principios de los años noventa, por medio de las rentas mínimas de inserción.

\section{2. ¿Para qué sirven los servicios sociales?}

A nuestro entender, una parte del problema deriva de un encaje insatisfactorio de los servicios sociales en el Estado de bienestar español (Aguilar Hendrickson, 2009). En nuestro país, se superponen dos concepciones de la acción social pública incoherentes entre sí:

- Por una parte, la concepción que heredamos del régimen de la asistencia liberal (fundado en la beneficencia pública) y que intentó modernizarse en los años sesenta y setenta en forma de asistencia social. Esta concepción preveía un dispositivo de atención global a la pobreza (en varios ámbitos, como el económico, el sanitario o el educativo), separado de la protección social del grueso de la población trabajadora (previsión social o Seguridad Social). Es decir, preveía la existencia de un dispositivo institucional encargado de ‘hacerse cargo' de los pobres. Su consistencia proviene de tener como objeto el conjunto de las necesidades de una parte de la población.

- La otra concepción distingue entre dispositivos institucionales encargados de atender diferentes partes de las necesidades de la población. Este modelo de Estado de bienestar se articula en torno a sectores de la acción social pública (sanidad, educación, garantía de rentas), y no de grupos de población. Su coherencia técnica, condición de su eficacia y eficiencia, deriva de atender una parte definida de las necesidades del conjunto de la población.

La posición contradictoria de los servicios sociales entre estos dos modelos es comprobable en la percepción de la opinión pública y de los propios ciudadanos que los usan (que los siguen identificando con la 'beneficencia' o la 'asistencia social'), en las ambigüedades de su encaje institucional (los servicios sociales como plasmación de la competencia autonómica en 'asistencia social') y en la propia acción de los servicios. Pensamos que clarificar el papel de los servicios sociales, en especial respecto a la exclusión, es condición imprescindible para salir del embrollo y las tensiones en las que están inmersos y para desarrollar una acción eficaz contra la exclusión.
Este encaje contradictorio se presenta de dos modos: en la pervivencia de concepciones y estructuras procedentes de la antigua beneficencia pública en los servicios sociales modernos; y en una delimitación insatisfactoria de las funciones propias, específicas de los servicios sociales como sector en el nuevo modelo.

\subsection{La pervivencia del modelo de la beneficencia pública}

La beneficencia pública fue, al menos como proyecto, el núcleo de un modo de acción social del Estado que Mariano Esteban de Vega (1992) ha denominado 'asistencia liberal'. La beneficencia pública intentó poner en marcha una regulación pública y una racionalización de la asistencia a los pobres incapaces de trabajar, y modificó sustancialmente su estructura financiera. Como proyecto, contó con fundamentos teóricos y con una articulación programática relativamente sólida, aunque su desarrollo fuese muy contradictorio y limitado (Carasa Soto, 2007). El modelo residual de política social liberal, lastrado por elementos arcaicos y nunca plenamente desarrollado (Carasa Soto, 2004), ciertamente mostró su incapacidad para hacer frente con eficacia a la cuestión social, a las nuevas formas de pobreza y de desigualdad nacidas del desarrollo económico, y ello ha llevado a leer su historia como la de un fracaso, lentamente superado por el progresivo desarrollo de la previsión social.

La beneficencia pública, sin embargo, sobrevivió al nacimiento y desarrollo de la previsión social, y siguió caracterizando un sector proporcionalmente cada vez menor de la acción social del Estado, hasta desaparecer entre la Constitución de 1978 y la Ley de Fundaciones de 1992. Suele verse como una reliquia fósil del pasado, cargada de connotaciones negativas, muchas de ellas probablemente justificadas. La beneficencia pública fue vista por buena parte de las clases trabajadoras como una respuesta inadecuada, insuficiente y teñida de paternalismo moralista y autoritario a sus dificultades, lo que explica el fuerte rechazo que despertaba en la cultura política del movimiento obrero y de la izquierda.

Paralelamente, los intentos de modernizar la atención social y resituarla en el contexto del naciente Estado social español en la década de 1960 cargaron en ocasiones las tintas sobre el arcaísmo de muchos de sus dispositivos, y sobre su carácter supuestamente graciable y voluntario. Tanto el proyecto de la 'asistencia social' (complemento de la Seguridad Social) de los años sesenta, como el de los 'servicios sociales' (nuevo sector con vocación universalista de la política social) de los setenta y ochenta, se definieron en términos de rechazo y superación de la beneficencia pública, y por ello cargaron las tintas en la crítica. Algunos autores trataron de matizar algunas de esas críticas (Aznar López, 1990, 1996; Casado, 2002), sin que ello cambiase sustancialmente el discurso dominante. 
El modelo de acción social pública sobre la pobreza de la beneficencia pública presentaba algunas características que es importante tener en consideración ${ }^{3}$ :

- La concepción de fondo era la de establecer un dispositivo de atención integral (social, sanitaria, educativa, laboral) para un sector de la población, el definido como pobre no culpable. Esta concepción incluye los dos aspectos, el de la 'selectividad' y el de la 'integralidad'. La opción por la selectividad (atender sólo a los pobres) es coherente con la concepción liberal de la atención pública sólo para los excluidos del mercado (el modelo 'residual' en los términos de Richard Titmuss). La opción por la integralidad, es decir, por una atención (en establecimientos o domiciliaria) que no establecía barreras absolutas entre el cuidado personal, la atención sanitaria, la educación y el trabajo, es otro rasgo del modelo, consecuencia de una baja especialización técnica de cada una de esas funciones. Cierto es que, a lo largo del desarrollo de la beneficencia pública, se fueron separando parcialmente algunas de ellas. La beneficencia sanitaria y social ('hospitalidad' y 'socorros') ya aparecían parcialmente deslindadas desde las primeras leyes de beneficencia, y desde principios del siglo XX se fue produciendo una separación de la beneficencia educativa. En todo caso, la concepción de fondo es la de hacerse cargo del conjunto de las necesidades de una parte de la población.

- Una regulación del acceso caracterizada por el establecimiento de obligaciones del Estado sin reconocimiento de derechos a los ciudadanos. De ese modo, la beneficencia pública se diferenciaba de la acción graciable o voluntaria (que, por definición, no está obligada a nada) y también de la acción que los ciudadanos que reúnen ciertas características pueden exigir de la Administración (los derechos). Lo que está en juego aquí no es la 'generosidad' o no en la provisión de apoyos. Lo que está en juego es la posición en la que quedan los ciudadanos respecto a la Administración. La persona socorrida queda en una posición equivalente a la minoría de edad: "Este doble infortunio constituye al hombre en un estado de minoría a que corresponde una solícita tutela en el gobierno cuyos paternales cuidados le revisten con el carácter de segunda providencia para el desvalido" (Colmeiro, 1850: 426). La persona, por tanto, puede exponer su situación y debe esperar que sea la Administración la que decida si su caso merece ser protegido o no. La obligación de la Administración, en este modelo, es la de proteger una serie de bienes (la 'función estatal' de la que habla Vida Soria [1968]), como el orden social, la salud pública y la vida de los miembros de la sociedad. El interés de las personas no está legitimado, salvo si satisfacerlo sirve a la función estatal, y la autonomía de las personas queda

3 Un análisis más detallado de esta cuestión puede hallarse en Aguilar Hendrickson (2010). muy limitada, al colocarse en una posición de 'menor tutelado'.

- La fragmentación de la responsabilidad pública entre tres niveles territoriales (central, provincial y municipal). La Ley de Beneficencia de 1849 cambió la responsabilidad exclusiva municipal (nunca implantada de hecho) por un reparto complicado entre los tres niveles, que conllevó, en la práctica, la concurrencia en un mismo territorio de diferentes acciones públicas, en ocasiones contradictorias. El nivel central se reservó funciones directas muy limitadas (establecimientos muy especializados, en principio) y la responsabilidad de la supervisión ('protectorado') de las entidades privadas (beneficencia particular). Los niveles provincial (sobre todo) y municipal cargaron con el peso de la acción pública, que se fue definiendo cada vez más en términos de obligación de disponer de determinado tipo de establecimientos, más que de garantizar la atención de determinadas situaciones.

Algunos elementos clave de estas tres características han pervivido tras la supresión de la beneficencia pública y el establecimiento de los servicios sociales modernos. La fragmentación de la responsabilidad pública sigue siendo una característica de los servicios sociales (a diferencia de la educación, la sanidad o las pensiones), ligeramente más compleja con la aparición del nivel autonómico, que, en parte, sustituye y, en parte, se añade al provincial. El escaso reconocimiento de derechos subjetivos a los ciudadanos en relación con los servicios sociales (al menos hasta la Ley de Dependencia y las últimas leyes de servicios sociales) ha mantenido un modelo de relación de tutela con los ciudadanos en términos de 'dígame usted qué le pasa y yo decidiré lo que le ofrezco'.

A pesar de fundarse en una obligación genérica de atención a los pobres, el desarrollo de la beneficencia publica en España combinó la creación obligatoria de determinados establecimientos por parte, sobre todo, de las diputaciones provinciales, con el desarrollo de numerosas actividades voluntarias (tanto públicas como de la llamada 'beneficencia particular'). Este carácter voluntario de buena parte de las acciones, junto a la multiplicidad de actores institucionales públicos, nos ha legado un sector público que, en ocasiones, se comporta aún hoy como un amplio y diverso sector voluntario de titularidad pública.

Finalmente, el paso de una concepción de atender todas las necesidades de 'una parte de la población' a la de atender 'una parte de las necesidades' de la población (toda o parte, según se opte por un modelo universalista o no) se ha producido sólo a medias. A la insuficiencia de esta transformación han contribuido varios factores, entre ellos la inercia institucional y social, pero también las peculiaridades del diseño del Estado de bienestar español entre los años sesenta y ochenta, por un lado, y la imprecisa 
delimitación del papel de los servicios sociales en la producción legislativa y teórica de los años ochenta en adelante.

\subsection{La división en sectores del Estado de bienestar}

Los Estados de bienestar desarrollados se caracterizan, entre otras cosas, por la diferenciación de sectores en su seno. Aunque las necesidades y los problemas de las personas constituyen un todo en la experiencia de sus vidas, las instituciones del Estado de bienestar van estableciendo progresivamente segmentos de esas necesidades, cada uno de los cuales es atendido desde un sector de la política social. Esos sectores tienden a institucionalizarse de forma diferenciada: definen su objeto (la enfermedad/ salud; el riesgo de perder el salario; la necesidad de adquirir conocimientos, destrezas y competencias), establecen su modelo de atención (la atención médica, las pensiones y prestaciones económicas, la enseñanza) y suelen articularse por medio de determinadas profesiones (las sanitarias -médicos, enfermeros-, las docentes). Su institucionalización diferenciada suele traducirse en el establecimiento de departamentos separados en la administración pública. Dicha configuración puede variar a lo largo del tiempo, por medio de reformulaciones de su objeto (de la 'enfermedad' a la 'salud', por ejemplo), de cambios de su modelo de atención (de la prioridad del hospital a la de la atención primaria, por ejemplo) y de reconfiguraciones de su mapa profesional.

En nuestro país, se habla con frecuencia de tres sectores o pilares, al que últimamente se le habría añadido un cuarto. Se trataría de: 1) la garantía de ingresos (pensiones y protección por desempleo), 2) la educación y 3) la sanidad, a los que se habría añadido 4) la atención a la dependencia o los servicios sociales, según los gustos. Hay otros sectores claramente visibles en nuestro Estado de bienestar, como el acceso al empleo (los servicios de colocación y las políticas activas de empleo) y la vivienda (por escuálida, ineficiente e ineficaz que sea su acción). Si aceptamos la presencia de estos dos últimos, estaríamos ante seis sectores, tal como lo formulaban Kahn y Kamerman (1987) hace ya unos años.

No hay que olvidar que esta diferenciación de las políticas sociales es una construcción social, y en cuanto tal, puede reconfigurarse subdividiendo o integrando sectores. Hay también espacios en los que podrían aparecer otros nuevos (por ejemplo, la gestión del tiempo libre y los equipamientos culturales y de ocio). Del mismo modo, la acción en cada sector puede articularse constituyendo un sistema, o puede aparecer fragmentada. El sector de la salud en España está articulado mayoritariamente en un único sistema (universal, con un financiador público único), aunque convive con servicios de salud privados externos al sistema (no al sector). Sin embargo, esta configuración es relativamente reciente: hasta la reforma de 1986 y su puesta en práctica a lo largo de los años noventa, el sector de la salud estaba compuesto por varios sistemas independientes (la atención sanitaria de la Seguridad Social y la de beneficencia, entre otros).

En el caso español, a la dificultad que supone la progresiva delimitación de ámbitos sectoriales, se añaden algunas peculiaridades del modelo adoptado de Estado de bienestar (Aguilar Hendrickson, 2009). Ya desde mediados del siglo XIX, se inician procesos de diferenciación sectorial, que, a lo largo del siglo $X X$, van madurando. En el decenio de los sesenta, se produce un primer impulso de diseño de un Estado de bienestar moderno con una fuerte inspiración conservadora o bismarckiana (Guillén, 2010; Rodríguez Cabrero, 1989). En este diseño empiezan a aparecer de manera bastante diferenciada un sector educativo (que tiende a orientarse hacia un modelo universalista, aunque internamente dualizado), y otros dos sectores (garantía de rentas y sanidad) construidos sobre un modelo contributivo. Hay algunos atisbos, que irán tomando cuerpo en los sesenta y setenta, de un 'cuarto' sector de servicios sociales (servicios para pensionistas y para minusválidos, sobre todo). Estos dos sectores 'y medio' (garantía de rentas, sanidad y los embrionarios servicios sociales) se configuran con un fuerte peso de los dispositivos contributivos, bajo el nombre de Seguridad Social. Pero al mismo tiempo, se hace evidente la necesidad de un segundo nivel de 'repesca' en los mismos sectores que proteja a la población de bajos ingresos que no ha cotizado (o no lo suficiente). Aunque este nivel no se desarrollase de forma plena, su denominación habitual era 'asistencia social' (o nivel asistencial), y parecía evidente que el punto de partida de su constitución debía ser un proceso de racionalización, modernización y división sectorial de la beneficencia pública. En esta concepción, la beneficencia pública debía desglosarse en garantía de rentas, asistencia sanitaria y atención social de asistencia social, en paralelo a la garantía de rentas, la asistencia sanitaria y la atención social contributivas de la Seguridad Social. Este proceso se inició y desarrolló de forma parcial, y sirvió para asentar en el lenguaje jurídico y administrativo el concepto de asistencia social, entendida como la protección no contributiva, condicionada a la insuficiencia de medios, pero reconocida como derecho subjetivo, en diferentes sectores de atención, complementaria de la Seguridad Social. Venía a ocupar un espacio parecido al de la beneficencia pública, pero integrada en el conjunto de una protección social mucho más amplia, reconocida como derecho y con una estructura de especialización sectorial más compleja.

Es esta 'asistencia social' la que aparece en la Constitución de 1978 y la que sirvió de base legal para que las comunidades autónomas pusieran en marcha sus políticas de servicios sociales. Pero los servicios sociales en cuestión no se concibieron a sí mismos como un nivel asistencial, o no contributivo, de protección, sino como un sector autónomo. Para que esta concepción definiera la realidad de los servicios sociales, era necesario, entre otras cosas, definir la especificidad de ese sector. Parte de las dificultades 
de los servicios sociales vienen de una insuficiente claridad en este asunto.

Para establecer los servicios sociales como sector de la política social, encargado de una parte de las necesidades de la población, es crucial identificar de qué parte de las necesidades se encargan, y de qué parte se encargan otros sectores. Los servicios sociales modernos en España han venido definiendo legalmente esta cuestión de un modo poco claro. Son frecuentes en las leyes definiciones inespecíficas (servicios tendentes a lograr el bienestar social y la calidad de vida de los ciudadanos) que poco dicen sobre de qué parte específica de ese bienestar se ocupan los servicios sociales, a diferencia de lo que sucede con la sanidad, la educación o la garantía de rentas (de las que sí sabemos de qué parte se ocupan). También abunda la identificación de grupos y situaciones atendidas (mayores, menores, adultos, personas con discapacidad, mujeres, inmigrantes, personas con problemas de drogas, entre otros). Debería ser evidente que los servicios sociales no se ocupan de todas las necesidades de estos grupos (como lo hacía la beneficencia pública), pero en las leyes no queda nada claro de qué parte concreta de las necesidades de estas personas se ocupan.

Definir los límites del encargo que se hace a los servicios sociales supone decidir entre diversas alternativas posibles. No hay una definición absoluta de servicios sociales, como ni siquiera es necesario que sus funciones se integren en un sector único y diferenciado de la política social. Los servicios sociales podrían no existir como tales, y las funciones que parece lógico atribuirles podrían ser ejercidas desde otros sectores. Se trata de optar entre diversas posibilidades de configuración del sector, ninguna de las cuales se debe a una realidad ontológica de los servicios sociales.

¿Cuáles son esas funciones? Las principales tienen que ver con: a) el apoyo en lo cotidiano a las personas que han perdido autonomía; b) la tutela y protección de los menores (pero también de personas incapacitadas o vulnerables a tratos inadecuados); y c) el apoyo a las personas con dificultades especiales de integración social en sus procesos de incorporación. Estas funciones son diferentes (en sus finalidades y métodos de acción) de otras 'cercanas', como la garantía de ingresos, la atención sanitaria o las políticas de empleo. Es posible desarrollarlas desde un sector conjunto (los servicios sociales) o desde sectores ya existentes. El apoyo en la vida cotidiana a las personas con pérdida de autonomía es diferente de la atención sanitaria, pero podría desarrollarse desde los servicios de salud. La protección económica por desempleo forma parte de la política de garantía de ingresos y, en España, se ha optado por gestionarla desde los servicios públicos de empleo y no desde la administración general de la Seguridad Social (como en otros países). Más aún, es admisible que los servicios sociales gestionen las rentas mínimas de inserción, pero no por ello dejan de ser parte de la política de garantía de rentas. Las opciones en juego presentan ventajas e inconvenientes, y no pueden ser resueltas desde posiciones de principio.

La función que más nos interesa aquí es la tercera. Hace referencia al apoyo a los procesos de incorporación de personas que se encuentran con especiales dificultades para su integración social, por razones muy diversas, desde la discapacidad a la discriminación, desde la marginalidad a los problemas graves de salud.

\subsection{Especificidad y transversalidad en la acción contra la exclusión social}

Parece un contrasentido insistir aquí en la especificidad de la función de un sector, cuando se insiste al mismo tiempo en la necesidad de acciones transversales o integrales. El discurso político y técnico sobre la exclusión y la inclusión ha puesto énfasis en la multidimensionalidad de los problemas de exclusión social y en la necesidad de políticas integrales o transversales de inclusión. La multidimensionalidad de los problemas de inclusión hace referencia a la coincidencia en las personas en dificultad de diferentes problemas y dificultades que afectan al objeto de más de un sector de la política social (salud, educación, trabajo, dinero, vivienda). Además de coincidir, esos problemas parecen retroalimentarse, y su resolución parece difícil si no se abordan de manera integrada y conectada. Ello requiere de acciones desde los diferentes sectores de la política social, acciones adaptadas a las dificultades específicas de esas poblaciones.

El Estado de bienestar desarrollado, diferenciado en sectores, espera de los ciudadanos que sean capaces de gestionar esa fragmentación. Un ciudadano 'normal', integrado, debe ser capaz de saber para qué tiene que ir al centro de salud y para qué a la escuela; en definitiva, debe saber cómo gestionar la tensión entre la unidad de su situación personal y la diferenciación institucional. Sin embargo, muchas cosas hacen pensar que, en el caso de las personas en dificultad social grave (eso que llamamos 'exclusión'), es frecuente que la autogestión de las necesidades no funcione como debería. Por un lado, con frecuencia se trata de situaciones en las que las dificultades, los problemas y las necesidades en varios sectores no sólo coinciden, sino que se enlazan y se afectan recíprocamente, por lo que resulta especialmente difícil tratarlas por separado. Por otro, en muchos casos las personas en dificultad tienen límites importantes para gestionar esa complejidad o, mejor dicho, para gestionarla adaptándose a la diferenciación institucional de las políticas sociales.

En el marco de las políticas integrales o transversales de inclusión o contra la exclusión, es importante diferenciar dos planos. Por un lado, hay acciones que pueden incrementar la accesibilidad y la adaptación de cada sector de la política social para las personas en dificultad y reducir sus mecanismos exclusógenos. Por ejemplo, un sistema educativo más flexible 
y adaptado a diferentes tipos de estudiantes, que ofrezca múltiples mecanismos de repesca y de acceso a sus diferentes niveles resultará seguramente menos exclusógeno y más accesible que un sistema educativo rígido, orientado sólo hacia la carrera académica y universitaria, donde los fallos no se perdonan. En las páginas que siguen, y de modo completamente convencional, llamaremos políticas y acciones de inclusión a este tipo de políticas y acciones. No van dirigidas específicamente a las personas en dificultad, sino a incrementar la inclusividad de los diferentes sectores. Por otro lado, hay acciones que van directamente dirigidas a las personas en dificultad y tratan de construir procesos concretos de incorporación social. Su foco son las situaciones y procesos de las personas en dificultad, y tratan de articular acciones en diferentes sectores que les permitan desarrollar procesos personales que mejoren su situación. Llamaremos aquí políticas y acciones de incorporación a este tipo de acciones. Una acción eficaz contra la exclusión social requiere de ambos tipos de política. Las políticas sólo de incorporación corren el riesgo de tropezarse muy rápidamente con bloqueos y barreras excluyentes en los espacios e instituciones donde debería desarrollarse la incorporación. Las políticas sólo de inclusión pueden reducir el riesgo de exclusión y tener importantes efectos preventivos, pero al mismo tiempo pueden dejar fuera a los casos más graves y extremos de dificultad, que, por sí solos, es poco probable que puedan gestionar su incorporación.

Si se acepta esta diferenciación entre políticas de inclusión y de incorporación, la cuestión de la multidimensionalidad o transversalidad se plantea de forma diferente en cada una de ellas. En el caso de las políticas de inclusión, la integración de políticas es un problema de coordinación y cooperación interadministrativa. Se trata de articular mecanismos que aseguren que, en cada sector, se eliminan barreras excluyentes, se abren oportunidades para las personas con más dificultades, se adaptan mejor los servicios a poblaciones diversas. Sin embargo, en el caso de las políticas de incorporación, la transversalidad consiste en la gestión integrada de un proceso personal de desarrollo. No se trata de una mera coordinación interadministrativa (aunque su existencia facilita mucho las cosas), sino de articular, gestionar y acompañar un proceso personal (un itinerario, si se quiere) de incorporación.

\subsection{Un papel para los servicios sociales}

Una condición para la coordinación entre instituciones y la cooperación interprofesional es establecer con suficiente claridad la responsabilidad de cada una de las partes. En las líneas que siguen intentaremos establecer cuál es el papel que puede (debe) corresponder a los servicios sociales como sector específico en la acción contra la exclusión.

Aunque las administraciones empezaron a articular planes de lucha contra la pobreza, contra la exclusión o por la inclusión a lo largo de los años noventa (el País Vasco se adelantó con el Plan Vasco contra la Pobreza a finales de los ochenta), hay un antecedente de diseño legal de una política de integración social transversal o interdepartamental que data de principios de los años ochenta y aún está en vigor: la Ley de Integración Social de los Minusválidos (LISMI).

La LISMI articula una política de integración social, para lo que define su objeto (la minusvalía, hoy redenominada discapacidad) como la 'reducción de las oportunidades de integración' laboral, educativa o social derivada de una deficiencia física, psíquica o sensorial previsiblemente permanente. En este sentido, es claramente diferente de la Ley de Promoción de la Autonomía Personal y Atención a las Personas en Situación de Dependencia (LAPAD) -aunque algunas personas puedan hallarse en el ámbito de las dos leyes-, que no se define en relación con límites en las posibilidades de integración, sino con la necesidad de apoyos personales de terceros para desarrollar actividades básicas de la vida diaria, normalmente propias del ámbito doméstico. En este sentido, son leyes claramente diferentes en su objeto y su marco conceptual, aunque la inclusión de la figura del asistente personal en la LAPAD parece contradecir la claridad del modelo (esta figura ofrece más un apoyo a la integración social que una compensación de la dependencia).

La LISMI prevé acciones para promover la integración en diversos ámbitos. En el educativo, prevé que el sistema educativo establezca dispositivos para la incorporación a las escuelas ordinarias de las personas con discapacidad. En el del acceso al empleo, establece la reserva de puestos de trabajo en empresas ordinarias y la creación de empresas especiales adaptadas (los centros especiales de empleo). En la garantía de ingresos, creó un subsidio de garantía de ingresos mínimos específico, que, con el tiempo, se transformó en la pensión no contributiva por invalidez. No se trata aquí de presentarlas todas, pero éste es un ejemplo claro de articulación (mejor o peor desarrollada en la práctica) de una política multidimensional, transversal o integral para la integración social de un colectivo excluido.

La LISMI atribuye un papel específico a los servicios sociales, y señala algunas funciones que, aunque no atribuye a ningún sector en concreto, han acabado por corresponder a los servicios sociales. Los servicios sociales tendrían como responsabilidad central 'el desarrollo personal y la integración en la comunidad'. Ese 'desarrollo personal' tiene un sentido -si se consultan los documentos técnicos de la épocabastante similar a la idea de 'proceso de incorporación’ al que nos hemos referido antes. La integración en la comunidad hace referencia a la integración en espacios distintos del empleo, la educación o la salud, ya previstos en otros apartados de la ley. Se mencionan las acciones de integración en espacios sustitutivos del empleo para quienes no pueden trabajar (los centros ocupacionales), las acciones de apoyo en la vida diaria (atención domiciliaria, 
residencias), en el ocio, el deporte y el tiempo libre, la orientación a las personas con discapacidad y sus familias. La ley formula un concepto de los servicios sociales más claro y preciso que el de muchas de las leyes posteriores de los servicios sociales. Además, aunque no lo establecía la ley, se encargó posteriormente a los servicios sociales la función de valoración y calificación de la discapacidad.

Pensamos que este esquema nos da algunas pistas sobre cuál podría ser la definición del papel de los servicios sociales en las políticas de inclusión e incorporación. Seguidamente señalamos algunas de las tareas y funciones propias y específicas de los servicios sociales en este campo:

- La entrada en contacto y el establecimiento de vínculos con las personas en dificultad que permitan iniciar procesos de desarrollo personal para la incorporación social.

- La identificación, conjuntamente con las personas en dificultad, de las dificultades, limitaciones, capacidades y oportunidades para su desarrollo personal y su incorporación social. De esa identificación puede derivarse lo que se suele denominar valoración, es decir, algún tipo de reconocimiento formal de las dificultades y capacidades de la persona con efectos para su acceso a servicios o prestaciones.

- El acompañamiento de los procesos de incorporación, entendidos como procesos de desarrollo personal. Esto significa algo diferente y mucho más rico y complejo que el seguimiento, entendido como la verificación periódica de la situación. Este acompañamiento incluye facilitar el acceso y la incorporación a dispositivos de otros sectores (educativos, de salud, de acceso al empleo), cosa que no debe entenderse como simple orientación y derivación, sino también como mediación social del acceso y la incorporación.

- La provisión de apoyos orientados al desarrollo personal y a la integración en la comunidad, en el terreno de las capacidades personales y sociales, el funcionamiento familiar y doméstico, y las actividades de la vida diaria distintos del acceso a la educación formal, la atención sanitaria, o la formación y la inserción profesionales. Incluye acciones de tipo socioeducativo o psicosocial-como las habituales en programas de apoyo y educación familiar-, de mejora de habilidades sociales y personales, de potenciación de las capacidades y las redes sociales, o de impulso de la interacción y la participación sociales, entre otras.

Estas acciones pueden desarrollarse en un espacio no residencial, en el que la persona mantiene su vida cotidiana en el marco de su hogar, o en un espacio residencial, cuando por diferentes razones la persona no puede mantener su vida cotidiana en su hogar (porque carece de él, porque se encuentra en una situación de pérdida temporal de aquél, o porque lo especial de su situación así lo aconseja).
Señaladas las que nos parecen tareas propias de los servicios sociales, se pueden señalar algunas otras que no serían propias:

- La provisión de ingresos económicos de subsistencia a las personas que carecen de ellos. La garantía de ingresos mínimos (mediante una renta mínima -de inserción o no- o mediante otras prestaciones económicas) forma parte del sistema (y sector) de la garantía de rentas (pensiones, prestaciones por desempleo, salario mínimo), con cuyos otros componentes tiene que ser coherente (en cuantías, requisitos de acceso, paso de una prestación a otra). Su gestión puede hacerse desde los servicios sociales (como los servicios de empleo gestionan el acceso a las prestaciones por desempleo) si se considera que el acceso por esa vía facilita otro tipo de acciones de los servicios sociales (aunque cabe pensar que también puede dificultarlas). Tampoco sería descabellado que las rentas mínimas de inserción se gestionasen en los servicios de empleo, y que éstos pusieran a los perceptores que lo necesitaran en contacto con los servicios sociales (como ya está previsto en la regulación de la renta activa de inserción).

- La formación para el empleo y la inserción laboral tampoco son una tarea propia de los servicios sociales, como tampoco lo es el alojamiento permanente en una vivienda. Sin embargo, en los últimos años se han creado espacios para desarrollar las tareas que sí son propias de los servicios sociales (acompañamiento, apoyo al desarrollo personal) en el marco del empleo de inserción y el alojamiento tutelado.

La posición acerca de estas tareas impropias de los servicios sociales debería combinar la claridad conceptual y de responsabilidades con un cierto pragmatismo. El peligro es que su desarrollo en el marco de los servicios sociales distorsione las dos cosas. La gestión de las rentas mínimas desde los servicios sociales puede tener la ventaja de hacer entrar muy directamente a las personas perceptoras en contacto con una oferta de acciones de apoyo social. Pero corre el riesgo doble de convertir a los servicios sociales en agencias de gestión de prestaciones ( $y$, en especial, de control de sus perceptores y del fraude) y de convertir las rentas mínimas en una prestación discrecional 'de los servicios sociales'. El primer riesgo puede limitar o acabar con la capacidad de los servicios sociales de desarrollar su tarea (ésa sí, suya propia) de acompañamiento y apoyo. El segundo puede degradar la renta mínima a un premio económico discrecional. En el caso de que se considere conveniente mantener en los servicios sociales una función de este tipo, parece imprescindible una clara separación conceptual y, probablemente, una diferenciación funcional en la gestión.

Los servicios sociales tendrían que abordar algunos ajustes en su estructura para desempeñar sus responsabilidades en la acción contra la exclusión. 
Entre ellos, y como ideas para debatir, sugerimos los siguientes:

- Diferenciar y separar las funciones de garantía de ingresos (rentas mínimas, pensiones no contributivas) de las propias de apoyo y acompañamiento social, con independencia de que sea (o no) responsable el mismo departamento de la Administración.

- Definir mejor las responsabilidades de los servicios sociales. El mecanismo más potente es reconocer derechos a los ciudadanos. Cuando (o mientras) eso no sea posible, es necesario empezar a establecer obligaciones claras. Por ejemplo, se podría establecer la obligación de ofrecer alojamiento temporal a quienes no tengan sitio para dormir, o la obligación de ofrecer un determinado proceso de acompañamiento a personas en determinadas situaciones (perceptores de renta mínima o renta activa de inserción, personas que salen de la cárcel).

- Repensar la articulación institucional de los servicios sociales. Hoy día el sector presenta un panorama de gran complejidad, en el que actúan (a veces en el mismo territorio y con el mismo tipo de acciones) varios niveles de administraciones públicas y en el que la colaboración entre la Administración y el tercer sector está marcada por la inestabilidad y la dependencia. Resulta imprescindible una clarificación y simplificación del mapa de actores públicos, y una delimitación más clara de las responsabilidades y obligaciones de cada actor. Igualmente debería repensarse la relación entre la iniciativa social y el sector público, de forma que se valoricen los elementos más positivos del tercer sector (flexibilidad, capacidad de innovación, motivación, proximidad) y se compensen sus limitaciones (selectividad, distribución desigual sobre el territorio, dificultad de garantizar derechos).

\section{Algunas líneas para el desarrollo de la acción de incorporación}

La parte final de este artículo pretende presentar algunas líneas de desarrollo de la acción de incorporación de los servicios sociales que creemos que pueden abrir perspectivas de mejora. Se trata, por tanto de propuestas de desarrollo que deben ser discutidas y que, en parte, nacen de prácticas que se han desarrollado de forma parcial o limitada.

La acción de incorporación social de los servicios sociales debe combinar los ejes de desarrollo personal e integración comunitaria a los que nos hemos referido en el apartado anterior. Estos dos ejes presentan analogías con diferentes formas de acción (la atención individual y los proyectos comunitarios) e incluso con métodos diferenciados de trabajo social (trabajo social individual o de casos, y trabajo social comunitario). Sin embargo, esta diferencia de focos de atención (lo individual y lo colectivo) no debería llevar a una contraposición entre ambas formas de acción, ni a su separación radical. Acompañar los procesos de desarrollo personal pasa por fortalecer los vínculos con otros individuos en su comunidad de las personas marginalizadas, y requiere, por tanto, de acciones de tipo colectivo. Desde el otro lado, una acción de dinamización u organización comunitaria concebida aisladamente puede tener utilidad para el desarrollo general de la comunidad, pero corre el riesgo de dejar fuera a los sectores sociales más excluidos. La acción sobre la que estamos discutiendo aquí, la acción de incorporación de personas con dificultades especiales de integración desarrollada por los servicios sociales, debe saber articular actuaciones más individualizadas y más colectivas sobre los sectores excluidos y la comunidad a la que pertenecen.

\subsection{La importancia de la estrategia comunitaria en el trabajo de incorporación social}

La acción comunitaria de los servicios sociales es vista, en muchos casos, como la tarea pendiente. Aunque las realidades locales son diversas, hay un lamento extendido sobre la ausencia de trabajo comunitario, bien sea por el exceso de demanda de atención individual, o por un escaso convencimiento institucional sobre la utilidad de la acción comunitaria.

En ocasiones, la intervención comunitaria se ha desarrollado como una línea de acción separada de los servicios sociales de atención primaria. Sin embargo, sería probablemente útil concebir el trabajo comunitario como una herramienta de intervención transversal a todos los programas; debería servir para complementar el resto de intervenciones del nivel individual o familiar, servir a sus objetivos de manera articulada. El trabajo comunitario debería permitir:

- Incrementar las conexiones sociales y fortalecer la red social de las personas en dificultad.

- Utilizar las entidades sociales como mecanismo integrador de las personas en dificultad.

- Desarrollar el apoyo mutuo de personas con problemas comunes como recurso complementario de las prestaciones e intervenciones de los profesionales del servicio.

- Incorporar a los sectores socialmente más débiles por problemas de dependencia o exclusión a las organizaciones y entidades ciudadanas, así como las actividades organizadas por ellas.

- Desarrollar la capacidad de interlocución y negociación con los agentes implicados, como mecanismo prioritario de participación en la marcha de los servicios sociales.

- Denunciar y favorecer la participación de los propios colectivos afectados.

Por señalar algunos ejemplos concretos, en el trabajo de incorporación social, el trabajo comunitario permi- 
tiría: la promoción de redes sociales de apoyo para la incorporación de personas en situación de exclusión social; favorecer la sensibilidad social del vecindario, la escuela y las empresas sobre la situación de colectivos con dificultades; mediar en conflictos vecinales; reducir las actitudes discriminatorias; y conseguir la coordinación de las entidades que trabajan con sectores excluidos, mejorando la intervención conjunta y articulada.

Las dificultades existentes para desarrollar esta línea de desarrollo comunitario no son pocas. En primer lugar, es preciso vencer la fuerte presión que la demanda directa y la opinión pública ejercen, en el sentido de que lo importante es atender las situaciones más graves. En segundo lugar, un obstáculo organizativo importante lo constituye la dificultad de combinar las exigencias normativas de la administración pública (sobre todo, las referidas a los horarios y dedicación laboral de los trabajadores, a la posibilidad o no de realizar determinadas acciones) con las del trabajo comunitario.

Conviene recordar que el trabajo comunitario constituye una de las finalidades con las que surge el nivel primario de los servicios sociales, y que justifica su carácter local y descentralizado. Busca favorecer la solución de los problemas antes de que éstos afecten de manera más intensa y requieran de recursos especializados; llevar a cabo acciones para que la propia comunidad prevenga situaciones de drogadicción, hábitos sociales y relaciones familiares, y sea más integradora con los más excluidos, luche contra los prejuicios y en pro de la sensibilización.

Una de las críticas que con más fuerza se han hecho a lo que podemos llamar modelo asistencial de trabajo social en el seno de los servicios sociales es la de tener un mero efecto paliativo de las situaciones de dificultad. Las situaciones de exclusión social son efecto de múltiples causas sociales e individuales, pero sus causas de fondo pertenecen, sobre todo, al campo de las estructuras sociales, es decir, son estructuras sociales, exclusógenas. En la actualidad, la pérdida de la capacidad integradora del trabajo, la reducción de la capacidad protectora de la familia, la inmigración o la propia reducción de la capacidad protectora del Estado se constituyen en causas estructurales que influyen en la generación de situaciones de dificultad. Los factores individuales pueden explicar el grado e intensidad de la dificultad, o el hecho de que afecte con gravedad a unas personas y no a otras, pero la raíz del problema, en muchos casos, es estructural. Es evidente que afrontar estas causas estructurales trasciende la capacidad de acción de los servicios sociales y tiene que ver con políticas más generales. Sin embargo, el tratamiento de estos factores estructurales sí puede incidir en las formas de intervención del trabajo social.

El desarrollo de una estrategia preventiva frente a la exclusión social debería implicar a la comunidad y al conjunto de sus instituciones, empresas, sindicatos y asociaciones. Esta implicación podría articularse en programas de sensibilización, denuncia de situaciones de dificultad, creación de oportunidades de colaboración conjunta destinadas a favorecer la creación de empleo u otras formas de participación social.

Las entidades del sector no lucrativo ocupan un lugar fundamental en la intervención con personas en situación de exclusión en nuestro país. Debido a las limitaciones del sector público para ofrecer respuestas ágiles y especialmente orientadas a los más excluidos, las entidades sociales siguen haciéndose cargo de colectivos que suponen las manifestaciones más extremas de la exclusión social: personas sin hogar, prostitución, personas con problemas de dependencia al alcohol o las drogas. En los últimos años también han asumido buena parte de la atención directa a personas extranjeras con dificultades de integración social.

Las entidades sociales presentan determinadas potencialidades que les han permitido desarrollar recursos de incorporación social diversos y adaptados a la diversidad de los casos atendidos. La acción de las entidades se desarrolla en entornos de carácter flexible, de forma individual o en grupos pequeños (en talleres, aulas o centros); con finalidades distintas a las del planteamiento de una demanda por parte de la persona excluida (formación, búsqueda de empleo, ocupación). La simplicidad de su organización, la falta de dependencias, su cultura y cercanía con los problemas les han permitido llevar a cabo en muchas ocasiones trabajos de incorporación que pueden ser tomados como modelos positivos de intervención. Por el contrario, la acción actual en los servicios públicos tiene lugar en torno a la respuesta a una demanda que debe plantear de forma explícita el usuario, y a la gestión profesional y administrativa de ésta.

En el primer caso, el desarrollo de las actividades formativas o laborales permite el contacto continuado, al menos en tanto que dura dicha actividad, mientras que en la acción pública son más frecuentes los contactos de carácter puntual. En muchos casos, la fuerte demanda de los servicios, su volumen de trabajo, la falta de profesionales y la rigidez de horarios impiden el correcto desarrollo de acciones de acompañamiento.

La discusión sobre si desde instituciones públicas se puede desarrollar directamente un trabajo de acompañamiento y apoyo social en profundidad no es nueva. Ya desde el siglo XIX ha existido una corriente de opinión que sostiene que desde la 'frialdad' del funcionamiento administrativo público no es posible desarrollar una acción 'cálida' de apoyo social. No pretendemos resolver aquí ese debate. Sin duda, una acción profesional próxima de acompañamiento requiere de fórmulas de organización del trabajo adecuadas, que no son las del funcionariado administrativo clásico. Pero éste es un problema que no se produce sólo en la atención social, sino en todos los servicios humanos públicos. 
Sin embargo, sí parece razonable esperar que la administración pública se rija por el criterio de garantizar determinado nivel de atención a todos los ciudadanos que se considere como necesitados de ella. Garantizar el ejercicio de derechos ciudadanos y de obligaciones públicas es algo que el tercer sector ni puede ni debe hacer, y constituye la primera responsabilidad de la administración pública. Dicho de otro modo, la acción de los servicios (sociales) públicos debería regirse mayoritariamente por derechos subjetivos o, en su defecto, por obligaciones, y sólo una pequeña parte, orientarse hacia acciones voluntarias o discrecionales. Las acciones voluntarias y discrecionales son el rasgo distintivo del tercer sector, y en ese tipo de acciones, la Administración sí debería ser subsidiaria.

\subsection{El acompañamiento del desarrollo personal}

La tarea propia y central de los servicios sociales en las políticas de inclusión e incorporación es el trabajo de ‘apoyo social a la incorporación'. Este trabajo social puede definirse como un proceso de 'acompañamiento del desarrollo personal en el contexto de la comunidad'. Concebir la atención de los servicios sociales en estos términos conlleva incorporar varias ideas importantes.

El concepto de desarrollo personal (Casado, 2008) incluye varias ideas en el trabajo por la incorporación. En primer lugar, la idea de proceso o itinerario. Estos términos se vienen utilizando desde hace años en este terreno. Este planteamiento se diferencia de una concepción de la intervención centrada en una situación en un momento del tiempo, caracterizada por determinadas necesidades o carencias que se han de satisfacer con determinados recursos. La idea de proceso o itinerario nos remite a una parte del proceso biográfico de las personas, proceso que puede ser reorientado por éstas bajo los efectos de una serie de intervenciones a lo largo del tiempo. Puesto que remite al proceso o itinerario biográfico de cada individuo, no es lo mismo que una sucesión predefinida y estandarizada de fases o acciones.

En segundo lugar, está la idea de partir de las capacidades de las personas para desarrollarlas y potenciarlas, más que de las carencias para colmarlas. Es evidente que es necesaria una consciencia clara de las limitaciones, las carencias y los obstáculos que afectan a las personas en dificultad. Sin embargo, un enfoque de desarrollo personal pasa por construir a partir de las capacidades, por limitadas que puedan ser en algunos casos. Es así, por otra parte, como se produce el desarrollo personal en la vida de las personas que consideramos como 'no en dificultad' o 'no excluidas'. Esta concepción fundada en el empowerment se diferencia claramente de la que pone el énfasis de la intervención en el llamado 'binomio necesidades-recursos', es decir, en el diagnóstico de las carencias (necesidades) y el acceso a los recursos que las satisfarían.
En tercer lugar, los desarrollos se producen a partir de una situación de partida y evolucionan en cierta dirección, o en diferentes direcciones en diferentes fases: no son el camino que lleva a una meta predefinida. A partir de la situación en la que se encuentra una persona (situación que es resultado provisional de un proceso anterior), su proceso vital puede desarrollarse ‘a mejor' o ‘a peor', y lo hará a lo largo de fases 'mejores' y 'peores'. Acompañar estos procesos e intervenir para favorecer los desarrollos 'positivos', contener cuando se pueda los 'negativos' y aprender de cada etapa significa romper con el esquema de una imagen predefinida de la ‘curación', de la 'integración' lograda y tratar de arrastrar a la persona hacia esa meta.

En cuanto a la idea de acompañamiento, incluye varios elementos:

- La idea de la gestión del caso, del trabajo de caso en su sentido clásico. Ello supone una continuidad en la relación de intervención social y una relación de colaboración y de cierta confianza (véase la proximidad construida en el punto anterior). Requiere igualmente de un nivel importante de autonomía de los intervinientes y las personas atendidas a la hora de determinar el curso de acción y los recursos que se han de emplear (cosa perfectamente compatible con el establecimiento de límites y la rendición de cuentas).

- La idea de participación de las personas en dificultad, que tiene varios sentidos. Por una parte, aceptar el concepto de codiagnóstico, es decir, renunciar a la visión tecnocrática que considera al técnico como el único capacitado para establecer un diagnóstico y establecer que la identificación de la situación debe hacerse de común acuerdo entre profesionales y usuarios. Por otra, la codeterminación del proceso que se ha de desarrollar, es decir, el diseño conjunto de las acciones previstas. Y, en tercer lugar, la coproducción de la atención, tanto en el sentido del establecimiento de tareas y acciones por todas las partes, como la valorización de la aportación que las personas atendidas pueden hacer a su propio proceso, al de otros y a la colectividad.

El concepto de proximidad hace referencia también a varias ideas. En primer lugar, la idea de proximidad 'construida', es decir, de la creación o construcción de vínculos de cercanía y confianza entre personas en dificultad e 'intervinientes' sociales. Ello supone que la relación de acompañamiento del desarrollo personal no puede limitarse al contacto burocrático entre un ciudadano y la administración pública. Supone la necesidad de construir esa relación de confianza tanto en el primer contacto como en el proceso de acompañamiento.

En segundo lugar, la idea de proximidad activa hace referencia a la necesidad de asegurar el acceso de las poblaciones excluidas a los servicios. Dicho acceso no siempre es fácil y no faltan mecanismos de funcio- 
namiento que, de hecho, excluyen a dichas poblaciones (desde requisitos administrativos hasta horarios, pasando por la misma imagen externa de los servicios). La proximidad activa hace referencia a la disposición a 'ir a buscar' a las personas en dificultad allá donde se encuentran. Las prácticas de outreach y de trabajo de calle, por ejemplo, son coherentes con esta idea. La proximidad activa conecta con la idea de proactividad, de anticiparse a la demanda que puede no hacerse explícita.

En tercer lugar, hay que aludir a la idea de proximidad existencial, que se refiere al papel de las propias personas en dificultad en la atención de personas en dificultad. Incorporar a las personas en dificultad, o que han pasado por dificultades, como profesionales o agentes de la atención, así como en el apoyo mutuo, es en ocasiones un modo de facilitar la construcción de la relación de confianza a la que hemos hecho referencia antes, pero también de movilizar saberes y capacidades de intervención diferentes de los de los profesionales. Supone establecer un eslabón entre los profesionales 'externos' a la población atendida y ésta 4 .

\subsection{Diversidad de situaciones y diversidad de respuestas}

La expansión de la acción de los dispositivos de política social parece conducir de forma irremisible a una estandarización y seriación de determinadas acciones. En los ámbitos que se han desarrollado con cierta rapidez, es frecuente el lamento nostálgico por la etapa artesanal y cálida de los inicios, y por la pérdida progresiva de la proximidad y la personalización de la atención. No es infrecuente que mecanismos pensados para la personalización puedan convertirse en rutinas burocráticas. Piénsese en los planes individuales de rehabilitación (PIR) de personas con discapacidad, los contratos de integración de perceptores de la renta mínima de inserción (RMI) o los planes individualizados de atención (PIA) de la LAPAD. Sin embargo, la seriación parece inevitable cuando un determinado tipo de acción afecta a decenas, o cientos de miles, de ciudadanos, y es necesario garantizar una cierta igualdad de trato formal. La única posibilidad de mantener lo positivo y necesario de ambos enfoques es una cierta diferenciación de niveles y de acciones. La LAPAD tiene previsto un mecanismo de este tipo.

Por un lado, una determinación bastante estandarizada del grado y nivel de dependencia conlleva un cierto volumen de recursos asignados a la persona. Por otro, el PIA debería permitir la traducción de ese volumen de recursos en una oferta personalizada y diferenciada de servicios para cada caso. Los contratos de integración en las rentas mínimas tenían una configuración similar sobre el papel: todos los perceptores tenían que tener un contrato, pero el contenido

${ }^{4}$ Véanse los resultados del proyecto de investigación PROXCIT en Barcelona, Montreal y Ámsterdam. (Baillergeau et al., 2010). del contrato se podía establecer con gran libertad, a medida de cada caso. Pero la experiencia nos demuestra que esta diferenciación formal no acaba de funcionar. Seguramente es necesario separar ambas tareas en servicios o equipos diferentes y, sobre todo, establecer un mandato claro a los equipos encargados de la personalización, en el sentido de centrarse en la persona atendida. Más aún, la clave está en dar a la persona atendida una importante capacidad de decisión autónoma sobre el contenido concreto del apoyo, aunque la dimensión del apoyo esté limitada por un mecanismo estandarizado.

Un segundo factor decisivo es el marco de espacio y tiempo que permite desarrollar una acción de acompañamiento. En la intervención social se dan varios tipos de entornos: la consulta en el despacho, la participación en una actividad o un proyecto, la presencia en el hogar, el contacto en la calle, la atención residencial. Cada uno de esos entornos se caracteriza por espacios y tiempos diferentes. Espacios abiertos o cerrados, de parte o neutrales; tiempos breves o más largos, puntuales o frecuentes. El trabajo de acompañamiento puede desarrollarse en una combinación de esos entornos, pero no puede desarrollarse sólo en el tiempo breve y discontinuo, ni en el espacio cerrado e institucional del despacho o la consulta. El trabajo de incorporación social con personas en situación de exclusión requiere de cierta especialización. La naturaleza multidimensional de las situaciones que acumulan dificultades relacionadas con salud mental, dependencia, convivencia, falta de ingresos $u$ otras requieren formas de intervención basadas en la acumulación de saberes y experiencias de trabajo en incorporación social.

Las distintas manifestaciones de la exclusión requieren codiagnósticos e intervenciones individualizadas y adaptadas a cada realidad, que incluyan la aplicación de distintos recursos, junto con fuertes dosis de apoyo personal. Esto hace necesario aplicar metodologías de trabajo social del tipo que se ha venido llamando gestión de casos $^{5}$. En el mundo de la intervención social, se denomina gestión de casos a la metodología de intervención que unifica las responsabilidades sobre cada caso en un mismo profesional o equipo, responsable de la gestión de aquél y de la coordinación de las respuestas diversas que deban ofrecerse. Ello implica una continuidad temporal y una asignación importante de capacidades de decisión (y las correspondientes responsabilidades) al profesional o al equipo encargado de la gestión del caso. Se trata, en definitiva, de crear una relación de referencia entre el caso (persona o familia) y el profesional o equipo que se encarga de su gestión. Significa invertir el esquema que se produce frecuentemente en la atención pública del profesional que atiende cada demanda y la remite a la instancia correspondiente, que es la que decidirá; significa afianzar un modelo en el que el profesional atiende el caso y asume la decisión y la consiguiente responsabilidad.

\footnotetext{
${ }^{5}$ Véase, entre otros, Aguilar Hendrickson et al. (1998).
} 
Precisamente en este nivel de la atención primaria, los profesionales pueden llevar a cabo ese proceso de liderazgo del conjunto de intervenciones y recursos que deben concentrarse en la gestión de casos. Además, el trabajo en el nivel primario permite contar con las potencialidades de incorporación de la propia red social. En los países en los que se inició el desarrollo de la atención primaria, como el Reino Unido, éste se produjo como resultado de un proceso de integración en el nivel local de servicios anteriormente especializados. Es decir, se partía de servicios que, por su especialización, tenían el inconveniente de una visión parcial de los problemas -servicios a menores, discapacitados, enfermos de salud mental-, y se dejaban de lado otras problemáticas relacionadas con la situación de la familia o el aislamiento social. El community care permitía, frente al cuidado institucionalizado, mantener a las personas en su entorno, en su familia, con sus relaciones sociales: aprovechar, en suma, el poder integrador de las redes comunitarias, el asociacionismo, las amistades, el empleo y el ocio. Lo que se pretendía con el cuidado en la comunidad era, precisamente, tratar de manera especializada, pero bajo una visión global, las situaciones. Los servicios comunitarios, además, favorecían la utilización de recursos sociales (familia, asociaciones) en el trabajo especializado, lo que multiplicaba el efecto integrador de los procesos de ayuda. De este modo, en el nivel local se coordinaba la atención a los problemas económicos, de empleo y de salud mental de una única familia.

Sin embargo, en nuestro país la atención primaria ha construido un modelo de atención generalista. El proceso de desinstitucionalización de la atención especializada de salud mental o de menores no se ha integrado en la red de servicios sociales primarios (Aguilar Hendrickson et al., 1998). Precisamente por esta distancia existente en la actualidad entre el trabajo especializado de los servicios de atención a menores y a personas con problemas de salud mental y los servicios comunitarios, es difícil construir procesos de trabajo integral frente a los itinerarios de exclusión social. Es por ello por lo que, en la actualidad, muchas veces se interviene en las mismas situaciones de exclusión desde diversos estamentos (educación, salud mental, atención primaria) de manera fragmentada, sin que desde ninguno de ellos pueda asumirse la responsabilidad global de la intervención.

Es preciso, por tanto, dotar de recursos especializados en la incorporación social al nivel de atención primaria, ya que este nivel presenta importantes potencialidades para la intervención con personas excluidas:

- Éste es el nivel más cercano al terreno y, por ello, en él se pueden llevar a cabo las funciones de detección, acogida, escucha y recogida de las demandas concretas, partiendo de la posición y el momento de cada persona, y detectando demandas no explícitas, por ejemplo.

- Es el nivel en que se pueden realizar diagnósticos exhaustivos que tengan en cuenta todos los aspectos de la situación -familiar, laboral, social-, así como considerar las potencialidades vinculadas a las redes sociales existentes.

- Permite propiciar una primera respuesta a las demandas más acuciantes, favoreciendo el acceso a recursos de garantía de ingresos y otras prestaciones y recursos del propio sistema o del resto. Este acceso debe producirse a través del acompañamiento en el acceso a recursos de empleo, sanidad y vivienda, entre otros.

- Se pueden diseñar de manera negociada los procesos de incorporación social basada en la metodología de trabajo de casos, contando con recursos profesionales propios para la resolución de problemas: educación familiar, motivación, apoyo psicológico, emocional, acompañamiento social. Esto implica la coordinación multidisciplinar entre educadores, psicólogos, técnicos de empleo y trabajadores sociales.

- Se pueden utilizar las potencialidades de la comunidad en cuanto a recursos de empleo, asociaciones, grupos de apoyo, voluntariado y otros.

Es erróneo pensar que todas las personas en situación de exclusión necesitan orientarse principalmente hacia el acceso al mundo laboral. Lo que llamamos de modo un tanto formalista itinerario es el proceso por el que una persona rehace su vida. Sólo cada persona puede rehacer su vida, aunque a veces no pueda hacerlo sin apoyos. El rehacerse de la vida de cada persona es diferente: parte de su historia es única y sigue un camino que es único. Un tratamiento o un proceso formativo puede diseñarse, e incluso estandarizarse. No pasa lo mismo con el proceso de rehacer la propia vida.

A partir de los estudios sobre las condiciones de vida de la población excluida y de la experiencia de intervención, se puede establecer cierta diferenciación de situaciones (Pérez Eransus, 2009):

- Hay personas que, por determinadas circunstancias, se encuentran en desempleo (minorías étnicas, inmigrantes, desempleados de más de 40 años, mujeres solas con cargas familiares), pero que presentan una clara capacidad de trabajar. En algunos casos, tienen cualificación y motivación para el empleo. Podría decirse que se encuentran en la línea de salida para acceder al empleo, pero debido a circunstancias personales, procesos de discriminación, a la alta competitividad del mercado laboral y, en momentos como el actual, a la coyuntura económica, no acceden a él. En muchos casos, llevan a cabo actividades laborales, pero de forma irregular. En estos casos, la estrategia de incorporación puede centrarse en la búsqueda de recursos de activación de carácter formativo y laboral. Sería preciso tener en cuenta, además del seguimiento laboral, un apoyo social continuado que permitiera superar otras problemáticas de la persona, como el acceso a la regularización o a la vivienda. En los casos de personas con cargas 
familiares, pueden ser valiosos los recursos de apoyo, como guarderías, centros de día y similares.

- Hay otras personas que no se encuentran en disposición de incorporarse rápidamente a un empleo, por la falta de experiencia, cualificación o de habilidades y hábitos para el empleo, o por la presencia de problemas personales o familiares. En estos casos, se hacen necesarios recursos prelaborales que favorezcan no sólo la formación ocupacional, sino también la adquisición de hábitos, la estabilidad personal, la mejora de la autoestima o la motivación, entre otras cuestiones; recursos tales como empresas de inserción, centros de empleo o empleo protegido. Con este colectivo, resulta aún más necesario un acompañamiento social paralelo que favorezca la resolución del resto de dificultades.

- Las personas con un nivel elevado de dificultad personal y social poseen una muy difícil empleabilidad. Es el caso de personas sin hogar, toxicómanos, personas con problemas de salud mental. Presentan falta de hábitos para el trabajo, problemas de disponibilidad real, de motivación y, en ocasiones, de marginación. Por esta razón, precisan más preparación personal y profesional previa, así como un acompañamiento más intensivo en el itinerario de incorporación sociolaboral. Los recursos de activación adecuados a estas situaciones (empleo protegido, talleres prelaborales u ocupacionales) deben ser más flexibles, y adaptados a sus ritmos y momentos personales. En estos casos, el eje de la intervención también debe ser el acompañamiento social orientado a mejorar las condiciones de vida de las personas.

- Hay que aceptar también que hay personas cuyas posibilidades reales de empleo son nulas o muy escasas. Sería el caso de personas con severas discapacidades físicas, psíquicas o sociales, en cuyo caso la activación deberá orientarse exclusivamente hacia otros objetivos personales y sociales, y a la mejora de sus condiciones de vida.
De este modo, los procesos de incorporación deben contemplarse como una estrategia que complemente la protección económica, reforzándola y adaptándose a las diversas situaciones analizadas, como hemos visto a través de distintas formulaciones:

- Dispositivos destinados a favorecer la disponibilidad para el trabajo de hogares con cargas familiares no compartidas (recursos de cuidado de menores y mayores).

- Mecanismos de intervención social de carácter integral que permitan superar situaciones de exclusión mediante la coordinación de acciones en distintos ámbitos, como salud, vivienda o acompañamiento social.

- Dispositivos de empleo de carácter ocupacional o social que permitan la utilización del empleo con el fin de 'activar' procesos personales de aquellas personas con problemas de salud mental, problemas físicos o avanzada edad.

- Programas de formación y empleo que favorezcan la cualificación de las personas que sí se encuentran en disponibilidad para incorporarse al mercado laboral normalizado.

El diseño de este último tipo de recursos de activación de carácter más cualificante debe realizarse en colaboración con los servicios de empleo, teniendo en cuenta las características de los usuarios y las necesidades del mercado laboral de cada zona. La situación actual de falta de empleo sin duda debe conllevar un esfuerzo extra por buscar recursos que favorezcan la cualificación a largo plazo, vinculada a salidas laborales específicas, potenciadas por iniciativas de parteneriado público-privado.

En suma, los servicios sociales de atención primaria deberían avanzar en el diseño de un abanico amplio de recursos de incorporación social adaptados a las características y el nivel de empleabilidad de la población excluida. 
AZNAR LÓPEZ, M. (1996): “En torno a la beneficencia y su régimen jurídico”, Civitas. Revista de Derecho Administrativo, № 96, págs. 555-565.

- (1990): “Lugares comunes en acción social sobre la pretendida graciabilidad de la beneficencia", Boletín del CEBS, $\mathrm{n}-23$.

AGUILAR HENDRICKSON, M. (2010): "La huella de la beneficencia pública en los servicios sociales modernos en España", Zerbitzuan, no 48, págs. 9-16 [/http://www.zerbitzuan.net/ documentos/zerbitzuan/La\%2ohuella\%20 de\%2ola\%2obeneficencia.pdf $\rangle]$.

- (2009): "Los servicios sociales: las tribulaciones de un sector emergente", en MORENO FERNÁNDEZ, L. (ed.), Reformas de las políticas de bienestar en España, Madrid, Siglo XXI, págs. 171-206.

AGUILAR HENDRICKSON, M. et al. (1998): "La atención social en la comunidad”, en DEPARTAMENTO DE BIENESTAR SOCIAL, DEPORTE Y JUVENTUD (ed.), Documento base para un plan de atención comunitaria de servicios sociales, Pamplona, Gobierno de Navarra, págs. 15-75 [<http://www. navarra.es/NR/rdonlyres/1EoCEE39-4B1F-4C27BA11-25811A31C598/91938/doc_comp.pdf〉].

BAILLERGEAU, E.; THIROT, M.; y LLOBET ESTANY, M. (2010): "Au contact des invisibles. L'intervention de proximité dans l'espace public", Revue du CREMIS, vol. 3, no 3 , págs. 32-40 [ [rhttp://www. cremis.ca/docs/Vol\%203\%20No\%203\%20 24\%20sept\%202010\%2096\%20dpi.pdf〉].

CARASA SOTO, P. (2007): "Lo privado y lo público en el sistema asistencial: el triángulo IglesiaAyuntamiento-Estado en la beneficencia española", en ABREU, L. (ed.), Asistencia y caridad como estrategias de intervención social: Iglesia, Estado y comunidad (siglos XV-
XX), Bilbao, Universidad del País Vasco, págs. 141-72.

- (2004): “Beneficencia y “cuestión social': una contaminación arcaizante”, Historia Contemporánea, nํ29, págs. 625-670 [khttp:// www.historiacontemporanea.ehu.es/soo21. con/es/contenidos/boletin_revista/00021_ revista_hc29/es_revista/adjuntos/29_04.pdf)].

CÁRITAS ESPAÑOLA (2010): Memoria 2009, Madrid, Cáritas Española [<http://www.caritas.es/memorias. aspx?Id=227〉].

CASADO, D. (2008): “Los servicios sociales: carencias relativas a las situaciones de pobreza y marginación social; y exclusiones y desigualdades de su acción protectora", en ARRIBA GONZÁLEZ DE DURANA, A. (ed.), Políticas y bienes sociales. Procesos de vulnerabilidad y exclusión social, Madrid, FOESSA-Cáritas, págs. 535-609.

- (2002): Reforma política de los servicios sociales, Madrid, CCS.

COLMEIRO, M. (1850): Derecho administrativo español, Madrid; Santiago, Librerías de Don Ángel Calleja.

ESTEBAN DE VEGA, M. (1992): “La asistencia liberal española: beneficencia pública y previsión particular", Historia Social, no 13, págs. 123-138.

GUILLÉN, A. M. (2010): "Defrosting the Spanish Welfare State: The weight of conservative components", en PALIER, B. (ed.), A Long Goodbye to Bismarck? The Politics of Welfare Reform in Continental Europe, Ámsterdam, Amsterdam University Press, págs. 183-206.

KAHN, A. J.; y KAMERMAN, S. B. (1987): Los servicios sociales desde una perspectiva internacional. 
El sexto sistema de protección social. Estudios comparados de diferentes sistemas nacionales de servicio social, Madrid, Consejo General de Colegios Oficiales de Diplomados en Trabajo Social y Asistentes Sociales.

LAPARRA; M.; y PÉREZ ERANSUS, B. (eds.) [2010]: El primer impacto de la crisis en la cohesión social en España. Un análisis provisional a partir de las Encuestas FOESSA, 2007-2009, Madrid, Fundación FOESSA; Cáritas [<http://www. vientosur.info/documentos/Informe\%20 Foessa\%20Caritas.pdf $>$.

PÉREZ ERANSUS, B. (2009): "La activación como estrategia de lucha contra la exclusión social", Documentación Social, no 134, págs. 125-142 [khttp://www.caritas.es/imagesrepository/ CapitulosPublicaciones/484/
Tribuna\%20Abierta\%20Capitulo\%20 02_25_09_2008_12_51_00.pdf〉].

RENES, V. (ed.) (2008): VI Informe sobre exclusión y desarrollo social en España 2008, Madrid, Fundación FOESSA; Madrid, Cáritas Española [rhttp://www.foessa.es/publicaciones_Info. aspx? $\mid$ dd=379>].

RODRÍGUEZ CABRERO, G. (1989): “Orígenes y evolución del Estado de bienestar español en su perspectiva histórica. Una visión general”, Política y Sociedad, no 2, págs. 79-87 ['http://revistas. ucm.es/index.php/POSO/article/view/ POS08989130079A/30671>].

VIDA SORIA, J. (1968): “Asistencia social en el ordenamiento de la Seguridad Social española”, Revista de Trabajo, no 21, págs. 51-73. 


\title{
Estrategia Europa 2020 e inclusión social: distanciamiento creciente entre objetivos, políticas e instrumentos.
}

\author{
José Manuel Fresno \\ Consejo para la Promoción de la Igualdad de Trato y no Discriminación \\ de las Personas por el Origen Racial o Étnico \\ <josemanuel.fresno@gmail.com>
}

\section{Víctor Renes Ayala}

Revista Española del Tercer Sector

\section{Andreas Tsolakis \\ Fundación Secretariado Gitano}

\begin{abstract}
Lisboako Estrategiaren ostean, Europar Batasunak hartu du hazkuntza adimentsu, iraunkor eta integratzailearen aldeko Europa 2020 Estrategia. Bertan zehazten dira enpleguaren arloko helburu handinahiak, hezkuntza-mailaren hobetzea eta pobrezia eta gizarte-bazterketaren urritzea; eta helburu horiek guztiak zehaztu dira herrialdeetan burututako Erreforma Programa Nazionalen baitan. Estrategia berriaren urtebeteko ibilbidea eginik eta krisialdiaren bete-betean nabarmentzen da, bereziki Espainian, gero eta alde nabariagoa helburu horiek lortzearren indartu beharreko politika, baliabide eta bitartekoen artean. Egileek erakusten dutenez, Espainiako kasuan, desberdintasun-mailaren hazkuntza ebidentzia harturik, urruntze hori krisialdiaren aurretik ere ageri omen zen Espainian, eta horren ondorioz, proposatzen dute hartzen ari diren politika eta neurri horietarako aurrekontuak berrikustea, betiere, nahi bada joeren aldaraztea eta erabat gizarteratzeko baliabide gertaraztea.
\end{abstract}

\section{HITZ-GAKOAK:}

gizarteratzea, bazterketa, pobrezia, Europa 2020 Estrategia, Erreforma Programa Nazionala.
Tras la Estrategia de Lisboa, la Unión Europea ha adoptado la Estrategia Europa 2020 basada en un crecimiento inteligente, sostenible e integrador. En ella, se fijan objetivos ambiciosos en materia de empleo, mejora de los niveles educativos y reducción de la pobreza y exclusión; estos objetivos han sido concretados por los Estados miembros en sus Programas Nacionales de Reforma. Tras un año de andadura y en plena crisis económica, se constata, especialmente en España, un distanciamiento creciente entre los objetivos marcados por la estrategia, las políticas, los instrumentos y los medios que se están poniendo en marcha para alcanzar dichos objetivos. Los autores demuestran que, en el caso español, este distanciamiento, evidenciado en el crecimiento de las desigualdades, era anterior a la crisis y, en consecuencia, proponen la necesidad de revisar los presupuestos de los que parten las políticas y medidas que se vienen adoptando, como requisito indispensable para que inviertan las tendencias y sean realmente inclusivas.

\section{Palabras Clave:}

inclusión social, exclusión, pobreza, Estrategia Europa 2020, Programa Nacional de Reforma.

${ }^{1}$ Este artículo toma como base un trabajo anterior, publicado originariamente en José Manuel Fresno y Andreas Tsolakis, Propuestas del tercer sector de acción social para una estrategia de inclusión social 2020 en España, Madrid, EAPN-España, 2010, actualizando los datos e incorporando nuevas perspectivas. 


\section{Introducción}

La Unión Europea plantea sus objetivos de crecimiento y desarrollo a largo plazo, normalmente para una década de duración. En la década de los noventa, los retos se concretaron en el libro blanco Crecimiento, competitividad, empleo (Comisión Europea, 1994). En la primera década de este siglo, se adoptó la Estrategia de Lisboa (Consejo de la Unión Europea, 2000), basada inicialmente en los ejes de crecimiento, empleo e inclusión, si bien este último eje fue cambiado por la gobernanza en la revisión de 2005 (Comisión Europea, 2005). Para la segunda década de este siglo, los objetivos se fijaron en la Estrategia Europa 2020 (Comisión Europea, 2010a).

Una de las enseñanzas más importantes de la Estrategia de Lisboa, de la que se tomó conciencia a medio camino de su andadura, es la necesidad de alinear estrechamente los objetivos con los instrumentos y los recursos que se disponen para alcanzarlos (Kok, 2004). Por eso se procedió a su revisión, introduciendo como uno de los elementos claves la cuestión de la gobernanza, pues aunque los objetivos se adoptan a escala europea, siguiendo el principio de subsidiariedad, han de ser aplicados por cada uno de los Estados miembros.

En un esfuerzo de simplificación, dado que la Estrategia de Lisboa se había hecho incomprensible con tantos objetivos y medidas, la Estrategia 2020 ha querido focalizarse en cinco ambiciosos objetivos cuantitativos, con resultados intermedios en $\mathbf{2 0 1 5}$, en torno a los cuales se articula todo el proceso de gobernanza. Por primera vez, se ha fijado un objetivo preciso y cuantitativo de reducción de la pobreza y de la exclusión social en la UE (“El riesgo de pobreza debería amenazar a 20 millones de personas menos") [Comisión Europea, 2010a: 3], superando las ambigüedades de la Estrategia de Lisboa, en cuyos textos se afirmaba pretender erradicar la pobreza en 2010 (Consejo de la Unión Europea, 2000).

Desde que se concibió y adoptó la Estrategia 2020, las tendencias sociales que se observan no solamente no conducen a alcanzar los objetivos fijados, sino que se distancian de ellos. De hecho, la crisis se ha llevado por delante diez años de progreso social en Europa y los niveles de protección social están decreciendo en un contexto de ajustes fiscales (Comisión Europea, 2010a: 3). Todo parece indicar que esta tendencia continuará, con lo cual nos alejaremos del objetivo en materia de pobreza, pues bien es sabido que contar con adecuados niveles de protección es un prerrequisito para reducirla.

Esta tendencia socioeconómica adversa cuestiona el objetivo planteado de reducción de pobreza y exclusión para España, máxime si se tiene en cuenta que los desequilibrios de partida (crecimiento de las desigualdades, mantenimiento de las tasas de pobreza y no eliminación de los problemas estructurales básicos que conducen a ésta) [Fresno y Tsolakis, 2010] vienen de una situación que ya se había ini- ciado antes de la quiebra del crecimiento económico, en 2008. En efecto, la situación 'poscrisis', nueva en su intensidad y permanencia, no significa que estemos partiendo desde cero; la 'antecrisis', nos había dejado tendencias que planteaban cuestiones de calado para poder cumplir el objetivo planteado en la Estrategia 2020. En síntesis, podemos hacer referencia a dos tipos de situaciones de partida.

Durante la etapa de gran crecimiento del PIB y del empleo (1995-2007), la falta de traducción de las mejoras de la renta media en reducciones de la desigualdad resultó de factores muy diversos, encontrándose claves explicativas tanto en el ámbito de la generación de las rentas primarias (las procedentes del mercado laboral) como en los límites de la intervención pública con objetivos redistributivos (el gasto social y la contención de la protección social, especialmente en su intensidad protectora) [Ayala, 2009]. En suma, el resultado fue que:

Desde comienzos de los años noventa, el nuevo patrón distributivo en España se caracterizó por una relativa estabilidad en la desigualdad de las rentas de mercado, sin mejoras visibles en la capacidad redistributiva de las prestaciones monetarias (ibídem, 2009: 100).

Junto a ese patrón poco distributivo, la 'sociedad del crecimiento' estaba atravesada por la 'fragilidad' de los componentes que, en una sociedad, producen cohesión y vinculación social, es decir, los sistemas sociales que deben garantizar los mecanismos de acceso a bienes básicos, fundamentales para la integración y la cohesión social. Su fragilidad se mostraba en que los propios sistemas generaban vulnerabilidades que no se contemplaban en su diseño y resultados negativos de los que no se hacían cargo, remitiendo a los perjudicados al sistema de servicios sociales y consolidando así su exclusión.

Cabe suponer que estas tendencias no solamente no remitirán, sino que se acrecentarán mientras no se promuevan las condiciones macrosociales y microsociales que facilitan el acceso a bienes básicos. Se plantea, por tanto, la necesidad de que las políticas sean definidas desde la óptica de los derechos sociales y de que las medidas de austeridad no ignoren el principio de la cohesión social, necesario para el progreso equitativo de las sociedades; se requieren, en definitiva, políticas inspiradas en los principios de garantía y protección de la ciudadanía, desarrolladas en un marco adecuado de gobernanza social.

\section{Concreción de la Estrategia Europa 2020 en los programas nacionales de reforma}

\subsection{Estrategia 2020}

La Estrategia Europa 2020 marcará las trayectorias nacionales, y en buena medida autonómicas, en los ámbitos económico y de desarrollo en la presente década. Propone un crecimiento para Europa que ha de 
tener tres características: inteligente, es decir, basado en una economía del conocimiento y de la innovación; sostenible, esto es, que haga un uso más eficaz de los recursos (economía verde); e integrador, para lo cual se requiere el fomento de una "economía con alto nivel de empleo que tenga cohesión social y territorial” (Comisión Europea, 2010a: 5). Tres de los cinco objetivos principales de la Estrategia están estrechamente relacionados con la inclusión y la cohesión social:

- En materia de empleo, se plantea que el $75 \%$ de la población de entre 20 y 64 años debería estar empleada (objetivo 1).

- En el ámbito educativo, el porcentaje de abandono escolar debería ser inferior al 10\% (objetivo 4).

- Al menos el 40\% de las personas con edades comprendidas entre 30 y 34 años debería tener estudios superiores completos; en cuanto a la exclusión social y el riesgo de pobreza, deberían amenazar a 20 millones de personas menos (objetivo 5).

Una de las siete iniciativas emblemáticas para alcanzar estos objetivos es la creación de una "plataforma europea contra la pobreza”, que permita garantizar la cohesión social y territorial, de tal forma que los "beneficios del crecimiento y del empleo sean ampliamente compartidos y las personas que sufren de pobreza y exclusión social puedan vivir dignamente y tomar parte activa en la sociedad" (ibídem: 6). Otra de las iniciativas es la creación de una "agenda de nuevas cualificaciones y empleos" (loc. cit.), para modernizar los mercados laborales y potenciar la autonomía de las personas mediante el desarrollo de capacidades a lo largo de su vida; de esta manera, también se conseguiría aumentar la participación laboral y adecuar mejor la oferta y la demanda de trabajos, en concreto, mediante la movilidad laboral.

El Consejo Europeo de Empleo, Política Social, Sanidad y Consumo (Consejo EPSSCO) acordó en 2010 la formulación de objetivos cuantificables para la inclusión social, que se han de traducir en que, en 2020, en Europa debería de haber 20 millones menos de personas excluidas (Consejo de la Unión Europea, 2010). Un cambio importante está relacionado con los criterios de medición de la pobreza, pues el número total de personas en situación de riesgo de pobreza y de exclusión tiene que medirse sobre la base de tres indicadores que reflejan sus diferentes dimensiones:

- El índice de riesgo de pobreza por debajo del $60 \%$ de la renta mediana.

- El índice de privación material, que hace referencia a una situación en la que las personas están privadas de los bienes y servicios considerados necesarios para gozar de un nivel de vida decente en el país donde viven ${ }^{2}$.

\footnotetext{
${ }^{2}$ La privación material severa tiene lugar cuando se presentan
} cuatro de siguientes nueve situaciones (Eurostat, 2010b):
- La baja intensidad laboral en el hogar, o proporción de personas que viven en hogares con personas desempleadas $(0,20)$.

En línea con los objetivos marcado por la Estrategia 2020, la Comisión Europea presentó al Consejo las directrices tanto para las políticas económicas como para las de empleo (Comisión Europea, 2010b y 2010c). En concreto, en lo concerniente al empleo, la directriz no 7 persigue "aumentar la participación en el mercado laboral y reducir el desempleo estructural” (Comisión Europea, 2010c: 9-10); la noㅡ 9 pretende "mejorar los resultados de los sistemas educativos y de formación en todos los niveles e incrementar la participación en la enseñanza superior" (ibídem: 10-11); y la no 10, "promover la inclusión social y luchar contra la pobreza” (ibídem: 11). Seguidamente transcribimos completa esta última directriz para dejar constancia de los contrates entre ésta y las políticas que se están llevando a cabo con motivo de los ajustes presupuestarios:

Los esfuerzos de los Estados miembros para luchar contra la pobreza deberán promover la plena participación en la sociedad y la economía, y ampliar las posibilidades de empleo, aprovechando al máximo el Fondo Social Europeo. Asimismo deberán concentrarse en garantizar la igualdad de oportunidades, entre otras cosas, mediante el acceso a servicios y servicios públicos asequibles, viables y de gran calidad (incluidos los servicios en línea, de conformidad con la directriz $n^{0} 4$ ), y especialmente la atención sanitaria. Los Estados miembros deberán establecer medidas efectivas contra la discriminación. De la misma manera, para luchar contra la exclusión social, potenciar la autonomía de las personas y promover la participación en el mercado laboral, deben reforzarse los sistemas de protección social, el aprendizaje permanente y las políticas de inclusión, a fin de crear posibilidades en distintas etapas de las vidas de las personas y protegerlas contra los riesgos de exclusión. Es necesario modernizar los sistemas de seguridad social y de pensiones a fin de poderlos desplegar plenamente, para garantizar un apoyo adecuado a las rentas y el acceso a la atención sanitaria -ofreciendo así cohesión social-, a la vez que siguen siendo viables desde el punto de vista financiero. Los sistemas de prestaciones deberán centrarse en garantizar ingresos durante los

- La familia no puede permitirse: 1) hacer frente a gastos ines perados; 2) una semana de vacaciones anuales fuera de casa; 3) pagar los atrasos (hipoteca o alquiler, facturas de servicios públicos o el alquiler de cuotas de compra u otros créditos); 4) una comida con carne, pollo o pescado o el equivalente vegetariano cada dos días; 5) mantener adecuadamente su casa caliente.

- La familia no podría permitirse (si lo quisiera): 6) tener una lavadora, un televisor en color, un teléfono o un coche personal.

- La vivienda se ve afectada por: 7) humedad en el techo, las paredes, los suelos o los cimientos, o bien marcos de ventanas podridos; 8) déficit de luz, o ausencia baño, ducha o inodoro con evacuación adecuada para el uso exclusivo del hogar; 9) falta de espacio (definido como un número insuficiente de habitaciones en comparación con el número de personas). 
periodos de transición y en reducir la pobreza, especialmente entre los grupos en riesgo de exclusión social, como las familias monoparentales, las minorías, los discapacitados, los niños y los jóvenes, los ancianos, los inmigrantes en situación regular y las personas sin hogar. Asimismo, los Estados miembros promoverán activamente la economía y la innovación sociales en apoyo de las personas más vulnerables (loc. cit.).

El hecho de que se haya introducido una nueva cláusula social en el Tratado de Lisboa contribuye a que la protección social y la lucha contra la exclusión adquieran más relevancia en la Estrategia 2020 que en la Agenda de Lisboa. Entre los objetivos sociales incorporados, se pueden destacar la posibilidad de incorporar transversalmente lo social en el proceso de gobernanza. Todo parece indicar que los importantes y ambiciosos objetivos políticos, educativos, de empleo y de reducción de la pobreza podrían verse truncados (al igual que ocurrió con la Estrategia de Lisboa) si no se ponen los mecanismos y recursos necesarios para conseguirlos. Por otra parte, si bien la Estrategia apunta a un modelo de crecimiento que tiene en cuenta aspectos del bienestar no reducidos a lo económico, no plantea ninguna redistribución de recursos, ni objetivos de reducción de las desigualdades (por ejemplo, mediante el índice Gini), prácticamente no hace referencia a las personas ni a los colectivos más vulnerables (con o sin empleo), y no plantea una transformación real en las actuaciones de los mercados financieros y en las relaciones de poder entre capital financiero y sociedad en su conjunto.

En cuanto a los instrumentos económicos con los que cuenta la UE para apoyar los objetivos de la Estrategia 2020, el más importante concierne a la política de cohesión, que se concreta en los Fondos Estructurales. La Comisión presentó en octubre de 2011 las propuestas reglamentarias para el periodo 20142020, que actualmente están en discusión (Comisión Europea, 2011c). Entre las once prioridades temáticas, destaca la $n^{0}$ 9, que se centra directamente en "promover la inclusión social y combatir la pobreza" (ibídem: parte I, pág. 5). Además, los borradores de reglamentos plantean que un $20 \%$ del Fondo Social Europeo sea destinado a la lucha contra la exclusión, y que se establezcan condiciones ex ante en materia de igualdad de género, discriminación y discapacidad, para que los Estados puedan acceder a determinados objetivos temáticos. Bien es cierto que todas estas exigencias parecen contar con pocas posibilidades de hacerse efectivas si nos atenemos a las deliberaciones del Consejo.

\subsection{Programas Nacionales de Reforma}

En el marco de las decisiones del Consejo y dentro del objetivos generales de reducción de la pobreza de la Estrategia 2020 y de la concreción que se haga ellos, los Estados miembros tienen la libertad de establecer objetivos basados en indicadores que con- sideren más apropiados y acordes con sus circunstancias y prioridades nacionales. Sin embargo, sus objetivos y prioridades nacionales tienen que contribuir a lograr los objetivos EU-2020. Los objetivos nacionales se concretan en los Programas Nacionales de Reforma, que los Estados prepararon en diálogo con la Comisión Europea y presentaron por primera vez en la primavera de 2011; en la primavera de 2012 los han actualizado.

Un primer análisis de los resultados de estos programas nos lleva a constatar que la suma de los objetivos marcados por cada uno de los países para el año 2020, en los ámbitos a los que nos estamos refiriendo, no permitirían alcanzar los objetivos que se han marcado en conjunto, especialmente en lo que respecta a la reducción de la pobreza. Además, las informaciones disponibles respecto a 2011, permiten ya indicar que los resultados conseguidos no van en la dirección esperada (Comisión Europea, 2012):

- El objetivo de la Estrategia 2020 es conseguir una tasa de empleo de $75 \%$ en 2020 . Sin embargo, aunque todos los Estados miembros cumplan con sus objetivos nacionales, la tasa de empleo de la UE llegaría a 73,5-74,0\%. En 2011, no hubo ningún progreso significativo, y se espera que la tasa de empleo no supere el $70 \%$ este año $(68,6 \%$ en 2010); el nivel más alto se situó en el 70,3\%, antes de la crisis.

- El objetivo de la Estrategia 2020 es sacar a 20 millones personas de la pobreza y de la exclusión hasta 2020. De acuerdo a la suma de los compromisos nacionales, este objetivo no se logrará, pues se llegaría a un total de 12 millones de personas. Cierto que puede haber repercusiones positivas con medidas de lucha contra la pobreza infantil y el desempleo de larga duración, que podrían incrementar el resultado en un $25 \%$ y llegar así a los 15 millones de personas, pero sería aún insuficiente.

- El objetivo de la Estrategia 2020 es reducir el abandono escolar a menos del 10\% y aumentar al $40 \%$ hasta 2020 la proporción de personas de 30 a 34 años de edad con estudios universitarios 0 similares completados.

- El objetivo de reducción del abandono escolar no se alcanzará basándose en los compromisos nacionales (se llegará al 10,5\% sumando estos compromisos). Téngase en cuenta, además, que se parte del $14,1 \%$ de abandono escolar en 2010 , pero con variaciones muy significativas entre países y en el seno de éstos; el caso español duplica la media comunitaria.

- El objetivo relativo a la educación terciaria no se cumplirá según los compromisos nacionales (37\%), aunque otras tendencias más recientes sugieren que se podría alcanzar.

- El último Programa Nacional de Reforma, presentado en la anterior legislatura (2011), planteaba cinco principales retos macroeconómicos para España en la próxima década: 


\begin{tabular}{|c|c|c|c|c|c|c|c|c|c|c|c|c|c|c|}
\hline \multirow[b]{2}{*}{ Años } & \multicolumn{4}{|c|}{ Tasa de empleo (\%) } & \multicolumn{4}{|c|}{ Abandono escolar (\%) } & \multicolumn{4}{|c|}{ Enseñanza superior (\%) } & \multicolumn{2}{|c|}{$\begin{array}{l}\text { Reducción de la población } \\
\text { en riesgo de pobreza o exclusión } \\
\text { social (en millones de personas) }\end{array}$} \\
\hline & 2008 & 2009 & 2010 & 2020 & 2008 & 2009 & 2010 & 2020 & 2008 & 2009 & 2010 & 2020 & 2010 & 2020 \\
\hline $\begin{array}{l}\text { Objetivos } \\
\text { generales de } \\
\text { la UE-27 }\end{array}$ & 70,3 & 69,0 & 68,6 & 75,0 & 14,9 & 14,4 & 14,1 & 10,0 & 31,1 & 32,3 & 33,6 & 40,0 & 115,7 & 20,0 \\
\hline $\begin{array}{l}\text { Objetivos de } \\
\text { España }\end{array}$ & 68,3 & 63,7 & 62,5 & 74,0 & 31,9 & 31,2 & 28,4 & 15,0 & 39,8 & 39,4 & 40,6 & 44,0 & 11,6 & $1,4-1,5$ \\
\hline
\end{tabular}

Fuente: Gobierno de España (2012: anexo 8).

consolidación fiscal y sostenibilidad de las finanzas públicas; mejora del funcionamiento del mercado laboral, mejora de los sistemas de fijación de salarios, mejora del crecimiento de la productividad, corrección de los equilibrios en el sector inmobiliario y refuerzo del sistema financiero. Además, identifica cinco retos temáticos en línea con los objetivos de la Estrategia Europea (empleo, investigación y desarrollo, energía y clima, educación, y pobreza/inclusión social) [Gobierno de España, 2011].

En cuanto a la educación, el Programa Nacional de Reforma fija como objetivo para España la reducción de la tasa de abandono escolar prematuro en 2020 , hasta dejarla en el $15 \%$. Las tasas de abandono escolar se situaban en el 31,2\% de la población en el 2009 (la media europea era del 14,4\%), si bien se han reducido algo en los últimos años (Eurostat, 2010). Los altos porcentajes de abandono escolar están relacionados con múltiples causas, entre las que se señalan de forma reiterada la insuficiencia de recursos en el sistema educativo, la falta de adaptación de estos recursos a las personas con necesidades específicas y la escasa calidad del citado sistema. De hecho, la inversión educativa permanece en niveles similares desde 2000 , es decir, en el 4,2\% del PIB, mientras que la media europea está en el 5,3\%. No parece que los programas de refuerzo, orientación y apoyo (PROA), de cualificación profesional inicial (PCPI) o de reducción del abandono escolar, entre otros, sean suficientes para corregir esta situación.

Algunas tendencias en España son preocupantes en este campo. En primer lugar, la elevada proporción de personas con muy poca formación educativa (estudios primarios o segundarios de primera etapa); una cifra que representa el $49 \%$, en comparación con el $29 \%$ en la OCDE. En segundo lugar, nos encontramos con la disminución significativa de la tasa de ingreso en la educación universitaria entre 2000 y 2008 , que ha pasado del $47 \%$ al $41 \%$, mientras que la media de los países de la OCDE se ha incrementado en un $9 \%$ (Ministerio de Educación, 2010). Esta disminución se agrava, por un lado, por el porcentaje tan alto de abandono de estudios universitarios, que se sitúa entre el $26 \%$ y el $30 \%$, el doble de la media europea; y por el otro, por el ineficaz aprovechamiento de los estudios universitarios (el 70\% de los estudiantes dedica dos años más de los previstos a cursar sus estudios, lo cual supone un coste de 3.300 millones de euros anualmente) [Cabrera et al., 2006].

El Programa Nacional de Reforma español propone, para 2020, llegar a un índice de ocupación del 74\% de las personas entre 20 y 64 años, índice muy cercano al $75 \%$ establecido por la Estrategia 2020. El desempleo en España, con tasas superiores al $24 \%$ es el más alto de Europa. La reciente reforma laboral (2012) y, en el marco de ésta, la transformación de las políticas activas de empleo, no están contribuyendo a incrementar la participación de las personas jóvenes y mayores en el mercado laboral, ni tampoco de los trabajadores con bajas cualificaciones y los inmigrantes (Jefatura del Estado, 2012). No parece que sea posible reducir sustancialmente las tasas de desempleo y, en consecuencia, incrementar los niveles de población activa si no se procede a reformas importantes en el tejido productivo, en línea con los objetivos de economía verde, economía inteligente y economía integradora. Por otra parte, el programa no aporta respuestas al desempleo estructural y de larga duración, que está muy por encima de los dos millones de personas y, previsiblemente, seguirá creciendo a corto plazo.

El Programa Nacional de Reforma español (Gobierno de España, 2012: 264) propone reducir el número de personas en riesgo de pobreza o exclusión social entre 1,4 y 1,5 millones. España se encuentra en una situación de debilidad estructural a la hora de cumplir los objetivos relativos a la reducción de las tasas de pobreza, máxime si se tiene en cuenta que no se prevé una reducción sustancial del desempleo a corto plazo y que existe una estrecha relación entre desempleo y riesgo de pobreza. Los cuatro ámbitos de acción propuestos -incrementar la renta de los hogares con miembros en edad de trabajar, promover la inclusión activa, reducir el riesgo de pobreza en determinados grupos de población y garantizar el acceso a la vivienda o a un alojamiento digno- no parecen suficientes, como se explicará más adelante, pues la fisionomía de la pobreza en España tiene características muy particulares. 


\section{Los efectos de la crisis y las respuestas políticas alejan a Europa de los objetivos 2020}

\subsection{Estancamiento e incertidumbres}

La Estrategia 2020 y los Programas Nacionales de Reforma han de ir ajustándose y adaptándose progresivamente al método de gobernanza de la Estrategia. Su supervisión se integra en el 'semestre europeo’, que es un ciclo anual de coordinación de las políticas económicas y fiscales. El semestre europeo empieza cuando se publica la Encuesta Anual sobre el Crecimiento, en la que se integra la supervisión macroeconómica, temática y fiscal. A partir de ésta, el Consejo analiza la situación macroeconómica general, los avances en la consecución de los cinco objetivos para toda la UE y los avances en las iniciativas emblemáticas.

Los Estados miembros presentan cada primavera sus estrategias presupuestarias a medio plazo en los Programas de Estabilidad y Convergencia, y establecen las medidas que han de acometerse (en ámbitos como el empleo, la investigación, la innovación, la energía o la inclusión social) en sus Programas Nacionales de Reforma. En abril, estos dos documentos se envían a la Comisión para su evaluación. Basándose en ésta, el Consejo emite las orientaciones específicas para cada país en los meses de junio y julio. Si los Estados miembros ignoran las recomendaciones y no toman medidas en el plazo establecido, pueden recibir advertencias. En caso de desequilibrios macroeconómicos y presupuestarios excesivos, también se puede recurrir a incentivos y sanciones.

De la Encuesta Anual sobre el Crecimiento 2012 (Comisión Europea, 2011a) se extraen fundamentalmente dos mensajes: en primer lugar, que los Estados miembros no han hecho lo suficiente para adoptar las medidas que se habían comprometido a aplicar, en lo relativo al saneamiento fiscal; y en segundo lugar, que en términos de empleo, de cohesión social y de reducción de la pobreza, en los inicios de la Estrategia 2020 no solamente no se ha progresado, sino que las condiciones han empeorado.

Por eso se hace un llamamiento a la UE y a los Estados miembros para que se centren en cinco prioridades: realizar una consolidación fiscal diferenciada y propiciar el crecimiento, restablecer en la economía la actividad normal de préstamo, impulsar el crecimiento y la competitividad, luchar contra el desempleo y las consecuencias sociales de la crisis, y modernizar la administración pública. Al mismo tiempo, se presenta una lista de propuestas pendientes o futuras, destinadas a estimular el crecimiento.

Desde la perspectiva económica, se constata que la recuperación económica se ha estancado en un contexto en el que la inversión y el consumo se ven perjudicados por los bajos niveles de confianza de las instituciones financieras, las empresas y la ciudadanía (ibídem). Además, esta falta de confianza se ve agravada por otros factores, como la crisis de la deuda soberana (que aumentó un $20 \%$ de media entre 2007 y $2010-y$, en 2012, representaba el $85 \%$ del PIB de la UE, y el 90\% del PIB de la zona euro-), la falta de liquidez y la inestabilidad del sector financiero, la desaceleración de la economía mundial (de un crecimiento del $4 \%$ en 2011 se ha pasado al $2,5 \%$ en 2012, mientras que en la zona euro fue del 0,3\%, con estimaciones a la baja). Como consecuencia de todo ello, el PIB global en la UE es muy débil (o,6\% para 2012). La contracción prevista de la economía española acaba de ser revisada al alza por el FMI: en vez del $-1,1 \%$ estimado para este año, el crecimiento en 2012 sería del -1,7\%, y del -0,3\% en 2013 (El Mundo, 2012). La recuperación es cada vez más distante en el contexto de la crisis del euro y del crecimiento más bajo de los flujos comerciales globales (incluida China). Hay que tener especialmente en cuenta, además, los síntomas actuales de una probable crisis energética, alimenticia y ecológica futura.

\subsection{Retroalimentación, desempleo, bajos niveles educativos y pobreza}

La multidimensionalidad de la pobreza dificulta su medición. La falta de uniformidad en el peso relativo de los tres indicadores de pobreza y exclusión (pobreza relativa, privación material, baja intensidad laboral en el hogar) aplicados para evaluar los objetivos de reducción de la pobreza de la Estrategia 2020 en cada Estado miembro hace que las respuestas políticas tengan que adaptarse a los tipos de riesgo predominantes en cada país. Por ejemplo, en la Europa de los Doce, se observa una prevalencia de privación material severa, mientras en los países occidentales y nórdicos prevalece la exclusión del mercado laboral.

A pesar de ello, existen coincidencias en los factores de riesgo, así como en los grupos objetivo en el conjunto de la UE: limitada vinculación al mercado de trabajo, edad, circunstancias familiares particulares (incluidas las generadas por las obligaciones de cuidado de personas mayores y menores), características individuales (discapacidad, origen étnico o migrante). Cuatro de cada diez europeos en edad de trabajar y en situación de pobreza o exclusión son inactivos. Las personas mayores de 65 años representan el $16 \%$ de la población europea, pero al mismo tiempo suponen el $22 \%$ de la población en riesgo de pobreza/exclusión (un riesgo que aumenta significativamente a partir de los 75 años). Las familias monoparentales, así como las minorías étnicas, sufren un riesgo mucho mayor de pobreza y exclusión (Comisión Europea, 2011b).

En cuanto al desempleo, lo más probable es que sus niveles sigan siendo altos: se calculan 23 millones de parados en la UE ( 5 millones en España a finales de 2011); las previsiones para el 2012 y comienzos de 2013 lo sitúan en torno al 10\%, lo que incrementará los efectos sociales de la crisis. Las elevadas tasas de desempleo en España se prevé que aumenten y 
se agraven a corto plazo, dado que más del $40 \%$ de los desempleados lo son de larga duración. En el conjunto de Europa crece la sensación de que se están dedicando demasiado tiempo y energía a medidas de emergencia, y de que no se concede el tiempo suficiente a la aplicación de los cambios políticos que permitirían recuperar altos niveles de crecimiento en nuestras economías.

El crecimiento del empleo fue insuficiente en la tímida recuperación económica de la UE desde 2009. Se crearon 1,5 millones de empleos entre 2009 y 2011, en comparación con los 6 millones de puestos eliminados durante la recesión. La creación de empleo ha sido muy desigual entre Estados miembros y regiones (la tasa de desempleo de la UE es del 9,5\%; en Austria, del 4,1\%; y en España, del 22,8\%). El desempleo juvenil es muy alto en el conjunto de la UE, pues alcanza el $20 \%$ como media y más del $25 \%$ en 10 Estados miembros (el $48 \%$ en España) [ibídem].

Una de las constataciones fundamentales es la polarización y desigualdad de los ingresos. La crisis ha intensificado la tendencia ya existente de polarización salarial y laboral, que determina en gran medida el crecimiento de las desigualdades sociales en la UE. En algunos países con niveles mayores de desigualdad de los ingresos, la madurez de los sistemas de seguridad social y de bienestar ha permitido una paulatina reducción (téngase en cuanta que la reducción de los ingresos medianos por la crisis implica a priori una reducción de la desigualdad); sin embargo, en los países más igualitarios (países nórdicos), se observa un crecimiento de la desigualdad (Jenkins et al., 2011).

La mayoría de los nuevos empleos en los años previos a la crisis se concentraban en los niveles salariales y de cualificación más altos y más bajos. La crisis ha causado la destrucción masiva de empleos de nivel salarial medio en los sectores manufacturero y de construcción. A su vez, las empresas han elevado sus exigencias en términos de formación y educación, lo que dificulta el retorno de desempleados con cualificaciones bajas y medianas al mercado laboral. Los empleos de baja cualificación seguirán existiendo, pero requerirán mayores conocimientos básicos (escritura, cálculo y otra serie de competencias formativas básicas). Si la educación terciaria no se adapta rápidamente a las nuevas necesidades del mercado, faltarán empleos de alta cualificación para abastecer la demanda de personas graduadas y especializadas (Centro Europeo para el Desarrollo de la Formación Profesional, 2010).

La pobreza es una consecuencia extrema del crecimiento de la desigualdad de ingresos; de hecho, la tasa de 'pobreza relativa' es más una medición de la desigualdad que del nivel absoluto de acceso a bienes materiales o culturales, que no pone en evidencia directa los desequilibrios de renta entre Estados miembros. En este contexto, fenómenos como el desempleo de larga duración, la disminución de ingresos, y las manifestaciones de una creciente pobreza y desigualdad incrementan significativamente el riesgo de exclusión a largo plazo del mercado laboral y de la sociedad. Crece el riesgo de una posible reproducción intergeneracional de la exclusión para una proporción mucho mayor de personas.

No hay duda de que tener un empleo es la mayor protección contra la pobreza. Sin embargo, en Europa, más del $8 \%$ de la población con empleo está en riesgo de pobreza, y son personas definidas como ‘trabajadores pobres'. El riesgo de pobreza crece para personas con empleo temporal, a tiempo parcial o de baja cualificación. La intensidad laboral en el hogar es determinante: una pareja en la que sólo trabaja uno de sus miembros tiene un riesgo de pobreza del $20 \%$ (del $5 \%$ en caso de que ambos trabajen); este riesgo se multiplica por dos en el caso de hogares con niños. Sin embargo, tener hijos no es un factor agravante para hogares en los que ambos padres trabajan. Esto demuestra la necesidad imperiosa de facilitar la participación a tiempo completo en el mercado laboral de los progenitores sin pareja, y de ambos padres (especialmente mujeres) en caso de hogares con hijos (Comisión Europea, 2011b).

La pobreza en el empleo es consecuencia de los bajos salarios y, especialmente, de los salarios mínimos, que están directamente relacionados con sistemas descentralizados de negociación salarial y pérdida de poder de la negociación colectiva (cfr. la última reforma laboral en España). Las desigualdades salariales y de ingresos se incrementan también con sistemas limitados o descentralizados de negociación colectiva y con bajos salarios mínimos. Niveles mayores de salarios mínimos causan niveles menores de pobreza en el empleo, aunque su efectividad puede ser limitada por su difícil aplicación a la gran mayoría de los trabajadores pobres (autoempleo, empleo temporal o a tiempo parcial).

También los altos niveles de temporalidad condicionan mayores tasas de pobreza en el empleo (con salarios un $14 \%$ inferiores que en contratos indefinidos). Existe una preocupación especial con los países donde la creación de nuevos empleos se centra principalmente en la temporalidad involuntaria, porque el riesgo de pobreza en el empleo crecerá significativamente en estos países (en España, la temporalidad es del 25\%).

Las personas con niveles educativos bajos tienen, en la UE, un riesgo cuatro veces mayor de caer en situaciones de pobreza en el trabajo, es decir, de ser personas pobres aunque tengan empleo (de baja cualificación, temporal o parcial, autoempleo), que las personas con altos niveles educativos. Este riesgo se transmite a sus hijos, lo cual genera una reproducción intergeneracional de la pobreza. Además, las personas con niveles educativos más bajos tienen menos posibilidad de acceder al aprendizaje permanente (hay un $\mathbf{2 0 0} \%$ de diferencia entre personas con educación primaria y terciaria en España). Esta diferencia se agrava cuando confluyen múltiples factores de desventaja y discriminación (mujeres, minorías étnicas, inmigrantes, personas con discapacidad) [Comisión Europea, 2011b]. 
La actualización del Programa Nacional de Reforma presentada por el Gobierno Español en mayo de 2012 marca como prioridades la consolidación fiscal, la modernización de las administraciones y de los servicios públicos, el saneamiento del sistema financiero, la reforma del mercado laboral y el crecimiento, y la competitividad. Es de destacar que, si bien se mantienen los objetivos de pobreza y riesgo de exclusión social marcados inicialmente, en la versión actualizada no se prevé ninguna medida ni actuación específicas al respecto (Gobierno de España, 2012).

\section{Exclusión y desarrollo social en España}

Partiendo del análisis de los datos más recientes ${ }^{3}$, se constata que la evolución de los patrones económicos y sociales más importantes en España ha generado "una pobreza que es más extensa, más intensa, más crónica, y una convivencia que se asienta cada vez más en una sociedad dual". Vamos a partir de la evolución de la desigualdad que configura al conjunto social, para ir luego a los dos factores clave, empleo y protección social, complementados con un contexto de pérdida de derechos, para terminar en el análisis de la situación de pobreza y exclusión, que nos hará especialmente visible el distanciamiento del objetivo propuesto en la Estrategia 2020.

\subsection{Una sociedad cada vez más polarizada}

La extensión de la crisis y sus efectos no están teniendo consecuencias únicamente en la extensión de la pobreza y la reducción de derechos. Estamos en un 'proceso en cambio' del más hondo calado, en presencia de un riesgo real de cambio de modelo social. Hoy asistimos a una sociedad con tendencias de polarización entre los que tienen más y los que tienen menos, o no tienen. $Y$ aunque el indicador de renta no sea suficiente para dar cuenta de esta hipótesis de cambio de modelo social, sí constituye el primer indicador de alarma.

La evolución de la renta media de la población española en el periodo reciente ha estado marcada por la profunda caída registrada desde el inicio de la crisis económica. De hecho, se ha producido una pérdida de bienestar, pues la renta media de la población española ha descendido en un $4 \%$, pasando de algo más de 19.300 euros en 2007 a cerca de 18.500 euros tres años después. Pero si además tenemos en cuenta la evolución del IPC, esta caída, en términos reales, está cerca del $9 \%$ en ese mismo periodo. Esta evolución a la baja del nivel medio de ingresos de la población española indica ya una acusada pérdida de bienestar, que, por si fuera poco, ha ido creciendo con el paso del tiempo.

${ }^{3}$ En este apartado nos vamos a basar en dos informes recientes que ofrecen un análisis de la situación de pobreza y exclusión social: Fundación FOESSA (2012) y EAPN-España (2012).
Tabla 2. Datos de renta y desigualdad. España, 2005-2011

\begin{tabular}{l|l|l|l|l|l|l}
\cline { 2 - 6 } & $\mathbf{2 0 0 5}$ & $\mathbf{2 0 0 6}$ & $\mathbf{2 0 0 7}$ & $\mathbf{2 0 0 8}$ & $\mathbf{2 0 0 9}$ & $\mathbf{2 0 1 0}$ \\
\hline $\begin{array}{l}\text { Renta nacional } \\
\text { disponible neta a } \\
\text { precios de mercado } \\
\text { por habitante, en } \\
\text { valor nominal (€) }\end{array}$ & 17.542 & 18.573 & 19.320 & 19.419 & 18.523 & 18.555 \\
\hline $\begin{array}{l}\text { Renta nacional } \\
\text { disponible neta a } \\
\text { precios de mercado } \\
\text { por habitante, en } \\
\text { valor real (€) }\end{array}$ & 15.733 & 16.303 & 16.603 & 16.158 & 15.368 & 15.149 \\
\hline $\begin{array}{l}\text { Renta media } \\
\text { por unidad de } \\
\text { consumo, en valor } \\
\text { nominal (€) }\end{array}$ & 12.926 & 13.654 & 14.583 & 14.948 & 14.747 & 14.153 \\
\hline $\begin{array}{l}\text { Renta media } \\
\text { por unidad de } \\
\text { consumo, en valor } \\
\text { real (€) }\end{array}$ & 11.593 & 11.985 & 12.532 & 12.438 & 12.235 & 11.555 \\
\hline $\begin{array}{l}\text { Indice de Gini } \\
\begin{array}{l}\text { Percentil 8o / } \\
\text { percentil 20 }\end{array}\end{array}$ & 0,318 & 0,311 & 0,313 & 0,312 & 0,323 & 0,339 \\
\hline
\end{tabular}

Fuente: Fundación FOESSA (2012), a partir de la Encuesta de Condiciones de Vida (INE) y la contabilidad nacional.

Hay que destacar también el rápido aumento de la desigualdad. Según el índice de Gini, que mide el grado de concentración de la renta, ésta pasó de 0,313 en 2007 a 0,339 en 2010, y muestra una tendencia especialmente preocupante, pues es un incremento sin precedentes en las dos décadas y media anteriores. Por tanto, la pérdida de bienestar no afecta a todos por igual, sino justo lo contrario. Esto queda corroborado por la distancia entre la renta correspondiente al $\mathbf{2 0} \%$ más rico de la población y al 20\% más pobre, que pasó de 5,3 en 2007 a 6,9 al término de 2010. El aumento ha sido el mayor de los 27 Estados de la UE, y supera con creces al de cualquier otro país. Entre los países de mayor renta de la Unión, el crecimiento de la desigualdad en España fue más del doble que el de Francia, triplicó el de Alemania y fue casi cinco veces mayor que el de la media de la UE-15 (Fundación FOESSA, 2012: 6-7).

Estos datos sustentan la pregunta de si estamos caminando a una situación de 'dos sociedades'. Si esto fuese así, podríamos afirmar que la polarización social, además de la ruptura de la cohesión social, genera una sociedad con una concentración de riqueza/pobreza en sus extremos y, fruto de ella, una alta agresividad. Veamos ahora otros aspectos de esta hipótesis.

\subsubsection{El trabajo pierde capacidad de asegurar el bienestar y la integración}

Al trabajo le adjudicamos un papel determinante en la integración social y en la función de asegurar el bienestar a través de la generación de rentas. Sin embargo, se ha producido un amplio retroceso en los últimos años en estas funciones. Así lo demuestran varios hechos: 
- La tasa de desempleo en España a principios del 2012 se aproximaba al 24,5\% de la población activa, y era la más alta de toda UE-27, a gran distancia de la media de este conjunto de países (9,7\%).

- Uno de cada dos parados es de larga duración (más de un año).

- La tasa de desempleo de los sustentadores principales ha pasado del $5 \%$ al $19 \%$, lo que constituye su máximo histórico.

- Los hogares con todos sus activos en desempleo han pasado del $2,5 \%$ del total antes del inicio de la crisis al $9 \%$ a finales de 2011 , creciendo incluso a un ritmo superior que el de la propia tasa de paro.

Otro rasgo que diferencia la evolución del desempleo en España es que afecta especialmente a los jóvenes. Ya antes de la crisis, las tasas de paro de los activos entre 20 y 24 años duplicaban la media nacional, mientras que las correspondientes a los jóvenes menores de 20 años las superan más de tres veces. Por otra parte, si analizamos la tasa de paro de la persona principal del hogar, la tendencia es claramente al alza, habiendo crecido todavía más que la del conjunto de la población activa. En los años anteriores a la crisis, esta tasa alcanzaba valores cercanos al 5\%, mientras que a finales de $2011 \mathrm{su}$ valor era del $19 \%$ del total, lo que representa su máximo histórico. Un ritmo de crecimiento parecido se registró entre los hogares con todos sus activos en desempleo, que ha pasado del $2,5 \%$ en 2007 a triplicarse, hasta superar el $9 \%$.
Tabla 3. Indicadores de empleo. España, 2005-2011 (\%)

\begin{tabular}{|c|c|c|c|c|c|c|c|}
\hline & 2005 & 2006 & 2007 & 2008 & 2009 & 2010 & 2011 \\
\hline $\begin{array}{l}\text { Tasa de } \\
\text { actividad }\end{array}$ & 57,7 & 58,6 & 59,1 & 60,1 & 59,8 & 60,0 & 59,9 \\
\hline Tasa de paro & 8,7 & 8,3 & 8,6 & 13,9 & 18,8 & 20,3 & 22,8 \\
\hline $\begin{array}{l}\text { Tasa de paro } \\
\text { juvenil }\end{array}$ & 18,6 & 17,8 & 18,8 & 29,2 & 39,1 & 42,8 & 48,6 \\
\hline $\begin{array}{l}\text { Parados que } \\
\text { llevan más } \\
\text { de un año } \\
\text { buscando } \\
\text { empleo }\end{array}$ & 28,7 & 25,0 & 22,7 & 21,4 & 34,5 & 45,9 & 50,0 \\
\hline $\begin{array}{l}\text { Tasa de paro } \\
\text { de la persona } \\
\text { principal del } \\
\text { hogar }\end{array}$ & 5,9 & 6,0 & 6,5 & 11,2 & 15,8 & 16,6 & 17,9 \\
\hline $\begin{array}{l}\text { Hogares con } \\
\text { todos los } \\
\text { activos en } \\
\text { paro }\end{array}$ & 2,6 & 2,5 & 2,7 & 4,9 & 7,1 & 7,7 & 9,1 \\
\hline
\end{tabular}

Fuente: Fundación FOESSA (2012), a partir de la Encuesta de Población Activa (INE).

Estos datos indican una tendencia al distanciamiento del objetivo marcado de reducción de la pobreza, pues si, como habíamos confirmado, antes de la crisis el mantenimiento de la pobreza en tasas cercanas al $20 \%$ de la población tenía uno de sus ejes fundamentales en las rentas primarias, las tendencias mencionadas generarán una situación de precariedad y pobreza aún mayor en sus hogares.
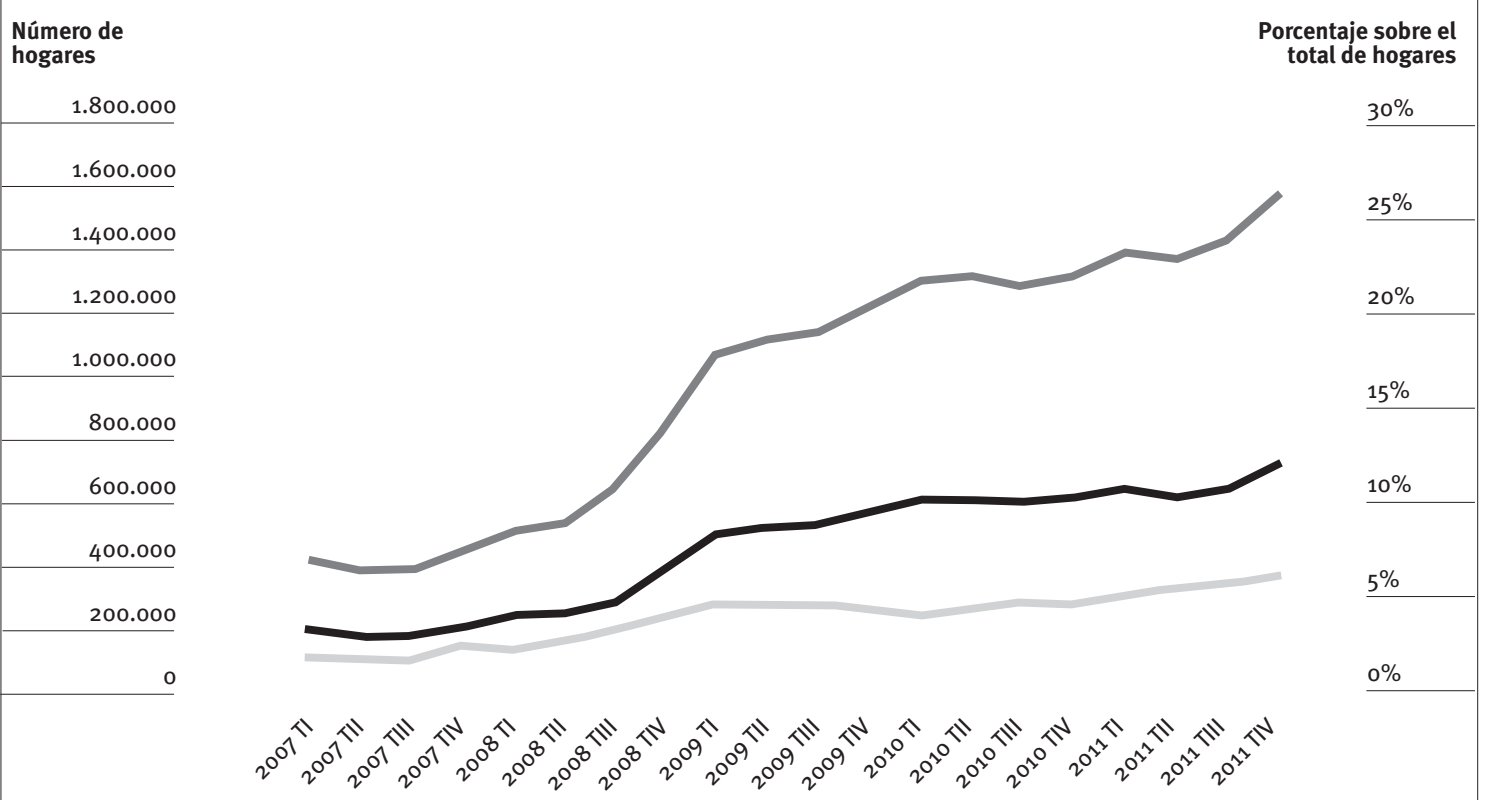

Todos los miembros activos en paro Sin ingresos

Todos los miembros activos en paro (porcentaje sobre total hogares) (eje de la derecha)

Fuente: EAPN-España (2012), a partir de la Encuesta de Condiciones de Vida (INE). 
Como indicamos anteriormente, esto, además, tiene su correlato en otro aspecto de gran efecto negativo en el aumento de la desigualdad, como es el de las personas con empleo que siguen siendo 'trabajadores pobres'. Mientras que en 2010 el 10,4\% de los ocupados en la Europa del euro estaban en riesgo de pobreza, en España nos encontrábamos en el 14,4\%. En España, 940.000 personas trabajan, y no por ello dejan de ser pobres, sino que se encuentran en situación de privación material severa. Esta circunstancia afecta de diversa manera a los hogares, dependiendo de su tipología; destacan en riesgo de pobreza los hogares en los que hay menores.

Ahora bien, esto no es lo único que ha ocurrido en el mercado de trabajo, pues la desregulación que plantea la nueva reforma laboral (Jefatura de Estado, 2012) introduce motivos suficientes como para que no se pueda revertir la tendencia a la baja en el efecto del empleo sobre la pobreza. Se trata de una cuestión que habrá que confirmar en el tiempo, pero que ya se vislumbra, dadas algunas de las decisiones tomadas, entre las que, a efectos de nuestro tema, pueden destacarse las siguientes.

Esta reforma laboral pretende alcanzar el equilibrio de la 'flexiguridad': introducir medidas de flexibilización y garantizar al mismo tiempo unas cotas de seguridad, protección y estabilidad para los trabajadores. Sin embargo, sus medidas van dirigidas principalmente a la flexibilidad interna y externa, que permite a la empresa un mayor margen de maniobra, proporcionándole instrumentos para disponer o prescindir fácilmente de trabajadores según las necesidades de producción. Por ello, los mecanismos introducidos generan más inseguridad que estabilidad y protección para los trabajadores, lo cual legitima un marco de incertidumbre permanente.

Además, se reduce significativamente la protección de los trabajadores, con medidas como priorizar los acuerdos de empresa y la posibilidad de descuelgue de convenio colectivo. Esto supone un nuevo escenario donde se debilita lo colectivo y se potencia la individualización, con el agravante de que los interlocutores no están en igualdad de condiciones. Por otra parte, se quiere alcanzar la competitividad del tejido empresarial español exclusivamente a través de la reducción de costes de producción, y en concreto, de costes salariales, con la consiguiente precarización de los derechos laborales. Y también hay que señalar que las medidas para combatir la supuesta rigidez del mercado laboral -supuesto que considera apodícticoestablecen medidas de flexibilidad interna, como la disminución drástica de la indemnización por despido improcedente y la ampliación de la casuística de los despidos por causas objetivas, que en realidad convierte la flexibilidad empresarial en una amenaza real para los derechos de los trabajadores.

Los análisis de las reformas laborales que se han venido produciendo a lo largo de las dos últimas décadas nos han enseñado que medidas de este tipo fragilizan las condiciones de vida de los trabajadores y generan riesgos de pobreza en los hogares cuyo vehículo de ingresos son las rentas primarias. Por ello, la hipótesis más verosímil es que estas medidas nos alejen del cumplimiento del objetivo europeo, máxime si se tiene en cuenta el rápido crecimiento del desempleo desde que entró en vigor la reforma laboral ${ }^{4}$.

\subsubsection{Los mecanismos de contención se repliegan}

Los niveles de gasto social en España están todavía muy por debajo de los de la mayoría de los países de nuestro entorno. El dato más reciente disponible muestra que la distancia respecto a los países del euro todavía es superior a quince puntos, pese al mayor aumento de los gastos en España, por el comportamiento diferencial del desempleo (Jefatura de Estado, 2012: 15-16).

Tabla 4. Derechos y servicios sociales

\begin{tabular}{|c|c|c|c|c|c|c|c|}
\hline & & & & & & & \\
\hline & 2005 & 2006 & 2007 & 2008 & 2009 & 2010 & 2011 \\
\hline Salario mínimo (€) & 513 & 541 & 571 & 600 & 624 & 633 & 641 \\
\hline Tasa de cobertura de las prestaciones por desempleo (\%) & 63,6 & 66,5 & 71,4 & 73,6 & 75,5 & 78,2 & 77,4 \\
\hline Pensión media (€) & 350 & 375 & 398 & 428 & 447 & 459 & 472 \\
\hline Pensión no contributiva $(€)$ & 289 & 302 & 312 & 328 & 336 & 340 & 343 \\
\hline Beneficiarios de rentas mínimas & 100.835 & 102.662 & 103.071 & 114.257 & 156.858 & 192.633 & N.D. \\
\hline Beneficiarios de prestaciones de dependencia & N.D. & N.D. & N.D. & 201.129 & $485 \cdot 526$ & 668.578 & 752.005 \\
\hline Retrasos en el pago de gastos relacionados con la vivienda (\%) & 4,7 & 4,9 & 5,2 & 5,4 & 7,2 & 7,7 & N.D. \\
\hline Ejecuciones hipotecarias & N.D. & N.D. & 25.943 & 58.686 & 93.319 & 93.636 & N.D. \\
\hline Abandono escolar (\%) & 30,8 & 30,5 & 31,0 & 31,9 & 31,2 & 28,4 & N.D. \\
\hline
\end{tabular}

N.D.: no disponible.

Fuente: Fundación FOESSA (2012), a partir de datos del Boletín de Estadísticas Laborales; el Ministerio de Sanidad, Servicios Sociales e Igualdad; el Consejo General del Poder Judicial; y el Ministerio de Educación, Cultura y Deporte.
4 Se registró un incremento del número de parados en 365.900 personas desde el inicio de la presente legislatura, alcanzándose la cifra total de 5.639.500 parados a principios de abril (Instituto Nacional de Estadística, 2012; Barcala, 2012). 
Después de los importantes aumentos del salario mínimo registrados hasta el inicio de la crisis, superiores incluso al $5 \%$ en 2008 , el crecimiento fue notablemente más moderado en 2010 y 2011, con incrementos por debajo del 1,5\%. Cabe contemplar con preocupación la decisión adoptada a finales de 2011, dentro del conjunto de medidas de ajuste, de congelar el salario mínimo en 2012. La brecha entre los salarios de los trabajadores con remuneraciones más bajas y la media, que se ensanchó drásticamente en los primeros años de la crisis, podría aumentar todavía más.

En cuanto a los ingresos que no proceden del trabajo, también se ha producido un claro repliegue. Dadas las medidas del programa de contención del gasto público de 2010, se ha producido un recorte en la actualización de las prestaciones por jubilación, y muy especialmente, de las pensiones no contributivas, con crecimientos en 2010 y 2011 del $1 \%$, muy por debajo de los de años anteriores, cuando el crecimiento anual del PIB llegó a superar el 3,5\% de media ( $5 \%$ en 1999).

Los hogares sin ingresos ni del trabajo, ni de prestaciones por desempleo o de la Seguridad Social alcanzaban, a finales de 2011, un 3,3\% del total, cifra un $34 \%$ más alta que la que había al comienzo de la crisis. En términos absolutos, a finales de 2011 este problema afectaba a 580.000 hogares. En la medida en que este indicador es representativo de las formas más severas de pobreza, lo que se está registrando es un crecimiento sin precedentes de ésta, que supera en casi 150.000 hogares el valor máximo registrado en los últimos 25 años.

En cuanto al número de personas en paro sin prestaciones por desempleo, ha aumentado de modo sustancial a lo largo de la crisis, de forma que 2011 se cierra con una situación en la que, de los 5,3 millones de personas en desempleo existentes según la Encuesta de Población Activa, aproximadamente sólo la cuarta parte recibe la prestación contributiva de desempleo. Algo más de otra cuarta parte recibe algún tipo de prestación asistencial o la renta activa de inserción, de modo que casi la mitad, en concreto, cerca de 2,4 millones, no reciben ninguna prestación del sistema de protección por desempleo y sobreviven, por tanto, de rentas mínimas de inserción, ayudas de familiares u otras fuentes de ingresos.

Por último, hacemos referencia a los sistemas de garantía de ingresos mínimos establecidos por las comunidades autónomas (EAPN-España, en prensa: 56-61). El número de personas beneficiarias de las rentas mínimas de inserción ha aumentado de forma considerable en el periodo de crisis, pasando de 103.071 personas titulares en 2007 a 192.633 en 2010 , es decir, un $87 \%$ más. Si se toma como referencia el número de personas beneficiarias miembros de una unidad de convivencia, el incremento en el periodo considerado se cifra en el $62 \%$, ascendiendo de 196.685 personas a 318.662 .

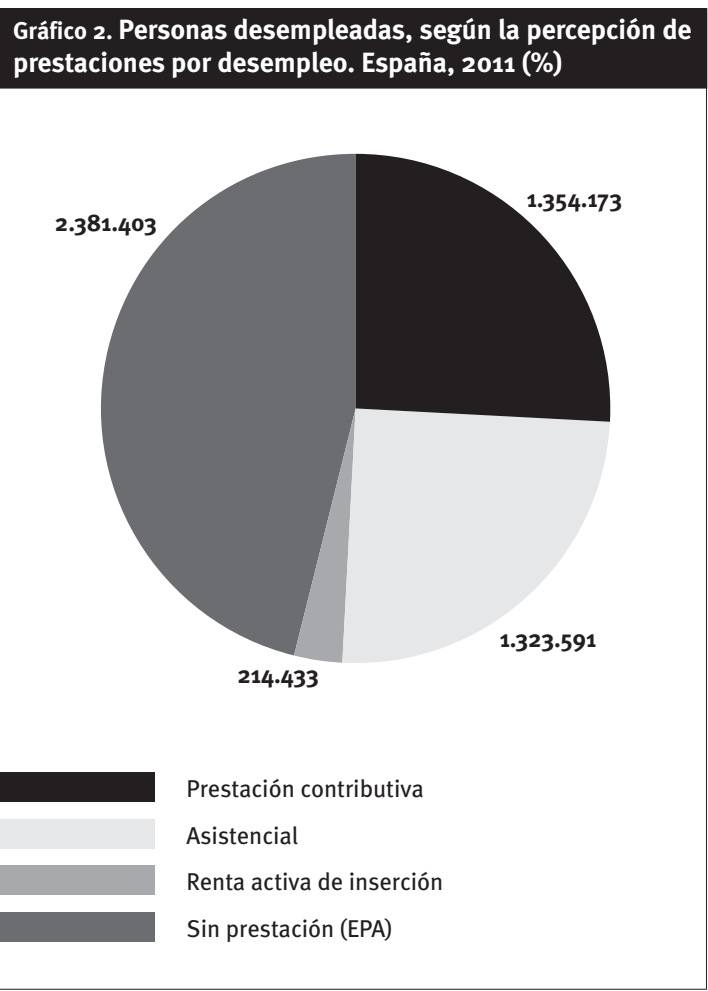

EPA: Encuesta de Población Activa.

Fuente: EAPN-España (en prensa), a partir de la Encuesta de Población Activa (varios periodos, INE) y datos estadísticos del Registro de Empleo y Servicio Público de Empleo Estatal (noviembre de 2011, Ministerio de Empleo y Seguridad Social).

Este notable incremento de beneficiarios no se ha repartido de manera homogénea por comunidades autónomas; además, salvo contadas excepciones, estos sistemas son de bajo nivel protector, pues las características de las rentas mínimas de inserción varían de forma considerable de unas comunidades a otras. En lo que se refiere a las cuantías de la renta, para 2010, oscilaban en un rango de entre los 300 euros mensuales de Murcia o los 372 euros mensuales de La Rioja a los 640 euros correspondientes al País Vasco. La media se situaba en 418 euros. El caso de Navarra es especialmente llamativo, en tanto que, desde 2008 hasta 2010, la cuantía de estas rentas se vio incrementada en un $20,4 \%$ en términos reales, lo que choca frontalmente con el escaso crecimiento medio, que se situó en el $1,1 \%$ en términos reales, es decir, descontando la inflación.

\subsubsection{Después de tres años de crisis, la pobreza es ahora más extensa, más intensa y más crónica}

Si éste es el contexto, ¿cuál es el texto? La desigualdad camina hacia la polarización; el mercado de trabajo pierde capacidad distributiva y de integración; los mecanismos de contención se repliegan, ahondando la tendencia de pérdida de derechos. ¿En qué dirección estamos caminando hacia la reducción de la pobreza? Parece ya confirmado que la crisis, y el recorrido del modelo social a partir de ella, lo que ha 
hecho es que la pobreza sea ahora más extensa, más intensa y más crónica.

Es una pobreza más extensa, porque se incrementa en número de hogares y personas. La tasa de pobreza monetaria es de un $21,8 \%$, una de las más elevadas de la UE. Esta medición de la pobreza a partir de los ingresos monetarios debe ser completada con otros indicadores recogidos en la Estrategia 2020. Así, disponemos de una tasa combinada de pobreza y exclusión social (AROPE5) según la cual, en España, tendríamos a una cuarta parte de la población (25,5\%) en situación de pobreza y exclusión en 2010, lo que representa 11.675 .000 personas.

Gráfico 3. Evolución de la tasa de riesgo pobreza y la tasa riesgo de pobreza y/o exclusión social (AROPE). España, 2008-2011 (\%)

${ }^{5}$ Acrónimo de at risk of poverty and/or exclusion (en riesgo de pobreza y/o exclusión).

Fuente: EAPN-España (en prensa), a partir de la Encuesta de Condiciones de Vida (INE). Los datos de 2011 son provisionales.

Esta evolución es plenamente ilustrativa del aumento de la distancia para el cumplimiento del objetivo europeo de reducción de pobreza y de que éste no ha aumentado solamente por la mayor pobreza monetaria, sino también en relación con los indicadores de privación severa y de baja intensidad laboral, tal como explicamos anteriormente. Veamos algunos datos respecto a estos indicadores en el caso de España.

Entre los indicadores de privación, hay algunos referidos a las situaciones de inseguridad económica, como la dificultad para llegar a fin de mes, que alcanza ya al $30 \%$ de la población. En otros indicadores referidos a cambios en condiciones de bienestar básicas, se aprecia una tendencia de empeoramiento, como es el caso de poder disfrutar de vacaciones una semana al año; poder disponer de una comida de carne, pollo y pescado de manera regular; mantener la vivienda a una temperatura adecuada; y, sobre todo, la capacidad de poder hacer frente a los gastos imprevistos. A finales de 2010, el $36 \%$ de los hogares españoles eran incapaces de cubrir esta última necesidad.

A estas situaciones de privación, habría que sumar, sin duda, lo que está ocurriendo con la vivienda, pues a pesar de que su precio de la vivienda intensificó su caída en el tercer trimestre de 2011, el acceso a este derecho supone todavía un importante esfuerzo para las familias, al que tienen que dedicar un $36,1 \%$ de sus ingresos, cuando no debería pasar del 30\%. Un indicador que ilustra muy bien la evolución de este derecho en España es el número de sentencias de ejecuciones hipotecarias, que en 2010 fueron casi 100.000 y multiplicaron por cuatro las registradas en 2007 (Tabla 4).

En cuanto a la intensidad laboral, se trata de una dimensión de gran consistencia, como hemos visto anteriormente, dada la importancia de lo que ocurre en el mercado de trabajo para conformar el objetivo de reducción de pobreza. Por eso es elocuente cómo se combinan las tasas de pobreza y exclusión con las de paro y de desempleo.

Si tenemos en cuenta estos tres indicadores -la tasa de pobreza monetaria, la privación material severa y la población con baja intensidad de trabajo por hogar-, podemos observar que aproximadamente el $4 \%$ de la población que no se encuentra bajo el umbral de pobreza presenta otro tipo de dificultades materiales o relacionadas con la intensidad laboral. En esos hogares, dichas problemáticas se dan en una intensidad severa.
Teniendo presentes los tres indicadores que componen el indicador europeo, tendríamos la distribución mostrada en el Gráfico 6 de la población en riesgo de pobreza o exclusión (AROPE). La extensión de la pobreza es el primer elemento que destaca; aunque no es el único grave, es lo que más acaba siendo percibido por la sociedad cotidianamente, pues se corresponde con el gran aumento de la demanda en los servicios sociales. Sólo con los datos de los servicios de ayuda social de Cáritas, se constata que el incremento de personas atendidas ha pasado de 400.000 a 950.000 en tres años (Cáritas, 2011).

En segundo lugar, es una pobreza más intensa, porque las situaciones de pobreza monetaria, privación material y la dificultad de acceso a derechos básicos se han acrecentado. Hay que destacar, en consecuencia, que los pobres son más pobres, pues se ha propasó de 8.000 euros (2009) a 7.800 (2010). La menor disponibilidad de renta -que se ha generalizado en la sociedad, por lo que ha aumentado la pobreza monetaria-, tiene su reflejo en la propia pobreza, haciéndola más intensa; de ello son representativas ducido una disminución en el umbral de pobreza, que 


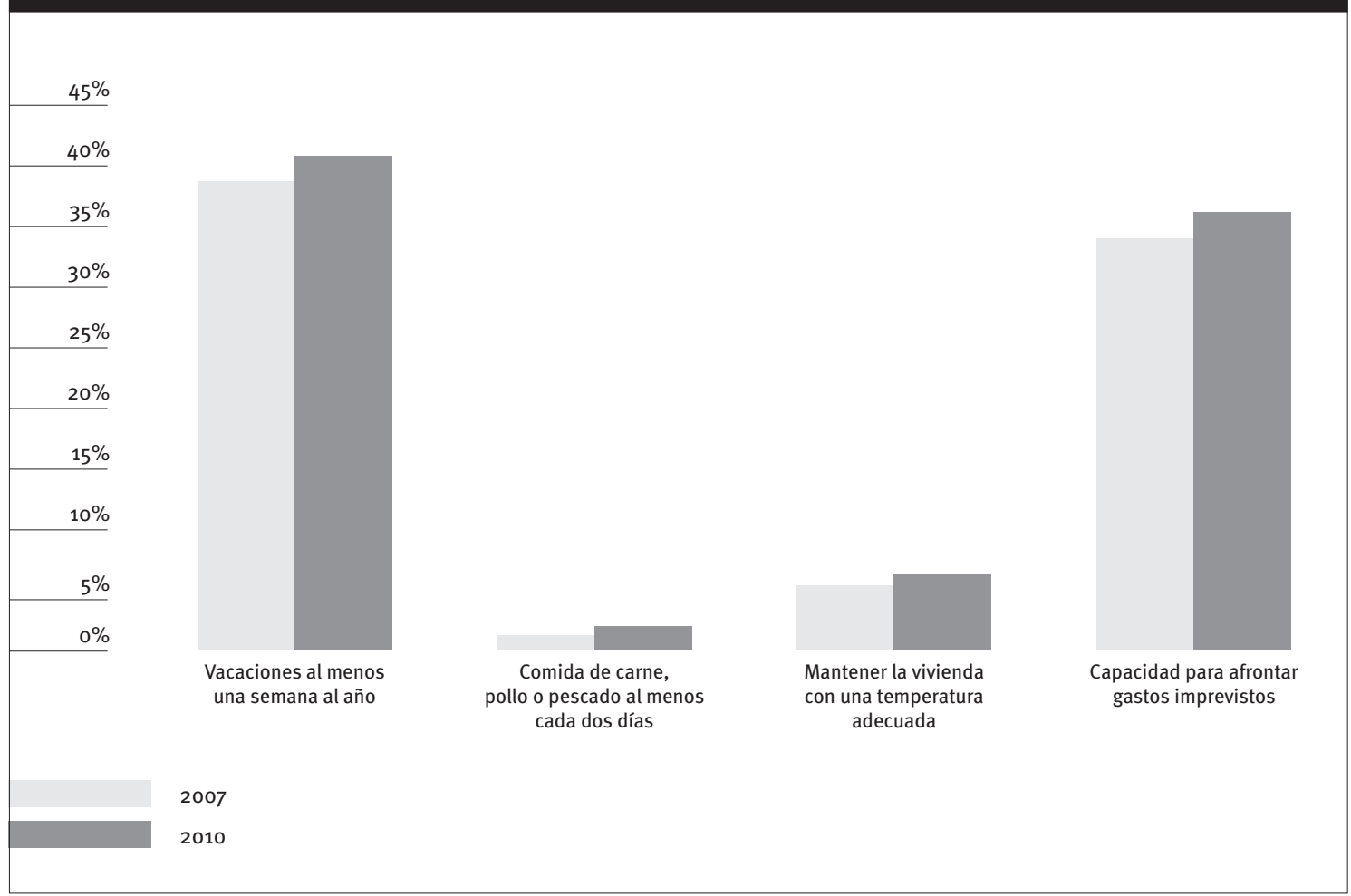

Fuente: Fundación FOESSA (en prensa), a partir de la Encuesta de Condiciones de Vida (INE).

\section{Gráfico 5. Tasas de pobreza, privación e intensidad laboral (\%)}

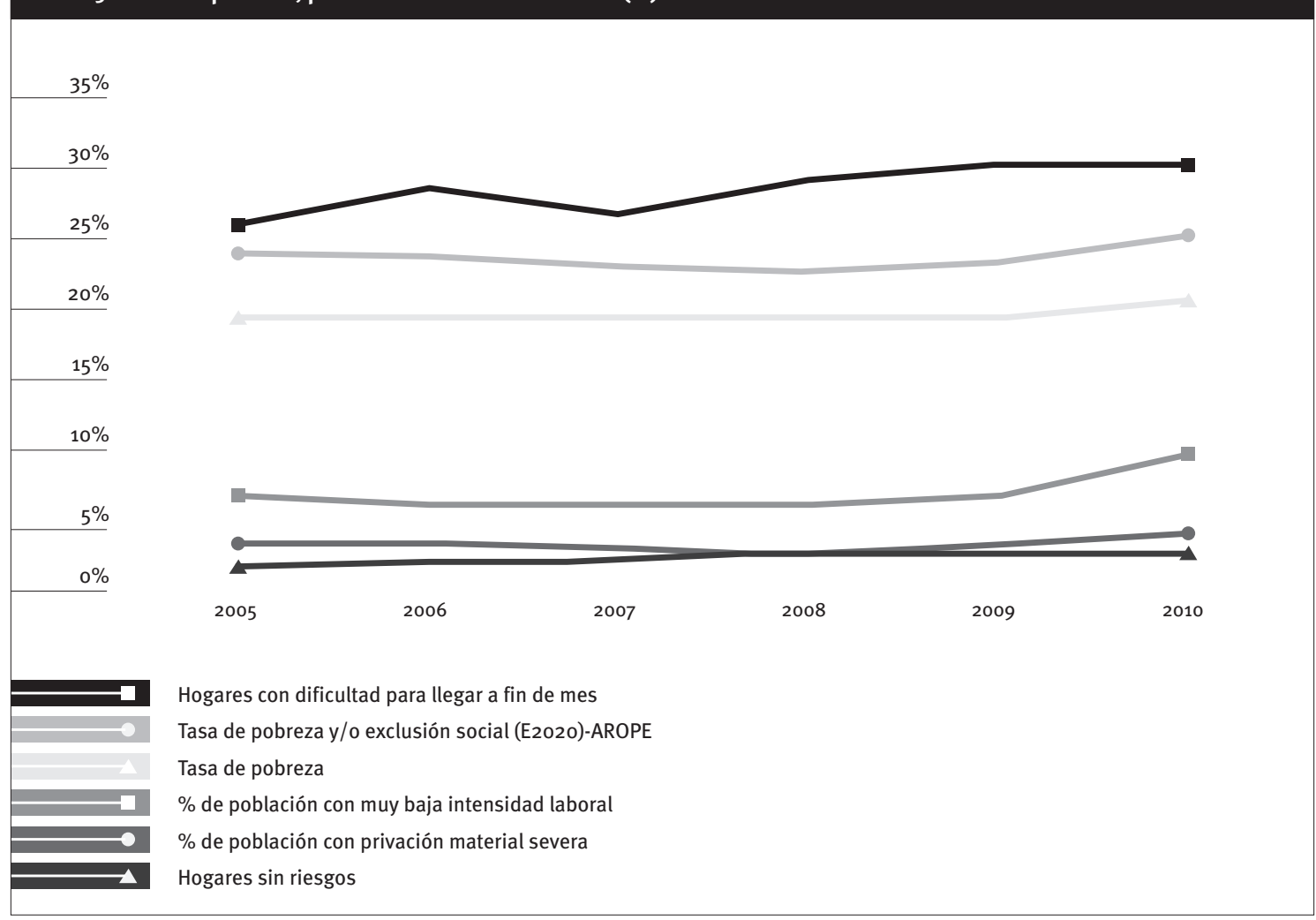

AROPE: población en riesgo de pobreza o exclusión.

Fuente: Fundación FOESSA (en prensa), a partir de la Encuesta de Condiciones de Vida y la Encuesta de Población Activa (INE), y Eurostat. 


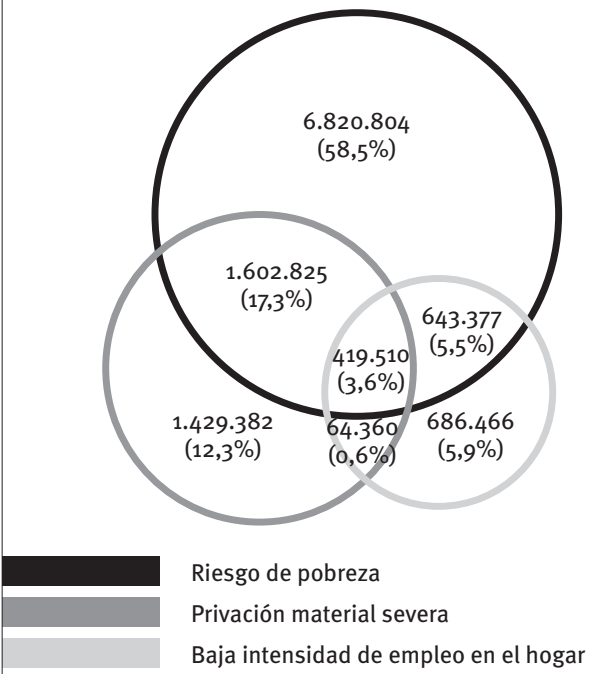

Fuente: EAPN-España (en prensa), a partir de la Encuesta de Condiciones de Vida (2008-2011, INE).
Gráfico 7. Tasa AROPE con diferentes umbrales de pobreza. España, 2010 (\%)

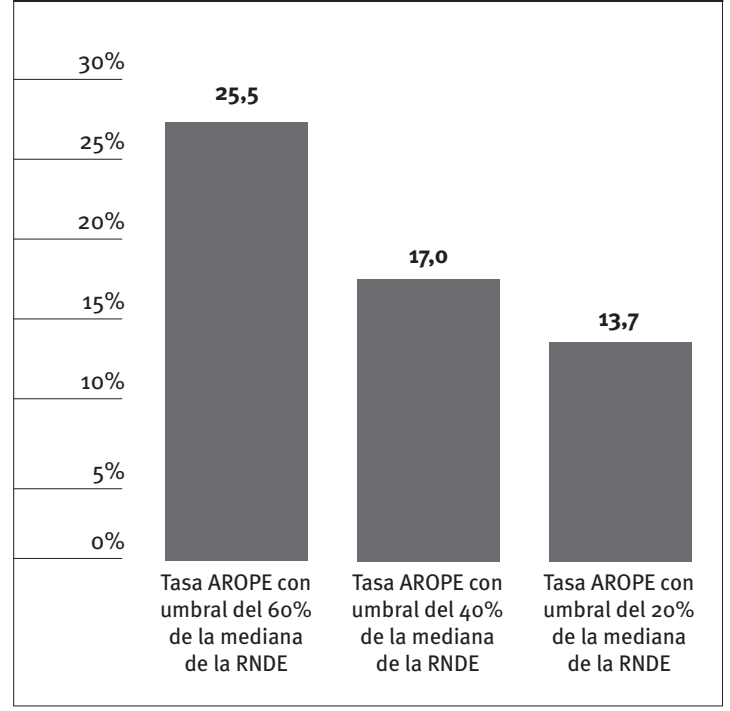

RNDE: Renta nacional disponible equivalente.

Fuente: EAPN-España (en prensa), a partir de la Encuesta de Condiciones de Vida (2008-2011, INE). las tasas de pobreza y exclusión en el conjunto de la población, en las que se observa un amplio porcentaje de personas en condiciones de pobreza extrema.

Por último, es una pobreza más crónica, porque la permanencia en condiciones de pobreza y exclusión se está consolidando durante esta crisis. Ya no hablamos de situaciones de pobreza pasajera, sino de años viviendo bajo el umbral de la pobreza, incluso entre personas con empleo que siguen siendo 'trabajadores pobres', como ya hemos señalado. A falta de indicadores específicos al respecto, hay una clara tendencia a la consolidación de la pobreza severa, la exclusión severa y la privación severa. Otra situación que tiene una amplia incidencia es la de los hogares con todos los miembros en desempleo y sin rentas, que no sólo se mantienen, sino que crecen y se están cronificando fuera del empleo y del sistema de protección social.

Todo ello nos indica que debemos trabajar con algo que ya nos han venido enseñando las últimas crisis económicas (Ayala, 2012). Si echamos la mirada atrás, emerge una realidad que introduce muchas sombras sobre la crisis actual: los aumentos de desigualdad y la pobreza no son transitorios. Así, nos encontramos que, en la crisis de los primeros años noventa, la pobreza aumentó, y en los años posteriores, se mantuvo esa tasa, a pesar del incremento del empleo. Es decir, los aumentos transitorios de las necesidades sociales se pueden convertir en crónicos con el paso del tiempo.

\section{La necesidad de invertir la tendencia}

El agotamiento de la ola expansiva del crecimiento ha transformado un importante porcentaje del alto nivel de vulnerabilidad que existía antes de la crisis en situaciones de pobreza y exclusión social. Se trata, pues, de un mismo proceso con una mayor magnitud de los problemas: la caída de la actividad económica y el empleo ha dado lugar al incremento de la desigualdad y, sobre todo, los mayores costes de la crisis han recaído en los hogares con menos recursos.

Pero no se trata de un simple aumento cuantitativo. Lo que se está produciendo es un cambio cualitativo que afecta a la propia estructura de las sociedades. No estamos en un paréntesis de 'mientras tanto', esperando que se retome el crecimiento económico; un paréntesis con el que se pretende justificar las medidas excepcionales que se están adoptando, aunque sean de muy difícil justificación, por los efectos muy graves y de larga duración que generan. ¿Cómo verificar este cambio? Tomando como punto de partida los derechos económicos y sociales, pues son los que marcan la dirección que lleva la política social $^{6}$. ¿Cómo establecemos su dirección? Analizando cómo se están resolviendo y articulando en la práctica los objetivos de cohesión social que se han de perseguir en la estructuración de una sociedad:

- Los fenómenos de desigualdad y exclusión social plantean como cuestión central la garantía de los derechos sociales: la 'garantía' real de los derechos. Ante la negación 'de hecho' que la imposibilidad de ejercerlos significa, es necesaria una acción de protección, garantía y seguridad en su ejercicio, especialmente en situaciones de pobreza y exclusión social.

${ }^{6}$ Para el análisis de los objetivos de la política social, véase Renes (2003: 312-314). 
- Es necesario prevenir los desequilibrios sociales e intervenir sobre los ya existentes. Esto implica hacer frente a los procesos y factores de empobrecimiento y vulnerabilidad social, así como promocionar las condiciones macrosociales y microsociales que favorezcan el ejercicio de los derechos y la autonomía de las personas.

- La garantía de derechos, la prevención de los desequilibrios y la promoción de las condiciones de su ejercicio son imposibles si no es desde una política de desarrollo social como meta. Debe perseguirse un desarrollo económico-social incluyente frente a la dualización social, en el que la participación en todos los aspectos y en todos los ámbitos constituya el eje de las decisiones socioeconómicas.

Éstos son los objetivos estructuradores de una política de bienestar social y, por extensión, de una estructura social. En estos momentos la garantía de los derechos está en cuestión, las condiciones en que se ejercen o se pueden ejercer esos derechos están fragilizándose y, para diversos grupos sociales, no sólo están disminuyendo, sino desapareciendo. Se plantea la exigencia de que estos objetivos sean redefinidos para el crecimiento económico, y de que marquen los límites de la que debe y no debe ser la dirección a tomar, el ajuste de lo que debe y no debe hacerse, al cual tiene que subordinarse cualquier decisión de estructuración social.

\section{1. ¿Continuidad en las tendencias o cambio cualitativo en la estructura de la sociedad?}

La gramática con la que se está escribiendo este proceso nos revela que la pobreza y la exclusión social se agudizan, de modo que lo que no es útil a la sociedad del crecimiento queda marginalizado, empobrecido, excluido; y también, que la pobreza y la exclusión social pueden alcanzar a cualquier persona o grupo social, según el devenir de los ajustes considerados imprescindibles para el crecimiento. Ahora bien, el fondo de la cuestión está en la sintaxis con la que se construye esa escritura, para así comprender cuáles son los valores, las opciones, las elecciones y las prioridades que en tiempos de bonanza no dejaban ver cómo estaban organizando, o desorganizando, las relaciones sociales, pero que en tiempos de crisis no encuentran límites para regir las decisiones, cumpliéndose el axioma de que todas las crisis redefinen las relaciones sociales. Por ello, lo que la pobreza y la exclusión desvelan por igual son los riesgos deshumanizadores y las estructuras que las decisiones adoptadas proyectan (Renes, en prensa).

Se argumenta que todo debe quedar subordinado al control financiero para reducir la deuda como requisito imprescindible para retornar al crecimiento económico, a pesar de los muy graves efectos en la garantía de los derechos y en las condiciones para su ejercicio. Pero se hace sin afrontar el problema básico de que nuestra estructura productiva es débil, poco competitiva y dificulta la creación de empleo, a pesar de que antes de la crisis la evolución de la ocupación hiciera parecer lo contrario. Una estructura productiva débil, en un contexto de creciente competitividad hace difícil competir sólo con estrategias basadas en bajos salarios. En las últimas décadas, la creación de empleo ha estado muy ligada a sectores cíclicos basados en un bajo valor añadido, que utilizaba ocupaciones de baja cualificación, donde se concentró la gran mayoría de los cinco millones de inmigrantes que se establecieron en España en la década anterior al inicio de la crisis (GonzálezEnríquez, 2009; Fundación Ortega-Marañón et al., 2011). Sin embargo, esa necesaria creación de empleo no va a ser resuelta por las reformas del mercado de trabajo.

Por ello es muy significativa la ausencia, en la actual reforma laboral, de un cuestionamiento profundo de los modelos económico y productivo que subyacen a nuestro mercado laboral, es decir, aquellos aspectos estructurales que son las verdaderas causas de la profunda crisis económica en la que estamos inmersos. Serán otras políticas económicas, públicas, sociales, financieras, fiscales, energéticas y ambientales, y otras medidas activas de empleo las que podrán generar oportunidades laborales también para las personas más distantes del mercado de trabajo. Sin estas políticas, no se crearán los puestos de trabajo necesarios, menos aún para las personas más alejadas del mercado laboral; además, se agravará el elevado coste que ello supone en términos de deterioro de derechos laborales.

Por otra parte, es algo muy constatado que las políticas de austeridad generan desigualdad y pobreza (Ayala, 2009). Lo hacen a través de una vía directa, que es el recorte de prestaciones y servicios básicos, y de otra más indirecta, relacionada con la caída de la producción y el empleo como consecuencia del recorte del gasto público. Estamos viendo en varios ámbitos, como la sanidad, la dependencia, la educación o las becas, que las condiciones de acceso se están volviendo cada vez más restrictivas, a la vez que los programas de bienestar social son más cuestionados. Parece que la política social se introduce por la puerta de atrás y el acceso a algunos de estos servicios cada vez es más estigmatizante. Ya no se trata tan sólo de menores o mayores gastos o ingresos, sino que estamos rebajando el principio de ciudadanía a la hora de diseñar el acceso a esos servicios.

La idea de austeridad no es neutral en términos distributivos, pues, por una parte, la sensibilidad de la pobreza al descenso del desempleo es mucho mayor que a aumentos de éste; y, por otra, la reducción de servicios y la pérdida de intensidad protectora afectan más a aquellos aspectos especialmente relacionados con el bienestar de los hogares. Por tanto, la austeridad presupuestaria no sólo no reduce la pobreza, sino que crea más desigualdad. Por eso es llamativo que, frente a la gran atención que ocupa el seguimiento de los grandes indicadores macroeconómicos, como la prima de riesgo, o el déficit, apenas 
se cuente con indicadores ni información que nos permitan seguir el efecto social de la crisis, más allá de las grandes cifras de desempleo y pobreza, y conocer quiénes son las personas y familias más afectadas. Por el mismo motivo, es curioso que la puesta en marcha de estrategias de austeridad no lleve consigo estudios de impacto, ni sean sometidas a debates públicos en relación con sus consecuencias sociales (Pérez Eransus, en prensa).

Se suelen esgrimir argumentos, en buena medida erróneos, en relación con buena parte de las políticas sociales amenazadas por los recortes. El fundamental es el del coste de las políticas sociales, que se suele confundir con el debate acerca de la eficacia de los sistemas públicos Precisamente en esta crisis, frente a los fallos de los mercados financieros o la debilidad de los sectores productivos, las políticas sociales europeas han mostrado su eficacia amortiguando los efectos negativos de aquéllos. ¿Estamos dispuestos a mantener el coste de estos mecanismos estabilizadores, o por el contrario, si los recortamos, estamos dispuestos a asumir los riesgos de una sociedad cada vez más desigual y, por tanto, con una grave fractura de la cohesión social?

Hay una cuestión de gran calado para la inclusión social que está configurando de modo decisivo el nuevo modelo social emergente: la tendencia al desprestigio de lo público. Podemos afirmar que existe una clara estrategia de abandono de servicios públicos fundamentales. Esto supone la pérdida de ‘músculo' estatal para una política de inclusión y la pérdida de la capacidad colectiva de hacer frente a las exigencias de la cohesión social, lo que significa igualmente la pérdida de 'músculo' social. El actor privado lucrativo, el mercado, que está marcando las políticas macroeconómicas fiscales y de ajuste, se está convirtiendo en el actor de referencia para el modelo de servicios, de su financiación y de su gestión. Este intenso proceso de institucionalización de lo privado y de privatización condensa en gran medida el paradigma del nuevo modelo de sociedad, lo que supone añadir a la pérdida de ‘músculo' colectivo y social, la pérdida societal, asociativa y solidaria.

\subsection{Algunos supuestos para una política de inclusión social}

\subsection{1. ¿Hay alternativas a la pura política de austeridad?}

Hay que partir de que no es viable una política de inclusión social si no se hace un planteamiento de equidad e inclusión en todas las políticas. En todas las reformas hay que contemplar las mejoras en términos de equidad.

En el sistema financiero, los márgenes de mejora siguen siendo muy amplios. Y en este ámbito, lo primero que se ha de señalar es que es imposible pensar en inclusión social de forma sustantiva sin aumentar el gasto redistributivo. Lógicamente, redes más sólidas de protección exigen mayores recursos de los más ricos, lo que no sólo pasaría por aumentar los tipos del IRPF, sino por un mayor gravamen de la riqueza. Es decir, es inviable cualquier política que no contemple los ingresos junto a la necesaria reducción de gastos que no aportan valor social. Es, por ello, imprescindible, junto a la definición de las prioridades en el gasto y la racionalización de otros gastos para liberar presupuesto para las políticas sociales, hacer frente a tres problemas endémicos: el excesivo riesgo en las actuaciones de las instituciones financieras ‘demasiado grandes para fracasar', la evasión fiscal y la economía sumergida.

Pero, además se puede seguir regulando y prestando más atención al crédito a proyectos emprendedores de colectivos en exclusión, por ejemplo, en los que la economía social debe tener un papel preponderante. La pobreza y la exclusión también tienen que contar en los criterios con los que se grava 'o desgrava' el IRPF. A priori puede parecer poco adecuado, porque los trabajadores con ingresos más bajos no están obligados a declarar, pero en otros países el uso de incentivos para trabajadores con salarios bajos ha sido una de las líneas dominantes de la reforma fiscal (Idesbald, 2011).

Cualquier política, por muy austera que sea, debe incluir objetivos de equidad, y estos criterios han de ser, además, evaluables. De lo contrario, se ponen en juego elementos sustanciales del modelo social. Las políticas de austeridad nos pueden condenar a convivir durante muchos años, incluso aunque se recupere la actividad económica, con niveles muy altos de desigualdad, pobreza y exclusión. Lo mínimo, por tanto, que podría exigirse a los ‘decisores' públicos en este momento es incorporar criterios de equidad y de reducción de la pobreza a sus actuaciones.

\subsubsection{Los ejes de la inclusión activa y de la cohesión social}

Desde este tipo de supuestos, se deberían marcar una serie de objetivos muy concretos. Podemos formular estos objetivos de una forma coherente siguiendo las orientaciones de la Comisión Europea sobre la 'inclusión activa' (Comisión Europea, 2008). Según éstos, la finalidad y los objetivos de las políticas de inclusión deberían tener una estructura articulada en su campo de actuación concreta, pues deberían ser la consecución concreta de los elementos de la inclusión activa que fueron definidos para lograr la cohesión social. Así, tendríamos tres ejes trasversales:

Cuadro 1. Ejes de la inclusión

\begin{tabular}{l|l}
\hline Ejes de la inclusión & Inclusión activa \\
\hline Garantías & - lo que propone como protección \\
\hline Integración & - lo que propone como integración laboral \\
\hline Ciudadanía & - lo que propone como servicios de calidad \\
\hline
\end{tabular}

Fuente: Elaboración propia. 
Las políticas de inclusión deben garantizar el ejercicio de los derechos que están en entredicho en las situaciones de pobreza y exclusión. Y en este objetivo, hay una serie de 'líneas rojas' que no se pueden traspasar si queremos evitar que la pobreza perdure durante las próximas décadas, y son las que afectan, sobre todo, a las pensiones mínimas, la extensión de la protección a los desempleados, y los recortes en sanidad, educación y dependencia. En este momento hay que lograr, como objetivo prioritario, la redefinición global de los sistemas de garantía de rentas. Tenemos que plantear, sin duda, qué nos falta para definir una red de seguridad económica coherente y cómo reducir las desigualdades de los subsistemas actuales.

Hay que mejorar también la eficiencia de los programas de mantenimiento de rentas y evitar el riesgo de políticas muy específicas para los más desfavorecidos, a fin de evitar la precarización de algunos colectivos. Pero, sobre todo, hay que reforzar la red de protección, ahora claramente insuficiente, para contener el aumento de la pobreza severa, que es uno de los aspectos más amenazantes de nuestro desarrollo social. Se trata de reformas que vienen demandadas por la situación actual, que no deben ser consideradas como una simple enumeración de medidas paliativas o de choque, sino que deben responder a una estrategia global y coherente con lo que la inclusión y la cohesión social requieren. Sólo en esta perspectiva se podrá reclamar la adopción de 'un plan de rescate para las personas' basado en:

- La protección a las familias sin recursos para que no sean desahuciadas. La situación crítica de las familias más afectadas requiere de intervenciones urgentes de carácter preventivo que eviten el deterioro de las situaciones de salud, endeudamiento y convivencia de un sector de la población joven en España. El futuro de estas familias y sus hijos requiere de intervenciones urgentes orientadas a la garantía de ingresos, al mantenimiento de la vivienda y al rendimiento escolar de los menores. En tanto en cuanto el mercado laboral no sea capaz de generar oportunidades laborales, es preciso ofrecer mecanismos de subsistencia para los más vulnerables.

- Recursos suficientes para las situaciones de necesidad que prevengan la intensidad de la pobreza y la cronificación de la exclusión.

- Protección a los desprotegidos por el desempleo y al creciente número de hogares sin ingresos, incluyendo la extensión y al aumento de la intensidad de las rentas mínimas de inserción.

- Potenciación de la red de servicios sociales públicos: las políticas sociales no han sido las causantes del problema, sino que, por el contrario, pueden ser parte de la solución. El de los servicios sociales a las personas (por ejemplo, la atención de o a 3 años, o la atención a la dependencia) está siendo, en muchos países europeos, un sector económico de alto rendimiento económico. Sin embargo, en nuestro país esta parte de la economía se encuentra sumergida, o se provee de manera informal y con fuertes costes personales las familias. Hacer emerger un sector de servicios personales de calidad bajo liderazgo público permitiría el doble objetivo de creación de empleo y riqueza económica, y la cobertura de estas necesidades sociales de las familias.

\subsubsection{Integración}

Las políticas de inserción también deben hacer accesibles los elementos y requisitos de las condiciones de la integración social que sean más necesarios y consistentes para lograr la autonomía y promoción de las personas, las familias y los grupos en situaciones de pobreza y exclusión. En este sentido, hay que contemplar dos aspectos. Por una parte, las dos estructuras fundamentales para la integración social:

- Educación/formación: debe asumir el reto del déficit educativo de los grupos en riesgo de exclusión, así como el desfase de los métodos en relación a estas situaciones.

- Empleo: no nos podemos permitir la pérdida de oportunidad que significa tener a tantas personas al margen de la dinámica social, económica y política del empleo. Por eso, la inversión social en las personas es la mejor garantía para el progreso social y económico de nuestra sociedad:

- Destaca como prioritaria la puesta en marcha de actuaciones dirigidas a los jóvenes sin formación. En este aspecto, hay mucho margen para actuar sin elevar los costes, a través de bonificaciones específicas.

- Hay que dedicar especial atención a los sectores sociales más afectados por el desempleo y a las personas con más dificultades de integración en el mercado de trabajo, promoviendo itinerarios personalizados de inserción laboral. De hecho, la experiencia muestra que los nuevos puestos de trabajo no irán a parar a los colectivos que más necesitan los ingresos o el empleo; por el contrario, irán a parar a aquellos desempleados de mayor cualificación, experiencia y mejor capital relacional. De este modo, es probable que la situación de las personas más vulnerables sea más duradera que la propia crisis económica.

- Hay que ampliar realizaciones contrastadas, como el Programa Operativo Lucha Contra la Discriminación, que debe ser impulsado y ampliado teniendo en cuenta la experiencia de las ONG y potenciando la participación de las entidades sociales.

- Los fondos destinados a la economía social deben ser impulsados, incluyendo el apoyo a empresas de inserción, la economía social alternativa o las clausulas sociales. 
- Las propuestas del sector social sobre la formación para el empleo deben encontrar respaldo sustancial y reconocimiento.

Por otra parte, es necesaria una acción expresa en las situaciones de mayor exclusión. Son necesarias actuaciones para la integración de los grupos más excluidos:

- Debe trabajarse con intensidad en la prevención de la formación de guetos territoriales y en los espacios sociales y habitacionales que concentran graves problemas de pobreza y exclusión.

- La situación del sinhogarismo en España exige una estrategia de Estado, pues es necesario articular los diversos niveles de la Administración que intervienen en este problema. Es exigible la puesta en marcha de las propuestas ya elaboradas por parte de la propia administración pública, así como la participación del sector social en ello.

- Urge afrontar con especial intensidad el grave problema de la transmisión intergeneracional de la pobreza.

- Los actuales procesos de exclusión de la población joven deben ser objeto de una actuación integral.

- Los procesos de exclusión de la población discapacitada deben ser objeto de una actuación integral.

Para prevenir las situaciones de discriminación y xenofobia, se han de potenciar los procesos de integración de colectivos minoritarios, especialmente las minorías étnicas y los colectivos inmigrantes.

\subsubsection{Ciudadanía}

Finalmente, las políticas de inserción deben acompañar a lo largo del proceso de ejercicio de los derechos como sujetos participantes en su propio proceso y como miembros de la sociedad. Dos aspectos hay que contemplar a este respecto. En primer lugar, los déficits en servicios fundamentales:

- La accesibilidad de la vivienda.

- Los aspectos sanitarios de la exclusión: es preciso actuar sobre la salud mental (en sí misma y por sus consecuencias que empujan a la exclusión, por ejemplo, el sinhogarismo), las adicciones y sus efectos, la pérdida de salud por incapacidad de acceso a la medicación y a tratamientos, entre otras cuestiones.
En segundo lugar, está la adecuación de los servicios y los proyectos, que debe realizarse desde las condiciones de las personas, las familias y los grupos sujetos a procesos de riesgo de pobreza o exclusión:

- Acompañamiento en el proceso de integración desde los servicios sociales, cuyo desarrollo, extensión y adaptación deben ser potenciados expresamente.

- Planes territoriales integrados con los que hacer frente a las situaciones de pobreza y a la transcripción espacial de ésta.

- Participación de las personas en procesos de integración social en los propios proyectos de actuación, así como visibilización de dicha participación ante las decisiones que afectan a sus propios recursos y a sus procesos vitales y sociales.

\section{Conclusiones: gobernanza y articulación del compromiso público}

Las políticas y planes no consisten simplemente en la selección de unas u otras medidas. Se trata de que esas medidas se articulen y estructuren de acuerdo con lo que cada una pueda aportar a los objetivos y las finalidades a las que deben servir. Por ello, una buena gobernanza debe identificar cuáles son las medidas que específicamente son más condicionantes y necesarias para una política económica y social efectiva contra la pobreza y la exclusión social.

La necesaria articulación e integración de actuaciones exige un acuerdo de responsabilidades y un pacto de garantía de los compromisos. Ello conlleva la necesidad de concretar un pacto y una estrategia estatal por la inclusión social (Fresno y Tsolakis, 2010; EAPN-España et al., 2010). Pero esa estrategia no se puede quedar en un ámbito genérico, sino que sus medidas deben tener muy presente la escala local. Por ello debe comprometerse en promover la inclusión en el plano local que priorice la acción en la proximidad de las personas (EAPN-España, 2011). Por último, los planes y medidas deben hacerse viables a través de nuevos enfoques para la acción y de nuevos procesos de trabajo, así como de la coordinación entre todos los actores que intervienen no solamente en la generación de capital y riqueza, sino también ante la pobreza y la exclusión social, por lo que hay que contemplar la participación en estas políticas no exclusivamente del Estado y de los agentes sociales, sino también del tercer sector. 
AYALA, L. (en prensa): “¿Es la política social la 'cenicienta” de la crisis? Retos y políticas para la inclusión social" [aportación a la mesa redonda], Nuevas propuestas para nuevos tiempos, Madrid, EAPN-España.

AYALA, L. (coord.) [2009]: Desigualdad, pobreza y privación, colección Estudios, Madrid, Fundación FOESSA.

BARCALA, D. (2009): “El fracaso universitario cuesta 3.300 millones al año", Público, 10-5-2009 [<http:// www.publico.es/espana/224664/el-fracasouniversitario-cuesta-3-300-millones-al-ano>].

CABRERA, L. et al. (2006): "El problema del abandono de los estudios universitarios", Relieve, vol. 12, n으 2 [rhttp://www.uv.es/RELIEVE/v12n2/ RELIEVEv12n2_1.htm>].

CÁRITAS (2011): VI Informe del Observatorio de Cáritas sobre las demandas atendidas a través de la Red Confederal de Acogida y Atención Primaria. Enero-diciembre 2010, Madrid, Cáritas [<http:// www.caritas.es/AdjuntoCampanaDownload. aspx?|d=1360〉].

CENTRO EUROPEO PARA EL DESARROLLO DE LA FORMACIÓN PROFESIONAL (2010): The Skill Matching Challenge. Analysing Skill Mismatch and Policy Implications, Luxemburgo, Oficina de Publicaciones de la Unión Europea [rhttp:// www.cedefop.europa.eu/EN/Files/3056 en.pdf $\rangle$.

COMISIÓN EUROPEA (2012): Commission Staff Working Document. Elements for a Common Strategic Framework 2014 to 2020, SWD(2012) 61 final, Bruselas, Comisión Europea, partes I y II, 14-3-2012 [<http://ec.europa.eu/ regional_policy/sources/docoffic/working/ strategic_framework/csf_part1_en.pdf>y 〈http://ec.europa.eu/regional_policy/sources/ docoffic/working/strategic_framework/csf_ part2_en.pdf s].

- (2011a): Comunicación de la Comisión. Estudio Prospectivo Anual sobre el Crecimiento 2012, COM(2011) 815 final, Bruselas, Comisión Europea, 23-11-2011 [shttp://ec.europa.eu/europe2020/pdf/annual_ growth_survey_es.pdf $\rangle$ ].

- (2011b): Employment and Social Developments in Europe 2011, Bruselas, Comisión Europea [rhttp:// dx.doi.org/10.2767/44905'].

- (2011C): Propuesta de reglamento del Parlamento Europeo y del Consejo por el que se establecen disposiciones comunes relativas al Fondo Europeo de Desarrollo Regional, al Fondo Social Europeo, al Fondo de Cohesión, al Fondo Europeo Agrícola de Desarrollo Rural y al Fondo Europeo Marítimo y de la Pesca, incluidos en el Marco Estratégico Común, y por el que se establecen disposiciones generales relativas al Fondo Europeo de Desarrollo Regional, al Fondo Social Europeo y al Fondo de Cohesión y se deroga el Reglamento (CE) $n$ - 1083/2006 del Consejo, COM(2011) 615 final/2; 2011/0276 (COD), Bruselas, Comisión Europea, 14-32011 [<http://eur-lex.europa.eu/LexUriServ/ LexUriServ.do?uri=COM:2011:0615:FIN:ES:P DF〉. Corrigenda: 〈http://eur-lex.europa.eu/ LexUriServ/LexUriServ.do?uri=COM:2011:0615: REV1:ES:HTML>].

- (2010a): Comunicación de la Comisión. Europa 2020. Una estrategia para el crecimiento inteligente, sostenible e integrador, Bruselas, COM(2010): 2020, Bruselas, Comisión Europea, 3-3-2010 [‘http://eur-lex.europa.eu/LexUriServ/ LexUriServ.do?uri=COM:2010:2020:FIN:ES:PDF)].

- (2010b): Propuesta de Decisión del Consejo sobre directrices para las políticas de empleo de los 
Estados miembros. Parte II de las Directrices Integradas Europa 2020, COM(2010) 193 final, Bruselas, Comisión Europea, 27-42010 [/http://eur-lex.europa.eu/LexUriServ/ LexUriServ.do?uri=COM:2010:0193:FIN:ES:P DF>].

- (2010c): Recomendación de recomendación del Consejo de 27.4.2010 sobre directrices generales para las políticas económicas de los Estados miembros y de la Unión. Parte I de las Directrices Integradas de Europa 2020, SEC(2010) 488 final, Bruselas, Comisión Europea, 27-4-2010 [/http://register.consilium. europa.eu/pdf/es/10/stog/stog231.es10.pdf)].

- (2008): “Recomendación de la Comisión, de 3 de octubre de 2008 , sobre la inclusión activa de las personas excluidas del mercado laboral", Diario Oficial de la Unión Europea, C(2008) 5737, 18-11-2008, págs. L 307/11-14 [khttp:// eur-lex.europa.eu/LexUriServ/LexUriServ.do?ur $\mathrm{i}=0$ J:L:2008:307:0011:0014:ES:PDF>].

- (2005): Comunicación al Consejo Europeo de primavera: 'Trabajando juntos por el crecimiento y el empleo. Relanzamiento de la estrategia de Lisboa. Comunicación del presidente Barroso de común acuerdo con el vicepresidente Verheugen', $\mathrm{COM}(2005) 24$ final, Bruselas, Comisión Europea, 2-2-2005 [rhttp://eur-lex. europa.eu/LexUriServ/LexUriServ.do?uri=COM: 2005:0024:FIN:ES:PDF>].

- (1994): Crecimiento, competitividad, empleo. Retos y pistas para entrar en el siglo XXI. Libro blanco, Luxemburgo, Oficina de Publicaciones Oficiales de las Comunidades Europeas [shttp://tinyurl. com/7n2pd7h>].

CONSEJO DE LA UNIÓN EUROPEA (2010): New European Strategy for Jobs and Growth - Progress of Work, 10772/10, Bruselas, Consejo de la Unión Europea, 8-6-2010 [<http://register.consilium. europa.eu/pdf/en/10/st10/st10772.en10.pdf>].

- (2000): Conclusiones de la Presidencia. Consejo Europeo de Lisboa, 23 y 24 de marzo de 2000, Lisboa, Consejo de la Unión Europea [rhttp://www. consilium.europa.eu/ueDocs/cms_Data/docs/ pressData/es/ec/o0100-r1.eso.htm〉].

EAPN-ESPAÑA (en prensa): Nuevas propuestas para nuevos tiempos, Madrid, EAPN-España.

- (2011): Propuestas de EAPN-ES a los partidos políticos ante las próximas elecciones generales, Madrid, EAPN-España, 1-10-2011 [khttp://www. eapn.es/attachments/1064_ELECCIONES\%20 $2011 \% 20 \% 20$ PROPUESTAS\%20EAPN-ES.pdf〉].

EAPN-ESPAÑA, PLATAFORMA DEL VOLUNTARIADO DE ESPAÑA Y PLATAFORMA DE ONG DE ACCIÓN SOCIAL (2010): Declaración del tercer sector de acción social. Por una Estrategia de Inclusión Social 2011-2020 [khttp://www.eapn.es/ attachments/734_declaracion_convencion. pdf>]
2010): Early school-leavers. Percentage of the population aged 18-24 with at most lower secondary education and not in further education or training, Luxemburgo, Eurostat [<http://epp.eurostat.ec.europa.eu/tgm/table. do $?$ tab $=$ table $\&$ init $=1$ \&language $=$ en $\&$ pcode $=t$ sisco6o〉].
- (2010b): Glossary: Material deprivation [rhttp://epp. eurostat.ec.europa.eu/statistics_explained/ index.php/Glossary:Material_deprivation〉].

FRESNO, J. M.; y TSOLAKIS, A. (2010): Propuestas del tercer sector de acción social para una Estrategia de Inclusión Social 2020 en España, Madrid, EAPN-España [<http://www.eapn.es/ attachments/822_Para_Web.pdf>].

FUNDACIÓN FOESSA (2012): Exclusión y desarrollo social en España. Análisis y perspectivas 2012, Madrid, Fundación FOESSA [rhttp:// www.caritas.es/imagesrepository/ CapitulosPublicaciones/4314/EXCLUSION\%20 Y\%20DESARROLLO\%20SOCIAL.\%20 Versi\%C3\%B3n\%2odigital.pdf \].

FUNDACIÓN ORTEGA-MARAÑÓN et al. (2011): Inmigración y crisis económica: impactos actuales y perspectivas de futuro. Anuario de la Inmigración en España 2010, Barcelona, Diputació de Barcelona; Barcelona, Centro de Estudios y Documentación Internacionales de Barcelona; Madrid, Fundación Ortega-Marañón; Málaga, Unicaja; Barcelona, Fundación ACSAR; Sevilla, Centro de Estudios Andaluces.

GOBIERNO DE ESPAÑA (2012): Programa Nacional de Reformas España 2012, Madrid, Gobierno de España [<http://www.lamoncloa.gob.es/ NR/rdonlyres/ADAB8001-F650-4132-9221FFEB2CEB784E/202005/PNRDEFINITIVO.pdf〉].

- (2011): Programa Nacional de Reformas España 2011, Madrid, Gobierno de España [«http://www. lamoncloa.gob.es/NR/rdonlyres/CCFCB04DBBED-4917-A9CD-B9BE4DDC6B45/o/ ProgramaNacionalReformasEspana2011.pdf〉].

GONZÁLEZ-ENRÍQUEZ, C. (2009): Undocumented Migration. Counting the Uncountable. Data and Trends across Europe. Country Report: Spain [<http://clandestino.eliamep.gr/wp-content/ uploads/2009/10/clandestino_report_spain_ final_2.pdf >].

IDESBALD, N. (2011): "The revenu de solidarité active as a tool to fight in-work poverty", en HIEBL, U. (dir.), Building the Tools to Fight In-work Poverty, París, Comisión Europea [khttp:// www.peer-review-social-inclusion.eu/peerreviews/2011/building-the-tools-to-fightin-work-poverty/discussion_paper_fr11/ download»].

INSTITUTO NACIONAL DE ESTADÍSTICA (2012): Encuesta de Población Activa (EPA). Primer trimestre de 2012, Madrid, Instituto Nacional de Estadística, 27-4-2012 [<http://www.ine.es/daco/daco42/ dac04211/epao112.pdf)].

JEFATURA DEL ESTADO (2012): “Real Decreto-ley 3/2012, de 10 de febrero, de Medidas Urgentes para la Reforma del Mercado Laboral”, Boletín Oficial del Estado, nํ36, 11-2-2012, págs. 12.483-12.546 [khttp://www.boe.es/boe/ dias/2012/02/11/pdfs/BOE-A-2012-2076.pdf)].

JENKINS, S. et al. (2011): "The great recession and the distribution of household income", en Fondazione Rodolfo De Benedetti XIII European Conference 'Incomes across the Great Recession', Palermo, 10-9-2011 [<http://www. frdb.org/upload/file/report_1_palermo.pdf)]. 
KOK, W. (2004): Ampliación de la Unión Europea. Logros y Desafíos. Informe de Wim Kok para la Comisión Europea [khttp://ec.europa.eu/enlargement/ archives/pdf/enlargement_process/past_ enlargements/communication_strategy/ report_kok_es.pdf〉].

MINISTERIO DE EDUCACIÓN (2010): Panorama de la Educación. Indicadores de la OCDE 2010. Informe Español, Madrid, Ministerio de Educación [<http://www.educacion.es/dctm/ministerio/ horizontales/prensa/documentos/2010/ septiembre/pg-informe-espanol-panorama-delaeducacion-2010-ver6sep.pdf?documentld=09 01e72b803fbabb>].

MUNDO, EL (2012): “El FMI prevé que España incumpla el objetivo de déficit durante dos años", El Mundo, 24-1-2012 ['http://www.elmundo.es/elmundo/2012/01/24/ economia/1327417891.html〉].
PÉREZ ERANSUS, B. (en prensa): “¿Es la política social la 'cenicienta' de la crisis? Retos y políticas para la inclusión social” [aportación a la mesa redonda], Nuevas propuestas para nuevos tiempos, Madrid, EAPN-España.

PÚBLICO (2012): “El Gobierno augura 630.000 parados más en 2012", Público, 2-3-2012 [<http://www. publico.es/dinero/424633/el-gobierno-augura630-000-parados-mas-en-2012〉].

RENES, V. (en prensa): “¿Un nuevo modelos social emergente? Una reflexión obligada”, Nuevas propuestas para nuevos tiempos, Madrid, EAPN-España.

- (2003): 'Integración/Inserción’, en ARIÑO, A. (ed.), Diccionario de la solidaridad (I), Valencia, Tirant lo Blanch, págs. 312-314. 



\section{Aktibazioa eta gizarteratzeko eskubidea, EAE-ko enpleguko eta diru-sarrerak bermatzeko politiken esparruan}

\section{SIIS Dokumentazio eta Ikerketa Zentroa}

Eguía-Careaga Fundazioa

<estudios@siis.net>

EAEko testuinguruan aktibazio-politikek izan beharko lituzketen oinarri teorikoak eta testuinguru horretan aktibazio-eredu inklusiboak izan behar lituzkeen ezaugarriak planteatzen dira artikulu honetan. Artikulua SIIS Dokumentazio eta Ikerketa Zentroak Eusko Jaurlaritzako Enplegu eta Gizarte Sailarentzat egindako txosten luzeago baten laburpena da. Txostenaren helburua da gogoetarako hainbat lerro teoriko proposatzea aktibazio-kontzeptua diru-sarrerak bermatzeko eta enpleguko politiken kudeaketan ezartzeko, batez ere Lanbideren esku hartzeko ereduaren esparru kontzeptuala eta filosofikoa izan dadin

\section{HITZ-GAKOAK:}

gizarte-bazterketa, enplegurako politika aktiboak, diruz emandako prestazioak, gutxiengo errentak bermatzeko sarea, gizarteratzeko programak.
En este artículo se plantean las bases teóricas en las que deberían sustentarse en el contexto de la CAPV las políticas de activación y las características que debería tener en ese contexto un modelo inclusivo de activación. El artículo resume un trabajo más amplio realizado por el SIIS Centro de Documentación y Estudios, a instancias del Departamento de Empleo y Asuntos Sociales del Gobierno Vasco. El objetivo del informe es el de proponer una serie de líneas de reflexión, de carácter teórico, sobre la aplicación del concepto de activación a la gestión de las políticas de garantía de ingresos y de empleo, que sirvan de marco conceptual y filosófico al modelo de intervención de Lanbide.

\section{PALABRAS CLAVE:}

exclusión social, política activa de empleo, prestaciones económicas, renta de garantía de ingresos, programas de inserción. 


\section{Sarrera}

2012ko urtarrilaren 1ean indarrean hasi ziren legegintza-aldaketen arabera, Lanbide Euskal Enplegu Zerbitzuak bere gain hartu du diru-sarrerak bermatzeko errentaren eta etxebizitza-osagarriaren kudeaketa, baita gizarteratze aktiboko hitzarmenen harpidetzaren eta jarraipenaren gaineko erantzukizuna ere.

Azken hilabeteetan, Eusko Jaurlaritzaren Enplegu eta Gizarte Gaietako Sailak kontzeptuzko eta antolamenduzko esparru bat garatu du legegintza-aldaketa horrek berekin dakarren erronkari erantzun egokia emateko. Ildo horretan, 2011n Plangintza eta Enplegu Sailburuordetzak gizarteratzeko eskubideari eta aktibazioari buruzko txostena ${ }^{1}$ egiteko bultzada eman zuen, EAEko diru-sarrerak bermatzeko eta enplegua sustatzeko politiken esparruan. SIIS Eguía Careaga Fundazioaren Dokumentazio eta Ikerketa Zentroak egindako txosten horren bitartez, zenbait gogoetaildo teoriko proposatu nahi ziren diru-sarrerak bermatzeko eta enplegua sustatzeko politiken kudeaketaren aktibazio-kontzeptuaren aplikazioari dagokionez, Lanbideren esku-hartze ereduaren kontzeptuzko esparru filosofiko gisa erabili ahal izateko.

Dokumentua urriaren 2oan aurkeztu zen jendaurrean, Gasteizen antolatutako jardunaldi batzuen esparruan. Aktibazioaren paradigmaren esanahia gainbegiratzen du dokumentu berriak. Gainera, dirusarrerak bermatzeko euskal sistemaren garapenean paradigma hori historian zehar zenbateraino egon den indarrean aztertzen du, eta, batez ere, eredu zehatz bat proposatzen du, kontzeptuzko oinarri filosofiko batzuetatik abiatuta. Eusko Jaurlaritzaren Enplegu eta Gizarte Gaietako Sailak ez du dokumentu horretan jasotako guzti-guztia ontzat hartzen, baina nolanahi ere dokumentu horretan planteatutako proposamena oinarri teoriko egokia izan daitekeela uste du, eta, hortik abiatuta, Euskal Enplegu Zerbitzuaren jardun-esparrua zehaztu litekeela, diru-sarrerak bermatzeko errentaren kudeaketari eta onuradunen gizarteratze aktiboari dagokienez.

Artikulu honen bitartez txosten hura laburtu nahi izan dugu, antzeko egitura bati eutsiz. Lehen zatian, aktibazioaren paradigma zehatz-mehatz deskribatu dugu, eskuragarri dagoen zientzia-literaturaren azterketatik abiatuta. Deskribapen horretatik abiatuta, bigarren zatiak gizarteratze aktiboko eredu bat proposatu du EAErentzat, herritar guztien eskubideak errespetatu nahi dituena funtsezko zenbait kontzeptutatik abiatuta, hala nola eskubide bikoitza, bidezko elkarrekikotasuna edo enplegagarritasun zabala.

${ }^{1}$ Txosten osoa ondoko helbidean kontsulta daiteke: [<http:// www.siis.net/documentos/ficha/197806.pdf)].

\section{Aktibazioaren paradigma}

\subsection{Gizarte-politiken aktibazioa: definizioa eta oinarrizko kontzeptuak}

Gutxienez azken 20 urteetan, mendebaldeko herrialdeetako gizarte-politiketan zenbait aldaketa nabari dira, guztiak ere aktibazioaren paradigma orokorraren barnean har daitezkeenak, nahiz eta, aurrerago ikusiko dugunez, paradigma horren barruan oso askotariko neurri eta politikak biltzen diren, oso helburu desberdinei erantzuten dietenak. Aditu guztiak ez dira bat etorri aktibazioaren kontzeptua zehazterakoan (Moreira, 2008), baina honako definizio hau onartua dago oro har: politika, neurri eta tresna multzoa, prestazio ekonomikoak jasotzen dituzten langabeak lan-merkatuan integratzeko eta horrela haien gizarte- eta ekonomia-integrazioko mailak hobetzeko abian jartzen direnak. Aktibazioaren paradigma oinarrizko zenbait printzipiotan oinarritzen da. Morenok eta Serrano Pascualek (2007) funtsezko hiru alderdi aipatu dituzte:

- Indibidualizazioa. Egile horien ustetan, paradigma berriak "norbanakoaren jokabide, motibazio eta jarreretan esku hartu nahi du, aberastasunaren bidezko birbanaketarako baldintza politiko egokiak ezarri baino gehiago. Aktibazio-politikek gero eta pertsonalizazio handiagoa sustatzen dute esku-hartzeetan, eta parte-hartze handiagoa eskatzen dute eraginpean hartutako pertsonaren aldetik. Norbanakoa da erreferentzia arau-emaile zein legitimatzailea”.

- Enpleguari lehentasuna ematea. Enpleguaren bitartez parte-hartze eta autonomia ekonomikoa sustatzea da politika horien helburua. Norbanakoak lan-merkatuaren aurrean ageri dituen portaeretan esku hartu nahi dute politika horiek, norbanakoa sustatuz, konbentzituz eta motibatuz. Hortaz, dimentsio ekonomikoei garrantzi handiagoa ematen die dimentsio politika eta sozialei baino gehiago, herritartasuna gauzatzean.

- Kontraktualizazioaren printzipioa. Serranoren eta Morenoren arabera, "kontratua metafora nuklear bihurtu da politika horien orientazioan eta legitimazioan. Baina horrek eskatzen du, halaber, herritartasun-kontzeptua betidanik eratu duen kontratu soziala aldatzea. Kontratuari balio morala ematen zaio balio politiko edo soziala baino gehiago: herritarrek, beren eskubideak jasotzeko, baldintza jakin batzuk bete behar dituzte, eta beren parte-hartze ekonomikoari dagokionez hartzen duten jarreraren eta portaeraren araberakoak izango dira eskubide horiek. Kontratua jaun eta jabe da gizarte-erregulazioko mekanismo gisa, eta, horrekin batera, 'elkarrekikotasun-araua' berresten da, 'merezimendua' funtsezko ardatz bihurtuz herritartasunaren legitimitatean”.

Azkenik, egile horiek honako hau adierazi dute:
Aktibazioaren paradigmak lan-merkatuan esku hartzea eskatzen du, baina esku-hartze soil 
horretatik haratago doa. Langabeziaren, prestakuntzaren edo gizarte-bazterkeriaren arazoen diagnostikoaren birdefinizioa eskatzen du, baita ongizatearen estatuaren, soldatakoen eta enplegu-emaileen artean erantzukizunak berriz antolatzeko abian jar daitezkeen alternatiba legitimoen birdefinizioa ere. Azken batean, hirugarren milurtekoaren hasieran, Europako gizarte-gaiak antolatzeko erabili ohi diren ardatz sozial eta moralak eraldatzeko prozesua planteatzen du aktibazioaren paradigmak.

\subsection{Paradigma berri bat? Zenbait aurrekari historiko}

Harritzekoa da, nolanahi ere, zenbait egilek behin eta berriz esatea aktibazio-kontzeptua elementu berria dela gizarte-politikak zehaztean. Pérez Eransusek adierazi duenez (2005), laguntzaren eta enpleguaren arteko harremana ez da berria, eta lan egiteko gaitasunik ez duten pobreei lagundu beharra gizartelaguntzaren garapenaren funts nagusietako bat izan da, hasiera-hasieratik. Izan ere, lanaren balioa eta norbanakoaren erantzukizuna aldarrikatzea gizartepolitiken historian oso sustraituta dauden ereduen ondorio da, eta pentsatzekoa da aktibazio-politikek ongizate-erregimen jakin batzuekiko haustura baino ez luketela ekarriko, hain zuzen ere, oso testuinguru geografiko eta historiko mugatu batean, diru-sarrerak bermatzeko garrantzi handiko sistema unibertsala ezarri zuten ongizate-erregimenekiko haustura.

Nolanahi ere, politika horiek abian jartzeko prozesuari buruzko analisi historikoaren arabera, gutxienez hiru iturri ideologiko nagusi bereiz ditzakegu, batzuetan kontrajarriak direnak eta beste batzuetan gainjartzen direnak, eta horiei dagokie ikuspegi hori orokortzeko lidertza politikoa:

- Iraultza kontserbadorea 8oko hamarkadan. Estatu Batuetan, 6oko hamarkadatik ezarri zituzten aktibazioaren filosofiarekin bat zetozen neurriak, baina neurri horiek bereziki garatu ziren Erresuma Batuan Margaret Thatcher eta Estatu Batuetan Ronald Reagan (1979an eta 1980an, hurrenez hurren) boterera iritsi ziren uneaz geroztik. Gizartean nahikoa hedatua zegoen pertzepzio baten arabera, gizarte-laguntzak jasotzen zituztenen artean hainbat kronifikazio- eta mendetasunegoera gertatzen ari ziren, eta onuradunen sektore bat parasitismoan erortzeko arriskua zegoen (bestetik aipatzekoa da hori ez dela berria gizarte-politiken historian, laguntza merezi duten eta merezi ez duten -deserving and undeserving poors- pobreen arteko bereizketa dakarrelako gogora). Gainera, buruzagi horiek norbanakoaren erantzukizunaren eta lanaren etikaren ohiko printzipioak birformulatu zituzten, ikuspegi zorrotzago bati jarraiki.

- Hirugarren bidea 9oeko hamarkadan. Politikaeremuan, nolanahi ere, aldaketa horren benetako indar sustatzailea zentro-ezkerreko alderdi anglosaxoien eskutik etorri zen, eta, oso bereziki, Tony Blairen Alderdi Laboristaren eskutik, Anthony
Giddensen postulatu ideologikoen babesean, eta Bill Clintonen Alderdi Demokrataren eskutik, besteak beste Lawrence Meaden pentsamolde neopaternalistaren eragin nabaria zuena. Ezbairik gabe, bi politikari horien agintearen eta eraginaren mendean (pixka bat geroago, Schroeder sozialdemokrata alemana atxiki zitzaien) hartu ziren gizarte-politikak aktibatzeko neurri nagusiak, hala nola Personal Responsability and Work Opportunity Act 1996an Estatu Batuetan, edo New Deal programa sorta, 1997az geroztik Erresuma Batuan garatu zena, hurrenez hurren: 'Lana lan egin dezaketenentzat eta segurtasuna ezin dutenentzat' izan zen administrazio laboristak eremu horretan erabili zuen goiburu nagusia. Laboristek liburu berdea argitaratu zuten, boterera iritsi ondoren urtebete igarotakoan, eta, liburu horren arabera, "Gobernuak Ongizatearen Estatua berreraiki nahi zuen, lanaren inguruan”, enplegu-politika aktiboak, laguntza-zerbitzuak eta zerga-murrizketak ezarriz, eta "eskubide eta erantzukizunen arteko oreka egokia bermatuz”.

- Nazioarteko erakundeak, eta bereziki, ELGA eta Europar Batasuna. Arribak eta Pérez Eransusek adierazi dutenez (2007), “lan-merkatuko politika aktiboak laurogeiko hamarkadan hedatu ziren nazioarteko erakundeen eskutik, hala nola NBE, ELGA, Nazioarteko Bankua, eta 9oeko hamarkadaren erdialdetik, Europar Batasuna. Une hartan kezka zen nagusi egiturazko langabezia zela medio, eta nazioarteko erakunde horiek Estatuei langabeen prestakuntza-maila hobetzeko neurriak abian jartzeko gomendatu zieten, langabe horiek eszenatoki lehiakor berriaren premietara egokitzeko aukera izan zezaten. Estatuei zera proposatu zitzaien, babes ekonomikoko politiken ordez (une hartatik aurrera pasiboak deitu zieten) langabeak berriz laneratzea sustatzeko neurri edo politika aktiboak abian jartzea”. EBk guztiz bat egin du eredu berriarekin -izan ere, hainbat egileren aburuz, neurri horiek abian jartzean erkidegoaren lidertza erabakigarria izan da ereduaren ezaugarriak zehaztean- ekiteko eta aktibazioaren alde egiteko gomendioetan, eta eredu hori eta mendetasunarekiko kezka Nizako Itunaz geroztik bultzatutako Gizarteratze Plan Nazionaletara eraman dira berehala.

Nolanahi ere ez dugu pentsatu behar aktibazioneurriak herrialde anglosaxoietara edo nazioarteko erakundeen eraginera mugatu direnik. Batetik, Escandinaviako herrialdeek gizarte-politikak aktibatzeko hainbat neurri jarri zituzten abian 8oko hamarkadatik aurrera, herrialde horietako enplegupolitika aktiboen garapen zabalarekin bat etorriz. Suedian, esaterako, 1998ko Gizarte Zerbitzuei buruzko Lege berriaren arabera, 20 urtetik gorako pertsonek gizarte-laguntza jasotzeko eskubidea dute, baina betiere lan- eta prestakuntza-jardueretan parte hartzen badute. Ildo beretik, 9oeko hamarkadan Danimarkak zenbait lege aldatu zituen aktibaziorako eskubidea eta betebeharra onartzeko. Besteak beste, arrazoizkotzat jotako lanpostuetan lan egiteko edo 
prestakuntza-jardueretan parte hartzeko betebeharra ezarri zuten (Moreira, 2008).

Bestetik, Frantziak -eta, aurrerago adieraziko dugunez, Espainiako autonomia-erkidego gehienek, EAE buruan- gizarteratzeko gutxieneko errentetan oinarritutako sistema bat ezarri zuten 8oko hamarkadaren amaieran, neurri handi batean aktibazioaren printzipioekin bat datorrena, eta, ikuspegi teorikotik behintzat, baldintzazkotasun-kontzeptu zorrotza ezarri duena. Frantziako ereduak badu beste zenbait bereizgarri gainerako aktibazio-formulen aldean. Esaterako, gizarteratzea laneratze soiletik haratago doala hartzen du aintzat, bazterkeria kausa anitzeko fenomenoa dela kontuan hartuta. Gainera, oreka handiagoa bilatzen du norbanakoaren erantzukizunaren eta erantzukizun kolektiboaren artean, bazterkeriaprozesuak interpretatzean eta horri dagokionez aplikatu beharreko politikak zehaztean.

\section{EAE-n gizarteratze aktiboko eredua zehazteko oinarrizko ildoak}

\subsection{Eredu berria zehazteko oinarrizko kontzeptuzko osagaiak: gizarteratze aktiboa diru-sarrerarik ez duten langabeen eskubide eta betebehar gisa}

Aurreko orrietan aktibazioaren paradigmari dagokionez egin dugun gainbegiratze ezinbestean partzialak aukera eman digu gure inguruko herrialdeetan aktibazio-eredu bat baino gehiago daudela ezartzeko, eta eredu horiek desberdinak direla, eta, erakunde-tradizio eta ikusmolde ideologiko desberdinen ondorio izanik, emaitza halaber desberdinak eman dituztenak, politika horiek herritarrengan eta zehazki langabe edota baliabiderik ez dutenengan duten eraginari eta emaitzei dagokienez.

Izan ere, Morenoren eta Serranoren ustetan (2009), aktibazioaren eredu berria ulertzean aurkako bi interpretazio nabari dira, batetik arauzko eta elkartasunezko printzipioak indartu nahi dituena, eta, bestetik indibidualizazioa indartzearen eta herritarren ongizatearen birmerkantilizazioaren alde egin nahi duena, eta horri jarraiki, Europako herrialdeek bateko edo besteko aktibazio-paradigmak sortu dituzte. Hala, batzuek "herritartasuna gauzatzeko baldintzak indartu" nahi izan dituzte, eta beste batzuek, aldiz, "ekonomia-lehiakortasunaren aldeko apustua egin dute, langilearen kondizio politikoari eta sozialari muzin eginez". Egile horiek diotenez, aktibazioaren kontzeptua ulertzeko zenbait modu egonik, aplikazio zehatzak ere anitzak dira, eta, hori hala izanik, oso bestelako politikak sortzen dira, herrialde bakoitzean nagusi den erakunde-konfigurazioaren arabera.

Hortaz, diru-sarrerak bermatzeko politiken eta enplegu-politiken arteko lotura etikoki justifikagarriak diren oinarrietatik zehazterakoan, funtsezkoa ez da aktibazioaren paradigma onartu behar den edo ez, baizik eta zehazki zer aktibazio-eredu aplikatu nahi den, zer ikusmolde teorikotatik eta zer oinarri filosofikotatik garatu nahi den zehaztea, eta, zehaz- kiago, aplikazioak oinarrizko zer osagai bildu behar dituen erabakitzea. Hau da, egungo zirkunstantzietan EAEn gizarteratze- aktiboko eredu bat nola antola litekeen zehaztea da kontua, aipatu berri ditugun egileek diotenez, herritartasuna gauzatzeko baldintzak indartzeaz gain gizabanakoaren emantzipaziorako eta trebakuntzarako tresna bihurtuko dena.

Aktibazioak, edo gutxienez aktibazioaren zenbait aplikaziok, hainbat kritika jaso dituzte, baina kritika horiei erantzunez, lehenik eta behin, paradigma horretan oinarritutako eredu baten aplikazioa sustatzera eraman duten arrazoiak justifikatu beharko lirateke. Zerk eraman du aktibazioaren paradigma, oro har behintzat, babestera? Lehenik eta behin, eta funtsezko argudioa hori ez bada ere, aipatzekoa da paradigmaren hedapena ia unibertsala dela, eta gure inguruko ia herrialde guztietan onartua dagoela, baita gizarte-politika aurrerakoienak garatu dituztenetan ere. EAEren ikuspegitik, halaber, aipatzekoa da, batetik, hasiera-hasieratik kontzeptu hori onartu egin zela gutxieneko errentei buruzko euskal politiketan, eta, bestetik, indarreko araudian jasotako lege-aginduak aktibazio-kontzeptuaren eta enpleguari lehentasuna ematearen aldeko apustu argia egin nahi duela gizarteratzeko tresna den heinean, eskubide bikoitzaren kontzeptutik abiatuta.

Nolanahi ere, funtsezko arrazoiek kontzeptuzko alderdiekin dute zerikusia:

- Lehenik eta behin azpimarratzekoa da, lan merkatua gaur egun egoera ezegonkorrean egonik ere, okupazioa, eta, zehazki, ordaindutako enplegua, gizarteratzeko, norberaren errealizaziorako eta pobreziaren aurka babesteko funtsezko mekanismoak direla. Ikuspegi horretatik, enplegurik ez dutelako (edo enpleguak behar adinako diru-sarrera ematen ez dizkielako) gutxieneko diru-sarrerak ez dituztenei enplegagarritasuna hobetzeko eta laneratzea sustatzeko tresna lagungarriak eskaintzeak gizarterazte-politika ororen oinarrizko helburua izan behar du, eta, horri jarraiki, gizabanakoari eskubide bat eskaini behar zaio, hain zuzen ere laneratzearen bitartez gizarteratzeko eskubidea.

- Aktibazio-kontzeptua justifikatzen duen bigarren arrazoiak diru-sarrerak bermatzeko prestazioen onuradunen erantzukizun, betekizun edo betebehar pertsonalarekin du zerikusia. Whitek adierazi duenez (2000), eta hurrengo orrietan zehatz-mehatz jaso denez, diru-sarrerak bermatzeko eskubidea gizabanakoaren autonomiaren interpretazio etiko batean oinarritzen da, eta, horren arabera, pertsonek, ahal dela behintzat, ez dute beren herritarrentzako zama izan behar, hori esplotazio modu bat litzatekeelako, eta, arrazoi berberengatik, besteek komunitateari eusteko egiten duten ahaleginari erantzunez, guztion ongizatea eraikitzeko ekarpena egin behar dute, bakoitzak ahal duen neurrian. Izan ere, T.H. Marshallek bere garaian esan zuenez, "herritarren eskubideak babestu behar dira, baina herritarrek betebehar batzuk ere badituztela ahaztu gabe". 
Hortaz, aktibazio-kontzeptua pertsonen eta oro har gizartearen eskubide eta erantzukizunen logikari lotzen zaio. Horrek aktibazio-eredu inklusibo bat aplikatzea eskatzen du, bidezko elkarrekikotasun-kontzeptuan oinarritua, gizabanakoaren erantzukizunaren eskakizuna legez planteatzeko aukera ematen duena.

- Bestetik, aktibazioaren paradigmari merkantilizatzailea izan daitekeela leporatu ohi zaio, baina ez dugu ahaztu behar beste zerbitzu publiko batzuk ez bezala, gizarte-babesaren eremuko zerbitzuak eta prestazioak, eta bereziki diru-sarrerak bermatzeko prestazioak, prestazio horien premia egiaztatzen dutenei ematen zaiela, banan-banan, edo premia-egoera esleitu ohi zaion kolektibo bateko kide izateagatik. Beste baldintza osagarri batzuk ezarri edo ez, argi dagoena da ez jardutearen aldeko erabaki indibiduala ez datorrela nahitaez premia-egoera batetik, eta, nolanahi ere, lanean ari ez direlako premia ekonomikoa duten pertsonek egoera horretatik irteten ahalegintzeko sen onari jarraiki beharrezkoak diren bitartekoak jarri behar dituztela.

Ikuspegi horretatik, gizarteratze aktiboak gizarteeskubideekin zein erantzukizun, betekizun edo betebehar indibidualekin du zerikusia:

- Eskubide bikoitzaren logikan, gizarteratze aktiboari esker, langabeek guztiz gizarteratzeko beharrezko laguntzak jasotzeko eskubidea bete dezakete, eta, zehazkiago, enplegagarritasuna hobetzeko eta lan-merkatuan benetan txertatzeko tresnak jaso ditzakete. Hortaz gizabanakoaren eskubidea gauzatu behar da, prestazio ekonomikoaren eskubideaz aparte, eta horretarako erakundeek enplegagarritasuna sustatzeko konpromisoa hartu behar dute, enplegagarritasuna ikuspegi zabal baten arabera ulerturik. Orain artean prestazioak arlo ekonomikora mugatu dira sarri, baina horrek ez du berez, inondik inora, gizarteratzea bermatzen. Eskubide bikoitz hori hautatzeak, ordea, erakundeei programa eta zerbitzu jakin batzuk abian jartzea eskatzen die, honako xede hauetarako: a) langabeei laguntzea gizarteratze- eta laneratze-prozesuan; b) langabeen enplegagarritasun-mailak hobetzea, trebetasun jakin batzuk eskatzen dituen lanmerkatuan sartzeko erraztasunak emanez; eta d) lan-merkatuaren baldintzetan eta enplegu-eskari erantsian esku hartzea, enpleguak integratzeko duen gaitasunaren galera saihesteko sen onari jarraiki jar daitezkeen bitarteko guztiak jarriz.

- Aurrerago aipatuko dugun bidezko elkarrekikotasunaren logikatik begiratuta, gizarteratze aktiboa betekizun edo betebehar pertsonala ere bada, legezkoa delako gizarteak zenbait eskakizun jartzea prestazioen hartzaile diren langabeentzat: a) ahalegin pertsonal bat, dauden premia-egoeratik ateratzeko; eta b) produkzio-ekarpen bat gizartearen funtzionamendu egokia bermatzeko. Nolanahi ere, ekarpen hori ez da kontraprestazio edo kontrapartida bat, jasotako zerbitzuengatiko ordainketa bat edo zor baten itzulketa ez den heinean, gizartearen funtzionamenduari egindako ekarpena baizik ${ }^{2}$, eta, bestetik, erakundeei baldintza batzuk betetzea eskatzen die, bereziki enpleguaren kalitateari eta lan-merkatuaren baldintzen gaineko esku-hartze publikoari dagokienez, ekarpena legez eskatzeko modukoa izan dadin.

Eskubide bikoitzaren eta gizabanakoaren erantzukizunaren kontzeptuak uztartzeak aukera ematen du gure gizarteetan diru-sarrerak bermatzeko politiken oinarri den gizarte-kontratuaren interpretazio egokiago bat egiteko. Eskubide bikoitzaren kontzeptuari bakarrik erreparatzea, ez badugu kontzeptu hori nahitaezko eskubide baten logikatik aplikatu nahi $^{3}$, ez dator bat diru-sarrerak bermatzeko politiken azpiko esparru teorikoarekin; izan ere, horren arabera hartzaileek ezin dute jardun gabe jarraitu, egoera hori saihestea haien esku badago behintzat. Azken batean laguntza jakin batzuk jasotzeko eskubideari uko egiteko aukera badute, baina zenbait konpromiso eta erantzukizun bete behar dituzte nahitaez, diru-sarrerak bermatzeko prestazioa jasotzearen azpian dagoen elkarrekikotasunkontzeptuari zein herritartasuna ulertzeko moduari berari dagozkien heinean. Gizarteratze aktiboa gizarte-eskubideak zabaltzean oinarritzen duen eredua justifikatzen da, halaber, prestazioen hartzaileek normalean enplegua eskuratzeko laguntzak nahiago izaten dituztelako baldintzarik gabeko prestazio ekonomiko bat jasotzeko eskubidea baino gehiago.

Hortaz, EAEn gizarteratzeko aktibazio-eredu bat defendatzeko behar adinako arrazoiak badaudelako ondorioa atera dezakegu, eta arrazoi horiek, funtsean, euskal erakundeetako arduradunek ezarritako kontzeptuzko ildo ideologikoekin -eta, areago oraindik, EAEko diru-sarrerak bermatzearen arloan indarrean dagoen araudian jasotako gizarteratzeereduarekin- bat datozela ere ondoriozta dezakegu.

Hala eta guztiz ere, eta aldez aurretik adierazi dugunez, zehaztu gabeko aktibazio-ikusmolde bat aldarrikatzeak ez du inolako zentzurik; ezaugarri espezifiko eta zehatz batzuk dituen eredu baten aldeko apustua egin behar da, argi eta garbi. Aurreko orrietan egindako analisiaren arabera, zein dira eredu horren oinarrizko ezaugarriak? Funtsean, hiru izan daitezke:

- Eskubide bikoitzaren printzipioa. Dokumentu honetan proposatzen dugun eredua, aldez aurretik adierazi dugun bezala, 18/2008 Legeak

2 Pertsona horiei gizartearen funtzionamenduari ekarpen bat egiteko eskakizuna bera inklusiboa da, eta ekarpen-betebehar hori aparte uztea, ordea, baztertzeko arrazoia da, Gorzek bere garaian adierazi zuen bezala.

${ }^{3}$ Nolanahi ere ez dugu ahaztu behar Espainiako Konstituzioaren 35. artikuluak honela dioela: "Espainiar guztiek lan egiteko eginbeharra dute, eta lanerako eskubidea dute, lanbide edo ogibidea as katasunez aukeratzeko eta lanean igotzeko eskubideak dituzte, eta beren beharrizanak eta beren familiarenak asetzeko adina ordainsari jasotzeko eskubidea ere, inoiz sexu-arrazoiengatik bereizkeriarik gertatu gabe". 
onartzen duen eskubide bikoitzaren kontzeptuan sakontzean oinarritzen da. Eskubide bikoitzaren kontzeptuak honako bi eskubide osagarri hauek onartzea eskatzen du:

a. Batetik, lanik edota baliabide ekonomikorik ez duten pertsonek administrazio publikoetatik gizarteratzeko behar dituzten laguntzak jasotzeko eskubidea dute. Egia bada ere printzipio hori hasiera-hasieratik jaso zela errentak bermatzeko euskal ereduan, beste herrialde batzuetan gertatu den bezala gurean ere ezer gutxi hedatu dela esan dezakegu, eta sarritan, askotariko arrazoiak direla medio, pertsona horiek jasotako laguntza bakarra prestazio ekonomikoa izan dela, gizarte- eta lan-arloetako laguntzak bereziki nabarmendu ez direla. Hortaz, dokumentu honetan proposatzen dugun gizarteratze-aktiboko ereduaren oinarrizko osagaietako baten arabera, laguntza horiek areagotu egin behar dira, eta bereziki, lanik ez duten edo gizartean integratzeko maila egokiak bermatzeko moduko lana ez duten pertsonen enplegagarritasuna hobetzearekin zerikusia dutenak. Gainera, proposatzen dugun helburuak enplegagarritasunaren ikusmolde zabala sustatu nahi du, gizabanakoaren gaitasun eta betebeharrei ez ezik gizarte- edo egitura-arlokoei ere helduko diena, baita giza kapitalaren garapena eta laneratze iraunkorren bilaketa jomugan izango dituen esku-hartze eredua sustatu ere.

b. Bestetik, diru-sarrerak bermatzeko prestazioak jasotzen dituzten hainbat pertsonak premia ekonomikoak baino ez dituzte, eta, hortaz, gizarteratzeko edo laneratzeko laguntzapremiarik ez dute. Ildo horretan, diru-sarrerak bermatzeko politika egokiak ezarri beharko lirateke, diru-sarrerei dagokienez egoera eta familia jakin baterako nahikoa ez den maila osatzera mugatuz, eta horretarako, aurrerago azalduko dugunez hobekuntza eta aldaketa jakin batzuk erantsi beharko lirateke prestazioaren kudeaketa bizkortu eta automatizatzeko.

- Gizarteratze-printzipioa. Dokumentu honetan jasotako proposamenak honako ideia hau hartu du oinarritzat: gizarte-politika publikoek, eta horien barnean enplegu-politikek, gizarteratzeari eman behar diote lehentasuna. Kontzeptua oraindik behar bezala zehaztu ez bada ere, kontzeptuaren oinarrizko osagaietako bik funtsezko eragina dute aktibazio-politiken edukia zehaztean:

a. Ezinbestean, bazterkeriaren kausa-aniztasuna onartzeak gizarteratzearen dimentsio-aniztasuna eskatzea dakar, hau da, gizabanakoaren premia eta egoeren arabera, gizarteratzea laneratzetik bakarrik ez, baizik eta askotariko bizi-eremuetatik lor daitekeela onartzea. Nolanahi ere, azpimarratu beharra dago agian bakarra ez bada ere, enplegu arruntera biltzea gaur egun funtsezko baldintza dela lan egiteko adinean dauden pertsonek guztiz gizartera- tzeko aukera izan dezaten. Hala eta guztiz ere, gizarteratzearen atzean kausa anitz badaudela onartzeak aukera ematen du, batetik, gizartearentzat baliagarri diren jarduerei, eta ez soilik ordaindutako enpleguari, lotutako gizarteratze-prozesuak planteatzeko, eta, bestetik, laneratzea zenbaitetan lehentasunezko beste zenbait helburuen mendean jarri behar dela onartzeko, osasunari, harreman pertsonalei edo gizarte-funtzionamenduari dagokienez.

b. Gizarteratzearen paradigma gizarte-integrazioaren paradigmaren azpian daudenez bestelako oinarrietatik abiatzen da, eta ezgaitasunaren gizarte-ereduari lotzen zaio zuzenean. Eredu horrek integrazioa ulertzeko zenbait ikuspegi zalantzan jartzen ditu; izan, ere, besteak beste, honako printzipio honetatik abiatzen da: ezgaitasuna sorrarazten duten arrazoiak ez dira indibidualak, baizik eta, batez ere, sozialak. Arazoaren sustraiak ez dira gizabanakoaren mugetan bilatu behar, gizarteak zerbitzu egokiak emateko eta ezgaituen premiak gizarte-antolamenduaren barnean behar bezala kontuan har daitezela ziurtatzeko erakusten dituen mugetan baizik (Palacios eta Bariffi, 2007). Gogoeta hori pobreziaren mundura eraman dezakegu, honako ideia honetatik abiatuta: emandako zerbitzuek zein gizarteratze-prozesuen helburuek ezinbestean aldatu behar dira nagusi diren faktore sozioekonomikoetan, eta bereziki lan-merkatuan, pertsona guztien ezaugarrietara egokitu ahal izateko. Garrantzitsua da pertsonen ezaugarriak lan-merkatuaren premietara egokitzea, baina garrantzitsua da, halaber, lan-merkatuaren premiak pertsonen premietara egokitzea.

- Konpromiso bikoitzaren (edo bidezko elkarrekikotasunaren) printzipioa. Gizarteratzea lortzeko eskubide bikoitzaren kontzeptua konpromiso bikoitzari lotu behar zaio, ezinbestean: batetik, prestazioen onuradunek bizi duten premiaegoeratik ahal den neurrian irteteko konpromisoa hartzen dute, eta, bestetik, kolektibitateak, funtsean Administrazioaren ekintzaren bitartez, baina baita enpresen eta gizarte zibilaren bidez ere, lan-merkatu inklusiboa bermatzeko konpromisoa hartzen du, baita, Lanaren Nazioarteko Erakundeak babestutako 'lan duinaren' ideian oinarritutako bidezko lan-harremanak eta kalitatezko laguntza-zerbitzu indibidualizatuak bermatzeko konpromisoa ere. Funtsean, konpromiso bikoitzaren kontzeptua bidezko elkarrekikotasunaren nozioan oinarritzen da. Horren arabera, ontzat hartzen bada pertsonek erantzukizun jakin batzuk dauzkatela, eta erantzukizun horiek legez betearazteko agindua eman daitekeela baldintza batzuk ezarrita, orduan Estatuak ere bere erantzukizunak bete behar ditu, eta, bereziki, aukeraberdintasuna bermatu behar du.

Grafikoki, eskubide eta betebeharren esparruan oinarritutako aktibazio-eredu inklusiboa ezar dezakegu, eta, horren arabera, gizabanakoaren eskubideak 


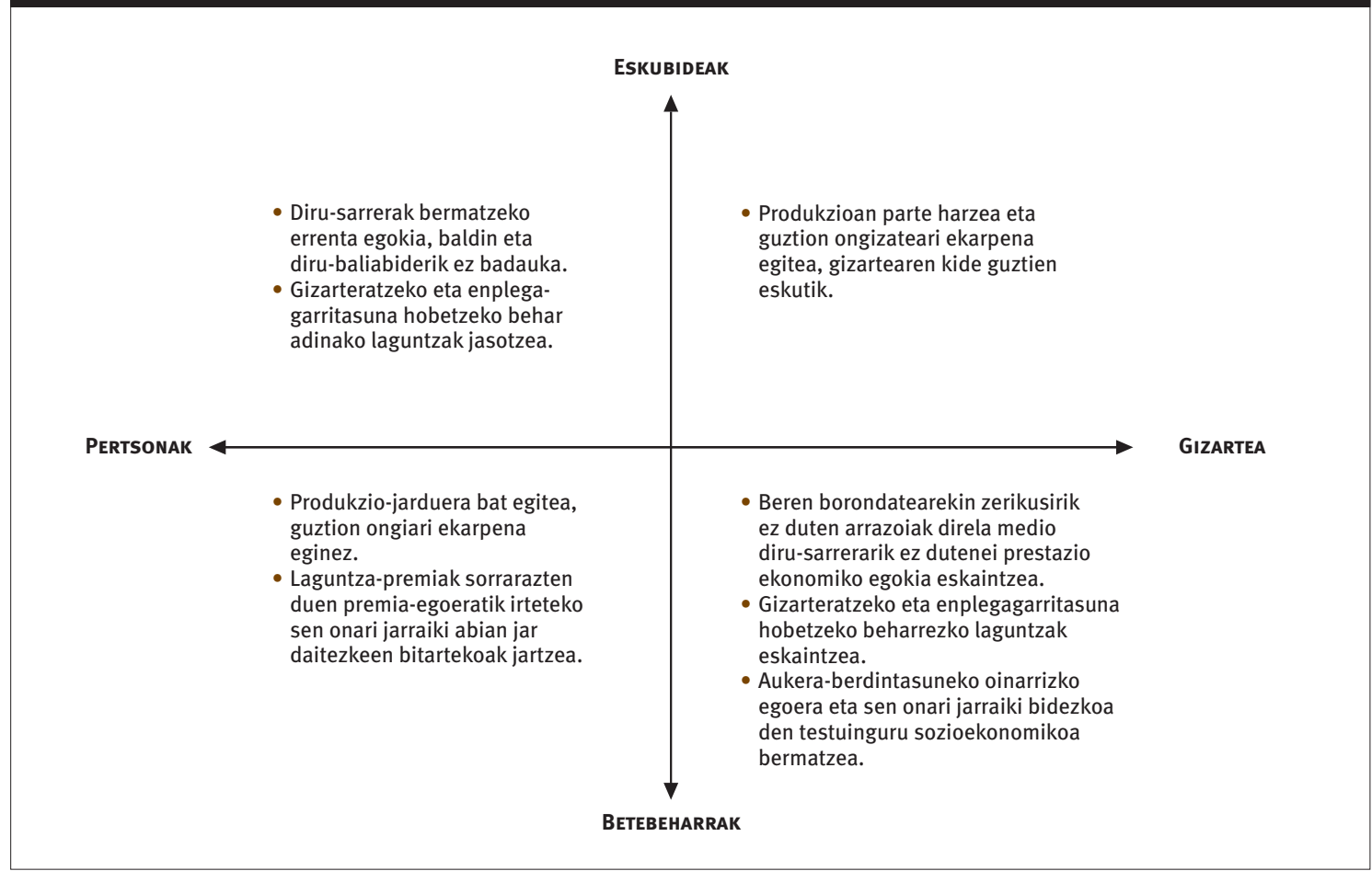

Iturria: Egileen lana.

bat etorriko lirateke gizartearen betebeharrekin, eta gizartearen betebeharrak, berriz, gizabanakoaren eskubideekin.

Hurrengo orrietan, aipatutako oinarrizko kontzeptuzko osagaietatik abiatuta, EAErako gizarteratze aktiboko ereduak bildu beharko lituzkeen ezaugarriak jaso ditugu, ikusi berri dugun eskeman oinarrituz.

\subsection{Eskubide bikoitzeko kontzeptuan oinarritutako diru-sarrerak bermatzeko eredu bat, enplegagarritasuna gizarte-eskubidea dela eta laneratzea gizarteratzearen oinarrizko osagaia dela aldarrikatzen duena}

\subsubsection{Enplegua gizarteratzeko eta pobreziatik babesteko mekanismo gisa, eta enpleguaren ahalmen gizarteratzailea lan-ezegonkortasuneko garaian}

Gaur egun prekarizazio-prozesuan murgilduta egonik ere, ordaindutako enplegua gizarteratzeko formula nagusia da oraindik ere. Izan ere, J. L. Retolazak Hilero Eguneratuz (2003) aldizkarian azaldu zuenez,

jasotako errentaren zenbatekoa edozein izanik ere, gizarteratzeari uko egiten dion edozein eredu ez da konponbidea, arazoa askoz ere sakonagoa delako diru-sarreren gabezia baino. Lana ez da diru-sarrera iturri soila, naturarekin eta gizartearekin harremanetan sartzeko oinarrizko bitartekoa ere bada, eta sakoneko ondorioak ditu pertsonaren prozesu kognitiboen garapenean. Arrazoizko lana eskubide bat da, ezinbesteko premia ukaezina. Ildo horretan, bazterkeriaren aurkako borrokak eraldaketa sozioekonomikoa eskatzen du eredu zabalago bat lortzeko, eta, eredu berriaren arabera, ekonomia, enpresak eta produkzioprozesuak pertsonen zerbitzuan egongo dira, kapitalaren mendean egon beharrean.

Ildo horretan, argi dago landunen egoerak langabeena baino hobea izaten jarraitzen duela, eta enpleguak pobreziaren aurka babesteko faktorea izateari eusten diola. Tohariaren eta beste batzuren ustetan (2008),

jarduera ekonomikoarekin zerikusia duten ezaugarri jakin batzuek, hala nola jardunean ez aritzeak, edo, bereziki, langabe egoteak, areagotu egiten dituzte gizabanakoek pobrezia erlatiboan edo pobrezia larrian egoteko dituzten aukerak. Gainera, une jakin bateko egoerak ez ezik, iraupenak ere garrantzi handia du, izan ere, aktiboak izanik enplegutik aparte denbora gehien ematen dutenek pobrezian erortzeko aukera gehiago dituzte.

Tohariaren arabera,

gizabanakoen eta etxekoen unitateen egoera ekonomikoari buruzko egoera haien bizi-baldintzekin (etxebizitza-arazoak, garrantzizko ordainketa jakin batzuetan berandutzea, erosketa jakin 
batzuk egiteko gabeziak) lotzean, errentari buruzko zeharkako adierazlearekin lortutakoaren antzeko emaitza lortzen dugu; ildo horretan, antza denez, lanarekiko lotura handiago batek bizibaldintza hobeak dakartza berekin.

Lanik gabe daudenen egoera ekonomikoa okerragoa da lana dutenena baino, eta, ezbairik gabe, horrek zerikusi handiagoa izan dezake langabeen edo ezaktiboen babesgabeziarekin enpleguaren gaitasun inklusiboarekin baino. Hala eta guztiz ere, ezin dugu alde batera utzi gaur egungo zirkunstantzietan, lana dutenek lanik ez dutenek baino maila handiagoak dituztela gizarteratzeari, ongizate ekonomikoari eta zoriontasunari edo bizi-gogobetetzeari dagokienez, eta, ikuspegi horretatik, laneratzeko estrategiak indartzea guztiz beharrezkoa dela. Ikuspegi horretatik, eta gizarteratzeko aktibazio-programak benetan eskubide bikoitzaren printzipioan oinarritzen badira, hau da, premia duten pertsona guztiei behar adinako prestazio ekonomikoa bermatzen bazaie eta lanmerkatuan txertatzeko modurik ez dutenen enplegagarritasuna hobetzeko eta gizarteratzeko beharrezko laguntzak jartzen badira, programa horiek abian jartzeak ez du inondik inora gizarte-eskubideen murrizketa ekarriko, eskubide horiek zabaltzea baizik.

Zehazki, gure inguruko beste herrialde batzuetan ikuspegi aurrerakoi batetik aktibazio-eredu inklusiboak garatzen ari diren erakundeen iritziz, enplegua lortzeko zailtasun handienak dituztenei gutxienez honako eskubide hauek bermatu behar zaizkie (McNeil, 2010):

- Laneratzeko oztopo indibidualei buruzko ebaluazio errealista egiteko eskubidea.

- Kalteberatasun-egoeran dauden pertsonei laguntzeko eskarmentua duten erakundeen arreta jasotzeko eskubidea.

- Pixkanakako plan indibidualizatu batean integratutako kalitatezko zerbitzuak jasotzeko eskubidea, enplegua lortzea eta trebetasun indibidualen hobekuntza oztopatzen duten trabei heltzeko.

Behar adinako lanbide-trebakuntza duten orientatzaileen aldizkako laguntza jasotzeko eskubidea.

Metamorfosis del trabajo (Lanaren metamorfosia, 1995) lanean, Gorzek argi eta garbi adierazi du lan arrunta oso garrantzitsua dela gizarteratzeko osagai gisa: “Edo gizarteko kide gara (zehazkiago, esklabista ez den gizarte moderno demokratikoko kide) eta horren gaineko eskubideak dauzkagu, edo bestela, gizarte horretatik baztertuta gaude nolabait, baldin eta parte hartzen ez badugu gizarte osoarentzat antolatutako produkzio-prozesuan”. Nolanahi ere, enpleguaren kalitateak, eta, ikuspegi horretatik, enplegu prekarioaren eta langile pobreen fenomenoaren hedadurak, ezinbesteko eragina dute enpleguaren gaitasun gizarteratzailean. Hala, esaterako, Laparraren iritziz (2006):

Enpleguak (enplegu egonkorra, ongi ordaindua, babes juridikoa eta gizartearen onespena duena) funtsezko betekizuna bete du Europan ia XX. mende osoan garatu den gizarte-integrazioaren ereduan, eta, eraldaketa ugari izan baditu ere, oraindik ere ordezkaezina da alor horretan. Enplegutik aparte, gure gizartek ez dute ahalmen integratzaile nahikoa duen bestelako bide alternatiborik aurkitu [...]. Alabaina, produkzio- eta deslokalizazio-ereduak eraldatzeko prozesuen haritik datozen lan-ezegonkortasuneko prozesuek oso ondorio kaltegarriak ekar ditzakete berekin. Hortaz, enpleguaren kalitatearen gaia gizartekohesioari buruzko eztabaidari, bazterkeriaren dinamikari eta integrazioari buruzko eztabaidari lotzen zaio.

Aldaketa horiek guztiak kontuan hartu behar dira enpleguaren balio integratzaileari buruzko gogoeta egitean. Izan ere, Sartu federazioak adierazi duenez (2010), gaur egungo testuinguruan zenbait kontzeptu zalantzan jarri edota birformulatu beharko lirateke, hala nola enpleguari lehentasuna ematea gizarteratzearen ardatz nagusia den heinean, lana herritartasuna lortzeko ate nagusi gisa, lan-merkatuarekin zerikusia duten zenbait alderdi, prestakuntza eta abar. Hala eta guztiz ere, Sartuk egindako azterlanean parte hartu duten pertsonen iritziz,

gaur egungo krisi-egoeran ere, enpleguak gizarteratzeko bide nagusietako bat izaten jarraitzen du. Gizarteratzea ez da enplegura mugatzen, baina enplegua hartu behar du aintzat ezinbestean, betiere pertsonak laneratzeko adina badu, lanerako ezinduta ez badago eta langabezia-egoera bestelako jarduerak (prestakuntza, hirugarren pertsonen zaintza eta abar) garatzeko aukera hartu izanaren emaitza ez bada. Zailtasunak zailtasun, enplegua gizarteratzearen funtsa da, edozein kasutan.

Ikuspegi horretatik begiratuta, enpleguaren ahalmen gizarteratzailea indartzen jarraitu beharko genuke, nola ikuspegi makroekonomikotik, soldata txikiei eta balio erantsi urriko jarduerei lotu gabeko produkzioeredu baten alde eginez, hala lan-merkatuaren erregulazioarekin zerikusia duen ikuspegitik. Hortaz, gizarteratze aktiboko ereduari buruzko gogoetari dagokionez, enpleguaren kalitatea bilatzen jarraitu behar dugu eta enpleguaren gaitasun gizarteratzailea berreraiki; hori izango da ildo nagusia aurrera begira, dokumentu honetan garatutako printzipioetatik eta LANEk babestutako lan duinaren kontzeptutik abiatuta.

Ezbairik gabe, argi dago enplegu guztiek ez dutela ongizatea, zoriontasuna, gizarteratzea edo bizikalitatea sorrarazteko ahalmen berdina. Eta egia da, halaber, enplegu prekario bat baliagarri izan daitekeela gizarteratze-prozesu batean, gaitasun inklusibo handiagoko egoeretarako trantsizioa errazten duen neurrian. Nolanahi ere, ez dago esaterik prestazio ekonomiko bat jasotzeko neurri soil bat, berez, lanpostu batean integratzea balio inklusiboagoa denik: prestazio ekonomiko hori gizarteratzerantz aurrera egiteko prozesuan txertatzen bada bakarrik esan 
dezakegu prestazioa positiboagoa dela enplegu jakin batzuk baino. Aurrerapen-prozesu horren ezaugarriak aldatuko dira pertsonaren ezaugarri, premia eta trebetasunen arabera -gizarte- eta hezkuntza-arloan esku hartzea, oinarrizko gizarte-trebetasunak berreskuratzea, oinarrizko premiak estaltzea, enplegurako prestatzea, lan babestua eta abar-. Prozesu horrek ez du zertan laneratzearekin lotuta egon, baina lan-merkaturatzea betiere izango da prozesuaren funtsezko helburuetako bat. Kasu horretan bakarrik esan daiteke prozesua inklusiboagoa dela lanpostu prekario bat lortzea baino.

Hortaz, ez laneratze prekarioa ez inolako gizartelaguntzarik gabeko prestazio ekonomikoak ezin daitezke alternatiba egokiak izan, ez batak ez besteak ezin dutelako, berez, gizarteratze-prozesurik sorrarazi. Aitzitik, alternatiba egokia bi aukera horien artean egongo da, eta, horrelakorik behar duten pertsonentzat, gizarteratzeko esku-hartze prozesuak jarri beharko dira abian, premia pertsonalen arabera zenbait tresnatan oinarri daitezkeenak, hala nola laguntza ekonomikoa, enplegurako aktibazioa, gizarte- eta hezkuntza-arloko esku-hartzea eta abar. Azken batean, enpleguaren prekarizazio-prozesuak lan-merkatuaren gaitasun integratzaileari kalte egin diezaioke, eta, arrisku horri aurre egiteko, prestazio ekonomikoei baldintza gutxiago jarri beharrean, gizarteratze aktiboko eredua aplikatu beharko da bere ondorio guztiekin, lan-merkatuaren baldintzen gaineko esku-hartzeari arreta berezia eskainiz.

Aldez aurretik adierazi dugunez, aktibazio-politiken azpiko indibidualizazio-kontzeptuak bere abantailak eta alde onak baditu, baina garrantzizko zenbait arrisku ere nabari zaizkio. Horietako bat langabeziarekin zerikusia duten arazoen despolitizazioa da, eta hortaz, lan-merkatuaren funtzionamenduan eragiten duten egiturazko baldintzei kasurik ez egitea. Alabaina, dokumentu honetan aldarrikatzen den aktibazio-eredu inklusiboak gaiaren birpolitizazioa eskatzen du, eta administrazio publikoei eskatzen die, prestazioen hartzaile direnei baldintzak ezartzeaz gain, bidezko lan-merkatua eta lan duina garatzea ahalbidetuko duten neurriak hartzea ${ }^{4}$.

Víctor Renesek adierazi duenez, enplegua gizartean integratzeko, errenta banatzeko eta gizartea babesteko funtsezko mekanismoa dela proposatzen bada, ez du inolako zentzurik, aldi berean, enpleguaren kondizioei eta kalitateari muzin egitea. Halaber, Whitek planteatutako bidezko elkarrekikotasuneko eskemak zera azpimarratzen du, prestazio horiek jasotzen

${ }_{4}$ LANEk eta lanaren zientzien alorreko adituek 1999an erabili zuten lehen aldiz, esanbidez eta formalki, lan duinaren esapidea, hain zuzen ere Lanaren Nazioarteko Konferentziako zuzendari nagusiaren izen bereko memorian. Lehen definizio bat ere ageri zen: produkziolana askatasuneko, berdintasuneko, segurtasuneko eta duintasuneko baldintzetan, eskubideak babesteaz gain ordainsari egokia eta gizarte-babesa eskaintzen duena. Lehen formulazio horretan, lan duinak honako osagai hauek edukiko lituzke: a) produkzio-lana; b) eskubide-babesarekin; d) diru-sarrera egokiekin, eta e) gizarte-babesarekin. Jarraian dokumentu berean jasotakoarekin bat etorriz, oinarrizko bosgarren ezaugarri bat erantsi beharko genuke: f) hiru alderdi izatea eta gizarte-elkarrizketa. dituztenei baldintza jakin batzuk ezartzen badizkie, Estatuak, trukean, lan egiteko eskubidea bermatu behar du, eta, zentzu orokorragoan, kalitatezko lan duina eta inklusiboa bermatzeko konpromisoa hartu behar du. Hortaz, ezinbestekoa da indibidualizazioaren interpretazioa planteatzea. Ildo horretan, langabeziaren alderdi indibidualei eta bazterkeriari heldu behar zaie, arazo horiek indarrean daudelako eta sarritan oso garrantzitsuak direlako, baina, horretara mugatu beharrean, lan-merkatuan eragiten duten egiturazko alderdiei buruzko esku hartzeari lehentasuna eman behar zaio: ordainsari-mailak, segurtasuna eta higienea lanean, kontratuzko baldintzak, lana eta familia uztartzea, negoziazio kolektiboa, langileek enpresen kudeaketan parte hartzea eta abar. EAEn Gobernuaren Saila da enpleguko eta gizarteratzeko politiken arduraduna, eta ezbairik gabe horrek erraztu egiten du horrelako estrategiak abian jartzea, bidezko elkarrekikotasuneko eta gizarteratze aktiboko eredu batean oinarrizkoak direnak, aldez aurretik adierazi dugunez.

\subsubsection{Enplegagarritasuna hobetzea gizarteratzeko prozesuetan aurrera egiteko tresna egokia den heinean}

Oinarritzat hartu dituen gainerako osagaiekin bat etortzeko, dokumentu honetan aldarrikatutako gizarteratze aktiboko ereduak, ezinbestean, enplegagarritasunaren ikusmolde zabala hartu behar du aintzat, besteak beste McQuaid eta Lindsay egileek adierazi dutenarekin bat etorriz (2005).

Oro har, enplegagarritasuna indibidualtasunari lotuta definitu ohi da. Caritasek (1999), esaterako, honela definitu du enplegagarritasuna: "pertsona baten enplegu-eskaintza batera egokitzeko gaitasuna, batetik, gaitasun horretan eragiten duten faktoreen kudeaketa egokiaren ondorio dena, eta, bestetik, lan-merkaturako bidea errazten dioten jarrera, interes, motibazio, jakintza, prestakuntza edo gaitasunen baturatik eratortzen dena". Caritasek darabilen kontzeptua oinarrizko hiru alderditan eragiten du, hain zuzen ere gaitasunean, egokitzean eta ikaskuntzan, prozesu-ideiari lotuta, eta bereziki alderdi pertsonalei ematen die lehentasuna, hala nola jarrerak, gaitasun pertsonal eta profesionalak, gizarte-eragileak eta abar. Enplegagarritasunen ideiari, ordea, zenbait kritika egin zaizkio, funtsean osagai indibidualei lehentasuna ematen dielako testuinguru-elementuen aurretik, eta aktibazioari buruzko literaturan sarri aurkitzen ditugu kontzeptu horri buruzko kritikak. Serrano Pascualen ustetan (2001), Enpleguko Europako Estrategiaren eta aktibazio-estrategia nazionalen esparruan zehaztu denez, enplegagarritasunak langabeziaren ikusmolde jakin bat dakar gogora eta, horren arabera, langabeak dira errudunak merkatuaren premietara ez direlako egokitzen, lan-merkatuaren barneko aukera-urritasuna aintzat hartu beharrean.

McQuaiden eta Lindsayen aburuz (2005), enplegagarritasun-kontzeptua modu askotara uler daiteke: 
ikuspegi horien guztien artean ${ }^{5}$, egile horiek enplegagarritasunaren ikusmolde elkarreragilea sustatu nahi dute Horri jarraiki, enplegagarritasunak hainbat oztopo indibidual eta sozial gainditzearekin du zerikusia, pertsonei enplegurako sarbidea galarazten dietenak; gainera, enplegagarritasuna sustatzeko politikek ez lituzkete gizabanakoak soilik aintzat hartu behar. Alabaina, aktibazio-politika gehienek oinarritzat hartu duten ikusmoldearen arabera, enplegagarritasunak, funtsean, gabezia indibidualekin du zerikusia, testuingurua eta egitura alde batera utzita. Kritika horietatik abiatuta, McQuaidek eta Lindsayek enplegagarritasun zabaleko kontzeptua planteatu dute, eta, horren arabera, ezaugarri eta zirkunstantzia indibidualek baldintzatzen dute enplegagarritasuna handiagoa edo txikiagoa izatea, baina baita kanpoko beste hainbat eragile sozial, instituzional eta ekonomikok ere, pertsonen enplegu bat lortzeko gaitasunean eragiten dutenak.

Hortaz, enplegagarritasun zabaleko kontzeptuak eragile indibidualen eta kanpoko eragileen arteko elkarreragina hartzen du hizpide, eta horik enplegagarritasun elkarreragilearen kontzeptua. Ikuspegi horretatik, gaitasun indibidualen, zirkunstantzia pertsonalen, lan-merkatuaren baldintzen eta testuinguruaren beste zenbait eragileren artean elkarreragin bizi bat indarrean dagoela azpimarratzen du.

McQuaidek eta Lindsayek enplegagarritasunaren ikusmolde zabala planteatu dute, beraz, eta, horren arabera, testuinguruaren baldintzatzaileak alde batera utzita gizabanakoa soilik aintzat hartzen duten ikuspegi guztiak zalantzan jartzen dira, baita, gizarteratze-prozesu ororen azpian dauden lanmerkatuaren zirkunstantzia aldakorretara egokitzeko eta ahalegintzeko ekimen pertsonalarekin zerikusia duen osagaia aintzat hartu gabe, egiturazko neurriez bakarrik arduratzen direnak ere. Beraien lanetan bildutako adibideek agerian uzten dute, halaber, enplegagarritasuna hobetzeko politikak eta programak zenbateraino heda daitezkeen, ikusmolde elkarreragin eta erlatibo batetik abiatuta. Izan ere, enplegagarritasunaren ikusmolde absolutu batetik urrun, kontzeptuari dimentsioa erlatiboa eman behar zaio. Izan ere, testuinguruaren arabera, gaitasun pertsonal berberek -jakintza berberek, trebetasun berberek, prestasun berberek- oso balio desberdina izan dezakete baldintzen arabera, ziklo ekonomikoaren arabera esaterako.

${ }^{5}$ Egile horiek honako bereizketa hau egiten dute: a) enplegagarritasunaren kontzeptu dikotomikoa (pertsona enplegagarriak eta pertsona enplegaezinak); b) gizarte- eta osasun-interpretazioa, urritasunak edo desgaitasunak dituzten pertsonak laneratzeko gaitasunari lotuta; d) giza baliabideen kudeaketarekin zerikusia duen interpretazioa, enplegagarritasuna lan-merkatuaren eskakizunetara egokitzeko gaitasun handiagoarekin edo txikiagoarekin lotzen duena; e) enplegagarritasuna enplegu-politiken emaitza objektiboa dela ezartzen duena; f) langileen malgutasuna, prestakuntza eta ekimen indibiduala indartzearekin zerikusia duena; eta g) enplegagarritasun elkarreragilea, ekimen indibiduala azpimarratzen badu ere, enplegagarritasunean testuinguruak, enplegu-eskaintzak eta lan-merkatuaren erregulazioak ere eragiten dutela onartzen duena.
Gaur egun gizarteratzearen arloko gaietan diharduten erakunde aurrerakoiek zera azpimarratzen dute, aktibazio-politikek ez dituztela enplegu-eskaintzarekin zerikusia duten gaiak bakarrik landu behar, eta, gai horiei ez ezik, enpresen lanpostuen eskariaren arloko gaiak ere aintzat hartu beharko lituzketela. Hala, Britainia Handiko Institute for Public Policy Research (IPPR) erakundea aktibazio-politikak egokitzeari buruz egiten ari den gogoeta zabalaren esparruan, Landingek (2010) zera azpimarratu du, laneskarian esku hartu beharra dagoela, areago oraindik langabezia-tasak handiak direnean, eskaintzaren ezaugarrietan soilik esku hartu beharrean, langabeen enplegua lortzeko aukerak hobetu ahal izateko. Landingen aburuz, "ongi ordaindutako enplegu iraunkorren gorakada sustatzeko neurriak funtsezkoak dira lan-merkatu justuagoak eta orekatuagoak sortzeko, ekonomia suspertu ahala”. Ikuspegi horrek oso sustraitua dagoen ideia bat zalantzan jartzen du, pobreziaren tranparen teoria oinarritzeko ere neurri handi batean erabili dena. Horren arabera, langabeziaren arrazoi nagusia ez da lanposturik ez izatea, langileek lanpostu horiek betetzeari uko egitea edota langabeen trebetasunik edo prestasunik eza baizik. Ildo horretan, aipatu berri dugun enplegagarritasun zabaleko kontzeptuarekin bat dator.

\subsection{Diru-sarrerak bermatzeko baldintzazko eredua, bidezko elkarrekikotasunaren kontzeptuan oinarritua}

\subsubsection{Prestazioen baldintzazkotasunaren justifikazioa eta bidezko elkarrekikotasunaren kontzeptua}

Aldez aurretik adierazi dugunez, gizarteratze aktiboko eredua justifika daiteke, batetik, herritarrek gizarteratzeko eta laneratzeko laguntza jasotzeko eskubidea dutelako, eta, bestetik, baldintzazkotasun- eta elkarrekikotasun-printzipio batzuk aplikatzea beharrezkoa delako. Izan ere, diru-sarrerak bermatzeko prestazioak jasotzean, baldintzazkotasuna funtsezko osagaietako bat da prestazio horien aktibazioari buruzko eztabaida akademikoan, eta, aldez aurretik ikusi dugun bezala, prestazio horiei egin zaizkien kritika gehienen oinarria ere bada. Aktibazioa ez da soilik baldintzazkotasunaren edo elkarrekikotasunaren arabera babestu edo aplikatu behar, hau da, ez da betekizun, erantzukizun edo betebeharretara mugatu behar, baina aldi berean argi dago, Marshallek aldarrikatu zuenez, herritartasunaren eskubideak eta betebeharrak uztartzen dituen diskurtso bati jarraiki ulertu behar dela.

Diru-sarrerak bermatzeko sistemen baldintzazkotasuna honako ideia honetan oinarritzen da: prestazio horien hornidura herritarraren eta komunitatearen arteko kontratuaren alderdietako bat da. Estatuak herritarrari legez agin diezazkiokeen betebeharrek osatzen dute beste alderdia. Aktibazioaren kritiko gehienek ez bezala, Whiteek (2000) ez du onartzen kontratuan oinarritutako gizarte-eskubideen ikuspegi hori atzerapena izatea Ongizate Estatuaren garapenean, eta, aitzitik, kontratua bidezko sistema ekonomiko bat garatzeko beharrezko betekizuna dela uste 
du, gizarte-produktuaren zati baten onura jaso nahi dutenek, beren herrikideen produkzio-ahaleginaren kontura bizi beharrean (hori esplotazio modu bat izango litzateke, Whiteren iritziz), beren ekarpena egiten dutela bermatzen duen neurrian.

Whiteren iritziz, baldintzazkotasun-printzipioa lanbetebeharrei aplikatzea legezkoa da, eta legitimitate hori elkarrekikotasunaren ideian oinarritutako justizia banatzailearen noziotik abiatzen da: gizarteproduktuaren onura jasotzen duen orok, trukean, komunitateari arrazoizko ekarpen produktibo eta proportzionala egin behar dio. Prestazio ekonomiko bat jaso behar dutenei enplegu batean jarduteko edo jarduteko prest egoteko baldintza jartzea bidezkoa da, beraz. Izan ere, elkarrekikotasun-printzipioak eskatzen duen ekarpena egin gabe gizarte-produktuaren onura jaso nahi dutenen asmoa saihestu daiteke horrela. Egile horren logikan, elkarrekikotasun-printzipioa garrantzitsua da, berez eta ikuspegi instrumental batetik:

a. Funtsezkoa da gizarte-produktuaren zati baten onura jasotzen duten herritarrek arrazoizko ahalegin bat egitea beste batzuek ere gizarte-kidetasun horretatik onura jaso dezaten, eta, beraz, herritar batzuek besteei gehiegizko karga ezar ez diezaieten, sen onari jarraiki hori saihesteko moduan egonik. Hortaz, gutxieneko diru-sarrerak baldintzarik gabe jasotzeko aukera ematea ez litzateke bat etorriko guztion ongirako elkarrekiko lankidetzarako oinarrizko arauekin, eta, ikuspegi horretatik, esplotazio modu baten aurrean egongo ginateke. Desberdintasunezko jarrera batetik urrun, Whiteren ustetan elkarrekikotasun-printzipioa elkartasunaren etikaren adierazpidea da. Haren hitzetan: "elkarrekikotasun-printzipioaren arabera, batetik, herrikideei laguntzen diet, beren ardura ez den gertaera baten ondorioak pairatzen dituztenean, eta, bestetik, arrazoizko ahalegin bat egiten dut nire herrikideei ondasunak eta zerbitzuak eskaintzeko, haiek eskaintzen dizkidaten ondasunen eta zerbitzuen truke". Whiteren iritziz, elkarrekikotasun-printzipioa oso sustraitua dago giza portaeran, psikologiaren, ekonomiaren edo biologia ebolutiboaren alorretako ikerketa ugarik agerian utzi dutenez, eta ez da, inondik inora, inolako ondoriorik gabe bazter daitekeen tramankulu ideologiko soila. Berdinzaletasun ekonomikoan oinarritutako edozein proiektuk porrot egin dezake baldin eta elkarrekikotasunaren araua kontuan hartzen ez badu, eta zentzu horretan egiten den erreforma oro printzipio horretan oinarritu beharko litzateke argi eta garbi, alde batera utzi beharrean

b. Ikuspegi instrumentalago batetik, Whiteren iritziz elkarrekikotasun-printzipioa kontuan hartzekoa da, horren ez-betetze nabariak baliorik gabe uzten duelako Ongizatearen Estatuaren oinarrian dauden erabakien legitimitatea, eta bereziki baldin eta erabaki horiek hainbat herritarren ahalegin handia eskatzen badute. Gizarte-berdintasuneko helburuak lortzeko, aprobetxamendu- eta parasitismo-arriskuak hartu behar dira kontuan. Bestela, helburu horiek sustatzen dituzten erakundeak eta helburu horien oinarrian dagoen espiritu solidarioa zalantzan jar genitzake.

Whiteren tesiari jarraiki, elkarrekikotasun mota hori, nolanahi ere, ez da kontuan hartu beharreko gauza bakarra justizia birbanatzaileari dagokionez. Aitzitik, kolektibitateak prestazio ekonomikoen onuradunei legez zer eskatu behar dien neurtzeko, gizarte horrek gizarte-justiziaren gainerako dimentsioak zenbateraino betetzen dituen hartu beharko da kontuan. Hortaz, bidezko elkarrekikotasun-printzipioaren arabera, aktibazioaren azpiko kontratu-mekanismoaren legitimitatea neurtzeko, kolektibitateak berdintasuneko, birbanaketako eta gizarte-justiziako oinarrizko irizpideak zenbateraino errespetatzen dituen hartu beharko dugu aintzat.

Hortaz, Whiteren aburuz, guztion ongiari ekarpenen bat egiteko betebeharra, elkarrekikotasun-printzipioaren azpian dagoena, dagokion testuinguru sozioekonomikoaren barnean bakarrik ezar daiteke. Hau da, ekarpen hori esparru jakin batean egin behar da, ondasunak eta aukerak banatzeko esparru jakin batean alegia. Bestela, zera sustatuko genuke, haren iritziz, argi eta garbi desorekatua den gizarte batean desabantailazko egoeran dauden pertsonek beren esplotazioari eusteko ekarpenak egin behar dituztela. Egile horren ustetan, elkarrekikotasun-printzipioa aplikatzean tokiko baldintzatzaile sozioekonomikoak alde batera uzten badira, Estatu Batuetan gertatu den bezala, gizarte-politika guztiz zigortzaile bihur daiteke, eta horregatik funtsezkoa da azpimarratzea elkarrekikotasun-printzipioak inplikazio bikoitza duela: batetik, komunitateak ahalegin berezi bat egin behar du birbanaketaren arloan oinarrizko maila bat bermatzeko, eta, bestetik, herritarrari itunetik dagokion zatia betetzeko eskatu behar zaie.

Testuinguru sozioekonomiko jakin batek bidezko elkarrekikotasuna aplikatzeko errespetatu beharreko betekizunetako batzuk zerrendatu ditu Whitek:

- Gizarte-produktuan gutxieneko parte-hartzea edukitzeko bermea, produkzioan parte hartzeko gutxieneko estandarrak errespetatzen dituzten guztientzat (edo, bestela, esanda, zenbateko nahikoak diru-sarrerak bermatzeko prestazioen zenbatekoak zehaztean, eta soldata-konpentsazioko mekanismoak jasotzeko eskubidea, baldin eta produkzio-sistemak eskainitako ordainsariak nahikoak ez badira oinarrizko premiak estaltzeko edota, epe laburrean, gizarte jakin batean itxarondako gutxieneko erosotasun- eta ongizate-mailei eusteko beharrezkotzat jotzen diren ohiko gastuei aurre egiteko).

- Produkzioan parte hartzeko behar adina aukerak (edo, bestela, esanda kalitatezko lan duina edukitzeko eskubidea eta egin beharreko lanjarduerei dagokienez aukera sorta bat edukitzeko eskubidea, ezin dezakegulako legezkotzat jo pertsonak oso jarduera gogor edo desatseginetan jardutera behartzea, baldin eta horrek gutxieneko bizi-gogobetetasuna galarazten badie). 
- Produkzioan parte hartzeko modu guztiak antzekotzat jotzea, etxeko edo familiako zaintzako lanak, boluntario-lanak, komunitate-garapena eta arte-zeregina ere komunitateari ekarpenak egiteko modu legitimoak direla onartuz, zeregin horiek guztiak ordaindutako enpleguaren parean jarriz.

- Elkarrekikotasun-printzipioaren aplikazio unibertsala eta proportzionala, edo, bestela esanda, betebehar jakin batzuk ezartzea, zergaarlokoak esaterako, herentzia bidez, prestazio ekonomikoen hartzaile direnei eskatzen zaizkien produkzio-ekarpenak egin gabe, ondasunen onuradun direnentzat. Gainera, zenbait neurri jar daitezke ekarpenaren tamaina mailakatzeko, pertsona bakoitzak eskura dituen ondasunen arabera (zerga-gehikortasuna ${ }^{6}$ ).

Zenbateraino errespetatu behar dira printzipio horiek gizarte-prestazioen baldintzazkotasuna legez erreklamatu ahal izateko? Oso-osorik betetzen ez badira, horrelako prestazioen hartzaileak beren konpromisoak betetzetik salbuesteko aukera dago? Whiterentzat, aukera hori gehiegizkoa da. Haren iritziz, aukera-berdintasunaren eta aberastasuna birbanatzearen alorretan maila egoki bat, baina ez goreneko maila, lortu duten herrialdeetan, Suedian adibidez, bazterkeria-egoeran dauden herritarrek ezarritako testuinguru sozioekonomikotik behar adina etekinik ateratzen dute, eta horregatik legezkoa da haiei ekarpen jakin bat eskatzea, bidezko elkarrekikotasunaren printzipioa betez.

Irizpide horiek bete-betean bete daitezela eskatu beharrean, Whitek, beraz, gutxieneko atalase-mailen irizpide baten alde egin nahi du: elkarrekikotasun unibertsaleko printzipio batean oinarrituta, komunitateari produkzio-ekarpen bat egin behar zaio, baldin eta dagokion komunitateak aukera-berdintasunen gutxieneko atalase-maila lortu badu. Herritar guztiek beren ekarpena egin behar dute, baldin eta lankidetzaren etekinen banaketa gutxienez bidezkotzat jo daitekeen tartearen barruan baldin badago.

Ildo horretan, bidezko elkarrekikotasunaren kontzeptua ezin daiteke Ongizate Estatuaren babesean bildutako zerbitzu eta prestazioen multzotik bereizi. Izan ere, esparru jakin batean biztanle guztien eskura gizarte-, hezkuntza- eta osasun-zerbitzuen sare zabala badago, eta zerbitzu horiek muga batzuk izanagatik ere, doakoak, arrazoizko kalitatezkoak eta estaldura zabalekoak badira, orduan bidezko elkarrekikotasunaren betekizuna behar bezala estaltzen ari dela esan dezakegu. Ezbairik gabe, printzipio hori aplikatzeko ezinbestekoa da erakunde publikoek ere lan-merkatuaren kalitatean eta lan-baldintzetan irmotasunez esku hartzea, baina nekez esan daiteke diru-sarrerak bermatzeko prestazioak jasotzen

\footnotetext{
${ }^{6}$ Izan ere, Whiteren iritziz, gizarte-politikako baldintzazko edo zein eredu legitimok zergak ezarri behar dizkie nola ondorengotzei hala ondareari, bide horretatik elkarrekikotasun-printzipioa urra ez dadin saihesteko.
}

produkzio-ahaleginaren edo laneko parte-hartzearen arloetako konpromisoak betetzetik lan-merkatuaren ezegonkortasuna dela medio, baldin eta, oro har, guztion ahaleginetik etekina ateratzen ari badira, gizarte-, osasun- edo hezkuntza-zerbitzuak doan eskuratuz. Ildo beretik, kontuan hartzekoa da merkatua askea izaki, ekintza publikoak lan-merkatuaren ezaugarri jakin batzuetan eragiteko duen gaitasuna urria dela, eta horrek, jakina, bidezko elkarrekikotasunaren kontzeptua baldintzatzen duela.

Whiteren ustetan, gizarte batek betekizun horiek betetzen baditu, gizarte-produktuan eskuzabaltasunez parte hartu nahi duen edozein pertsonak komunitateari produkzio-ekarpen bat egin behar dio nahitaez, oinarrizko lan-itxaropena ekar dezakeena, jarduera zibikoetan gutxieneko ordu kopuru bat sartuz. Zerbitzu batek komunitatearen mesedetan sortutako jarduera mota guztiak bilduko lirateke kontzeptu horren barnean, hala nola ordaindutako lana, guraso-zaintzak, mendekoentzako arreta edo etxeko lanak. Whiteren proposamena urrun dago gutxieneko diru-sarrerak jasotzeko eskubidearen baldintzazkotasuna ulertzeko, kontratuari garrantzi txikiagoa ematen dioten beste ikusmolde batzuetatik. Meadek edo Selbournek, adibidez, araua nahitaezkoa dela azpimarratzen dute, eta komunitateak prestazio ekonomikoaren ekarpena egitea, berez, nahikoa dela uste dute.

\subsection{Garapen pertsonalerako eta gizarteratzeko eskubidea, aktibazio-politiken esparruan}

\subsubsection{Bazterkeriaren kausa anitzeko izaera eta gizarteratzearen dimentsio anitzeko errealitatea onartzea}

Aldez aurretik adierazi dugunez, proposatutako eskemaren oinarrizko kontzeptuzko hirugarren alderdiak ezarritako aktibazio-neurrien izaera inklusiboarekin du zerikusia.

Ezbairik gabe, gure ingurunean gizarteratzea integrazioaren sinonimo edo baliokide gisa erabili da bereziki. Nolanahi ere, kontzeptualizazio gutxi batzuen arabera, bata eta bestea ongi bereizi dituzte, argudio sendoak emanez. Hala, gizarteraztearen kontzeptua integrazioaren sinonimo gisa erabili da, baita normalizazioaren sinonimo gisa ere, eta kontzeptu horiek zenbait kritika jaso dituzte ezgaitasunaren eremuan adibidez, ezgaitasunaren osasunedo errehabilitazio-ereduarekin identifikatu direlako. Horregatik, batzuetan gizarteratzea normalizazio/ integrazio-ereduaren aurrerapena dela esaten $\mathrm{da}^{7}$.

\footnotetext{
${ }_{7}$ Agian hezkuntzaren eremuan nabarmendu dira gehien integrazioaren eta gizarteratzearen arteko alde horiek. Hala, pedagogiaren eremuan, eskolak aniztasunari erantzuteko erabili beharreko jarraibideekin du zerikusia gizarteratze-kontzeptuak. 9oeko hamarkadan sortutako hitz horrek integrazioa ordeztu nahi zuen, hezkuntzajardunbidean ordura arte nagusi izan zena. Oinarrizko xedea da eskola-sistema aldatu beharra dagoela ikasle guztien premiei erantzuteko, ikasleak sistemarekin bat eginez sistemara egokitu beharrean. Eskolan kontzienteki eta nahita heterogeneotasunaren alde egitea da ikuspegi inklusiboaren funtsezko zutabeetako bat.
} 
Ildo beretik, Renzagliak eta beste batzuek (2003) adierazi dutenez, integrazioa -norbait sistema bateratu batean txertatzea alegia- eta gizarteratzea bereizi behar dira, azken kontzeptu horrek desberdintasunari balio positiboa ematea eta pertsona guztien premiei erantzutea eskatzen duen heinean. Ikuspegi horretatik, eta modu sinplista samarrean bada ere, integrazio-ideiaren aldean, gizarteratzekontzeptua nolabait ezgaitasunaren gizarte-ereduarekin uztar liteke, gizarte-inguruneen baztertzeko joera handiagoari edo txikiagoari lehentasuna ematen dion heinean.

Hortaz, gizarteratze-kontzeptua, nolabait, aurrerapauso bat da berez bazterkeria-sortzailetzat jo daitezkeen beste kontzeptu batzuen aldean, normalizazioaren aldean adibidez. Izan ere, pertsona ezgaituek (edo, lan honen xedeetarako, langabeak edo desabantailazko edo bazterkeriako beste edozein egoera pairatzen dutenak) pairatzen duten bazterkeriaren arrazoia pertsona horien errealitatearekin bat ez datorren arau baten ezarpenean egon liteke. Izan ere, ezgaituak "ezinduta egon litezke gizarte-bizitzaren oinarrian dauden hainbat jardueratan parte hartzeko, eta, gauzak horrela, eguneroko bizitzaren ohiko korrontetik aparte geratuko lirateke. Hori hala da eguneroko bizitzako egituretarako -hezkuntza, lana, familia, gizarte-elkarreragina eta abar-sarbide guztiak, neurri handi batean, nagusi den arauari jarraiki -ez-ezgaituei dagokiena, kasu honetanezartzen direlako. Hala, normalean hautatutako arauari buruzko desberdintasun edo desbideratzeetarako egokitzapenik aurreikusten ez denez, desberdintasuna diskriminazio fin (eta batzuetan ez hain fin) baterako oinarri gisa erabiltzen da" (Palacios eta Bariffi, 2007).

Ildo horretan, eta Mike Oliver gogora ekarriz, ezgaitasunaren gizarte-ereduaren aitetako bat den heinean, egile horiek gizarteratze-kontzeptua planteatu dute haien ustez gainbehera datorren integrazio-eredu bat gainditzeko edo eredu horretan aurrera egiteko: "integrazio-ikuspegi zaharraren arabera, desberdinak direnek gainerako guztien onarpena eta tolerantzia izan behar dute. Alabaina, integrazio-ikuspegi berria -edo, egileen ustetan, gizarteratzea- guztiz bestelako filosofia batean oinarritzen da, nortasun pertsonalaren politikan alegia. Ikuspegi horri jarraiki, desberdintasuna toleratzea eta onartzea ez da nahikoa, eta modu positiboan baloratu behar da”. Hortaz, honako parekatze hauek egin genitzake, metaforak erabiliz: integrazioa pieza bat aldez aurretik zehaztutako molde batean txertatzea litzateke; gizarteratzeak, berriz, molde malguak sortzearekin izango luke zerikusia, eta molde horiek malgumalguak beharko lukete, askotariko piezen ezaugarrietara egokitzeko modukoak.

Hortaz, ikuspegi horren arabera, gizarteratzea batetik, eta integrazioa edo normalizazioa bestetik, bereizi beharko lirateke, dokumentu honetan aipatu diren konpromiso bikoitzeko eta enplegagarritasun zabaleko kontzeptuekin bat etorriz. Horiek guztiek era batera edo bestera adierazi dute gizarteratzea- ren zama guztia ez dela langabezia-egoeran dagoen pertsonaren gainean utzi behar, eta, hortaz, testuingurua edo egituretan ere eragin beharko litzatekeela uste dute, pertsonen premia eta aukeretara egokituz.

Bestetik, gizarteratzearen paradigma aplikatzeko, behar-beharrezkoa da bazterkeriaren kausa-aniztasuna eta horren inplikazioak onartzea. Izan ere, adostasun-maila handia lortu da gizarte-bazterkeria pertsonaren bizitzako oso eremu desberdinetako -hezkuntza, etxebizitza, osasuna, enplegua, eskubide politikoak, harreman pertsonalak eta abardesabantaila-metaketa dela zehaztean. Bazterkeriaren kasua anitzeko ikusmoldea ez dator bat aktibazio modu jaki batzuekin, gizarteratzea eta laneratzea parekatzean dutenez, gizarteratze-prozesuen kausa anitzeko osagaia kontuan hartzen ez dutenak. Ildo horretan, eta aldez aurretik esan dugun bezala, argi badago ere enplegua lortzea gizarteratzeko funtsezkoa dela, ezin dezakegu ahaztu enplegua ez dela, berez edo bakarka, gizarteratzea bermatzeko nahikoa. Izan ere, kasu edo egoera jakin batzuetan litekeena da gizarteratze-prozesuek laneratzearen premiarik ez izatea, eta bizitzaren beste dimentsio batzuei lehentasuna eman behar izatea.

Izan ere, Pérez Eransusek dioenez (2006), “gizarteratzea autonomia eta mendetasuna hobetzeko gaitasunez jabetzeko prozesutzat jotzen badugu, prozesu hori ez da lan- edo prestakuntza-jarduera bat egitera mugatu behar. Gizarteratzea gizarte-laguntzako prozesu iraunkorra da, berekin baliabideen sinergia ekarri beharko lukeena, jarduerak egiteaz gain, trebetasunez jabetzea, gizarte-problematikak konpontzea, babes-sistemak eskuratzea eta abar barne hartuta8". Izan ere, egile horrek beste artikulu batean adierazi duenez (Pérez Eransus, 2009), azken urteetan aktibazioaren "ikusmolde zabalago bat" nagusitzen ari da, eta, "horren arabera, aktibazioak lanaren eremua gainditu nahi du, eta beste zenbait eremu bildu, hala nola gizarte parte-hartzea, gizarte-harremanak edo aisia". Bestetik, ideia hori guztiz bat dator aktibaziorako esku-hartzeen indibidualizazioaren ideiarekin, pertsona bakoitzaren premia eta aukerak kontuan hartu behar direlako gizarteratze-prozesuaren fase bakoitzean.

Euskadin laneratzearen eremuan diharduten erakundeek antzeko iritziak dituzte. Hala, Sarturen ustetan (2010),

gizarteratzean faktore anitz biltzen direla esaten badugu, ezin dezakegu kausa edo faktore bakar baten arabera azaldu, gizarteratze-prozesuei heltzerakoan ezin dezakegu faktore horietako bakar bat aintzat hartu, enplegua, etxebizitza edo osasuna izan, eta faktore guztiei erantzuten dieten prozesu integralak antolatu behar dira.

${ }^{8}$ Egilearen ustetan, gizarteratzea produkzio-jarduerak garatzera mugatze hori gutxienekoen prestazioak jendaurrean legitimatzeko helburuarekin sortu zen, eta, horrela, baliabidearen kronifikazioaren eta eraginkortasun-galeraren eraginaren haritik sortutako beldurrak uxatzeko. 
Nolanahi ere, egungo krisi-une honetan ere enplegua gizarteratzeko bide nagusietako bat izan arren, enpleguarena ez da bide bakarra.

\subsubsection{Gizarteak baloratutako jardueretara irekitako eredua, baina ordaindutako enplegua lortzeari lehentasuna ematen diona}

Aktibazioaren ereduari egin zaizkion kritikak azaltzeko aipatu ditugun proposamenek giza jokabidearen eta lanaren ikuspegi eudemonikoa ezartzeko joera erakutsi dute, lanerako bizi beharrean bizitzeko lan egin behar dela adieraziz. Izan ere, lanak askoren errealizazio pertsonalerako eta bizi-gogobetetzerako zeregin garrantzitsua betetzen duela alde batera utzi beharrean, egia da lanaren balioa ikuspegi pragmatikoagoetatik interpretatu beharko litzatekeela, gizarteak baloratutako jardueren multzora zabalduz, hainbatetan aipatu den bezala. Ildo horretan, egile askoren aburuz aktibazio-kontzeptua ez litzateke ordaindutako enpleguaren eremura mugatu behar, eta gizarteari beste zenbait ekarpen egin beharko lizkioke, bereziki, baina ez bakarrik, familia-zaintzen eta komunitate-ekintzaren eremuan. Ildo horretan, aldez aurretik aipatu dugun bidezko elkarrekikotasunaren printzipioaren arabera, ekarpen mota guztiak hartu behar dira aintzat, batzuk arbitrarioki lehenetsi edo baztertu beharrean, eta, ildo horretan, produkzio-ekarpenaren kontzeptua ez litzateke ordaindutako enplegura mugatu behar (White, 1999).

Moreira (2008) da produkzio-ekarpenaren kontzeptua beste jarduera batzuetara zabaldu beharra gehien azpimarratzen duen eta sendoen justifikatzen duen egileetako bat. Whiteren lan zibikoaren kontzeptuan oinarrituz, Moreirak zera adierazi zuen, bidezko elkarrekikotasunaren betekizunak beteko lituzkeen ekarpen baliodun batek lan arruntaren merkatuan parte-hartzeari lehentasuna eman beharko liokeela, ondasunak eta zerbitzuak elkartrukatzeko lehentasunezko osagaia den heinean, baina aldi berean ondasun publikoen edo baliagarritzat jotzen diren ondasunen -hala nola etxeko lana, haurren arreta edo beste jarduera batzuk, betiere gizartearen benetako premiei erantzuten badieteprodukzioari ere garrantzia eman beharko lioke. Moreiraren aburuz, ikuspegi horren arabera, honako hauekin zerikusia dutenak jo beharko lirateke baliagarritzat produkzio-ekarpen gisa:

a. Ordaindutako enplegua sektore pribatuan.

b. Ordaindutako enplegua sektore publikoan.

d. Borondatezko edo ordaindutako lana gizarteekonomiako erakundeetan, baldin eta, sektore publiko edo pribatuak betetzen ez dituzten gizarte-premiei erantzuteko, ondasun eta zerbitzuen produkzioan parte hartzen badute.

e. Guraso-arreta, gizarte-ugalketarako oinarrizko baldintzak bermatzen dituen neurrian. f. Mendekoentzako arreta, pertsona horiek beren kabuz bete ezin ditzaketen zenbait premia betetzen dituen heinean.

Argudio horren harira zera erantsi behar da, aldez aurretik esan dugun bezala, pertsona bakoitza gizarteratze-prozesuko zein fasetan dagoen hartu behar dugula aintzat. Hala, pertsona batzuentzat ekarpenik logikoena lanpostu bat lortzea izango litzateke; beste batzuentzat, aldiz, eraginkorragoa eta bidezkoagoa litzateke prestakuntza-programetan, errehabilitazio psikosozialeko programetan edo oinarrizko lan- eta harreman-gaitasun batzuez jabetzeko programetan parte hartzeko aukera ematea.

De la Calek eta De la Fuentek (2010) antzeko argudioak planteatu dituzte. Egile horien ustetan, lanaren kontzeptua zabaldu behar da, “ordaindutakoa eta ordaindu gabea barne hartuta. Gure gizarteetan baliagarri eta beharrezkoak diren zeregin guztiak zehaztu beharko lirateke. Ildo horretan, etxeko lanari, zaintza-lanari eta borondatezko lanari adibidez, gaur egun ukatzen zaizkien balorazioa eta onespena onartu beharko litzaieke. Prestakuntzaeta hezkuntza-jarduerak ere lanaren parean jarri beharko lirateke, etorkizuneko garapen ekonomiko eta sozialari egiten dioten ekarpena aintzat hartuta. Garrantzizko urratsa izango litzateke hori. Izan ere, lan horien guztien arduradunek enpleguaz bestelako rol alternatiboak beteko lituzkete gizartean, baina gizarteak berdin-berdin onetsi, legitimatu eta balioetsiko lituzke. Jarduera horien bitartez, pertsonek gizartea hobetzen eta mantentzen laguntzen dute, eta horregatik jarduera horien ahalmen inklusiboa handia da, betiere gizarteak ekarpen hori onesten badu. Enpleguaz aparteko lanaren definizioa ez da zeregin tekniko soila, gizartearen balio eta objektiboetan ongi sustraitutako proiektu politikoa baizik".

\subsection{Gizarteratzeko prozesuen ikusmolde indibidualizatua, egiturazko faktoreak ere aintzat hartzen dituena}

\subsubsection{Pertsonarengan oinarritutako aktibazioa}

Aktibazioaren ohiko paradigmaren alde zein kontra duden guztiak bat datoz indibidualizazio-kontzeptuaren garrantzia azpimarratzean. Izan ere, testuinguruko eta egiturazko faktoreek langabezia- eta bazterkeria-egoerak sortzean duten garrantzia azpimarratu behar da, baina, aldi berean, faktore indibidualek ere egoera horiek gainditzeko garrantzi handia dutela onartu behar da. Hala, esaterako, Sarturen Gizarte Bazterketa eta Gizarteratze Prozesuen Behatokiak (2005), gizarteratzeko ibilbide arrakastatsuen azpian dauden faktoreak azaltzean, zera adierazi zuen, ibilbide horiek arrakasta izan dezaten, pertsonak bere egoera aldatzeko premia sentitu behar du, eta, esanbidez edo isilbidez, hobekuntza-plan bat ezarri behar du. Gaitasun pertsonal jakin batzuk -autoestimazioa, segurtasuna eta abar- eta gizarte eta familia-harremanen sare sendo bat edukitzea eta prestakuntza (berekin dakartzan harreman-alderdiei 
dagokienez bereziki) funtsezkoak dira hobekuntzaprozesu horiek azaltzerakoan.

Hortaz, aktibazio-eredu legitimo batek ez dio zerbitzu indibidualizatuak emateko helburuari uko egin behar, baldin eta zerbitzu horiek pertsonen premietara egokitzen badira, pertsona horiek zer egoeratan dauden eta nola bilakatuko diren aintzat hartuta, eta baldin eta oso askotariko premia, espektatiba eta aukerei erantzuteko behar adinako malgutasuna badute. 1999an Caritasek enplegu-politikak pertsonalizatzeko eredu bat planteatu zuen, batetik, langabezia arazo makroekonomiko erantsi gisa har ez zedin saihesteko, eta, bestetik, neurrien despertsonalizazioa galarazteko, oso askotariko problematikei era berean heltzen dieten bereizkuntzarik gabeko neurri unibertsalak aplikatuz. Ildo horretan, Caritasek enplegagarritasun-eredu bat garatu nahi zuen honako hauetan oinarrituta: jarrera-aldaketa, gaitasun pertsonalen garapena eta enplegu-bilaketa aktiboaren sustapena, enplegagarritasuna garatzeko plan indibidualizatuen bitartez.

Erresuma Batuan eta beste zenbait herrialdetan egin berri diren zenbait proposamenek helburu hori ezarri dute ${ }^{9}$, pertsonarengan oinarritutako aktibazio-eredu bat garatu nahi dutelako (Harker eta Oppenheim, 2007), egungo lagun-egite ereduen zorroztasunaren eta gehiegizko uniformetasunaren aldean ${ }^{10}$. Ikuspegi horren alde daudenentzat, laguntza-eredu pertsonalizatu batek honako hauek guztiak eskatzen ditu: emandako laguntza jasotako prestazioaren mende ez jartzea; kasu bakoitzaren jarraipenaren eta orientazioaren arduradunei autonomia handia ematea funtsak erabiltzeari eta zerbitzuak esleitzeari dagokienez, edo laguntzak jarraipena izatea behin pertsonak lana aurkitu duenean. Zehazki, pertsonarengan oinarritutako aktibazio-ereduak oinarrizko ezaugarri hauek edukiko lituzke:

- Pertsonen premietara egokitzen diren zerbitzu pertsonalizatuak ematea; eta hainbat programa, zerbitzu eta jardueratan barrena ibiltzea ahalbidetuko duen antolamendu-esparrua sortzea, programa eta zerbitzu horiek kolektibo espezifikoen arabera esleitu beharrean, pertsona bakoitzaren egoeraren, premien eta espektatiben arabera esleitzeko.
- Zuzeneko arretako langileek ekiteko eta erabakitzeko gaitasun handiagoa izatea, pertsona bakoitzarentzako zerbitzu multzoak osatzeari dagokionez ${ }^{11}$. Gainera, horrek esan nahi du onuradunek erabakietan parte hartzeko gaitasun handiagoa eduki behar dutela jasotzen duten laguntza motari dagokionez, eta, ildo horretan, profesionalek, funtsak erabiltzeko eta erabakiak hartzeko ahalmen handiagoa izateaz gain, laguntza-zerbitzuen onuradunek adierazitako iritzi eta premietara egokitzeko gaitasun handiagoa ere erakutsi beharko lukete, jarrera paternalistak edo zorrotzak saihestuz.

- Gizarteratzeko laguntza-zerbitzuak esku hartzeko pakete zabalagoetan integratzea, arreta integralagoa eta holistikoagoa eskaintzeko, premia anizkoitzak dituzten pertsonen kasuan bereziki.

- Zerbitzu-hornitzaile pribatuak erabiltzea, irabaziasmoa duten eta irabazi-asmorik ez duten erakundeak barne, erakunde publikoek eskainitako zerbitzuez gain; nolanahi ere, erakunde publikoak zerbitzuan sartzeko bitartekari izango lirateke.

Aktibazio-programen indibidualizazioaren inguruan garatutako nazioarteko esperientziak (Ben-Galim eta Sachrajda, 2010) hiru alderdi jarri ditu agerian horren eraginkortasunari dagokionez: lan-orientatzaileen trebakuntza eta egokitzapena, kolektibo jakin batzuen (buruko gaixotasunak edo ezgaitasunak dituzten pertsonak, etorkinak, bakarrik dauden amak eta abar) premietara egokitzeko beharra, eta enplegua lortu eta laneratzeari eta lanpostuari eusteko laguntzari arreta berbera eskaintzea, lan-merkatua zertan den ikusita, enplegu bati eustea enplegu hori lortzea bezain zaila delako. Ildo horretan, ezgaituen enplegu lagunduaren arloa asko garatu da, eta gure ingurune hurbilenean ugari dira, halaber, lana dutenei laguntzeko abian jarritako ekimenak. Esperientzia horiek guztiak oso interesgarriak dira, eta, eredu honen esparruan, ahal den neurrian sustatu eta garatu beharko lirateke.

Indibidualizazioaren arabera, zerbitzuak pertsonen premia espezifikoetara egokitzen dira, eta helburu hori guztiz bidezkoa da, baina indibidualizazioari jarraiki, halaber, baldintzazkotasun-irizpideak aplikatzen dira, batetik, gutxieneko errenten prestazioak zehazteko, eta, bestetik laguntzen onuradunei aktibazio-betekizun batzuk bete ditzaten eskatzeko. Dokumentu honetan justifikatu nahi izan dugu zenbateraino eta zer testuingurutan izan daitekeen bidezkoa baldintzazkotasun-irizpide horiek ezartzea. Nolanahi ere, indibidualizazio-arazo horrek baldintzazkotasun-kontzeptuari berari eragiten dio, gizarteratze aktiboko programen onuradunei agindutako baldintzak moldatu behar direlako pertsona bakoitzaren egoera espezifikoaren arabera.

${ }^{11}$ Horretarako funts diskrezionalen erabilera proposatu da (adviser dicretionary funds), orientatzaile pertsonalen eskura daudenak gizarteratzearekin zerikusia duten gastu jakin batzuk estaltzeko.
${ }_{9}^{9}$ Gizartean gure ingurune hurbilenean garatu den lagun-egite kontzeptuarekin bat etorriz.

${ }_{10}$ Pertsonarengan oinarritutako aktibazio-kontzeptua pertsonarengan oinarritutako plangintzarekin du zerikusia, desgaituen arretaren eremuan asko erabili dena. FEAPS elkartearen arabera, pertsonarengan oinarritutako plangintza lankidetza-prozesu bat da, eta, bereziki, bizi-kalitatea hobetzeko behar dituzten laguntza eta zerbitzuak jarri nahi ditu pertsonen eskura, haien esperientzia eta balioetatik abiatuta. Bizitza planifikatzeko estrategia multzoa da, pertsonaren eta pertsonaren gertukoen iritzian eta erabakietan oinarritzen dena. Berez desgaituen kolektiboen eskutik sortu bazen ere, lanmetodologia baliagarria da gizarte-bazterkeriako egoeran edo egoera horretan erortzeko arriskuan dagoen edozein pertsonarentzat. 


\subsubsection{Enplegutik urrunen dauden egoerak}

Baldintzazkotasun indibidualizatuko irizpide batzuk muga jakin batzuen barruan aplikatzeak zerikusia $\mathrm{du}$, halaber, bazterkeria-egoera larrienean dauden pertsonen egoerarekin, hain zuzen ere lan-merkatutik urrunen egonik oso enplegagarritasun-maila txikiak dituzten pertsonen egoerarekin.

Izan ere, ez dugu ahaztu behar Lanbide Euskal Enplegu Zerbitzura diru-sarrerak bermatzeko prestazioen eske jotzen dutenetako asko -pentsiodunak alde batera utzita, lan-arloko eskakizunik bete beharrik ez dutenak- ez daudela lanpostu bat lotzeko moduan, eta litekeena dela denbora askoan horrela jarraitzea. Ikuspegi horretatik, muga fisiko, psikiko edota sozialak dituztelako edo guraso-erantzukizunak dituztelako (bakarrik egonik oso haur txikiak dituzten amen kasuan, zehazki) ${ }^{12}$ enplegu bat lortzeko moduan ez dauden pertsonei lan-baldintzarik gabeko irizpide bat aplikatu beharko litzaieke, aktibazio-erregimen zorrotzen alde dauden herrialdeek ere egiten duten bezala. Beste zenbaitetan, neurri txikiagoan bada ere, laneratzeko zailtasunek bestelako harreman- eta funtzio-zailtasunekin dute zerikusia, eta Gizarte Zerbitzuek horien gaineko ardura hartu behar dute, ezinbestean. Kasu horietan, gizarteratzeko zailtasunak zailtasun eta gabezia sorta zabal baten zati bat baino ez dira, edo bestela, horien ondorio, eta Enplegu Zerbitzuek, Gizarte Zerbitzuek eta gainerako ongizate-sistemek elkarlanean jardun beharko dute, ezinbestean. Gainera, sistema egoki batzuk ezarri beharko dira, gabezia horietako bakoitzak pertsonaren egoeran zenbaterainoko garrantzia duten neurtzeko eta esku-hartzearen ardura hartuko duen zerbitzua zehazteko.

Edozein kasutan, egoera horretan edozein elkarrekikotasun-eskari gehiegizkotzat jo daiteke, baita abusuzkotzat ere, bereziki ezarritako baldintzek enplegua lortzeari lehentasuna ematen badiote. Kasu horietan, eta gizarteratze-kontzeptuaren esanahiari dagokionez aldez aurretik aipatu diren faktoreak kontuan hartuta, onartu beharra dago kasu horietan laneratzea bigarren maila batean geratzen dela, eta honako arlo hauetan esku hartzeari lehentasuna eman behar zaiola: funtzionamendu psikosozialeko oinarrizko maila batzuk berreskuratzea, familiaedo gizarte-harremanetan sor daitezkeen arazoak konpontzea, etxebizitza- edo ostatu-arazoak eta abar.
Ikuspegi horretatik abiatuta, aktibazio-irizpide zorrotzagoak aplikatu direnean ere kontuan hartu da baldintzazkotasun-printzipioaren aplikazio zorrotzegi bat oso kaltegarri gerta daitekeela egoera bereziki kalteberenean dauden pertsonentzat. Egoera horien aurrean, bi esku-hartze ildo susta daitezke. Lehenik, Deanen proposamenekin bat etorriz (2003), lanbetebeharren aldean bizi-premia indibidualei lehentasuna emango dien ikuspegia sustatu behar da (life first approach). Aktibazioaren paradigmara hobeto moldatuko den lan-ildo errealistago batek, ordea, estrategia bikoitza aplikatzea ekarriko luke berekin:

- Batetik, aldez aurretik aipatutakoaren haritik, baldintzazkotasun-irizpide indibidualizatuak aplikatu beharko lirateke, pertsona bakoitzaren unean uneko egoera aintzat hartuko luketenak, oso egoera desberdinetan eta oso arazo desberdinak dituzten pertsonei baldintza berberak jarri gabe.

- Bestetik, aktibazio-programen ardura eta jarduna laneratzeko zailtasun gehien edo lan-merkatutik urrunen dauden kolektiboetara bideratu beharko lirateke. Ildo horretan, Peckek eta Theodorek (2000) agerian utzi dute enplegagarritasunaren ohiko ikuspegiaren arabera "enpleguak pertsona enplegagarrienei ematea” sustatzen dela, enplegagarritasunaren hobekuntzak ez dakarrelako berekin enplegu-eskari erantsia igotzea. Ikuspegi horri jarraiki, egile horiek aldarrikatzen duten aktibazio-ikuspegiaren arabera, lan-aukerak birbanatzerakoan lehentasuna eman beharko litzaieke desabantailazko edo bazterkeriako egoera larrienean dauden taldeei, baliabideak eta energiak laneratzeko oztopo gehien dituzten enplegu-eskatzaileen eskura jarriz. Hortaz, lan-merkatuan indarrean dauden desberdintasunereduak iraunarazteko eta lan-merkatutik gertuen daudenak laneratzeko joera duen enplegagarritasun-ikusmoldearen aldean, Theodorek eta Peckek aktibazio-programen ikuspegi birbanatzailea proposatzen dute, enplegua lortzeko aukera gutxien dituzten pertsonei lehentasuna emanez eta lan-merkatuaren barruan desberdintasunak mugatuz, diskriminazioaren aurkako, hezkuntzako eta kalitatezko prestakuntzako neurrien eta prestazio egokien bitartez, eta lan-eskubideak hedatuz. 


\section{Aipatutako bibliografia}

ARRIBA, A.; eta PÉREZ ERANSUS, B. (2007): “La última red de protección social en España: prestaciones asistenciales y su activación", Política y Sociedad, 44. bol., 2. zenb. 115-133 or. [khttp:// revistas.ucm.es/index.php/POSO/article/view/ POSO0707230115A〉].

BEN-GALIM, D.; eta SACHRAJDA, A. (ed.) [2010]: Now It's Personal: Learning from Welfare to Work Approaches around the World, Londres, Institute for Public Policy Research [khttp:// www.researchonline.org.uk/sds/search/ download.do;jsessionid $=97495 \mathrm{E} 74 \mathrm{BB} 1 \mathrm{EA6677E}$ 16C70614F4530A?ref $=$ B16954'].

DEAN, H. (2003): "Re-conceptualising welfare-to-work for people with multiple problems and needs", Journal of Social Policy, 32. bol., 3 zenb., 441459 or. ['http://eprints.lse.ac.uk/338/>].

GORTE NAGUSIAK (1978): “Constitución española”, Boletín Oficial del Estado, 311. zenb., 29-12-1978, 29.313-29.424 or. [<http://www.boe.es/buscar/ doc.php?id=BOE-A-1978-31229'].

GORZ, A. (1995): Metamorfosis del trabajo, búsqueda del sentido: crítica de la razón económica, Madrid, Sistema.

HAINBAT EGILE (2010): Joera sozialak eta gizarteratzea / Tendencias sociales e inclusión social, Bilbo, Sartu Federazioa [<http://www.sartu.org/files/ JoerasozialakAZK.pdf〉, 〈http://www.sartu.org/ files/TendenciasSocialesDEF.pdf $\rangle$.

JAURLARITZAREN LEHENDAKARITZA (2008): 18/2008 Legea, abenduaren 23koa, Gizarteratzeko eta Diru Sarrerak Bermatzekoa, Euskal Herriko Agintaritzaren Aldizkaria, 250 zenb., Il.alezatia, 2008-12-31, 32.729-32.804 or. [khttp://www. euskadi.net/bopv2/datos/2008/12/0807235a. pdf〉].
MCNEIL, C. (2010): Now It's Personal? The New Landscape of Welfare-to-work, Londres, Institute for Public Policy Research [<http://www.ippr.org/ publication/55/1797/now-its-personal-the-newlandscape-of-welfare-to-work>].

MCQUAID, R. W.; eta LINDSAY, C. (2005): "The concept of employability", Urban Studies, 42. bol., 2. zenb., 197-219 or. [<http://eprints.whiterose. ac.uk/50721/1/Concept_of_Employability_ FINAL.pdf >].

MEAD, L. M. et al. (1997): From Welfare to Work. Lessons from America, saila: Choice in Welfare, Londres, Institute of Economic Affairs.

MOREIRA, A. (2008): The Activation Dilemma. Reconciling the Fairness and Effectiveness of Minimum Income Schemes in Europe, Bristol, Policy Press.

MORENO, L.; eta SERRANO PASCUAL, A. (2009): “Modelo social europeo y políticas sociales: una evaluación formativa institucional", Gestión y Análisis de Políticas Públicas, 2. zenb., 11-32 or. [rhttp://revistasonline.inap.es/index. php?journal $=$ GAPP $\&$ page $=$ article $\&$ op $=$ view $\& p$ ath[]=419>].

- (2007): “Europeización del bienestar y activación”, Política y Sociedad, 44. bol., 2. zenb., 31-44 or. [khttp://revistas.ucm.es/cps/11308001/ articulos/POSO0707230031A.pdfs].

PALACIOS, A.; eta BARIFFI, F. (2007): La discapacidad como una cuestión de derechos humanos. Una aproximación a la Convención Internacional sobre los Derechos de las Personas con Discapacidad, saila: Telefónica Accesible, 4. zenb., Madril, Ediciones Cinca [<http://info. telefonica.es/ext/accesible/html/home/ pdf/0004_discapacidad.pdf)]. 
PECK, J.; eta THEODORE, N. (2000): “Beyond 'employability”, Cambridge Journal of Economics, 24. bol., 6. zenb., 729-749 or.

PÉREZ ERANSUS, B. (2009): “La activación como criterio político para la intervención social en el ámbito de la exclusión”, in: Actuar ante la exclusión. Análisis, políticas y herramientas para la inclusión social, bilduma: Estudios, 29. zenb., Madril, Cáritas Española; Madril, Fundación FOESSA.

- (2006): “Rentas mínimas y políticas de activación”, Documentación Social, 143. zenb., 77-92 or. [<http://tinyurl.com/7hw58j6>].

- (2005): Políticas de activación y rentas mínimas, saila Estudios, 11. zenb., Madril, Cáritas.

RENZAGLIA, A. et al. (2003): "Promoting a lifetime of inclusion", Focus on Autism and Other Developmental Disabilities, 18. bol., 3. zenb., $140-149$ or. [khttp:// www.worksupport.com/documents/proed promotingLifetimelnclusion.pdf $\rangle]$.

RETOLAZA, J. L. (2003): “La validez de las políticas activas de inserción / Gizarteratze politiken baliagarritasuna", in Hilero Eguneratuz, 31. zenb., 1. or.
SIIS DOKUMENTAZIO ETA IKERKETA ZENTROA (2011): Activación y derecho a la inclusión en el marco de las políticas de empleo y de garantía de ingresos en la CAPV, Gasteiz, Eusko Jaurlaritza [khttp://www.siis.net/documentos/ ficha/197806.pdf>].

TERGEIST, P.; eta GRUBB, D. (2006): Activation strategies and the performance of employment services in Germany, The Netherlands and the United Kingdom, Paris, Ekonomia Lankidetza eta Garapenerako Antolakundea [khttp://www. oecd.org/dataoecd/32/22/37848464.pdfı].

TOHARIA, L. et al. (2007): Empleo e inclusión social, Madril, Lan eta Gizarte Gaietako Ministeritza.

WHITE, S. (2000): "Social rights and the social contract. Political theory and the new welfare politics", British Journal of Political Science, 30. bol., 3. zenb., 507-532 or. [shttp://www.brynmawr. edu/socialwork/GSSW/schram/whitemead.pdf〉].

- (1999): "Rights and responsibilities: A social democratic perspective”, Political Quarterly, 70. bol., S1. zenb., 166-179 or. 


\section{Las empresas de inserción social en un contexto de cambios sociolaborales. Un análisis crítico de su regulación desde la normativa vasca y estatal}

\section{Ignacio Martínez Morales}

Departamento de Sociología y Antropología Social, Facultad de Ciencias Sociales, Universitat de València

<lgnacio.Martinez@uv.es>

\section{Joan Carles Bernad i Garcia}

Departamento de Psicología Social, Facultad de Psicología, Universitat de València

\section{Almudena Navas Saurín}

Departamento de Didáctica y Organización Escolar, Facultad de Filosofía y Ciencias de la Educación, Universitat de València

Artikulu honetan gizarteratzeko enpresen erregulazioa aztertzen da herritartasunaren egungo laneko ezegonkortasun eta Ongizate Estatuaren gizarte-politika bermatzaileak ahuldu diren testuinguru honetan. Horietatik honako hauek nabarmentzen ditugu: a) erabiltzailea estigmatizatu egiten du kolektiboak artatzeko baliabide gisara hartzen duen orientazio horrek; b) enplegagarritasunaren kontzeptuaren erdiz erdiko garrantziak baztertutako pertsonengan bideratzen du egoeraren ardura hori, horrela, 'gabezien diskurtsoetan' legitimatzen dira esku-hartzeak, eta 'aktibazioaren diskurtsoak' ordezkatzen du soldataren baldintzetan oinarritzen den eskubideak bermatzearen aldeko diskurtsoa; c) banakoa oinarri hartzen den lan-harremanen ikusmoldea, betiere funtzionala gertatzen da alde kolektiboak gutxitzen dituen lan-merkatuarentzat; eta d) baliabide autonomo gisara azaldu nahia, izan ere, merkatuaren, hirugarren sektorearen eta administrazioaren bestelako logika eta interesak gurutzatzen diren gunea baita.

\section{HITZ-GAKOAK:}

gizarteratzeko enpresak, gizarte-politikak, bazterketa, enplegagarritasuna, herritartasuna.
Este artículo analiza la regulación de las empresas de inserción social en un contexto de precarización del trabajo como clave de ciudadanía y de debilitamiento de las políticas sociales garantistas del Estado del bienestar. Destacamos: a) su orientación como recursos dirigidos a colectivos específicos, que generan propuestas estigmatizadoras de sus usuarios; b) la centralidad de un concepto de empleabilidad que responsabiliza de su situación a los excluidos y construye un 'discurso de la carencia', desde el que se legitima la intervención, y un 'discurso de la activación', que sustituye al de la garantía de los derechos basados en la condición salarial; c) una concepción individualizada de las relaciones laborales, funcional para un mercado de trabajo en que se minimizan las claves colectivas; $y$ d) su articulación como un recurso pretendidamente autónomo, que se sitúa en un cruce de lógicas e intereses dispares entre el mercado, el tercer sector y la Administración.

\section{PALABRAS Clave:}

empresas de inserción social, políticas sociales, exclusión, empleabilidad, ciudadanía.

Una versión preliminar de este trabajo se publicó en Ignacio Martínez Morales, Joan Carles Bernad y Almudena Navas, “¿ltinerarios hacia una ciudadanía precaria? Critica de la regulación de las empresas de inserción social”, en Ana Córdoba e Ignacio Martínez Morales (coords.), Trabajo, empleabilidad y vulnerabilidad social: condicionantes y potencialidades de la integración a través de las empresas de inserción social, Valencia, Servicio de Publicaciones de la Universitat de València, 2011. Ese trabajo se ha realizado en el marco del proyecto financiado por el Ministerio de Educación (ref. SEJ2007-62145), titulado 'Prácticas de intermediación laboral y fomento de la empleabilidad: la gestión de itinerarios de inserción de colectivos vulnerables'. El presente artículo contextualiza y amplía ese estudio, en especial desde la consideración de la normativa vasca sobre las empresas de inserción social. 


\section{Introducción}

Las empresas de inserción social son estructuras empresariales que introducen como objetivo, junto a la producción, el apoyo a la inserción sociolaboral de personas en situación de riesgo de exclusión. En España, las empresas de inserción social no son muchas, aunque cuentan con una mayor tradición y presencia en algunas comunidades autónomas, como es el caso del País Vasco ${ }^{2}$. Las diferentes raíces de estas empresas (algunas ligadas al mundo de la economía social, otras al del asociacionismo de acción social) y la diversidad de las entidades promotoras que existen detrás de ellas han generado un panorama heterogéneo en cuanto a modelos organizativos y procedimientos de trabajo, tanto por lo que se refiere a su dimensión productiva como a la intervención socioeducativa que desarrollan (Federación de Asociaciones Empresariales de Empresas de Inserción, 2003; Claver y Vidal, 2004). De hecho, hasta diciembre de 2007 no contaban con una legislación estatal, que es la que constituye el foco central de este artículo, y mostraban, por tanto, una cierta disparidad autonómica en su regulación. A partir de ese año, se ha ido produciendo la adaptación de esas normativas al marco estatal; en concreto, en el País Vasco se aprobó el Decreto 182/2008 (que también abordamos en este artículo) para sustituir la regulación anterior, que se recogía fundamentalmente en el Decreto 305/2000.

Este artículo se centra, pues, en algunas claves de la normativa de las empresas de inserción social, en la medida en que entendemos que condicionan fuertemente la actuación socioeducativa de éstas, e incluso su capacidad productiva. Al tratarse de un recurso definido normativamente desde la Administración, estas empresas incorporan una serie de claves de control y homogeneización que entran en conflicto con la lógica que hay en la raíz de estas entidades, procedentes de una tradición que se sitúa en el terreno de encuentro entre el tercer sector y la economía social. Un conflicto que, como vamos a señalar, puede anular algunas de las potencialidades que estas empresas encierran de cara a la integración social, llegando incluso a reforzar las tendencias de dualización social que buscan combatir los actores que las promueven.

Estos conflictos se han expresado de modo muy evidente en las diversas entrevistas que hemos sostenido a lo largo de nuestra investigación con profesionales de las empresas de inserción, así como en todos aquellos foros en los que hemos podido debatir con ellos sobre su situación ${ }^{3}$. En todos ellos,

${ }^{2}$ Véase al respecto Veciana (2007). En ese libro se señala cómo entre Cataluña y el País Vasco reúnen más de la mitad (55 y 50, respectivamente) del total de 189 empresas de inserción social que el estudio recogió en su base de datos ese año.

${ }^{3}$ Sin ir más lejos, surgían en el debate que se desarrolló en los talleres de trabajo que tuvieron lugar en las II Jornadas de Trabajadores Acompañantes de la Comunidad Valenciana, celebradas en julio de 2010, organizadas por la Asociación Valenciana de Empresas de Inserción, y en las que participamos. hemos podido escuchar múltiples comentarios sobre la dificultad que implica adaptar las prácticas cotidianas de las empresas y de sus trabajadores -especialmente gerentes y trabajadores acompañantes- a unos criterios que emanan más de la lógica de la Administración que de las necesidades, tanto productivas como educativas, propias del recurso. Esto genera multitud de dinámicas burocratizadoras, duplicidades en los procesos de evaluación, dedicación de horas de trabajo, tempos que no se ajustan ni a las necesidades del mercado, ni a las de los procesos educativos. Todo ello es vivido como interferencias y dificultades añadidas a las propias de la función específica de estos profesionales, que requieren dedicación de tiempo y esfuerzo, y que, además, han de afrontarse sin recursos suficientes y, en ocasiones, sin la suficiente cooperación y sintonía con los recursos públicos.

Lo que pretendemos en estas páginas es considerar cómo la configuración normativa de este recurso de intervención social responde a las circunstancias sociohistóricas dominantes - que trazamos brevemente en el siguiente apartado4- reforzándolas $^{5}$. En una sociedad caracterizada por la individualización de los procesos de negociación laboral, la dualización del mercado de trabajo y la precarización de los derechos de ciudadanía, nos preguntamos por qué tipo de integración generan estos recursos, hacia dónde se dirigen los itinerarios que desde ellos se potencian y, en definitiva, a qué ciudadanía generan acceso.

\section{Cambios en el contexto de las políticas sociolaborales}

Para comprender adecuadamente las transformaciones en las políticas sociolaborales, es preciso enmarcarlas en el contexto de los cambios que se han producido en el capitalismo occidental. En ese sentido, creemos relevante comentar tres grandes transformaciones que constituyen el contexto que configura -al menos en su definición reglamentariaa las empresas de inserción social. En primer lugar, el actual énfasis en la flexibilización e individualización de los mercados de trabajo, que está en la base del actual cuestionamiento del vínculo entre trabajo y ciudadanía. En segundo lugar, el auge de las políticas de activación -en torno a conceptos como el de empleabilidad-como modo de afrontar la crisis del empleo. En tercer lugar, la definición de políticas

4 Para un desarrollo más en profundidad sobre estos condicionantes sociohistóricos, puede consultarse Bernad, Martínez Morales y Molpeceres (2011).

5 Por supuesto, esto no excluye que los actores que desarrollan su función en el día a día de estas empresas puedan generar prácticas resistentes a esas tendencias dominantes. Pero eso es algo que no podemos extraer del análisis de esta normativa, por lo que queda fuera del ámbito de lo que pretende este artículo. En ese sentido, podremos realizar alguna aportación significativa más adelante, gracias al trabajo de interpretación que estamos haciendo a partir de las entrevistas en profundidad realizadas a trabajadores de las empresas de inserción, y que esperamos pueda formar parte de una futura publicación. 
sociales fragmentarias y focalizadas en colectivos vulnerables, frente a los modelos universalistas del Estado del bienestar, así como la progresiva incorporación de nuevos agentes a la gestión de las políticas sociales, procedentes tanto del mercado como del tercer sector, lo que cambia el equilibrio de intereses y fuerzas en este campo con referencia al modelo público de gestión del bienestar.

\subsection{Las transformaciones en el trabajo como clave de ciudadanía}

Como ya describiera Castel (1997), en el capitalismo del pacto keynesiano, la 'sociedad salarial' se articulaba en torno a una serie de condiciones estables que permitieron que el trabajo se convirtiera en el elemento vertebrador de la ciudadanía. En ese contexto, el trabajo dejaba de ser simplemente una relación mercantil y daba lugar al estatuto del empleo, que conllevaba una dimensión económica, pero también jurídica, de derechos sociales y de políticas públicas dirigidas a satisfacer tales derechos (Alonso, 2000). Así, la articulación entre ciudadanía y trabajo era la clave de la integración social.

En la actualidad, este modelo de ciudadanía salarial, que requería una estabilidad laboral, así como un esfuerzo colectivo y político dirigido a lograr el pleno empleo, ha entrado en crisis. El discurso económico dominante presenta la flexibilidad como la clave organizativa de una producción que ha de adaptarse a un entorno en permanente cambio. Desde esa perspectiva, la remercantilización aparece como una condición necesaria para el crecimiento económico de la relación laboral, lo que requiere que desaparezcan los dispositivos de regulación y negociación colectiva que impiden que el factor trabajo fluctúe de acuerdo con la oferta y la demanda. Y en este proceso se desdibujan, se debilitan e incluso desaparecen buena parte de las seguridades jurídicas asociadas al estatuto de trabajador (Castel, 1997; Alonso, 2000).

De ese modo, se provoca la fragmentación de la relación salarial, la individualización del trabajo, y los procesos de desafiliación o de pérdida de sus referencias colectivas o soportes institucionales. En definitiva, la ciudadanía se fragmenta, el acceso a los derechos se desdibuja y se particulariza, y se cuestiona su universalidad. En ese sentido, es fundamental el paso de estrategias de macroconcertación -convenios y procesos de negociación de las condiciones laborales colectivos e incluyentes- a estrategias de microconcertación -convenios particularizados y procesos de negociación individualizados ${ }^{6}$-.

\footnotetext{
${ }^{6}$ En este sentido, es especialmente relevante considerar la reforma del mercado laboral que introduce el Real Decreto Ley 3/2012, ampliamente contestado en las calles por la ciudadanía, que, en su artículo 14, establece la prioridad de los convenios de empresa sobre los sectoriales para las siguientes materias: salario; abono y compensación de horas extra y retribución del trabajo a turnos; horario; distribución del tiempo de trabajo y vacaciones; clasificación profesional adaptada a la empresa; adaptación a la empresa de las modalidades de contratación; medidas para favorecer la conciliación de la vida laboral, familiar y personal, así como las que atribuyan los
}

La dinámica flexible lleva a una dualización del trabajo (Alonso, 2000): por un lado, se consolidan mercados internos de trabajo estable, ligados a los núcleos centrales de las empresas y a altos niveles de especialización; por otro, se genera un elevado número de empleos atípicos, inestables, temporales, con condiciones de contratación precarias, que son usados tanto para abaratar la cadena productiva general, como para responder a las fluctuaciones de la coyuntura comercial. Se produce una fractura entre el centro y la periferia laboral, entre el núcleo corporativo de las empresas y la actividad subcontratada, entre los mercados internos y los externos, y se imponen modos de relación laboral diferenciados y desiguales entre ambos espacios.

La combinación de las dinámicas de individualización y dualización da lugar a la pérdida de cohesión social, y se generan procesos de exclusión, de ampliación de los segmentos laborales más desprotegidos y de acoplamiento de los sujetos más vulnerables a los espacios laborales más precarios (Castel, 1997). En ellos se produce un profundo dislocamiento y una fragmentación de los ciclos y trayectorias biográficas laborales (Sennett, 2000; Paugam, 2000), que se mueven entre importantes periodos de inactividad, y continuas entradas y salidas del empleo regular, a la vez que dan lugar a relaciones laborales débiles y discontinuas, en una situación de riesgos permanentes.

\subsection{Las políticas centradas en la activación para el empleo}

Esa dificultad del capitalismo actual para conciliar flexibilidad y seguridad le lleva a desplazar hacia el individuo la generación de estrategias que articulen su vida laboral. Los riesgos que ocasionan la mercantilización y la flexibilización del mercado laboral han de ser internalizados -comprendidos e interpretados-y gestionados por los individuos mismos, desde su disponibilidad y adaptabilidad a las nuevas dinámicas. En ese sentido, los complementos discursivos de los dispositivos de flexibilidad son la empleabilidad, la adaptabilidad y la 'empresarialidad', como claves de la construcción del mercado de trabajo (Alonso, 2000). Éstos transmiten la concepción del trabajador como ‘empresario de sí mismo', que debe admitir y gestionar sus riesgos -al tiempo que se individualizan las medidas de seguridad- en torno al concepto de empleabilidad: la seguridad del trabajo consiste en ser un buen gestor del propio capital humano y relacional, e ir incrementándolo, de modo que se haga más necesario para las empresas. La importancia de la cualificación, de la experiencia, de los contactos y de la iniciativa constituye la base de ese potencial.

acuerdos interprofesionales. Igualmente el artículo establece que, cuando concurran causas económicas, técnicas, organizativas o de producción, se podrá dejar de aplicar en la empresa las condiciones de trabajo previstas en el convenio colectivo que afecten a la jornada de trabajo, horario y distribución del tiempo de trabajo, régimen de trabajo a turnos, sistema de remuneración y cuantía salarial, sistema de trabajo y rendimiento, movilidad funcional y mejoras voluntarias. 
Así, se pasa del establecimiento de garantías colectivas y vinculadas al derecho de ciudadanía, a la gestión personal y estratégica de recursos y oportunidades para afrontar la inseguridad y el riesgo (Alonso, 1999), de modo que cada individuo ha de competir, trabajar, ahorrar e invertir para garantizar su bienestar. Sin embargo, esta dinámica de gestión de oportunidades en un contexto caracterizado por la inestabilidad laboral, la precariedad o la descualificación, supone, en la práctica, la condena a la exclusión social de todos aquellos cuyas condiciones laborales no permiten construir una base de recursos (económicos, personales o relacionales) desde la que afrontar los riesgos. Estos trabajadores se ven relegados a espacios secundarios del mercado laboral, con su propia dinámica de supervivencia, o son instalados en espacios protegidos, vinculados a las políticas asistenciales. Se trata, en definitiva, de la ruptura de la cohesión social: los grupos más débiles generan estrategias adaptativas para la supervivencia, y los mejor situados se consagran a una carrera personal independiente de cualquier necesidad o situación colectiva.

\subsection{La transformación de las políticas sociales}

La década de los noventa supuso una derivación de las políticas sociales hacia el espacio de la lucha contra la exclusión social, como respuesta amortiguadora de las consecuencias del avance del mercado flexible, con el consiguiente incremento de la vulnerabilidad social que venimos describiendo (Rodríguez Cabrero, 1998). La consolidación de esta tendencia ha supuesto limitar las políticas universales y redistributivas en materia de derechos sociales y económicos. Frente a ese debilitamiento de las políticas de integración, se han ido consolidando las políticas de inserción, con un carácter asistencial y compensatorio (no redistributivo), que plantean una lógica de discriminación positiva, focalizándose sobre grupos y sectores sociales vulnerables y excluidos de los mercados de trabajo. En ese proceso ha sido especialmente relevante la separación formal entre las políticas laborales y las políticas sociales. El hecho de que dos décadas después sigamos apoyándonos en esas políticas de inserción es un indicador, como ya advirtiera Castel (1997), de la instalación en la provisionalidad como régimen de existencia de los sectores poblacionales más vulnerables, y consolida la sospecha de que, en la actual coyuntura, son inintegrables.

Por otro lado, las políticas sociales se ven sometidas, de manera creciente, a la tensión entre lógicas e intereses propios de los diferentes agentes que participan en ellas. La progresiva privatización de estas políticas ha supuesto la participación en este sector de agentes provenientes del entorno del mercado y del ámbito asociativo. Esto supone otra dinámica de fragmentación de estas políticas (Rodríguez Cabrero, 2004): por un lado, se potencia una mercantilización de los derechos, a través de la búsqueda individual en el mercado de garantías de estabilidad de cara al futuro; por otro lado, y como garantía contra el conflicto social, se plantea un asistencialismo de mínimos, financiado por los impuestos y, en buena medida, gestionado por entidades sin ánimo de lucro, en forma de prestaciones sociales de emergencia para aquellos que no pueden acceder al mercado. Se genera así una polarización de la ciudadanía (de primera y de segunda), debido a la pérdida del carácter garantista de las políticas sociales, vinculado, a su vez, a la universalidad de los derechos de ciudadanía.

Además, la participación de estos agentes en las políticas sociales ha generado una creciente necesidad de controlar el gasto derivado a la gestión privada, pero sobre el que existe una responsabilidad pública, para que su uso responda adecuadamente a las necesidades asistenciales propuestas. Las inercias burocratizadoras que provoca esta necesidad de control chocan con un mercado que se define por la flexibilidad y el cambio, y con un tercer sector que presenta como uno de sus grandes activos la agilidad de respuesta 'sobre el terreno' ante las necesidades sociales y sus transformaciones. Por ello, se ponen en juego -y la experiencia de las empresas de inserción es un buen ejemplo de ello- nuevas formas de 'control auditor', más flexible, basado en objetivos y en la aplicación de indicadores, y que parece aprovechar mejor el potencial de los agentes sociales, a los que se otorga así una supuesta autonomía de funcionamiento. El papel de las administraciones públicas pasa de ser agentes de las políticas sociales y garantes de su universalidad, a ser auditoras de los agentes que trabajan en los diferentes ámbitos de intervención. En el fondo, se trata de una nueva forma de burocratización, que introduce una serie de dinámicas de 'objetivación' en el quehacer de estos agentes, que han de preocuparse por la categorización de sus destinatarios, la visibilidad de sus resultados y su sujeción a los indicadores definidos desde instancias ajenas.

\section{Las empresas de inserción social como instrumento de las políticas sociales}

Las empresas de inserción social son un recurso que hay que entender en el marco de las políticas sociales de promoción de empleo para los colectivos más vulnerables. Un recurso que combina la intervención educativa con la apuesta por la capacidad estructuradora que tiene el trabajo sobre la persona, en la medida en que la socializa para el entorno social actual. Por supuesto, estas empresas deben combinar el objetivo de la integración social por medio del trabajo, con la productividad de la empresa.

Para comprender adecuadamente lo que implican estas empresas, es indispensable entenderlas como fruto de las actuales condiciones y concepciones de las políticas sociolaborales que hemos definido en el apartado anterior. Al respecto, creemos relevante destacar aquí tres grandes transformaciones que inciden en su configuración -al menos en su definición reglamentaria-. 
En primer lugar, las empresas de inserción social, en la medida en que son a) empresas, b) que están promovidas por el tercer sector, pero c) se hallan bajo la tutela de la Administración (Nyssens, 2006), aparecen como un recurso que refleja perfectamente la pluralización de los agentes sociales y las dificultades de su interacción. La centralidad que ejercen las entidades sin ánimo de lucro como promotoras de estas empresas es clave para entender su orientación, a veces a pesar de la normativa de la que aquí vamos a hablar.

En segundo lugar, el actual énfasis en la flexibilización e individualización de los mercados de trabajo, que está en la base del actual cuestionamiento del vínculo entre trabajo y ciudadanía, supone el auge de las políticas de activación -en torno a conceptos como el de empleabilidad-como modo de afrontar la crisis del empleo. Las empresas de inserción social asumen, en este sentido, el compromiso de moldear a los sujetos, trabajar con ellos para incrementar la empleabilidad de cada uno de ellos, definiendo un itinerario particular en cada caso. $Y$ entre los factores clave que definen esa empleabilidad y que deben moldear estas empresas, está la adaptabilidad y las actitudes de compromiso en el trabajo, muy por encima de los conocimientos básicos de oficio.

Y en tercer lugar, la definición de políticas sociales fragmentarias y focalizadas en colectivos vulnerables, frente a los modelos universalistas del Estado del bienestar, implica el tránsito desde las políticas de integración a las políticas de inserción social. De lo que se trata es de crear espacios 'de velocidad lenta', protegidos o autorizados, en los que los sujetos puedan reestructurar aquellas condiciones personales, o de su entorno relacional, que dificultan su incorporación a la sociedad. Las empresas de inserción social responden fielmente al carácter particular y transitorio con que se definieron estas políticas de inserción. En definitiva, son espacios laborales tutelados que permiten que, en un plazo máximo de tres años, los trabajadores hayan recorrido -con un acompañamiento educativo y un contraste continuado de su proceso- el itinerario que debe permitirles reconstruir su modo de estar en la sociedad e incrementar su empleabilidad, lo que, en teoría, les va a preparar para incorporarse al mercado laboral normalizado como unos ciudadanos más. Sin embargo, alrededor de estas empresas el contexto deriva hacia una creciente precarización de las condiciones laborales, una mayor indefensión de los trabajadores y un incremento fuera de toda expectativa del paro. De modo que, si las políticas de empleo no actúan sobre ese contexto, las posibilidades que tienen los trabajadores que salen de estas empresas de incorporarse a ese mercado laboral son cada vez más pequeñas.

En definitiva, como ya indicó Castel (1997), nos estamos encontrando con que las políticas de inserción, lejos de cumplir su papel de transición a la sociedad, están generando una dinámica de 'estabilización en la inestabilidad' para sus colectivos destinatarios, condenándolos a una situación de ciudadanía de segunda. En el caso de las empresas de inserción social, esto se traduce en que muchos trabajadores han de salir a un entorno que lo que les ofrece es trabajo precario y descualificador, o ayudas de subsistencia, manteniéndolos, en todo caso, en una zona asistida y generando dependencias.

\section{Análisis del marco normativo regulador de las empresas de inserción social}

En el marco del trabajo de investigación más amplio que desarrollamos en torno a los discursos y las prácticas de los agentes implicados en estas empresas de inserción social, hemos analizado cómo se regulan estas empresas en la legislación estatal (Ley de Empresas de Inserción, Ley 44/2007, de 13 diciembre) y autonómica. Ese análisis, que constituyó el objeto del capítulo citado en la nota 1, se amplía en este artículo con la revisión de la normativa vasca posterior a la ley estatal (Decreto 182/2008, de 11 de noviembre, por el que se regula la calificación de empresas de inserción, se establece el procedimiento de acceso a las mismas y su registro; y Orden de 4 de mayo de 2009, del Consejero de Justicia, Empleo y Seguridad Social, por la que se regulan las ayudas para la creación y el sostenimiento de las empresas de inserción).

A partir de este análisis, nuestra intención es preguntarnos sobre qué tipo de ciudadanía se pretende construir desde una política social que genera este tipo de recursos. Para ello, y de acuerdo con las claves sociohistóricas ya comentadas, proponemos ahora la consideración de cuatro ejes relevantes en la configuración de las empresas de inserción social, tal como las plantea la normativa:

- Su orientación como un recurso no universalista, sino dirigido a colectivos específicos, que genera propuestas estigmatizadoras de sus usuarios.

- La centralidad de un concepto de empleabilidad que responsabiliza de la situación de exclusión a los excluidos, construyendo un 'discurso de la carencia' desde el que se legitima la intervención, y un 'discurso de la activación' que sustituye al de la garantía de los derechos de ciudadanía basados en la condición salarial.

- La centralidad de los procesos educativos en torno a la definición de un itinerario individualizado de inserción, negociado y seguido personalmente por los educadores, que genera una dinámica en que, de entrada, lo colectivo no forma parte de la dinámica laboral.

- Su articulación como un recurso pretendidamente autónomo que compite en el mercado (empresa), se orienta desde el tercer sector (entidades promotoras), y es apoyado y controlado desde la Administración, lo cual lo sitúa en un cruce de lógicas e intereses dispares que lo configuran como un recurso vulnerable y sometido a tensiones hegemónicas desde diferentes ámbitos. 


\subsection{Las empresas de inserción como respuesta a colectivos específicos}

Comienza la regulación estatal, en su preámbulo, con una referencia a la centralidad que, para la Administración del Estado español, debe ser garantizar la posibilidad de todos y cada uno de sus ciudadanos y ciudadanas de participar en todos los ámbitos de la vida social, lo que conlleva la atención especial a los colectivos que presenten mayores dificultades:

Los principios que inspiran la presente Ley se fundamentan en el mandato de la Constitución Española, que, en el apartado 2 de su artículo 9, ordena a los poderes públicos facilitar la participación de todos los ciudadanos en la vida política, económica, cultural y social de nuestro país, lo que motiva al legislador para que contemple la necesidad de establecer cauces adecuados que faciliten tal participación, especialmente la de aquellas personas que, por circunstancias diversas, se encuentren en situaciones de dificultad y exclusión social (Extracto del punto I del preámbulo de la Ley de Empresas de Inserción).

Lo mismo ocurre con el decreto vasco, en el que se especifican tres 'ámbitos de carencia' que señalan a los individuos como objetivo de la acción de estos recursos: el personal, el social y el económico. Si bien la actuación de las empresas de inserción social se dirige a hacer posible la participación en el trabajo $y$, por tanto, tiene una dimensión netamente económica, su enfoque en tanto que recurso educativo incide de manera prioritaria, como veremos más adelante, en las carencias personales de los sujetos, que se suelen señalar como claves para el proceso de desarrollo de la empleabilidad ${ }^{7}$ :

El mencionado Decreto 305/2000, de 26 de diciembre, se dictaba en desarrollo de las medidas previstas en la Ley 12/1998, de 22 de mayo, contra la Exclusión Social y con la finalidad de contribuir a la inserción de quienes carecen de los recursos personales, sociales o económicos suficientes para desarrollar una vida independiente (Párrafo segundo del preámbulo justificativo del Decreto 182/2008 del Gobierno Vasco, que se refiere al argumentario incluido en la normativa vasca anterior, derogada por la ley estatal; el subrayado es nuestro).

Como hemos expuesto anteriormente, la fragmentación de las políticas sociales a través de su focalización en determinados colectivos definidos como 'de riesgo' genera una dinámica de disolución de las políticas garantistas de carácter universalizador, y la dualización de la ciudadanía (y del acceso a los derechos) en función de las categorías sociales resultantes. Se produce así una 'segmentación' de

7 Para un análisis en profundidad de los elementos que se consideran clave en el desarrollo de la empleabilidad en estas empresas, así como para una discusión del mismo concepto de empleabilidad, se puede ver el trabajo de Llinares, Córdoba y Zacarés (2011). las prestaciones basada en la 'prueba de necesidad' - o, como en el caso de las empresas de inserción, en la certificación de la exclusión-, lo que supone la renuncia al principio de universalidad, que genera prestaciones sociales selectivas 'para los necesitados'. Si bien éstas se plantean como medidas de discriminación positiva, aplicables en el diseño de ‘itinerarios de inserción', tienden a convertirse en itinerarios sin salida, bien hacia espacios mercantiles precarizados, bien hacia zonas vulnerables protegidas, que constituyen espacios ciudadanos de segunda (Castel, 1997).

En esa línea, el marco regulador de las empresas de inserción social responde a la tendencia, dominante desde los años noventa, de situar las políticas sociales en un ámbito acotado, que es el de la lucha contra la exclusión social, al marcar como su objetivo específico atender a los colectivos que presentan más dificultades, aunque, en este caso, partiendo de la premisa de que la participación social pasa por la integración en el mercado de trabajo:

En el Capítulo I se establecen el objeto y los fines de la Ley, pasándose a definir los trabajadores contratados por las empresas de inserción destinatarios de los procesos y medidas para la inserción sociolaboral: personas en situación de exclusión social, con especiales dificultades para su acceso al mercado de trabajo, y pertenecientes a colectivos socialmente desfavorecidos (Extracto del punto III del preámbulo de la Ley de Empresas de Inserción).

[...] la no participación o la participación residual en el mercado de trabajo determinan, casi necesariamente, el inicio de un proceso de exclusión con consecuencias directas en el ejercicio de otros derechos sociales. [...] Dicha constatación llevó al Gobierno Vasco a desarrollar una serie de medidas capaces de actuar desde diversos ámbitos, especialmente en el ámbito del empleo, con políticas públicas dirigidas a facilitar el acceso de los colectivos más desfavorecidos a la formación y al mercado laboral ordinario. [...] Una de las vías para ponerlo en práctica es el apoyo a la creación y el sostenimiento de empresas de inserción (Extracto de los párrafos tercero, cuarto y quinto del preámbulo justificativo del Decreto 182/2008 del Gobierno Vasco).

La delimitación de dichos colectivos no queda en una mera formulación genérica, sino que se concreta tanto en la regulación estatal como en las regulaciones autonómicas de manera detallada. Así, se configuran una serie de categorías sociales públicamente reconocidas como 'de riesgo' o 'excluidas', que constituyen el objeto de las políticas marginales dirigidas a los segmentos periféricos de la ciudadanía. La polarización de ésta se consolida también, de esta manera, mediante las definiciones institucionales de colectivos diana. A modo de ejemplo, en el siguiente extracto queda recogido el listado de colectivos incluidos en la ley estatal: 
Las empresas de inserción podrán contratar como trabajadores, a efectos de lo previsto en esta Ley, a las personas en situación de exclusión social desempleadas e inscritas en los Servicios Públicos de Empleo, con especiales dificultades para su integración en el mercado de trabajo, que estén incluidos en alguno de estos colectivos: a) perceptores de Rentas Mínimas de Inserción [...]; c) jóvenes mayores de dieciocho años y menores de treinta, procedentes de Instituciones de Protección de Menores; d) personas con problemas de drogodependencia u otros trastornos adictivos que se encuentren en proceso de rehabilitación o reinserción social; e) internos de centros penitenciarios cuya situación penitenciaria les permita acceder a un empleo [...], así como liberados condicionales y ex reclusos; f) menores internos incluidos en el ámbito de aplicación de la Ley Orgánica 5/2000, de 12 de enero [...], así como los que se encuentran en situación de libertad vigilada y los ex internos; g) personas procedentes de centros de alojamiento alternativo [...]; h) personas procedentes de servicios de prevención e inserción social autorizados por las CC. AA. y las ciudades de Ceuta y Melilla (Extracto del artículo 2, apartado 1, de la Ley de Empresas de Inserción).

Esta enumeración de colectivos destinatarios ha sido adaptada y modificada por cada comunidad autónoma, de forma que nos encontramos casos como el de Cataluña, cuya normativa incluye también a parados de larga duración y mayores de 45 años, 0 el de la normativa valenciana, que incluye también a personas discapacitadas como colectivo. En este sentido, la normativa vasca incluye, además de los anteriormente descritos en la normativa estatal, “a personas procedentes de programas prelaborales de orientación y formación o procedentes de los Servicios Sociales de Base de la Comunidad Autónoma del País Vasco concretada a través de un convenio de inserción sociolaboral" (Decreto 182/2008, artículo 5, apartado 1, subapartado h).

Pero, yendo más allá, y no conformes con enumerar los colectivos destinatarios, para poder ser contratado por una empresa de inserción se necesita una acreditación de la administración pública, concretamente de los servicios sociales competentes, que certifique la situación de exclusión del individuo y su pertenencia a alguno de los colectivos que prevé:

La situación de exclusión de las personas pertenecientes a los colectivos a los que se hace referencia en el apartado 1 deberá ser acreditada por los Servicios Sociales Públicos competentes (Extracto del artículo 2, apartado 2, de la Ley de Empresas de Inserción).

Este requisito se recoge también en las regulaciones autonómicas. De hecho, en el decreto del Gobierno Vasco aparece expresado con las mismas palabras que en el estatal (véase el Decreto 182/2008, artículo 5, apartado 2).
Esta necesidad de 'certificar' la exclusión es una fuente de estigmatización de las personas que han de someterse a este proceso de evaluación y diagnóstico de su grado de exclusión, y son etiquetadas de manera legal como 'incapaces' de conseguir y mantener un puesto de trabajo en el mercado laboral ordinario. La inclusión en esta categoría implica, pues, el reconocimiento de la situación de exclusión por parte de las instituciones públicas sociales y de empleo, su aceptación por parte del individuo y su consolidación en su expediente personal, ya que su contratación 'proveniente de programas de inserción' -y por tanto, que reconozca su 'certificación'- implica una serie de beneficios, tanto para la empresa de inserción, que ve como se cumple su cuenta de objetivos ante la Administración, cómo para la empresa que la contrate, que puede acceder a diferentes ventajas económicas.

Así, la dinámica que genera la lógica burocrática -aun en su vertiente más flexible del 'control auditor', del que hablaremos más adelante- refuerza el carácter indeleble de este tipo de estigmas exclusores: creando una categorización que se pretende descriptiva, se está calificando y encuadrando socialmente a los sujetos. Pese al pretendido carácter 'de transición' de las empresas de inserción social, su definición institucional genera una dinámica que puede acabar estabilizando la identidad social de los individuos en las categorías directamente vinculadas a la zona de exclusión.

\subsection{El concepto de empleabilidad en las empresas de inserción social: entre el 'discurso de la carencia' y la responsabilización de los individuos}

El concepto de empleabilidad aplicado en el marco normativo de las empresas de inserción social parte de un discurso donde se enfatizan las carencias de aquellas personas para las cuales se considera necesario este recurso. No aparece referencia alguna a aquellos aspectos de carácter sociohistórico que estén determinando y minando su participación como ciudadanos y ciudadanas de pleno derecho, sino que toda explicación sobre su situación de vulnerabilidad o exclusión social recae en aspectos relativos a sus carencias y limitaciones personales:

[...] se define la exclusión como «la imposibilidad de ejercer los derechos sociales, fundamentalmente el derecho al trabajo, pero también el derecho a la educación, a la formación, a la cultura, a la salud, a una vivienda digna, a la protección social [...] (Extracto del párrafo tercero del preámbulo justificativo del Decreto 182/2008 del Gobierno Vasco).

[...] estas personas particularmente desfavorecidas, en situaciones de marginación o de exclusión, encuentran especiales dificultades para acceder al mercado de trabajo, debido a sus carencias sociales, económicas, educativas y de cualificación laboral, con lo que el ejercicio de 
un trabajo, derecho y deber de todo ciudadano consagrado en el artículo 35 de la Constitución, presenta para ellas numerosos problemas debido a la desmotivación personal, al desconocimiento o abandono de los hábitos sociales y laborales básicos, así como a la carencia de niveles educativos mínimos y la falta de adaptación profesional (Extracto del punto I del preámbulo de la Ley de Empresas de Inserción; el subrayado es nuestro).

Como queda recogido en los extractos anteriores, son carencias personales de distinto tipo -sociales, económicas, educativas y de cualificación laborallas que se encuentran tras las dificultades de integración, lo que conlleva también un abanico de consecuencias de cara a que puedan 'ocuparse' de manera normalizada -desmotivación, abandono de hábitos básicos, falta de adaptabilidad-. Dichas consecuencias siguen moviéndose en el marco de las carencias y dificultades que residen en el individuo.

Una vez realizado el diagnóstico, la acción de las empresas de inserción social se enmarca en las políticas europeas que pretenden dar respuesta a los problemas de inclusión de colectivos específicos desde el paradigma de la 'activación'. Desde esa perspectiva se definen las prioridades de la Unión Europea en su estrategia de empleo: la oferta de mano de obra, la adaptabilidad y el capital humano. Tres claves que se presentan como fundamentales para la promoción de un mercado laboral inclusivo.

En el ámbito comunitario cabe resaltar que uno de los tres objetivos globales de la Estrategia Europea de Empleo (EEE) es consolidar la inclusión social, prevenir la exclusión del mercado laboral y apoyar la integración en el empleo de las personas desfavorecidas. Las directrices integradas establecidas bajo las tres prioridades de la EEE (oferta de mano de obra, adaptabilidad, capital humano) prestan una considerable atención a la promoción de un mercado laboral inclusivo (Extracto del punto I del preámbulo de la Ley de Empresas de Inserción).

Esta perspectiva permite vincular la integración de las personas en situación social vulnerable con las políticas activas de empleo, que se centran en la formación de un capital humano flexible, adaptable y polivalente. Al mismo tiempo, será el esfuerzo que el individuo ponga de su parte la verdadera llave de la inclusión social, ya que -desde esta perspectivasólo la adaptación del trabajador a los requerimientos del mercado laboral le permitirá retomar la senda de integración social.

Esa ‘psicologización’ de la problemática del paro permite desrresponsabilizar al mercado y a sus instituciones, así como diluir la dimensión colectiva que permitía articular un modelo sostenible de bienestar vinculado al estatuto del salariado. En el fondo, supone una despolitización aparente del funcionamiento del mercado de trabajo, coherente con el proceso de progresiva individualización de las rela- ciones laborales que hemos descrito anteriormente y sobre el que volveremos en el siguiente apartado.

De esta manera, como se describe en el extracto siguiente, la tarea en el marco de las empresas de inserción social es una ingeniería de 'reajuste' de las personas en situación vulnerable, para que crezcan en empleabilidad, entendida ésta como superación de sus carencias e impedimentos para adaptarse adecuadamente a las necesidades del mercado de trabajo:

Las metodologías que se desarrollan durante un itinerario de inserción, dentro del cual se lleva a cabo la actividad laboral en la empresa de inserción, tienen como objetivo potenciar las capacidades de las personas a través de los conocimientos técnicos, habituación sociolaboral y determinación de prioridades adecuadas a sus posibilidades y a las del mercado laboral (Extracto del punto II del preámbulo de la Ley de Empresas de Inserción).

O bien, como vemos en este otro fragmento de la ley de ámbito estatal:

Las medidas de intervención y acompañamiento consistirán en el conjunto de servicios, prestaciones acciones de orientación, tutoría y procesos personalizados y asistidos de trabajo remunerado, formación en el puesto de trabajo, habituación laboral y social encaminados a satisfacer o resolver problemáticas específicas derivadas de la situación de exclusión, que dificultan a la persona un normal desarrollo de su itinerario en la empresa de inserción (apartado 2, artículo 3, de la Ley de Empresas de Inserción).

La cuasi literalidad de estos dos extractos la podemos encontrar también en la normativa vasca (véase el preámbulo justificativo, párrafo sexto, y el artículo 6, apartado 2, del Decreto 182/2008 del Gobierno Vasco).

Por otro lado, la cuestión es que, en un contexto de mercado laboral dual, la transición de los trabajadores de inserción al 'mercado laboral ordinario' del que habla la ley se va a producir siempre en los sectores menos cualificados y más precarizados ${ }^{8}$. De ese modo, cuando en esta ley se conceptualiza la empleabilidad vinculada a la adaptabilidad a las necesidades del mercado de trabajo, no se tiene en cuenta que ese mercado está fragmentado, y que la mayoría de los trabajadores que pasan por las empresas de inserción social salen al mercado de trabajo secundario. Éste se caracteriza por generar itinerarios laborales fragmentados, en entornos de

${ }^{8}$ Si bien, como es lógico, esto no se puede desprender del texto de la ley, sí que resulta claro en las respuestas que estamos obteniendo en nuestra investigación, tanto mediante el cuestionario que aplicamos -cuyos datos se expusieron en el V Congreso Internacional del Formación para el Trabajo (Marhuenda, 2009)-, así como, especialmente, a través de las entrevistas en profundidad, cuyo análisis está en proceso. 
muy baja cualificación, por lo que no permite desarrollar un capital humano especializado, ni un capital relacional, que serían, en todo caso, los factores de empleabilidad que introducen algunas posibilidades de estabilidad o movilidad ascendente en un entorno laboral flexible. Estos factores no se pueden desarrollar a través de herramientas como las empresas de inserción, ni siquiera mediante la posibilidad que abren de incorporar a los trabajadores a un mercado laboral no cualificado y altamente precarizado. Sin desdeñar la relevancia que tienen esos trabajos para la supervivencia cotidiana de los trabajadores en situación de riesgo, no podemos considerar que sean indicativos de una política de integración universalista e igualitaria, sino que profundizan aún más en la dinámica de dualización social que, en principio, se pretende combatir.

\subsection{Relaciones educativas individualizadas y contrato de inserción: los riesgos de la individualización de las relaciones laborales}

Como ya hemos indicado, existe una tendencia a la psicologización de los recursos desde los que desarrollar políticas activas de empleo. El énfasis en la motivación, en las competencias individuales, las actitudes y compromisos personales son claves que se sitúan en esta línea. En definitiva, las empresas de inserción social han de plantearse todo un proceso de resocialización de los sujetos, de cara a posibilitar su inserción en el mercado laboral.

Pero, además, ese proceso de socialización que se produce en estas empresas se plantea a priori -independientemente de las prácticas cotidianas que luego desarrollen los agentes- como un proceso que pone en juego la adaptación del individuo al contexto organizacional, con sus prioridades, objetivos y cultura. Porque, en definitiva, eso es lo que luego van a pedirles sus potenciales empleadores. Así, el modo en que se configura la experiencia del trabajador en las empresas de inserción supone un 'entrenamiento' que prepara para el paso a la empresa ordinaria. En estas empresas, el acuerdo de inserción como estrategia educativa se configura como una situación asimétrica en la que el trabajador ha de asumir una serie de objetivos de los que depende su continuidad en la empresa. Una asimetría por la que el trabajador de inserción asume que los agentes institucionales -los mismos que han certificado su situación de exclusión-definan el itinerario de inserción al que ha de adaptarse y con el que ha de comprometerse para poder acceder al trabajo:

Las empresas de inserción aplicarán itinerarios de inserción sociolaboral en función de los criterios que establezcan los Servicios Sociales Públicos competentes y los Servicios Públicos de Empleo, de acuerdo con las propias empresas de inserción, teniendo que ser aceptados dichos itinerarios por la persona en situación de exclusión social contratada, con el objetivo de promover su integración en el mercado laboral ordinario, definiendo las medidas de intervención y acompañamiento que sean necesarias (Artículo 3, apartado 1, de la Ley de Empresas de Inserción; recogido íntegramente en el artículo 6, apartado 1, del Decreto 182/2008 del Gobierno Vasco).

Por supuesto que, en muchos casos, los agentes actúan contando con la participación activa del trabajador. Pero esto siempre depende de los criterios y sensibilidades de esos agentes. Y, en cualquier caso, la situación resultante, tal como la diseña la norma, implica una relevante asimetría en las posiciones, que viene justificada por el carácter de tutela que ejercen los educadores y responsables de la empresa, así como por el papel de garante público que ejercen los servicios sociales.

Pero creemos relevante plantear si esta dinámica de concertación de las condiciones de participación en la empresa, al margen de su potencialidad para generar compromiso en el proceso, da lugar a una experiencia de negociación individualizada de las condiciones de trabajo que, a modo de currículum oculto, prepara al trabajador para asumir un modelo de concertación social en que desaparece la dimensión colectiva de la negociación. Esto nos parece preocupante, en la medida en que propicie una dinámica de adaptación y potencial sumisión, que corre el riesgo de generar indefensión en el trabajador una vez sale al mercado laboral normalizado, debilitando su capacidad de propuesta, de negociación y de organización para defender sus derechos.

Por otro lado, esta dinámica asimétrica implica también una cierta tutela institucional de las condiciones de trabajo en estas empresas. Por supuesto, ello entra en la lógica de estos recursos, en la medida en que se focalizan sobre colectivos vulnerables, lo que requiere ciertas medidas de 'discriminación positiva’. No lo comentamos aquí por ese carácter -ya lo comentamos en un punto anterior de este artículo-, sino porque la manera en que la norma plantea esas medidas nos ofrece un ejemplo más de asimetría en la gestión de las relaciones laborales.

Sin duda que, en un recurso de este tipo, se hace necesario regular las circunstancias particulares que puedan afectar a las condiciones de trabajo. Lo contrario podría dar lugar a abusos, tanto por parte de las empresas como de los trabajadores, en la medida en que las situaciones que se planteasen en torno a las condiciones de riesgo de los trabajadores quedasen a la interpretación de los agentes implicados en la empresa. Por ello, la norma recoge una serie de medidas que pretenden garantizar la objetividad en el tratamiento de las situaciones que pudieran darse por las condiciones específicas de los colectivos a los que se dirige el recurso. Como ejemplos, podemos ver los siguientes extractos de la ley, en que se recogen y regulan algunas excepciones del régimen laboral general debido a circunstancias de carácter físico, psíquico o social vinculadas a las condiciones de vulnerabilidad de los sujetos: 
Las ausencias o faltas de puntualidad al trabajo motivadas por la situación física o psicológica derivada de la situación de exclusión social del trabajador se considerarán justificadas cuando los Servicios Sociales Públicos competentes así lo determinen, y sin perjuicio de que sean comunicadas por el trabajador a la empresa (Extracto del apartado 2 del artículo 13 de la ley).

No será de aplicación a los trabajadores a que se refiere el artículo 2.1 d) de esta Ley la causa de despido disciplinario establecida en el artículo 54.2 f) del Estatuto de los Trabajadores. En los supuestos en que, durante la vigencia del contrato, la empresa de inserción tuviera conocimiento de que el trabajador incurre en la causa mencionada en el párrafo anterior, lo pondrá en conocimiento de los Servicios Sociales Públicos competentes, a fin de que por los mismos se proponga al trabajador afectado iniciar un proceso de deshabituación o desintoxicación. En este caso, el contrato de trabajo podrá suspenderse cuando, a juicio de los citados Servicios Sociales, fuera necesario para el éxito de dicho proceso. Si el trabajador no iniciara dicho proceso de deshabituación o desintoxicación, o lo abandonara sin causa justificada, se considerará un incumplimiento de las obligaciones asumidas en el itinerario de inserción, siendo entonces de aplicación lo establecido en el artículo 54.2.f) del Estatuto de los Trabajadores (Artículo 14, apartado 3 de la ley).

Por su parte, la normativa vasca directamente se acoge a todo lo recogido en el capítulo IV de la normativa de ámbito estatal, capítulo al que pertenecen los extractos anteriores (véase: artículo 20, apartado 1 del Decreto 182/2008 del Gobierno Vasco).

Pero la otra cara de esta dinámica implica un cierto sometimiento de la normativa general reguladora de las condiciones de trabajo a las decisiones tutelares tomadas desde la Administración, lo que implica mantener la asimetría y la dependencia de la que ya hemos hablado. Incluso, como vemos en el extracto que citamos seguidamente, el contrato laboral ha de incorporar las decisiones tomadas sobre el itinerario de inserción y las medidas que éste implica, institucionalizando así la aceptación a la que antes aludíamos:

El contrato de trabajo, sus prórrogas y variaciones se formalizarán siempre por escrito, en el modelo establecido por el Servicio Público de Empleo Estatal y se comunicará a la oficina pública de empleo. El contrato necesariamente incorporará en el correspondiente anexo la expresión de las obligaciones que las partes asumen en el desarrollo del itinerario personal de inserción y las medidas concretas a poner en práctica (Extracto del artículo 12, apartado 2 de la ley).

0, como vemos en este otro apartado de la ley:

El contrato podrá concertarse por un período mínimo de doce meses y máximo de tres años.
No obstante, podrá celebrarse por una duración menor si, dentro del itinerario de inserción previamente pactado, así se aconseja por los Servicios Sociales Públicos competentes para el seguimiento del proceso de inserción, sin que en ningún caso dicha duración pueda ser inferior a seis meses. Si se concierta por una duración inferior a la máxima prevista en el párrafo anterior, podrá prorrogarse hasta alcanzar la referida duración máxima, siendo la duración mínima de cada prórroga al menos igual a la duración inicial del contrato. Los Servicios Sociales Públicos competentes deberán informar sobre la adecuación de la prórroga (Artículo 15, apartado 4 de la ley).

Como en casos anteriores, la normativa vasca directamente se acoge a todo lo recogido en el capítulo IV de la normativa de ámbito estatal, capítulo al que pertenecen también los extractos que se acaban de citar.

En definitiva, el carácter individualizado de las relaciones educativas y laborales en las empresas de inserción social, que adquiere su legitimidad desde el argumento del acompañamiento personal y de la necesidad de configurar un itinerario de inserción ajustado a las necesidades de cada trabajador, hace que desaparezca -al menos en el diseño del recursocualquier atisbo de dinámica colectiva en la relación entre la empresa y sus trabajadores. Parece como si los procesos de integración en un entorno precarizado no requiriesen de un esfuerzo colectivo por mejorar las condiciones de trabajo, sino que fuera todo cuestión de desarrollar la propia empleabilidad, mejorando las oportunidades competitivas que permiten negociar particularmente la propia posición en la empresa.

Dicho de otro modo: desde la perspectiva de la empleabilidad como factor de inserción laboral, la clave es que tener algo que le interese a la empresa permite posicionarse con ventaja en el mercado laboral. Y eso depende de la actitud y el compromiso de cada cual. Un discurso que enlaza con las tendencias de microconcertación que ya hemos descrito, y que desactivan el carácter político y colectivo de la cuestión laboral. Y, además, un discurso que no se sostiene como clave de garantía de integración laboral cuando nos situamos en entornos laborales de muy baja cualificación y de alta temporalidad y precariedad, en los que la individualización de las relaciones laborales genera una gran indefensión en los trabajadores.

\subsection{Un recurso que se debate entre lógicas en conflicto}

Si hay algo que resulta llamativo en las empresas de inserción social, es que se trata de un tipo de recurso definido en la 'intersección' de tres sectores sociales con lógicas internas tradicionalmente diferentes: el mercado, el Estado y el tercer sector. Por un lado, son empresas inscritas en los registros mercantiles correspondientes, que deben competir en el mercado 
normalizado y ser rentables. Pero, por otro, cuentan con el apoyo de la administración pública, en la medida en que se convierten en herramientas de las políticas sociolaborales, como recursos de inserción, dando cabida a trabajadores con déficits que inciden en la productividad, por lo que se les compensa con diferentes tipos de incentivos. Para que eso sea así, estas empresas deben someterse -a diferencia de las empresas ordinarias- a la lógica administradora de los recursos públicos -control presupuestario, indicadores diversos, cumplimiento de objetivos predefinidos-. Además, al tratarse de entidades vinculadas al sector no lucrativo a través de sus promotoras -básicamente, fundaciones y algunas asociaciones-, deben mantener un nivel de independencia en su funcionamiento. Esto suele considerarse como la clave que les aporta un plus de adaptabilidad a las necesidades cambiantes de la realidad social, al tiempo que permite exonerar a la Administración del control en aquellos elementos que pudieran generar una mayor rigidez en su funcionamiento - pero también una mayor garantía, por ejemplo, en lo que se refiere a la gestión del personal-.

En definitiva, se trata de un recurso que ha de combinar las lógicas propias de los tres sectores, optimizando las sinergias que se generan y solventando, en la medida de lo posible, los conflictos resultantes, lo que en ocasiones se realiza mediante la 'hegemonía' de una lógica sobre las demás. Es cierto que la mayoría de estos conflictos sólo se pueden estimar cuando se contrasta el parecer de los diferentes agentes implicados - lo que se pretende en otras aproximaciones de nuestra investigación-. Pero al considerar la normativa, como estamos haciendo ahora, sí que podemos señalar algunas de las claves que, respondiendo más nítidamente a la lógica administrativa o burocratizadora de la administración pública, son una fuente de conflicto potencial con las otras lógicas.

La ley pretende establecer toda una serie de medidas de control como modo de responder a su responsabilidad de garantizar el uso adecuado de los fondos públicos cuando se derivan a la gestión privada. En definitiva, las empresas de inserción social son empresas, aunque promovidas por entidades sin ánimo de lucro. Pero dado que se pretende acceder a recursos públicos como compensación de los déficits de productividad que puedan generar los trabajadores de inserción, es preciso vincularse a una serie de mecanismos específicos de control. Esos mecanismos se plantean como obligatorios sólo en la medida en que las empresas pretenden acceder a las subvenciones y ventajas definidas para este tipo de empresas. La cuestión es que esas necesidades de control pueden entrar en conflicto con los criterios de flexibilidad imperantes en la lógica productivista del mercado actual, a la vez que con las necesidades del acompañamiento personalizado en los itinerarios de inserción.

Las empresas de inserción, una vez inscritas, vendrán obligadas a presentar en el Registro Administrativo competente de la Comunidad Autónoma dentro de los plazos que se determinen, la siguiente documentación, sin perjuicio de aquella otra que se pueda establecer por parte de las Comunidades Autónomas: a) la documentación acreditativa de las modificaciones estatutarias que afecten su calificación, una vez inscritas en los Registros competentes a su forma jurídica; b) el plan de actividades y el presupuesto de cada año con anterioridad al inicio del mismo; c) las cuentas anuales, el informe de gestión y el balance social correspondiente al cierre de cada ejercicio económico, sin perjuicio de las obligaciones de depositar las cuentas y el informe de gestión en los Registros que correspondan a su forma jurídica (Artículo 9, apartado 3 del de la Ley de Empresas de Inserción).

En la misma línea, el decreto vasco detalla lo determinado en la ley de ámbito estatal:

La concesión de la calificación de empresa de inserción conllevará las siguientes obligaciones, cuyo cumplimiento se deberá acreditar ante la Dirección de Inserción Social: a) presentar anualmente la memoria de actividades y la evaluación de las intervenciones desarrolladas; b) presentar las cuentas anuales y el informe de gestión correspondiente al cierre de cada ejercicio, en un plazo de 90 días a contar del mismo; c) realizar una auditoria social y presentar un balance social con carácter anual; d) presentar el plan de actividades y el presupuesto estimativo, en ambos casos con carácter anual y antes de iniciarse el año; e) presentar la documentación acreditativa de las modificaciones estatutarias que afecten a su calificación, en un plazo de 10 días a contar de su inscripción en el Registro correspondiente a su forma jurídica [...] (Extracto del artículo $10 \mathrm{del}$ Decreto 182/2008 del Gobierno Vasco).

Al mismo tiempo, como modo de gestionar el control sin encorsetar excesivamente la labor de estas empresas y sus promotoras mediante rígidos procedimientos burocráticos, se proponen procesos que responden al modelo aparentemente más flexible del control 'auditor' que, respetando una cierta autonomía en el funcionamiento de las entidades, las somete a toda una suerte de procesos de auditoría que permiten valorar sus resultados, en función de una serie de indicadores previstos.

[...] presentar anualmente un Balance Social de la actividad de la empresa que incluya la memoria económica y social, el grado de inserción en el mercado laboral ordinario y la composición de la plantilla, la información sobre las tareas de inserción realizadas y las previsiones para el próximo ejercicio (Requisito F para ser empresa de inserción, de los enumerados en el artículo 5 de la Ley de Empresas de Inserción; recogido literalmente en la normativa vasca en su artículo 10 , requisito l).

Como vemos, además de estar en los registros mercantiles correspondientes, estas empresas han 
de estar en el registro autonómico de empresas de inserción social; deben presentar un balance económico y social -cuyos indicadores están vagamente definidos-. Este control, presentado como coordinación de agentes autónomos, afecta a cualquier cambio en la dinámica de personal de estas empresas, desde la certificación de las condiciones de exclusión y la idoneidad para el puesto de trabajo, hasta la proporción de trabajadores de inserción y la duración de sus procesos.

El contrato de trabajo, sus prórrogas y variaciones se formalizarán siempre por escrito, en el modelo establecido por el Servicio Público de Empleo Estatal y se comunicará a la oficina pública de empleo. Una copia de estos documentos se remitirá a los Servicios Sociales Públicos competentes para el seguimiento del itinerario personalizado de inserción (Extracto artículo 12, apartado 2, de la Ley de Empresas de Inserción).

Los Servicios Sociales Públicos competentes emitirán informe con carácter previo a la extinción del contrato de trabajo, cualquiera que sea su causa. Asimismo, el empresario comunicará a los citados Servicios y a los Servicios Públicos de Empleo la extinción del contrato de trabajo de los trabajadores contratados, cualquiera que sea también la causa de extinción del contrato (Artículo 14, apartado 4, de la Ley de Empresas de Inserción).

Estos extractos pertenecen al capítulo IV de la ley, que, como ya hemos mencionado, es incorporado a la normativa autonómica vasca.

Todo ello permite, en principio, un seguimiento de los casos de mayor alcance. Aunque las relaciones de coordinación se exponen -como se puede ver en los fragmentos precedentes y siguientes- en un contexto de clara asimetría entre la Administración -servicios sociales y de empleo- y los otros agentes.

Las empresas de inserción se relacionarán con los Servicios Sociales Públicos competentes a efectos de [...] facilitar el seguimiento que corresponde hacer a los indicados servicios de los itinerarios y procesos de inserción sociolaboral de los trabajadores y prestar apoyo a aquellos que se incorporen a un puesto de trabajo en el mercado de trabajo ordinario, una vez finalizado su proceso de inserción (Extracto del artículo 10, apartado 2, de la Ley de Empresas de Inserción).

\section{[...] f) comunicar, en el momento en el que se} produzcan, las modificaciones cuantitativas y cualitativas en la plantilla del personal y la forma en la que, en su caso, afecten a los procesos de inserción; g) prestar la colaboración adecuada a los Servicios Públicos de Empleo así como a los Servicios Sociales de Base que participen en el proceso de inserción, a fin de que pueda realizarse el oportuno seguimiento [...] (Extracto del artículo 10 del Decreto 182/2008 del Gobierno
Vasco, donde se recogen las obligaciones de las empresas de inserción).

[...] e) prestación de servicios de acompañamiento social durante el proceso de inserción en la empresa, pudiendo intervenir, bien directamente, bien concertando dicha intervención con las propias empresas de inserción o con las entidades promotoras [...] (Extracto del artículo 23 del Decreto 182/2008 del Gobierno Vasco, donde se recogen las funciones de los servicios sociales de base).

En todo caso, el control auditor basado en objetivos implica la dificultad de que los objetivos cuantificables y consignables reglamentariamente no siempre coinciden con los indicadores de éxito -a menudo más vagos y difícilmente exportables de modo sistemático- que utilizan los mismos profesionales de las entidades sin ánimo de lucro ${ }^{9}$ del acompañamiento, o de las empresas. Aunque el objeto de este artículo se centra en la reglamentación, una de las líneas de trabajo abiertas a partir de las entrevistas en profundidad a los diferentes agentes implicados, recoge precisamente esas faltas de sintonía entre 'lo que hay que justificar' y lo que realmente se valora como objetivos de éxito. En definitiva, estamos ante una fuente de tensiones potenciales en la que pretendemos profundizar a lo largo de esta investigación.

\section{Conclusiones}

A lo largo de este artículo, hemos descrito cómo la legislación ha definido a las empresas de inserción social como un recurso socioeducativo funcional para una configuración del mercado de trabajo vinculada a los conceptos de flexibilidad y adaptabilidad. En un contexto en que las políticas sociales se han fragmentado, perdiendo su carácter redistributivo, esa funcionalidad se convierte en un factor que profundiza en la dualización social. De entrada, estas empresas pretenden ser un recurso para la inserción, lo que en una sociedad como la nuestra implica la transición al mercado laboral ordinario. Pero su enfoque compensatorio y el énfasis en la responsabilidad individual en la gestión de los riesgos provocan una dinámica que estabiliza a los vulnerables en la 'zona de inestabilidad'. Por supuesto, la resolución de este conflicto -las empresas de inserción como herramientas de inclusión o como reproductoras de la dualización social-implica considerar -lo estamos abordando en nuestro proyecto de investigación, pero va más allá de la intención de este artículo- las prácticas y discursos de los participantes en estas experiencias, y no sólo del discurso institucional consignado en la ley.

Somos conscientes (Marhuenda, Bernad y Navas, 2010; Marhuenda, 2009) de que esas prácticas

\footnotetext{
${ }_{9}$ Nos consta, no obstante que existen diferentes intentos de sistematizar estos 'indicadores cualitativos' sobre el desarrollo personal y social, llevados a cabo por entidades promotoras de empresas de inserción social. Parte de nuestro trabajo pretende profundizar en su elaboración y en el uso que se le dan en la práctica.
} 
generan en numerosas ocasiones dinámicas más inclusivas, cooperativas y críticas, de lo que plantea la normativa, a menudo actuando contra corriente, y en ocasiones desde la sintonía con recursos institucionales. Muchas se plantean la necesidad de superar las asimetrías y las dependencias que aquí citamos como riesgos. Y lo hacen con creatividad, desde la experiencia cotidiana en el trabajo, desde la definición más crítica de los procesos de formación y orientación laboral, desde procesos de mediación más potenciadores de la autonomía de los trabajadores y más participativos, así como desde la cooperación en red con otras entidades.

Pero igualmente es cierto que la definición normativa que hemos analizado delimita las condiciones de posibilidad de las empresas de inserción social, reforzando las dinámicas menos igualitaristas de éstas. Unas condiciones, además, fuertemente marcadas por la tensión entre el control administrativo -aun en sus formatos más flexibles o menos burocratizados- que puede entrar en conflicto con los objetivos de carácter más integrador de este tipo de empresas, incluso hasta imponerse a ellos.
Por otro lado, como hemos visto, la adaptación de la normativa autonómica a la estatal supone homogeneizar el recurso en los parámetros aquí destacados, independientemente de la tradición que cada autonomía haya desarrollado en este sector. Por supuesto, estamos convencidos de que las redes locales, las particularidades del tejido productivo y la organización de los servicios sociales permitirán modelos de intervención diferentes y más ajustados a cada realidad local. Pero en cualquier caso, la regulación aquí analizada establece unos límites y características comunes que atienden más a la funcionalidad ante el mercado de trabajo.

En definitiva, con este texto queremos señalar el riesgo de que el modo en que se están planteando las políticas sociolaborales potencie un tipo de cultura de la inserción que responsabiliza, en última instancia, a los más vulnerables de su situación, dejando de lado las condiciones estructurales que impiden que el trabajo sea realmente un factor que nos vincule socialmente y que nos permita acceder en igualdad de condiciones a una ciudadanía plena. 


\section{Referencias bibliográficas}

ALONSO, L. E. (2000): Trabajo y posmodernidad: el empleo débil, Madrid, Fundamentos.

- (1999): Trabajo y ciudadanía: estudios sobre la crisis de la sociedad salarial, Madrid, Trotta.

BERNAD, J. C.; MARTÍNEZ MORALES, I.; y MOLPECERES, M. A. (2011): "Trabajo, precariedad y ciudadanía. Las políticas sociolaborales en el contexto del desmantelamiento de la sociedad salarial”, en CÓRDOBA, A.; y MARTÍNEZ MORALES, I. (coords.): Trabajo, empleabilidad y vulnerabilidad social: condicionantes $y$ potencialidades de la integración a través de las empresas de inserción social, Valencia, Servicio de Publicaciones de la Universitat de València.

CASTEL, R. (1997): La metamorfosis de la cuestión social. Una crónica del salariado, Barcelona, Paidós.

CLAVER, N.; y VIDAL, I. (2004): Las empresas de inserción social por el trabajo en España. Síntesis resultados del proyecto PERSE. Junio 2004, CIES [rhttp://www.ameei.org/IMG/pdf/ eitrabajoenespana.pdf〉].

DEPARTAMENTO DE JUSTICIA, EMPLEO Y SEGURIDAD SOCIAL (2009) "Orden de 4 de mayo de 2009, del Consejero de Justicia, Empleo y Seguridad Social, por la que se regulan las ayudas para la creación y el sostenimiento de las empresas de inserción”, Boletín Oficial del País Vasco, noำ 98, 26-5-2009, [khttp://www.euskadi.net/bopv2/ datos/2009/05/0903002a.pdf>].
- (2008): “Decreto 182/2008, de 11 de noviembre, por el que se regula la calificación de empresas de inserción, se establece el procedimiento de acceso a las mismas y su registro", Boletín Oficial del País Vasco, n-0 225, 24-11-2011, págs. 28.250-28.264 [<http://www. gizartelan.ejgv.euskadi.net/bopv2/ datos/2008/11/0806515a.pdf>].

- (2001) “Decreto 305/2000, de 26 de diciembre, por el que se regula la calificación de las empresas de inserción, se establece el procedimiento de acceso a las mismas y se crea el registro de empresas de inserción”, Boletín Oficial del País Vasco, no 24, 2-2-2011, págs. 1.900-1.913 [khttp://www.euskadi.net/cgi-bin_k54/bopv_2 $0 ? c \& f=20010202 \& a=200100592\rangle]$.

FEDERACIÓN DE ASOCIACIONES EMPRESARIALES DE EMPRESAS DE INSERCIÓN (2003): Identificación y diagnóstico integral de las empresas de inserción en España, Madrid, Popular.

JEFATURA DEL ESTADO (2012): “Real Decreto-ley 3/2012, de 10 de febrero, de medidas urgentes para la reforma del mercado laboral", Boletín Oficial del Estado, n- 36, 11-2-2012, sec. I, pág. 12.48312.546 [shttp://www.boe.es/diario_boe/txt. php?id=BOE-A-2012-2076)].

- (2007): “Ley 44/2007, de 13 de diciembre, para la regulación del régimen de las empresas de inserción”, Boletín Oficial del Estado, n0 299, 14-12-2007, págs. 51.331-51.339 [khttp://www. boe.es/aeboe/consultas/bases_datos/doc. php?id=BOE-A-2007-21492)].

LLINARES, L.; CÓRDOBA, A.; y ZACARÉS, J. J. (2011): "La medida de la empleabilidad desde las empresas de inserción social”, en CÓRDOBA, A.; y MARTÍNEZ MORALES, I. (coords.), Trabajo, empleabilidad y vulnerabilidad social: condicionantes y potencialidades de la integración a través de las empresas de inserción social, Valencia, Servicio de Publicaciones de la Universitat de València. 
MARHUENDA, F. (2009): "Formación y empleabilidad en las empresas de inserción social”, en $V$ Congreso Internacional de Formación para el Trabajo. 24, 25 y 26 de junio de 2009, Granada.

MARHUENDA, F.; BERNAD, J. C.; y NAVAS, A (2010): “La práctica en empresas como estrategia de enseñanza e inserción laboral: las empresas de inserción social", Revista de Educación, no 351, págs. 139-161 [<http://www.revistaeducacion. mec.es/re351/re351_06.pdf >].

MARTÍNEZ MORALES, I.; BERNAD, J. C.; y NAVAS, A. (2011): "¿Itinerarios hacia una ciudadanía precaria? Critica de la regulación de las empresas de inserción social”, en CÓRDOBA, A.; y MARTíNEZ MORALES, I. (coords.), Trabajo, empleabilidad y vulnerabilidad social: condicionantes y potencialidades de la integración a través de las empresas de inserción social, Valencia, Servicio de Publicaciones de la Universitat de València.

NYSSENS, M. (ed.) [2006]: Social Enterprise. At the Crossroads of Market, Public Policies and Civil Society, London, Routldege.

PAUGAM, S. (2000): Le salarié de la précarité, París, PUF.

PRESIDÈNCIA DE LA GENERALITAT (2007): “Llei 1/2007, de 5 de febrer, de la Generalitat, per la qual es regulen les empreses d'inserció per a fomentar la inclusió social a la Comunitat Valenciana”, Diari Oficial de la Comunitat Valenciana, nํ⒌447, 9-2-2007, págs. 6.653-6.660 [khttp:// www.docv.gva.es/datos/2007/02/09/pdf/ doc/2007_1587.pdf>].

PRESIDÈNCIA DE LA GENERALITAT (2002): “Llei 27/2002, de 20 de desembre, sobre mesures legislatives per a regular les empreses d'inserció sociolaboral”, Diari Oficial de la Generalitat de Catalunya, nํ⒊793, 3-1-2003, págs. 53-56 [rhttp://portaldogc.gencat.cat/utilsEADOP/ AppJava/PdfProviderServlet?documentld=3081 41\&type $=01$ \&language $=$ ca_ES〉].

RODRÍGUEZ CABRERO, G. (2004): El Estado del bienestar en España: debates, desarrollos y retos, Madrid, Fundamentos.

- (1998): "Política social y pobreza”, en AYALA, L. et al., Las condiciones de vida de la población pobre en España, Madrid, Fundación FOESSA.

SENNETT, R. (2000): La corrosión del carácter, Barcelona, Anagrama.

VECIANA, P. (coord.) [2007]: Las empresas de inserción en España, Fundación Un Sol Món, Obra Social Caixa Catalunya [<http://obrasocial. catalunyacaixa.com/osocial/idiomes/2/fitxers/ solidaritat/empresesin_cas.pdfı]. 



\title{
La medida de la empleabilidad en las empresas de inserción en el País Vasco: de la exclusión a la inserción sociolaboral
}

\author{
Lucía I. Llinares Insa
}

Departamento de Psicología Social, Facultad de Psicología, Universitat de València <lucia.llinares@uv.es>

\author{
Ana I. Córdoba Iñesta \\ Departamento de Psicología Evolutiva y de la Educación, Facultad de Psicología, \\ Universitat de València
}

\section{Juan José Zacarés González}

Departamento de Psicología Evolutiva y de la Educación, Facultad de Psicología, Universitat de València

\begin{abstract}
Azterlan honetan aurkezten da Euskadiko gizarteratzeko enpresen ibilbideetan agertzen diren enplegagarritasunerako politikaren inguruko ikusmoldeak. Gaiak garrantzia du laneko bazterketa bidezko egiten laguntzen duelako. Azken batean, banakoaren arduraren arloko gaia baita ahulezia bizi duten kolektiboen egoera hori; izan ere, gaitasun eta trebezia batzuen gabeziek sortzen baitute langabezia haztaraztea. Errealitatearen interpretazio hori baliabide gertatzen da gizarte-ekintzaren gidalerro eta ebaluazioen oinarri gisara. Lan hori burutzeko aztertu dira gizarteratzeko enpresetan enplegagarritasunaren elementuak ebaluatzeko erabiltzen diren tresnak. Artikulu honen bidez, gogoeta piztu nahi da errealitatearen interpretazio horren eta egunerokoan duen berroren eraginaz; eta, horrela, partaide izan nahi da laneratzea praktikan gidatzen duen maila sinboliko hori zuzentzeko gizarteratzeko enpresa horiek elkarlanean egindako ahaleginean.
\end{abstract}

\section{HITZ-GAKOAK:}

laneratze eta gizarteratzea, sartzeko ibilbideak, enplegagarritasuna, gizarte-bazterketa, gizarteratzeko enpresa.
Este artículo presenta un análisis de las concepciones de la empleabilidad que están presentes en los itinerarios de las empresas de inserción del País Vasco. Su importancia reside en ser el constructo que justifica la exclusión laboral: la situación en la que se encuentran los colectivos vulnerables es responsabilidad individual, ya que el desempleo es causa de la falta de determinadas competencias y habilidades. Esta interpretación de la realidad sirve de eje de evaluación y guía para la acción social. Para elaborar este trabajo, se han analizado los elementos de empleabilidad que se evalúan en los instrumentos utilizados en las empresas de inserción. El artículo trata de suscitar una reflexión sobre los modos de interpretar la realidad y su influencia en la práctica diaria, y participar así en la acción conjunta, emprendida por las empresas de inserción, dirigida a corregir el mundo simbólico que rige la práctica de la inserción laboral.

\section{Palabras ClaVe:}

inserción sociolaboral, itinerarios de inserción, empleabilidad, exclusión social, empresa de inserción. 


\section{Introducción}

Estamos de acuerdo con Álvarez-Uría cuando dice que, desde finales de los años setenta, la retórica neoliberal se ha impuesto de forma acrítica "como si se tratara de una verdad revelada" (2002: 15). Ésta tiene un nombre clave, la empleabilidad, y una repercusión inmediata, 'el aumento de la exclusión'. Ahora bien, el discurso de la empleabilidad no se introduce por implosión; se desarrolla en un marco laboral cambiante que pasa del Estado del bienestar a la era neoliberal, a través de etapas sucesivas, pero intrusivas, en las lógicas sociales y en las organización de la vida de las personas. Estos cambios paulatinos y continuos se constatan en las políticas económicas y en la organización de las empresas, y derivan en cambios en el mercado de trabajo y en las bases que los sustentan. Dichos cambios, por supuesto, tienen como elemento discursivo la empleabilidad.

La empleabilidad se puede analizar desde diferentes perspectivas (Llinares, Córdoba y Zacarés, 2011). Desde una perspectiva posibilista, se refiere a la capacidad que tienen algunas personas para obtener y mantener el empleo, cambiar de empleo o progresar en la misma organización (Campos Ríos, 2003; Finn, 2000; Formichella y London, 2005; McQuaid y Lyndsay, 2005). Esta visión convierte a la persona en responsable de su situación sociolaboral e implica dotar a la persona de las competencias dinámicas consideradas relevantes en el mundo laboral, y de estrategias de búsqueda de empleo. Por tanto, desde esta perspectiva, las desigualdades se interpretan como incapacidad para aprovechar las oportunidades laborales, y no como desigualdad real de posición social (Santos Ortega, 2003). El marco que lo acoge se fundamenta en la reducción de los niveles de protección y reglamentación laboral legal, y en el uso libre y económico de los recursos humanos, todo ello sobre la base de la necesidad del ajuste flexible y competitivo de las empresas (Brunet y Pastor, 2003). El fin de las políticas públicas se dirige, pues, a incrementar la seguridad del beneficio mercantil, la competitividad del tejido productivo, la adaptación del capital humano y la formación tecnológica (Mingione, 1994; Prieto, 1999b). Las políticas de ocupación, por su parte, se basan en el uso libre y lo más económico posible de los recursos humanos (Alaluf y Martínez, 1999; Prieto, 1999a). En ellas, la producción de bienes económicos pasa a ser el objetivo prioritario (Noguera, 2002).

La empleabilidad también genera un nuevo marco en las relaciones laborales empresario-trabajador. De este modo, al recaer la responsabilidad de su situación profesional en el trabajador, la carrera laboral, que anteriormente se concebía como la formación en un único oficio y en una única empresa, desaparece y pasa a considerarse clave la libertad del trabajador en la construcción de su futuro (Clarke y Patrickson, 2008). Es la persona la que acumula capital humano a partir de una decisión individual de optimización y de un balance entre los costes y los beneficios; y es ella quien tiene la responsabilidad de generar su currículo (Kippenberger, 2000) y de mejorar su empleabilidad (Fugate, Kinicki y Ashforth, 2004). Así, la autogestión de su carrera proporciona al trabajador un reparto justo para el futuro y mayor probabilidad de éxito (Baruch y Peiperl, 2000).

Ahora bien, desde una perspectiva alternativa, la perspectiva crítica, esto es una falacia en un contexto en el que el mercado laboral aparece segmentado (Casal, 2003). Actualmente, nos encontramos con un mercado primario que ofrece empleos estables y condiciones aceptables de trabajo y promoción, porque se mantienen las antiguas relaciones laborales en vías de extinción, aunque los recursos humanos tienen exceso de trabajo. Junto a él, existe un mercado secundario, que se caracteriza por ofrecer puestos de trabajo precarios e inestables, y malas condiciones de trabajo (De la Fuente y González-Castro, 2009). Tal y como indica Pérez (2003), la diferencia de pertenencia a uno u otro segmento no depende de la inversión en capital humano, sino de otros factores sociales que determinan la inclusión. La tendencia es la desaparición del primero en vías a la consecución del segundo, y la primacía de la movilidad laboral entre empresas y, por tanto, el continuo cambio de empleo (De Cuyper et al., 2011; Forrier, Sels y Stynen, 2009; Rothery y Roberstson, 1995) gracias a las nuevas modalidades de ocupación temporal y de facilidad de despido (Alaluf y Martínez, 1999; Prieto, 1999). Esto supone un cambio en las condiciones de contratación en varios sentidos (Añez, 2004; Capelli, 1995; Harrison, 1998; Macía, 2003; Osterman, 1994): por una parte, se reduce el salario del capital productivo y, por otra, las contrataciones se regulan por las necesidades de la empresa. Junto a ello, nos encontramos con otra contradicción: para Tezanos (2001), el proceso de degradación del trabajo no sólo supone el intercambio de trabajadores en las empresas y el empobrecimiento de la población, sino también el aumento del desempleo estructural de larga duración.

La perspectiva crítica también pone de manifiesto que, desde la perspectiva posibilista, que es la que legitima el sistema laboral actual, el problema del desempleo se percibe como la falta de ajuste entre la oferta de trabajo y las características de los demandantes de empleo. Así pues, desde esta última perspectiva la empleabilidad legitima lo que hace el mercado, y lo hace sobre la base de la responsabilidad personal de la situación social que viven las personas. Es, pues, el mérito de cada individuo, y no un proceso social, el que configura la representación social de las diferencias laborales de las personas, lo que justifica que los salarios se determinen sobre la base de las aportaciones del trabajador y, por tanto, sobre sus capacidades (Thurow, 2000). Esta diferenciación es percibida por la perspectiva crítica como debilitadora y tiende a excluir a parte de la población del sistema normalizado (Luttwak, 200o). Acrecienta, además, las dificultades de inserción laboral en el mercado reglado de los grupos poblacionales desfavorecidos y en riesgo de exclusión social, ya que los más desfavorecidos tienen menos oportunidades 
para adquirir competencias de empleabilidad, lo que determina que continúen en las capas más pobres y no sean empleables (Weinberg, 2004).

Castells (2001) conceptualiza la exclusión social como un proceso por el cual a ciertos individuos y grupos se les impide acceder a unas posiciones sociales. De esta forma, ciertas personas o grupos son excluidos de determinadas redes sociales, económicas o culturales (De la Fuente y GonzálezCastro, 2009). En este contexto, se diferencia entre ser empleable y no empleable, y esta bipolaridad etiqueta a las personas en función de su capacidad para conseguir un empleo (Finn, 2000; Van der Heijden y Van der Heijden, 2005).

Si el fin último es conseguir y mantener el empleo, y éste se debe a las competencias y habilidades de la persona, desde el discurso posibilista y legitimador del sistema laboral actual, la inversión que se realice para aumentar la empleabilidad hará disminuir las tasas de desempleo (Weinberg, 2004). Ello conlleva la generación de acciones e intervenciones individualizadas destinadas a aumentar la empleabilidad de los grupos desfavorecidos, a través de una combinación de actividades de formación y búsqueda de empleo (McQuaid y Lindsay, 2005). Es por ello por lo que, actualmente, la empleabilidad no sólo ocupa un lugar central en las políticas de mercado, sino que es uno de los cuatro pilares de la Estrategia Europea de Empleo (Comisión Europea, 1999). La Comisión Europea tiene el objetivo de promocionar el capital humano por medio de medidas activas y preventivas para los desempleados (Comisión Europea, 2003). Se parte de la creencia de que la empleabilidad que tiene una persona se debe a la inversión social que le permite acceder a ellas y, por tanto, es responsabilidad del sujeto defender ese patrimonio (Weinberg, 2004). La finalidad de la intervención, por tanto, es la integración/inserción sociolaboral con el fin de garantizar una participación activa en la vida social.

La inserción laboral es un territorio muy amplio y difuso: contempla todos los procesos, las herramientas, los análisis del mercado laboral y las metodologías de acceso al empleo que se dirigen a las personas que desean participar en el mundo laboral (De la Fuente y González-Castro, 2009). Los servicios sociales y algunas asociaciones sin ánimo de lucro ofrecen determinados colectivos a profesionales (psicólogos, pedagogos, educadores sociales y otros expertos) que analizan la empleabilidad de los desempleados y proponen programas de intervención, combinando medidas básicas de socialización, cursos de formación, periodos de prácticas o experiencias ocupacionales (Santos Ortega, 2003). Una de las iniciativas actuales más demandadas para el periodo formativo-laboral profesional previo, y que se percibe como clave en la sociedad actual, por su aportación a la inserción sociolaboral, es la empresa de inserción.

Las empresas de inserción llevan a cabo un acompañamiento individualizado del sujeto en la inserción laboral de las personas (González Barriga, 2003).
Son empresas que realizan una actividad económica planificada en el mercado de bienes y servicios, con la finalidad de proporcionar puestos de trabajo a personas en situación o riesgo de exclusión social (González Barriga, 2003); su objetivo es contratar a personas con un nivel de empleabilidad básico y suficiente para desempeñar un puesto de trabajo, pero no suficiente para su inclusión en el mercado de trabajo normalizado (Marhuenda, Bernad y Navas, 2010). Son, pues, un contexto propicio para trabajar la formación en un oficio concreto, y la interiorización y el desarrollo de los indicadores de empleabilidad requeridos en el mundo laboral normalizado, considerados como elementos indispensables de la normalidad laboral actual (Marhuenda, 2009; Santos Ortega, 2003).

\section{El estudio sobre los indicadores de empleabilidad}

Al igual que cualquier otra entidad que pretende la inserción sociolaboral, las empresas de inserción evalúan la empleabilidad de las personas y fijan itinerarios de formación personalizados. En ellas, la empleabilidad se mide en tres momentos: acogida, seguimiento, y transición o tránsito al mercado laboral ordinario.

- La fase de acogida, también denominada de incorporación o de evaluación inicial, es una fase de comunicación y conocimiento de expectativas mutuas entre el trabajador y la empresa. En ella se lleva a cabo la valoración inicial, dentro de la cual se enmarca el diagnóstico de empleabilidad. A partir de diversos procedimientos de evaluación (entrevistas, dinámicas grupales, aplicación de cuestionarios y pruebas estandarizadas, y observación, entre otras), se elabora un itinerario de inserción personalizado. De la evaluación anterior surge una propuesta de intervención, que trata de incidir en las causas, más que en los síntomas, de las limitaciones o carencias detectadas. Esta propuesta se concreta en el diseño, junto con el trabajador, de su propio itinerario de inserción.

- La fase de seguimiento, o de permanencia y acompañamiento en la empresa de inserción, es la de mayor duración y tiene como objetivo acompañar a la persona en un puesto de trabajo real. En ella se lleva a cabo una evaluación continua de la actuación en el trabajo, y de revisión y mejora del plan de trabajo trazado.

- Por último, el tercer momento es el de transición al mercado laboral ordinario, o de finalización y apoyo a la inserción sociolaboral. En él se evalúa si se han alcanzado gran parte de los objetivos acordados en el plan de trabajo y se determina si el proceso de inserción ha finalizado. Ésta es una de las fases más complejas si se producen resistencias por parte del trabajador a abandonar la empresa. Tales resistencias pueden interpretarse tanto como temores del propio trabajador hacia un entorno ‘menos protegido’ como, paradójica- 
mente, un indicador de buen funcionamiento de la empresa de inserción, al ajustarse a las necesidades personales del trabajador. Resulta adecuado asumir dichas resistencias como una nueva posibilidad para el trabajo educativo, pues exige revisar las expectativas y la empleabilidad inicial, y compararlas con la representación que la persona en inserción y que los agentes sociales de la empresa se hacen de su situación previa a la salida de la empresa de inserción. Las concepciones teóricas y las representaciones sobre la empleabilidad y los elementos que la constituyen que tienen estos agentes sociales son el objetivo del trabajo que aquí se presenta (Zacarés et al., 2011).

Para analizar las representaciones sobre la empleabilidad de los agentes sociales implicados en las empresas de inserción, se han identificado y clasificado los elementos de empleabilidad que se evalúan en sus instrumentos, a modo de indicadores. Como preparación previa del I Encuentro Estatal de Trabajadores/as Acompañantes, Técnicos/as de Acompañamiento y Trabajadores/as de Producción, organizado por la Federación de Asociaciones Empresariales de Empresas de Inserción (FAEDEI) y la Asociación Española de Recuperadores de Economía Social y Solidaria (AERESS), se solicitó a las empresas de inserción participantes diversos documentos sobre su práctica profesional. Entre dichos documentos, se hallaban los instrumentos y protocolos que cada empresa de inserción aplicaba en las tres fases del itinerario de

Gráfico 1. Distribución de las empresas de inserción de la muestra, según comunidad autónoma de procedencia (\%)

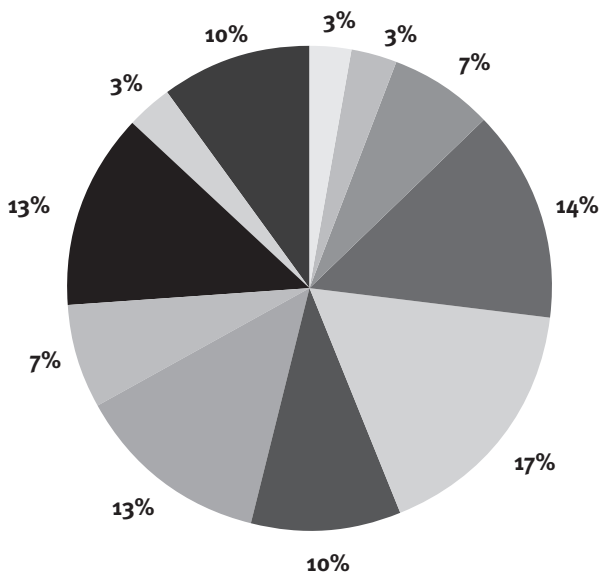
La Rioja
Cataluña
Principado de Asturias
Illes Balears
Castilla-La Mancha
Canarias
Com. Valenciana
Región de Murcia
Castilla-León
País Vasco
Com. de Madrid

Fuente: Zacarés et al. (2011). inserción. FAEDEI y AERESS contactaron así con sus entidades asociadas y gestionaron la recogida de los instrumentos demandados, para su posterior envío al equipo de investigación de la Universitat de València. Sesenta de las empresas de inserción contactadas enviaron algún tipo de información, si bien únicamente se recibieron instrumentos de valoración de la mitad de ellas. En el Gráfico 1, se presentan las treinta empresas de las que se recogieron instrumentos, distribuidas por comunidades autónomas.

Todos los instrumentos recogidos se solicitaron a las empresas, pidiéndoles al mismo tiempo que los enmarcasen en una de las fases generales del itinerario de inserción. Los instrumentos de acogida se refieren a todo tipo de instrumentos utilizados en el momento de ingreso del trabajador de inserción en la empresa. Los instrumentos de seguimiento son aquellos utilizados con el fin de evaluar el proceso que sigue cada trabajador de inserción durante el periodo de permanencia en la empresa. Y, por último, los instrumentos de transición se refieren a los utilizados para evaluar el proceso seguido, así como la adecuación final del trabajador a la empresa ordinaria (Zacarés et al., 2011). En la Tabla 1 se presentan los instrumentos recogidos, según las distintas fases, en función de la comunidad autónoma de procedencia.

Se utilizó el Instrumento para el Análisis de los Indicadores de Empleabilidad (IPAIE), de Llinares, Cordoba y Zacarés (2011). Esta herramienta -creada a partir de la estructuración realizada, entre otros, por McQuaid y Lindsay (2005), y Navarro et al. (2008)-, presenta y clasifica todos los indicadores de la empleabilidad que, hasta el momento, se han presentado en la literatura sobre el tema. Tal y como puede observarse en el Cuadro 1, los indicadores de empleabilidad se estructuran en torno a tres ejes: factores individuales, características personales y factores externos.

Los factores individuales recogen todos aquellos indicadores que se refieren a variables actitudinales o aptitudinales que están relacionadas con las competencias laborales. En la categoría de circunstancias personales, se recogen aquellos aspectos sociofamiliares que inciden en los factores individuales y que determinan la capacidad de integración de la persona en el mundo laboral. Los factores externos incluyen indicadores del mercado de trabajo de cada contexto concreto, así como dimensiones del macrosistema que inciden en la consecución y mantenimiento del empleo.

En el estudio llevado a cabo en Llinares, Córdoba y Zacarés (2011), se analizaron todos los instrumentos que han desarrollado las empresas de inserción españolas anteriormente descritos. En este estudio se ha analizado qué se mide y desde qué perspectiva en los instrumentos elaborados por empresas localizadas en el País Vasco; se pretende, pues, profundizar en el ámbito de la inserción laboral en un territorio que ha mostrado una especial sensibilidad social y política al respecto. 
Tabla 1. Instrumentos analizados, por comunidad autónoma de origen y fase a la que se asignaron

\begin{tabular}{|c|c|c|c|c|c|c|}
\hline & \multicolumn{5}{|c|}{ Instrumentos } & \multirow{3}{*}{ Empresas de inserción } \\
\hline & \multicolumn{3}{|c|}{ Por fase } & \multirow{2}{*}{ Protocolos } & \multirow{2}{*}{ Total } & \\
\hline & Acogida & Seguimiento & Final & & & \\
\hline Canarias & 8 & 8 & 2 & 2 & 20 & 4 \\
\hline Castilla-La Mancha & 3 & 15 & 2 & 7 & 27 & 2 \\
\hline Castilla-León & 15 & 7 & 4 & 5 & 31 & 5 \\
\hline Cataluña & 18 & 18 & 5 & 6 & 47 & 4 \\
\hline Com. de Madrid & 5 & 5 & 3 & 1 & 14 & 3 \\
\hline Com. Valenciana & 16 & 25 & 2 & 2 & 45 & 4 \\
\hline Illes Balears & 6 & 8 & 0 & 0 & 14 & 2 \\
\hline La Rioja & 3 & 6 & 1 & 2 & 12 & 1 \\
\hline País Vasco & 4 & 6 & 1 & 0 & 11 & 3 \\
\hline Principado de Asturias & 4 & 9 & 1 & 4 & 18 & 1 \\
\hline Región de Murcia & 4 & 5 & 1 & 0 & 10 & 1 \\
\hline Total & 86 & 112 & 22 & 29 & 249 & 30 \\
\hline
\end{tabular}

Fuente: Zacarés et al. (2011).

Cuadro 1. Indicadores de la empleabilidad: ejes estructuradores e indicadores primarios

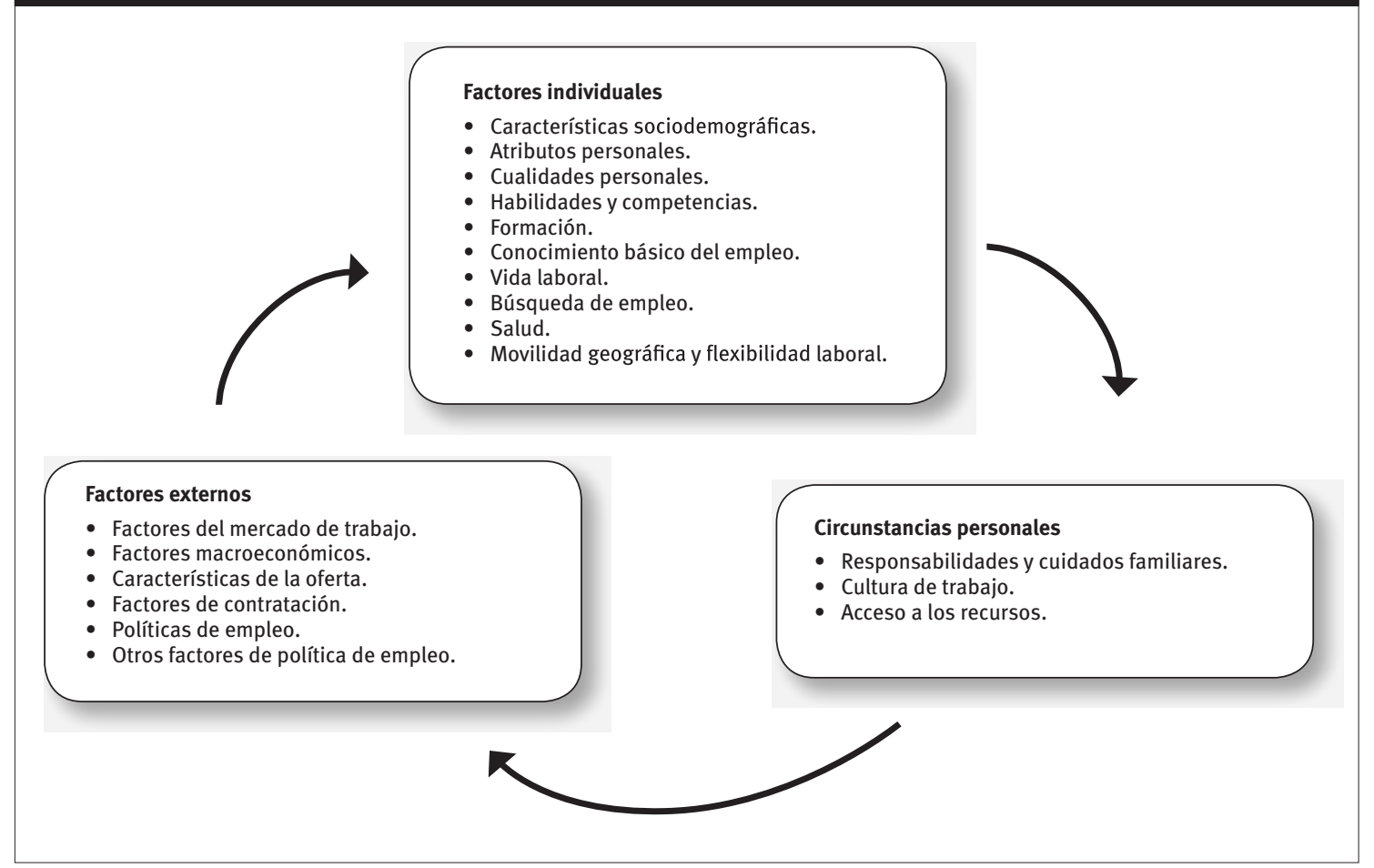

Fuente: Elaboración propia.

\section{3. ¿Qué medimos cuando evaluamos la empleabilidad?}

La primera pregunta que nos planteamos en el análisis de la medida de la empleabilidad hace referencia a qué indicadores tienen en cuenta las personas que trabajan en las empresas de inserción cuando la evalúan. El Cuadro 2 muestra los porcentajes de indicadores en función de los ejes estructuradores para todos los instrumentos que se remitieron desde las empresas de inserción localizadas en el País Vasco, sin tener en cuenta las fases de inserción. Cabe señalar que, al igual que sucede en el resto de España, los instrumentos con los que se lleva a cabo el análisis de la empleabilidad miden, sobre todo, factores individuales y, en menor medida, circunstancias personales. 


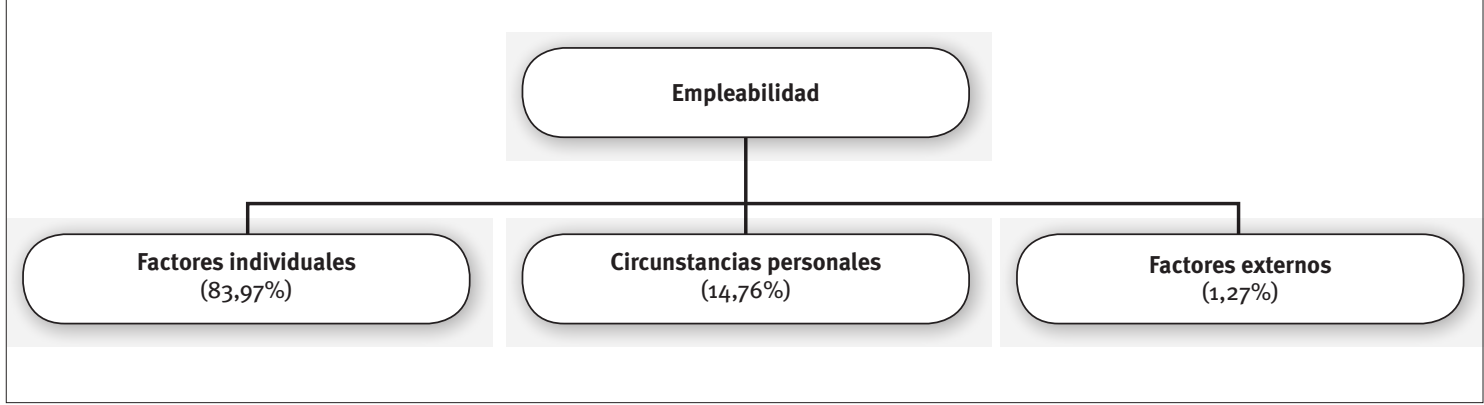

Fuente: Elaboración propia.

El mayor porcentaje referido a los factores individuales muestra que lo que medimos en nuestra población en riesgo de exclusión son, sobre todo, aspectos relativos al sujeto. De entre ellos, tal y como muestran los Gráficos 2 y 3, se analizan las habilidades y competencias, y los atributos personales. La categoría de habilidades y competencias es la más amplia dentro de los factores individuales. Los aspectos más analizados por las distintas empresas en esta fase de acogida son, al igual que el resto de empresas de inserción de España, las habilidades y competencias personales generales, así como las habilidades sociales. Los indicadores que más se tienen en cuenta en las habilidades y competencias personales generales son la iniciativa, la independencia y la autoorganización (en la gestión del tiempo y las tareas). Con respecto a las habilidades sociales, se miden, sobre todo, el trabajo en equipo, la aceptación de críticas, las habilidades sociales básicas de comunicación interpersonal y la gestión del conflicto.

Con respecto a la categoría de atributos personales, cabe señalar que no es tan amplia como la de habilidades y competencias, pero recoge más o menos el $19 \%$ de los elementos que se preguntan para evaluar la empleabilidad. En ella, las cualidades personales son las que aparecen en mayor medida en los instrumentos de evaluación y, entre éstas, cabe destacar la autoestima, la tolerancia y el respeto, la tolerancia al estrés y la frustración, y la responsabilidad.

La categoría de características sociodemográficas está presente en casi todos los cuestionarios y tiene en cuenta indicadores que preguntan, sobre todo, por la edad, el sexo, la nacionalidad, el estado civil y la situación legal administrativa. Aunque en menor grado, también parece relevante para la medida de la empleabilidad las cuestiones relativas a: a) la salud, sobre todo en lo que concierne a salud física y dependencias; b) la formación académica reglada y no reglada; c) el conocimiento básico del empleo, sobre todo en lo que hace referencia a las habilidades profesionales específicas; y d) las técnicas de búsqueda de empleo. Menos relevante, aunque se ha tenido en cuenta, parece resultar la vida laboral. No obstante, sí se consideran la experiencia laboral en el mercado normalizado, la movilidad geográfica, la flexibilidad laboral y la disponibilidad de la persona.

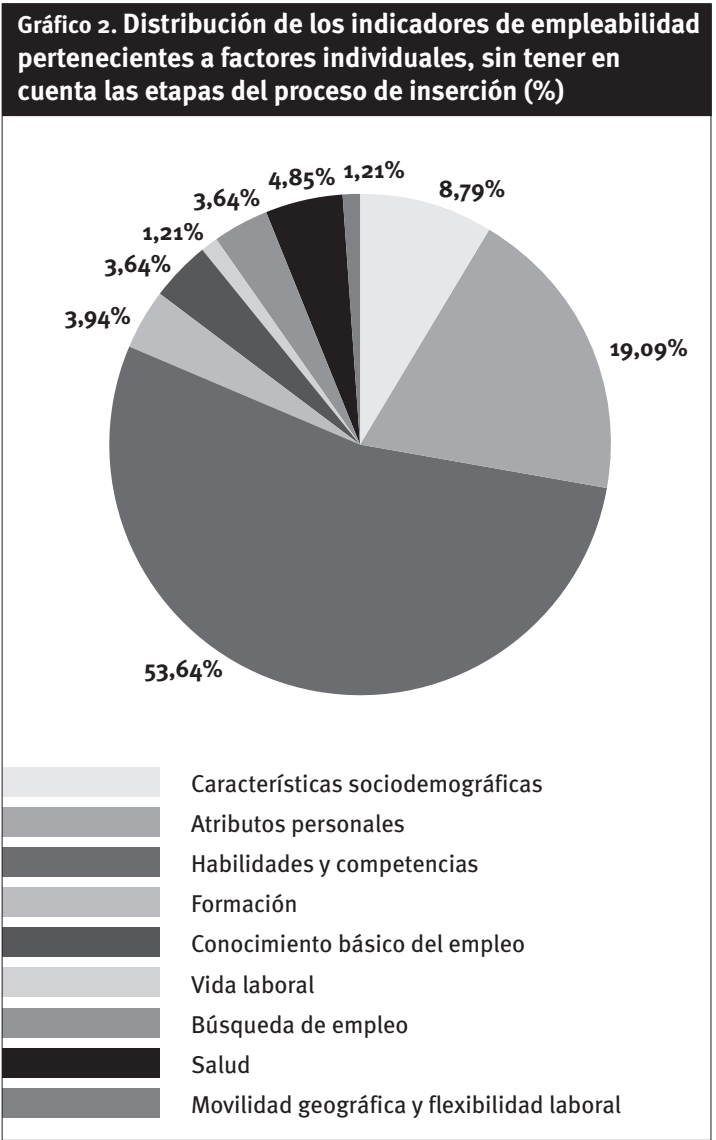

Fuente: Elaboración propia.

Tal y como se ha comentado anteriormente, en las empresas de inserción la empleabilidad se mide en tres momentos que tienen como telón de fondo las fases generales del itinerario de inserción (acogida, seguimiento, y transición o tránsito al mercado laboral ordinario). Resulta interesante observar que, en la fase de acogida, cuando se lleva a cabo la valoración inicial que incluye el diagnóstico de empleabilidad, hay más dispersión de indicadores, lo que nos muestra que se evalúan aspectos muy diversos de la persona. Sin embargo, cabe resaltar la gran cantidad de habilidades y competencias que resultan relevantes para conocerla. 
Fuente: Elaboración propia.

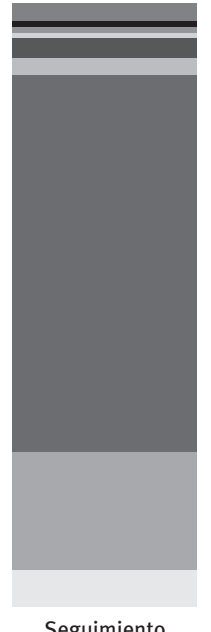

Seguimiento

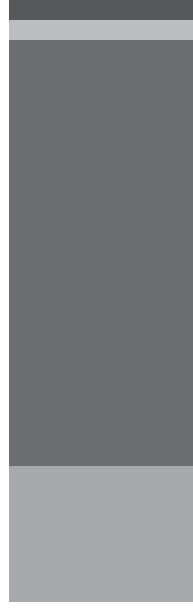

Evaluación

Características sociodemográficas

Atributos personales

Habilidades y competencias

Formación

Conocimiento básico del empleo

Vida laboral

Búsqueda de empleo

Salud

Movilidad geográfica y flexibilidad laboral

El Gráfico 3 también nos muestra un hecho muy curioso: en la fase de seguimiento, se acompaña al trabajador en el desempeño de un puesto de trabajo; en las empresas de inserción, esto supone su capacitación laboral, pero también personal y social, y, por tanto, el seguimiento de la empleabilidad. Como puede observarse, los instrumentos creados a tal efecto por las entidades se centran, sobre todo, en habilidades y competencias. Aunque en esta fase también tienen presencia otros indicadores generales, casi el $83 \%$ de ellos se aglutinan en habilidades, competencias y atributos personales. Lo mismo sucede en la fase de transición. En ésta, los instrumentos valoran la empleabilidad del trabajador para su incorporación en una empresa en el mercado laboral ordinario, la cual parece depender de las habilidades y competencias (71\%) y, también en parte, de los atributos personales (22,6\%).

Las circunstancias personales como indicadores que completan la medida de la empleabilidad incluyen todos aquellos aspectos que repercuten en la persona, condicionando su posición en el mundo laboral, pero que no son propios de ella misma. Tal y como se puede observar en la Tabla 2, el acceso a los recursos es el elemento más relevante de las circunstancias personales en cuanto a la medida de la empleabilidad se refiere.

De entre los aspectos considerados relevantes en la valoración de la empleabilidad, cabe resaltar la importancia del acceso a redes de apoyo, y la variedad y número de éstas. Además, se tiene en cuenta la situación económica y, en concreto, se pregunta por el acceso a fuentes formales/informales de apoyo financiero (prestaciones sociales). El transporte y la vivienda también son considerados importantes para el acceso al empleo. En cuanto al elemento 'hijos', se tiene en cuenta en gran parte de los cuestionarios como una categoría de las circunstancias personales que condiciona la empleabilidad. No sucede lo mismo, por ejemplo, con las cargas familiares de padres ancianos, ni se presta especial atención a la estructura familiar.

Con respecto a los factores externos, y tal y como muestra la Tabla 3, cabe señalar que las empresas de inserción no los consideran en la valoración inicial de la empleabilidad. Los aspectos que se han tenido en cuenta en uno de los cuestionarios hacen referencia a la remuneración y a las condiciones de trabajo. 
Tabla 2. Frecuencias de los indicadores que pertenecen a la categoría de circunstancias personales

\begin{tabular}{l|l|c|c|c|c}
\cline { 2 - 5 } & \multicolumn{1}{|c|}{ Aspectos más relevantes } & Total & \multicolumn{2}{c}{ Fases } \\
\cline { 4 - 6 } & & & Acogida & Seguimiento & Evaluación \\
\hline $\begin{array}{l}\text { Responsabilidades, cuidados } \\
\text { familiares }\end{array}$ & $\bullet$ Hijos. & 10 & 7 & 3 & 0 \\
\hline Cultura del trabajo & & 0 & 0 & 0 & 0 \\
\hline Acceso a recursos & & 24 & 24 & 0 & 0 \\
\hline Transporte y vivienda & $\begin{array}{l}\text { - Régimen vivienda. } \\
\text { - Acceso a transporte privado o } \\
\text { fácilmente disponible. }\end{array}$ & 7 & 7 & 0 & 0 \\
\hline Situación económica & $\begin{array}{l}\text { - Acceso a fuentes formales/informales } \\
\text { de apoyo financiero. }\end{array}$ & 8 & 8 & & 0 \\
\hline Apoyo social & $\begin{array}{l}\text { - Acceso a redes de apoyo. } \\
\text { Número, variedad y estado de las redes } \\
\text { de apoyo. }\end{array}$ & 9 & 9 & & 0 \\
\hline
\end{tabular}

Fuente: Elaboración propia.

Tabla 3. Frecuencias de los indicadores que pertenecen a la categoría de factores externos

\begin{tabular}{|c|c|c|c|c|c|}
\hline & \multirow{2}{*}{ Aspectos más relevantes } & \multirow{2}{*}{ Total } & \multicolumn{3}{|c|}{ Fases } \\
\hline & & & Acogida & Seguimiento & Evaluación \\
\hline Factores del mercado de trabajo & & 0 & 0 & 0 & 0 \\
\hline Factores macroeconómicos & & 0 & 0 & 0 & 0 \\
\hline Características de la oferta & $\begin{array}{l}\text { - Remuneración. } \\
\text { - Condiciones del empleo. } \\
\text { - Horas de trabajo y turnos. }\end{array}$ & 4 & 0 & 4 & 0 \\
\hline Factores de contratación & & 0 & 0 & 0 & 0 \\
\hline Políticas de empleo & & 1 & 1 & 0 & 0 \\
\hline Otros factores de política de empleo & & 0 & 0 & 0 & 0 \\
\hline
\end{tabular}

Fuente: Elaboración propia.

Hasta el momento, se ha llevado a cabo un análisis en función de las categorías en las que se clasifican los indicadores de empleabilidad; con ello conseguimos saber qué cualidades debe poseer una persona empleable para los profesionales que trabajan en las empresas de inserción. Ahora bien, para conocer el núcleo central de la representación de la empleabilidad, necesitamos examinar los elementos de la empleabilidad en los que la mayor parte coinciden. Para ello, se han estudiado los indicadores que tienen una incidencia superior al $65 \%$. Si se tienen en cuenta los indicadores más utilizados por la mayor parte de las empresas, cabe señalar que, como se observa en el Cuadro 3, los cuestionarios coinciden en valorar aspectos individuales del sujeto. La mayor parte de ellos consideran la autoestima, la iniciativa, el actuar de forma autónoma, el trabajo en equipo y las habilidades profesionales específicas como elementos clave de la empleabilidad. Más del $80 \%$ de ellos también resaltan la importancia de la tolerancia al estrés y la frustración, la tolerancia y el respecto, la autoorganización, la aceptación de críticas y el aprender a aprender. También resultan relevantes en la medida de la empleabilidad la edad, el sexo, el cuidado personal, la autoeficacia, la capacidad de lectoescritura y de comunicación oral y escrita, la autodisciplina, la perseverancia, la proactividad, las habilidades sociales básicas de comunicación interpersonal y la asertividad, la gestión positiva del conflicto, la toma de decisiones, y las cualificaciones académicas y profesionales formales.

Así pues, parece que los profesionales que trabajan en las empresas de inserción tienen una representación de la empleabilidad como competencia individual cuyos indicadores principales y comunes son algunas habilidades y competencias generales (dentro de las que se encuentran, sorprendentemente, la iniciativa y la autonomía, habilidades sociales (se observa la actual importancia del trabajo en equipo en nuestro modo de comprender la realidad laboral) y algo de conocimiento básico del empleo, en concreto, las habilidades profesionales específicas. Este último contenido del núcleo central de la representación de la empleabilidad dista mucho de los anteriores indicadores de la empleabilidad. Mientras iniciativa y autonomía son básicas para la adaptación a puestos de trabajo cambiantes y difusos, el conocimiento concreto de un puesto de trabajo resulta crucial en la etapa del Estado del bienestar en donde se pretendía el ajuste entre personas y puestos de trabajo. De esta forma, se observa cómo las lógicas legitimadoras de la nueva forma de comprender el trabajo y la situación social de la persona nos inducen a tener discursos cuyos elementos pueden llegar a ser contradictorios, porque su universo simbólico no excluye los contenidos de las anteriores imágenes de los requerimientos laborales. 
Características sociodemográficas

- Edad.

- Sexo.

Atributos personales

- Cuidado personal.

- Cualidades personales: responsabilidad, tolerancia al estrés y la frustración, seguridad en uno mismo, autoeficacia, autoestima, y tolerancia y respeto.

Habilidades y competencias

- Habilidades básicas: capacidad básica de lectoescritura, cálculo, capacidad para la comunicación oral y escrita.

- Hábitos laborales básicos: puntualidad.

- Habilidades y competencias personales generales: autodisciplina, iniciativa, actuar de forma autónoma, perseverancia, gestión del tiempo y de las tareas.

- Adaptabilidad: proactividad.

- Habilidades sociales: habilidades sociales básicas de comunicación interpersonal, aceptación de críticas, gestión positiva del

conflicto, trabajo en equipo.

- Potencial de aprendizaje: aprender a aprender.

- Análisis de situaciones y toma de decisiones: toma de decisiones.

\section{Formación}

- Calificaciones académicas y profesionales formales.

Conocimiento básico del empleo

- Habilidades profesionales específicas.

Fuente: Elaboración propia.

\section{La representación de la empleabilidad desde las empresas de inserción del País Vasco y su evaluación de los colectivos vulnerables}

Las representaciones sobre la empleabilidad proporcionan nociones y teorías estables y eficaces sobre las características del desempleado, y el motivo de su situación y de las relaciones que establece con su entorno. Este proceso tiene repercusiones en la estigmatización y categorización de las personas vulnerables que, a menudo, son vistas, y se ven a sí mismas, como responsables de la situación que están viviendo.

En este artículo no se pretende ni responsabilizar ni dejar de responsabilizar a la persona de sus circunstancias; su objetivo es el análisis de la concepción de empleabilidad que tienen los agentes sociales implicados en la inserción laboral de colectivos vulnerables $y$, en concreto, que trabajan en empresas de inserción del País Vasco. El porqué del estudio recae en la influencia que tiene la evaluación en las variables de la persona que influyen en el afrontamiento de situaciones estresantes y los mecanismos que activan para salir de ellas. Como la representación social actúa como ‘atajo' mental, no permite el análisis racional e individual de las características de cada persona, lo que implica que no se atienda a su singularidad, sino a sus características como miembro del grupo social al que pertenece: empleable/no empleable. El artículo también hace una llamada al análisis de las prácticas en función de las teorías implícitas sobre las que se basan, y de las que, a menudo, no somos conscientes.
Para alcanzar el citado objetivo, se ha realizado un estudio sobre los indicadores que las empresas de inserción incluyen en las evaluaciones de la empleabilidad en los tres momentos del proceso. Parece que la empleabilidad se mide a partir del análisis de, sobre todo, los factores individuales; junto a ello, las circunstancias personales completan la medida de la empleabilidad. De entre los factores individuales, la empleabilidad parece concretarse en determinadas habilidades y competencias, atributos personales, características sociodemográficas, de búsqueda de empleo y de salud. Aunque algunas entidades, en sus instrumentos, también reflejan que la empleabilidad debe evaluarse a partir de indicadores que reflejen la formación, la vida laboral, la movilidad geográfica y la flexibilidad laboral, así como el conocimiento básico del empleo. De entre las circunstancias personales, parece que las que se tienen en cuenta son el acceso a los recursos, y las responsabilidades y cuidados familiares.

Este panorama requiere retomar la meta de toda empresa de inserción: la integración y formación sociolaboral de personas en situación de exclusión social como tránsito al empleo ordinario. En ese intento de inclusión en el mercado normalizado de trabajo, las empresas de inserción tienen que evaluar la empleabilidad. La empleabilidad proporciona la base discursiva que legitima la desigualdad social, en general, y de las clases vulnerables y en riesgo de exclusión laboral y social, en particular. Desde la perspectiva posibilista de la empleabilidad, la inclusión/ exclusión de una persona depende del desarrollo de ciertas características personales. Desde esa base, se plantea la nueva psicología del trabajo, que se 
centra en la persona y no en sus circunstancias ni en el mercado laboral; que se ocupa de las competencias y no de los puestos de trabajo; que pasa de considerar la empresa como la principal creadora de las carreras laborales y de la estabilidad en el empleo, a percibirla como potenciadora de los proyectos de futuro de los trabajadores y camino de paso de trabajadores en búsqueda de su desarrollo. Es por eso por lo que, tal y como hemos podido observar en los resultados obtenidos, la representación de la empleabilidad tiene en su núcleo aspectos como la iniciativa y la autonomía, que podrían ser considerados 'competencias de alto nivel de complejidad', propios de profesionales de elevada cualificación, y no tanto de colectivos excluidos del mundo laboral.

Junto a ello, y partiendo del modelo ecológico de Bronfenbrenner (Bronfenbrenner y Morris, 1998), que contempla a la persona en su contexto, consideramos que las circunstancias personales y los factores exteriores son parte fundamental para el análisis de la empleabilidad. La representación de la empleabilidad tiene en cuenta algunos indicadores referidos a las circunstancias personales y presupone el grado de empleabilidad considerando las responsabilidades familiares y el acceso a los recursos. De esta forma, la percepción individualista de la empleabilidad queda mediatizada por su historia individual y social.

No sucede lo mismo con los factores externos. Parece, pues, que la representación de la empleabilidad no contempla el contexto social, político y laboral que la enmarca. Es percibida ajena a aspectos económicos, como los nuevos modos de contrata- ción; políticos, como las políticas de ocupabilidad; socioculturales, como la relación entre las redes sociales y el empleo; y tecnológicos, como Internet. De este modo, parece que se conceptualiza la empleabilidad, sobre todo, desde variables individuales que tienen en cuenta algunas relacionales, en concreto, aquellas que se vinculan directamente al microsistema del sujeto.

Nos situamos, pues, ante una percepción de la realidad acorde con un prototipo de trabajador (el del alto ejecutivo), cuya presencia en la sociedad actual es mínima, y que es contemplada desde una perspectiva cognitiva que desconsidera el contexto. $Y$ es en ese marco en el que las empresas de inserción se plantean como un instrumento para la integración de aquellos colectivos que parecen no tener un lugar en el mundo laboral. Sin embargo, a ese colectivo vulnerable, cuyos recursos están muy alejados de los del alto ejecutivo, se le exigen determinadas habilidades y competencias que no le son propias y resultan difícilmente accesibles para él.

Todas las cuestiones que se han planteado pretenden aportar un primer acercamiento analítico a una realidad relativamente nueva, que requiere mayor sistematización, tanto por parte de los investigadores como de los agentes sociales, para quienes resulta ser un instrumento de trabajo. La medida de la empleabilidad requiere de las empresas de inserción continúen la reflexión conjunta que permita su uso en función de los fines sociales para los que fueron creadas, y amplíen su concepción a otras instancias que no sean únicamente el individuo. 
ALALUF, M.; y MARTÍNEZ, E. (1999): “Bélgica: el empleo desestabilizado por el desempleo. Empleo precario y desempleo activo", en PRIETO, C. (ed.), La crisis del empleo en Europa, Alzira, Germania.

ÁLVAREZ-URÍA, F. (2002): "Estado social versus neoliberalismo", Acciones e Investigaciones Sociales, $\mathrm{n}$ ำ16, págs. 13-23 [<http://www. unizar.es/centros/eues/html/archivos/ temporales/16_AIS/AIS_16\%2805\%29.pdfs].

AÑEZ, C. (2004): “El Estado del bienestar social y el neoliberalismo ante los derechos laborales", Revista de Ciencias Sociales, vol. X, n- 1, págs. 70-82 [<http://redalyc.uaemex.mx/src/inicio/ ArtPdfRed.jsp?iCve=28010106〉].

BARUCH, Y.; y PEIPERL, M. (2000): “Career management practices: An empirical survey and implications", Human Resource Management, vol. 39, no 4, págs. 347-366 [shttp://tinyurl. com/6nvylkg)]

BRONFENBRENNER, U.; y MORRIS, P. A. (1998): "The ecology of developmental processes", en DAMON, W.; y LERNER, R. M. (eds.), Handbook of Child Psychology. Vol. 1. Theoretical Models of Human Developments, Nueva York, John Wiley and Sons.

BRUNET, I.; y PASTOR, I. (2003): “Tercera vía, comisión europea y estrategias de empleabilidad", Anduli, no 3, págs. 11-24 [<http:// dialnet.unirioja.es/servlet/dcfichero_ articulo? codigo $=1973117>$ ).

CAMPOS RÍOS, G. (2003): “Implicaciones económicas del concepto de empleabilidad", Aportes, vol. 8, no 23, págs. 101-111 [rhttp://redalyc.uaemex. $\mathrm{mx} /$ redalyc/pdf/376/37602308.pdf〉].
CAPPELLI, P. (1995): “Rethinking employment”, British Journal of Industrial Relations, vol. 33, nํㅜ 4 .

CASAL, J. (2003): “La transición de la escuela al trabajo", en FERNÁNDEZ PALOMARES, F, (coord.), Sociología de la educación, Madrid, Pearson Educación, págs. 179-200.

CASTELLS, M. (2001): La era de la información. Vol. III. Fin del milenio, México, Siglo XXI.

COMISIÓN EUROPEA (2003): Comunicación de la Comisión al Consejo, al Parlamento Europeo, al Comité Económico y Social y al comité de las Regiones. El futuro de la Estrategia Europea de Empleo (EEE): "Una estrategia para el pleno empleo y mejores puestos de trabajo para todos", Bruselas, Comisión Europea [shttp://eur-lex. europa.eu/LexUriServ/LexUriServ.do?uri=COM: 2003:0006:FIN:ES:PDF>].

- (1999): The European Employment Strategy: Investing in People; Investing in More and Better Jobs, Luxemburgo, Oficina de Publicaciones de la Unión Europea.

CLARKE, M.; y PATRICKSON, M. (2008): "The new covenant of employability”, Employee Relations, vol. 30 no 2, págs. 121-141.

DE CUYPER, N. et al. (2011): "The role of job resources in the relation between perceived employability and turnover intention: A prospective two-sample study", Journal of Vocational Behavior, vol. 78, no 2, págs. 253-263.

DE LA FUENTE, R.; y GONZÁLEZ-CASTRO, J. L. (2009): "Empleo, formación e inserción de colectivos en riesgo de exclusión. Un reto social y económico para la empresa receptora", Bordón. Revista de Pedagogía, vol. 61, no-3, págs. $33-46$ [<http://dialnet.unirioja.es/servlet/dcfichero_ articulo? codigo $=3054918$ > . 
FINN, D. (2000): "From full employment to full employability: A new deal for Britain's unemployed?", International Journal of Manpower, nํㅜ 21, págs. 384-399.

FORMICHELLA, M. M.; y LONDON, S. (2005): Reflexiones acerca de la noción de empleabilidad, Buenos Aires, Asociación Argentina de Economía Política [<http://www.aaep.org.ar/anales/ works/works2005/formichella_london.pdf〉].

FORRIER, A.; SELS, L.; y STYNEN, D. (2009): “Career mobility at the intersection between agent and structure: A conceptual model", Journal of Occupational and Organizational Psychology, vol. 82, nํㅜ 4, págs. 739-759.

FUGATE, M.; KINICKI, A. J.; y ASHFORTH, B. E. (2004): "Employability: A psycho-social construct, its dimensions, and applications", Journal of Vocational Behavior, vol. $65, \mathrm{n}^{\circ}$ 1, págs. $14-38$ [<http://dx.doi. org/10.1348/096317909X470933)]

GONZÁLEZ BARRIGA, J. R. (2003): “Introducción y marco jurídico de las empresas de inserción laboral”, Acciones e Investigaciones Sociales, $\mathrm{n}-18$, págs. 89-101 [khttp://www.unizar.es/centros/ eues/html/archivos/temporales/18_AIS/AIS$18 \% 2805 \% 29$.pdf $>$ ].

HARRISON, B. (1998): "Labor market restructuring and workforce development”, en GILOTH, R. P. (ed.), Jobs and Economic Development, Londres, Sage.

KIPPENBERGER, T. (2000): "The scouring effect of change", The Antidote, $\mathrm{n}-5$, págs. $18-20$.

LLINARES, L.; CÓRDOBA, A.; y ZACARÉS, J. J. (2011): "La medida de la empleabilidad desde las empresas de inserción social”, en CÓRDOBA, A.; y MARTÍNEZ MORALES, I. (coords.), Trabajo, empleabilidad y vulnerabilidad social: condicionantes y potencialidades de la integración a través de las empresas de inserción social, Valencia, Servicio de Publicaciones de la Universitat de València.

LUTTWAK E. (2000): Turbocapitalismo. Quiénes ganan y quiénes pierden en la globalización, Barcelona, Crítica.

MACÍA, M. C. (2003): "Neoliberalismo y relaciones de trabajo", en KURCZY, P.; y PUIG HERNÁNDEZ, C. A. (coords.), Estudios jurídicos en homenaje al Doctor Néstor de Buen Lozano, México, Universidad Nacional Autónoma de México.

MARHUENDA, F. (2009): "Formación y empleabilidad en las empresas de inserción social”. Comunicación presentada en el V Congreso Internacional de Formación para el Trabajo. 24/26 de junio de 2009, Granada.

MARHUENDA, F.; BERNAD, J. C.; y NAVAS, A (2010): “La práctica en empresas como estrategia de enseñanza e inserción laboral: las empresas de inserción social”, Revista de Educación, no 351, págs. 139-161 [<http://www.revistaeducacion. educacion.es/re351/re351_06.pdf〉]. employability”, Urban Studies, vol. 42, no 2 , págs. 197-219.
MINGLIONE, E. (1994): Las sociedades fragmentadas. Una sociología de la vida económica más allá del paradigma del mercado, Madrid, Ministerio de Trabajo y Seguridad Social.

NAVARRO, J. A. et al. (2008): Cuestionario Sociométrico de la Empleabilidad, Valencia, Pactem Nord.

NOGUERA, J. A. (2002): “El concepto de trabajo y la teoría social crítica”, Papers, no 68, págs. 141-168 [<http://www.raco.cat/index.php/papers/ article/viewFile/25717/25551)].

OSTERMAN, P. (1994): "How common is workplace transformation and who adopts it?", Industrial and Labor Relation Review, vol. 47, no- 2.

PÉREZ, C. (2003): “El discurso de la empleabilidad y las funciones del sistema educativo. Repercusiones para la sociología de la educación". Comunicación presentada en la X Conferència de Sociologia de l'Educació, Valencia, 18-20 de septiembre de 2003.

PRIETO, C. (1999a): "Crisis del empleo, ¿crisis del orden social?”, en MIGUÉLEZ, F.; y PRIETO, C. (eds.): Las relaciones de empleo en España, Madrid, Siglo XXI.

- (ed.) (1999b): La crisis del empleo en Europa, Alzira, Germania.

ROTHERY, B.; y ROBERSTSON, I. (1995): The Truth about Outsourcing, Nueva York, Gower Publishing.

SANTOS ORTEGA, A. (2003): "La invasión de la ideología empresarial en los márgenes del mercado de trabajo: inseguridad laboral, paro e inserción", Cuadernos de Relaciones Laborales, $\mathrm{n}-21$, págs. 107-128.

TEZANOS, J. F. (2001): El trabajo perdido. ¿Hacia una civilización postlaboral?, Madrid, Biblioteca Nueva.

THUROW, L. (2000): Construir riqueza, Buenos Aires, Javier Vergara Editor.

VAN DER HEIJDE, C. M.; y VAN DER HEIJDEN, B. I. J. M. (2005): "The development and psychometric evaluation of a multidimensional measurement instrument of employability-and the impact of aging", International Congress Series, vol. 1.280, págs. 142-147.

WEINBERG, P. D. (2004): “Formación profesional, empleo y empleabilidad". Ponencia presentada al Foro Mundial de Educación, Porto Alegre, julio [shttp://ilo-mirror.library.cornell.edu/public/ spanish/region/ampro/cinterfor/publ/sala/ weinberg/index.htm〉].

ZACARÉS, J. J. et al. (2011): ·Análisis de los instrumentos de valoración empleados por las empresas de inserción social. Una visión desde las fases del proceso", en CÓRDOBA, A.; y MARTÍNEZ MORALES, I. (coords.), Trabajo, empleabilidad y vulnerabilidad social: condicionantes y potencialidades de la integración a través de las empresas de inserción social, Valencia, Servicio de Publicaciones de la Universitat de València. 


\title{
La identidad profesional de los trabajadores sociales como elemento clave en el acceso a los programas de rentas mínimas: el caso de Catalunya
}

\author{
Joan Cortinas Muñoz \\ Centre de Recherches Sociologiques et Politiques de Paris \\ <joan.cortinas@csu.cnrs.fr>
}

Bertan azaldutako lanak ezagutu nahi ditu arlo sozialeko profesionalek eguneroko praktikan erabiltzen dituzten arauak. Izan ere, arauen ezagutza horren arabera, herritarrak ezegonkortasunaren kontrako baliabide publikoetara iristeko txostena egin edo ez erabakiko baita. Horretarako, kontuan hartzen da Kataluniako sailen arteko oinarrizko errentaren programako (PIRMI) kasuen azterketa. Bertan defendatutako tesiaren arabera, arau horiek oinarritzen dira nortasun profesional batean, aztertutako gizarte-langintzako profesionalek bereberea duten hezkuntzaren alorreko langintzan. Ikuspegi honetatik, -oinarrizko errentaaitortzeko agirien tramitazioa egitean, hein handi batean behintzat, gizarte-langileak ulertuko du hezkuntzaren alorreko betekizuna egiten duela, eta, azken batean, baliodunduko du bere nortasun profesionala.

\section{HITZ-GAKOAK:}

oinarrizko errenta, gizarte-laguntza, Katalunia, ezegonkortasuna, pobrezia.
El trabajo que aquí presentamos quiere explorar las normas que usan los profesionales de lo social en su práctica cotidiana para proceder o no a la tramitación del informe que puede dar acceso a un ciudadano a los dispositivos públicos que intentan luchar contra la precariedad. Para ello, nos centramos en el estudio de caso de los procesos de acceso al Programa Interdepartamental de la Renta Mínima de Inserción (PIRMI) en Catalunya. La tesis defendida es que esas normas se apoyan en una identidad profesional basada en el concepto de trabajo 'educativo' propia a los profesionales del trabajo social analizados. Desde este punto de vista, la tramitación de los documentos que dan acceso al derecho -la renta mínima de inserción- será sometida, en parte, al hecho que el trabajador social considere que dicho acceso le permitirá desarrollar una tarea 'educativa', o lo que es lo mismo, validar su identidad profesional.

\section{Palabras clave:}

renta mínima, trabajo social, Catalunya, precariedad, pobreza. 


\section{Introducción}

A partir de finales de los años ochenta, los diferentes Gobiernos autonómicos del Estado español ponen en marcha los dispositivos conocidos como políticas de rentas mínimas (Aguilar et al., 1995; Arriba, 1999). Estos dispositivos se caracterizan, entre otras cuestiones, por el hecho de establecer una magistratura de lo social en el acceso al derecho (Castel, 1995: 763). Es decir, los criterios de los profesionales de lo social -trabajadores sociales y educadores- tienen un peso en los procesos de acceso o en el disfrute del derecho.

En este artículo nos interesaremos en el contenido de dicha magistratura de los profesionales de lo social. Para ello, nos centramos en el estudio del programa de renta mínima en Catalunya: el Programa Interdepartamental de la Renta Mínima de Inserción (PIRMI) [Generalitat de Catalunya, 1990, 1997, 1998, 2001a y $2001 b]$. Nuestra tesis será que uno de los elementos que estructura la magistratura ${ }^{1}$ ejercida por los trabajadores de los servicios sociales estudiados está relacionado con la identidad profesional de éstos. Más concretamente, la decisión de tramitar el acceso al PIRMI no suscita ninguna duda al trabajador social cuando dicha tramitación valida su identidad profesional: desarrollar un trabajo ‘educativo'. Y a la inversa, la tramitación se torna más tortuosa y peor vivida por parte del trabajador social cuando sus motivos no refuerzan dicha identidad profesional. Defenderemos también que dicha identidad profesional está fuertemente vinculada a las trayectorias sociales de las personas entrevistadas.

Para exponer dicha tesis describiremos, en un primer momento, la posición que ocupan los trabajadores sociales de los servicios sociales de base ${ }^{2}$ en la arquitectura del PIRMI. En segundo lugar, nos centraremos en presentar la estructura de la identidad profesional de dichos trabajadores sociales, y terminaremos dando algunos ejemplos en los que dicha relación entre identidad profesional y magistratura de lo social se materializa.

Este artículo se basa en un estudio etnográfico llevado a cabo en los servicios sociales de dos grandes ciudades catalanas, y que se inscribe en los trabajos sociológicos basados en el estudio etnográfico de la política pública en sus materializaciones locales (Dubois, 2003a y 2003b; Lipsky, 1980; Tissot,

${ }^{1}$ Para conocer la totalidad de elementos que dan contenido, en el caso catalán, a la noción de magistratura de lo social, véase Cortinas (2010).

${ }^{2}$ Los servicios sociales de base son la puerta entrada al sistema de servicios sociales en Catalunya. Estos servicios son de carácter municipal y se sitúan en el territorio a partir de una lógica de proximidad con los ciudadanos. Se accede a estos servicios pidiendo una simple cita por teléfono, o presencialmente en una de las oficinas existentes. Estos servicios reciben a los ciudadanos y tienen la potestad de tramitar el informe que materializa la demanda de acceso al PIRMI. Son los profesionales de estos servicios los que están encargados del seguimiento de los usuarios una vez que han accedido al PIRMI. En este rol de seguimiento, pueden proceder a pedir la suspensión temporal o permanente de un usuario en el PIRMI.
2007). El estudio ha consistido en una observación no participante en una oficina de servicios sociales durante cuatro meses, durante los cuales asistimos a las entrevistas que los profesionales tienen con los usuarios del PIRMI y con usuarios que aún no gozan de dicha prestación. Igualmente, hemos realizado 21 entrevistas con educadores y trabajadores sociales ${ }^{3}$ acerca de sus maneras de concebir la renta mínima y el uso que hacen de dicha prestación: cuándo la consideran importante, cuándo deciden evitar la tramitación, cuándo deciden suspender la prestación, entre otras cuestiones. La segunda ciudad ha servido de dispositivo de control respecto a los resultados obtenidos en la primera. El estudio fue realizado entre 2006 y 2009.

\section{Los trabajadores sociales como actores centrales en los procesos de tramitación y suspensión de demandas de acceso al PIRMI}

Los trabajadores sociales de los servicios sociales de base manifiestan tener una gran facilidad, o dicho de otra manera, no tener ningún tipo de restricción remarcable o directiva a la hora de tramitar o gestionar la renta mínima de inserción. Al contrario, la mayoría de ellos parecen no tener ningún problema en que las demandas que tramitan gocen de un alto porcentaje de aprobación por el órgano técnico del PIRMI. Este órgano, compuesto esencialmente por trabajadores sociales y dirigido por un educador Francesc Coll- goza, a su vez, de una gran autonomía en dichas aprobaciones. Así, el hecho de que no se apruebe una demanda de acceso al PIRMI realizada por un trabajador social es vivida como una sorpresa y una rareza4.

De la misma manera, la suspensión de un expediente propuesta por un trabajador social difícilmente encuentra obstáculos por parte del organismo de gestión del PIRMI, e incluso algún trabajador social nos cuenta que el órgano técnico del PIRMI -que proporciona soporte a la gestión y decisión del principal órgano responsable del PIRMI, la Comisión Interdepartamental de la Renta Mínima de Inserción-, cuenta con un técnico de referencia a cada equipo de los servicios sociales de base, con el que se puede establecer fácilmente contacto telefónico para arreglar cuestiones relativas a los expedientes. Estas decisiones se toman de forma individual y se someten a una supervisión que actúa más como soporte de dicha decisión que como evaluadora, y hacen que podamos hablar de un dispositivo en el que el acceso y la permanencia están, en buena parte, en manos del trabajador social de los servicios sociales.

${ }^{3}$ A las personas entrevistadas se las identificará en este artículo mediante sus iniciales y año de nacimiento. El entrevistador aparece indicado como 'Ego'.

${ }^{4}$ Los datos oficiales facilitados por el órgano técnico del PIRMI sitúan las demandas denegadas alrededor del $20 \%$ entre 2005 y 2009 (en concreto, $20,6 \%$ en $2005,20,8 \%$ en $2006,20,6 \%$ en $2007,21,3 \%$ en 2008 , y $20,6 \%$ en 2009), años de realización de nuestro trabajo de campo. 
En varias ocasiones los trabajadores sociales entrevistados hablan de los procesos de concesión o suspensión de la renta mínima de inserción en primera persona. Así, una trabajadora nos cuenta:

-D. A.: Tenía a unos a quienes se la cerré, y se generó un pitote. La cerré yo, aunque la demanda era la de la trabajadora social, porque el tío llevaba 10012 años en motivación, y el tío se lo había tomado como una pensión [...]. Ahora, el hijo ha venido y me ha pedido la PIRMI [...].

(D. A., 1976, educador social, dos años en los servicios sociales de base) [subrayado del autor].

Vemos cómo el educador social se pone como sujeto de la suspensión, "la cerré”, reforzando así la idea de que los profesionales de atención primaria gozan de una autonomía en la decisión que parece no estar sometida a directivas políticas, ni al control de sus superiores, y que trasladan estas decisiones al terreno puramente profesional, en el marco de una relación interpersonal entre el profesional y el 'usuario'.

Esta característica del PIRMI lo distingue de otros dispositivos, como los procesos de gestión de las demandas de permisos de residencia o de asilo político, en los que las directivas políticas parecen influir directamente, mediante fuertes controles y sanciones, en las lógicas de gestión de los agentes del Estado que las ejecutan, y donde se trata, ante todo, de actuar en función de las directivas políticoadministrativas, es decir, de ejecutar una tarea de aplicación de las normas (Spire, 2008). Este ausencia de conexión entre directivas políticas y proceso localizado de decisión, seguimiento y evaluación de la renta mínima de inserción da al trabajador social un margen de libertad respecto a coyunturas políticas, pero no lo libra, sin embargo, del hecho de que el PIRMI es un dispositivo extremamente burocratizado y jerarquizado en su funcionamiento, en el que el trabajador social de los servicios sociales de base ocupa una posición subordinada en lo que concierne las decisiones respecto a los recursos existentes para la ‘inserción' -naturaleza y cantidad-y sus temporalidades -inicio y duración de las actividades-.

\section{Una identidad profesional estructurada alrededor de la noción de trabajo 'educativo'}

Los profesionales que componen nuestro universo de estudio se asemejan, por toda una serie de elementos que vamos a ir desgranando en las próximas líneas, a un segmento de lo que Bourdieu (1979) llama la pequeña burguesía. A grandes rasgos, sus trayectorias sociales están definidas por procesos de ascenso social desde unos orígenes populares o medios (Serre, 2009). Este ascenso tiene como base la escolaridad, pero la fragilidad de capitales iniciales les impide acceder a posiciones dominantes del espacio social y les conduce a una lógica de distinción respecto a estas posiciones. Es decir, se adhieren a la institución escolar y su valor como medio de ascenso social, pero buscan una profesión que sea accesible -por voluntad o falta de alternativas-, a partir de la cual se teje una posición social basada en recompensas simbólicas que provienen de la producción de valores distintivos de las clases dominantes y de las populares de las que son originarias: 'hacer tareas que sean enriquecedoras personalmente', 'que aporten cambios'. En resumen, 'tareas con sentido'.

De los 21 profesionales que componen nuestro universo de estudio, nos encontramos con una mayoría de diplomados en Trabajo Social. Así, 11 de los 21 son trabajadores sociales, mientras que 7 son diplomados en Educación Social, dos personas tienen como título académico principal la licenciatura de Psicología, y una, la de Magisterio.

El primer elemento que caracteriza a estos profesionales es la mayoritaria presencia de individuos de origen social que podríamos calificar de clase popular, si nos atenemos a la profesión de los padres y a los lugares de residencia. Así, de los 21 individuos, 15 (el 71\%) proceden de familias de padres obreros y sólo 6 (29\%) son pequeños empresarios o empleados calificados. Además, dentro de estos pequeños empresarios, dos poseen comercios en barrios populares. El resultado es que el lugar de residencia originario de 17 de nuestros 21 individuos son barrios populares de grandes ciudades. Por otro lado, en ninguno de los casos los progenitores poseen estudios superiores.

Estos orígenes populares se combinan, en la mayor parte de los casos, excepto uno, con una importante atribución de valor a los estudios de los hijos, que se traduce de distintas maneras, según los casos. Por ejemplo, toma la forma de una estrategia en la elección de escuelas:

-Ego: 0 sea, que te llevaron a una escuela del centro de la ciudad, y no del barrio.

-S. M.: Eso. Fíjate, mi madre quería llevarme a una escuela de fuera del barrio. Ellos eran andaluces, y mi madre decía: "Claro, si la llevo a una escuela del barrio, no hablará catalán; si la llevo al centro, le enseñarán a hablarlo”. ¡Uy! Y está muy orgullosa de haberlo hecho así [risas], por eso, por eso me llevaron a la escuela del centro.

(S. M., 1972, trabajadora social, un año en los servicios sociales de base).

-A: En La Salut, en un [colegio] concertado. Pues imagínate, mi padre no estaba de acuerdo que fuera concertado.

-Ego.: ¿Y por qué fue concertado?

-A.: Porque mi madre dijo ‘aquí mando yo’; es la escuela más cercana que tenemos, y porque en 
esa época la escuela pública no estaba como tan bien vista, y mi madre, como quería que estudiáramos aquí, mi madre dijo a mi padre que era un colegio de monjas.

(A., 1972, educadora social, ocho años en los servicios sociales de base).

En otros casos, se produce una participación activa de los padres en las asociaciones de padres de la escuela y, en la mayoría de casos, en un apoyo y una preocupación por la carrera escolar del hijo o la hija, materializada en conversaciones entre los padres e hijos sobre las decisiones escolares:

-Ego: ¿Tus padres daban importancia al hecho [de] que estudiases?

-A. N.: Sí, ¡mucho! Hasta que le dije a mi madre lo que iba a estudiar y me dijo que estaba medio loca, que ¡qué era eso que iba a estudiar!

-Ego.: 0 sea, [que] valoraban mucho los estudios hasta que entraste en Trabajo Social.

-A. N.: ¡Claro! “¿Qué es eso? ¿Por qué no haces Magisterio? ¿O Administración, y trabajas con tu tío, en el banco?".

(A. N., 1963, 23 años en los servicios sociales de base).

Esta inversión familiar en los estudios parece traducirse en escolaridades continuadas hasta el acceso a la Universidad. Es decir, todos los profesionales que forman parte de nuestro universo, excepto dos casos que ahora abordaremos, llegan a los cursos de acceso a la Universidad sin ninguna interrupción en dicha escolaridad. Los estudios primarios se encadenan con los secundarios con toda naturalidad. Sólo dos casos parecen salirse de esta norma, ya que interrumpen sus estudios secundarios a la mitad para ponerse a trabajar. Sin embargo, esta interrupción quedará en una anécdota, ya que años más tarde retomarán los estudios -las dos excepciones forman parte de las generaciones (1950 y 1960) en las que la entrada al mercado laboral sin calificación se produce de manera bastante cómoda-. A pesar de esa continuidad en los procesos de escolarización, sólo una minoría accede a los estudios de Educación Social o Trabajo Social como primera opción después de la Selectividad (4 de 21).

En otras palabras, la entrada a Educación Social o Trabajo Social es, para 17 de 21 (el 71\%), una oportunidad por defecto - nota baja que determina la elección o el acceso después de ser descartados en otros estudios- de acceso a los estudios universitarios, o una oportunidad de consolidar una experiencia profesional que demanda un título para conseguir una posición profesional más estable. En el primer caso, esta oportunidad por defecto -y vivida como un tanto casual- puede ser vivida como una manera de ver realizado el deseo de ejercer una profesión dedicada a 'los otros'. Es el caso de las tres mujeres que querían, o pensaron dedicarse a, profesiones del campo sanitario, pero que no consiguieron entrar en dichos estudios. El trabajo social parece cumplir esa función de estar en contacto con 'lo humano’:

-M. C.: Lo mío es un poco película. Yo hacía ciencias puras, pero tuve la mala suerte [de] que, en el instituto, me quedó una asignatura pa' septiembre, y tuve que hacer la Selectividad en septiembre. Iba para enfermera, no tenía en la familia nadie que me pudiera asesorar, era la primera que tenía estudios; en la familia paterna había gente, pero alrededor mío no tenía nadie que me pudiera asesorar. Entonces tuve la mala suerte [de] que no pude entrar en la Universidad. Entonces alguien me orientó hacia Trabajo Social; como era una de las carreras que quedaba, pues...; pero claro, para mí era algo nuevo. Entonces, en aquella época, hacía poco que era carrera universitaria, pero claro, lo que yo estudié no tiene nada que ver con lo que te encuentras en la realidad, pero fue un poco... interesante. ¡Hay que ver! Estuve a punto de dejarlo, pero como iba bien y sacaba buenas notas, pues...

-Ego: ¿Algo positivo de la profesión?

-M. C.: Bueno, positivo, hombre, hay cosas positivas, cuando veías que antiguamente podías informar de cosas. Lo mejor, cuando has visto familias que han cambiado, de ser ellos los que pedían y que, en un momento, se vuelven autónomos; o cuando la gente te viene a ver y te dan las gracias, porque les has informado muy bien, aunque no les des nada; o sea, la parte más humana. Aquí es lo que falta: la parte humana no existe, vienen a quejarse, enfadarse, pero nunca a darte las gracias; a nivel humano no hay ninguna valoración.

(M. C., 1967, trabajadora social, veinte años en los servicios sociales de base).

0:

-Ego: ¿Y terminaste en Trabajo Social?

-V. R.: No, yo no quería, yo quería ser odontóloga. Hice el bachillerato de ciencias de la salud.

-Ego.: ¿No te llegó la nota?

-V. R.: No me llegó la nota. La otra opción era Enfermería, pero tampoco me llegó, y me llegó para Trabajo Social [...], pero estoy muy contenta.

-Ego.: ¿Alguien te aconsejó o elegiste sola?

-V. R: Totalmente por azar, pero sí que, emmm..., [entre] las personas que nos dedicamos al mundo de lo social, sí que hay una serie de aptitudes. Cuando tú decides qué tipo de estudios, qué profesión quieres, pues ya sabes si van enfocados 
más a la ayuda a las personas, o algo más técnico, y entrarían las profesiones que están relacionadas.

(V. R., 1980, trabajadora social, cuatro años en los servicios sociales de base).

En otros casos, la falta de nota vinculada a escolarizaciones continuas, pero sin elevadas calificaciones, se combina con socializaciones en el mundo de lo social -asociaciones de ayuda a drogodependientes- o 'lo educativo’ -socialización en los esplais ${ }^{5}$ católicos o laicos, monitores de niños en dichos esplais-, que lleva a considerar los estudios de Trabajo Social o Educación Social:

-S. F.: Primero me interesaba[n] Periodismo y Derecho, y me fui a informar al Salón de la Enseñanza, y me cayó en las manos la información de Educación Social, y cuando vi el contenido, me pareció muy atractivo [...] como formación personal.

-Ego.: O sea, que fuiste por otras cosas y te encontraste con Educación Social

-S. F.: Sí, lo que tenía en mente era Derecho y Periodismo, que también tenían bastante vertiente social [...]. El tema social me llamaba mucho la atención [...].

(S. F., 1976, educador social, cinco años en los servicios sociales de base).

-T. T.: Hice bachillerato y empecé los estudios de Historia, que Historia no...

-Ego.: ¿Hiciste toda la carrera?

-T. T.: ¡No! Ya me hubiese gustado, pero era demasiado para mí.

-Ego.: ¿Por razones económicas?

-T. T.: Yo siempre he trabajado; además, mi memoria es bastante... Ya lo dice mi padre, que para hacer Historia hay que tener mucha memoria, y realmente no iba muy bien, no aprobaba, por mucho que me pusiera. Entonces decidí -porque mi idea era hacer Antropología, que me hubiera gustado-, pero al final fui realista, dejé Historia y empecé Educación Social.

Ego.: Pero tu deseo era Antropología, ¿por qué lo dejaste correr?

-T. T.: Porque yo hacía Historia para poder entrar en Antropología, y como no pude hacer Historia, no podía hacer Antropología, y como tenía mucha experiencia, e incluso había trabajado a nivel de chavales en exclusión social, no en esplais, pero había trabajado en este tema, entonces me dije:

${ }^{5}$ Los esplais son asociaciones que realizan actividades de ocio para niños y jóvenes orientadas a la educación en valores.
"Pues que para algo me sirva”, ¿no? Además, yo había estado en un centro abierto dos años con chavales [...].

(T. T., 1974, educadora social, dos años en los servicios sociales de base).

En continuidad con esta lógica que acabamos de describir, encontramos a individuos (5 de 21) en los que una oportunidad laboral real en el mundo de 'lo educativo' o 'lo social' les lleva a la facultad de Trabajo o Educación Social. De nuevo, en estos casos existe una socialización en 'lo educativo’ o, marginalmente, en 'lo político':

-D. A.: Hice BUP y COU en un instituto público de Santa Coloma, empecé Psicología por la UNED [Universidad Nacional de Educación a Distancia], lo dejé al cabo de tres años, porque hice la PSS [Prestación Social Substitutoria] en un centro de acogida, vi el mundo de los educadores sociales, me gustó y empecé Educación Social [...]. Cuando estaba haciendo la PSS, me impliqué mucho y la directora me dijo que, si estudiaba Educación Social, ella podría irme haciendo contratos de auxiliar educativo y, con eso, me iría pagando los estudios [...].

(D. A., educador, dos años en los servicios sociales de base).

$-N$. A.: Fui escolta [scout] de $1^{\circ}$ a $3^{0}$ de BUP, que es el momento en el que empecé a trabajar, pero antes ya había estado en Santo Cristo [un barrio popular de la ciudad de Badalona] e incluso en algún esplai de parroquia.

-Ego: ¿Los estudios sociales?

-N. A.: Yo estudié Educación Social, pero ya había empezado a trabajar en el Esplai Llevant con disminuidos psíquicos.

-Ego: ¿Cobrando?

-N. A.: ¡No, no! A partir de lo del Esplai Llevant, se hizo ESPANIN [Asociación de Disminuidos Psíquicos de Badalona], que es una entidad que ha montado muchos servicios para los disminuidos psíquicos de Badalona. [...] entonces ahí tuve un contrato de seis meses, se crearon los pisos para adultos y es entonces que entré contratada. Fue en ese momento que empecé los estudios de Pedagogía, y lo dejé al poco tiempo para estudiar Educación Social en Flor de Maig [...]."

(N. A. educadora social, catorce años en los servicios sociales de base).

-E.: Estamos hablando de hace casi 25 años. Yo por ese entonces trabajaba; de hecho, soy delineante, tengo un FP de primer y segundo grado. Entonces trabajaba en una tienda de maquinaria industrial, pero en mi tiempo libre me relacioné 
con una serie de gente, entre ellos, el director de un centro de menores con quien yo colaboraba de forma voluntaria, dando clases de refuerzo -en Girona-, acompañando a alguna salida. En eso que quedó vacante un puesto de educadora, y me lo propusieron y dije que sí. Fue un poco por casualidad: no tenía formación alguna y la fui haciendo de a poco, y así entré en la primera promoción de la Escuela de Educadores de Girona.

(E., 1961, educadora, doce años en los servicios sociales de base).

Estas socializaciones en el mundo de 'lo educativo' o 'lo social', ya sea en esplais o escuelas religiosas, están también presentes en el caso de escolarizaciones que llegan con mayor puntuación al acceso a la Universidad y, por tanto, no se encuentran con la fatalidad de tener que elegir carreras por defecto.

Un último elemento que nos interesa señalar, y que es común a todos los miembros de nuestro universo de estudio, es que movilizan la noción de realizar un trabajo con 'sentido'. Es decir, la elección profesional, más allá de las condiciones objetivas que la condicionan, tiene relación con un rechazo de las profesiones 'sin sentido'. Dicha concepción de la profesión puede tener distintas interpretaciones. Con algunos de los nacidos en los años sesenta, parece relacionarse con la socialización de estos jóvenes en un momento histórico -años setenta- de cuestionamiento de estilos de vida más tradicionales, que corresponden a los de sus padres, y en el que la noción de una profesión 'con sentido' pasa por ejercer profesiones poco convencionales:

-A. N.: Mi madre me decía: “¿Qué es eso? ¿Por qué no haces Magisterio? ¿Por qué no haces Administración y trabajas con tu tío, en el banco?”. Pues yo no quiero estar en un banco, yo quiero ser asistente social, porque yo era muy jipi.

(A. N., 1963, trabajadora social, 23 años en los servicios sociales de base).

Para otros, esta concepción de la profesión como 'algo más' que un medio para ganar dinero parece relacionarse, en el caso de los nacidos a partir de los años setenta, con una concepción de la formación en términos de 'crecimiento personal', en oposición a una visión únicamente instrumental de los estudios. En los individuos de esta generación -la que nace a finales del Franquismo o al inicio de la democracia-, que se caracterizan por la ausencia de socializaciones militantes en partidos o sindicatos, y por la socialización en esplais o instituciones parecidas, se produce un cierto distanciamiento del trabajo como un medio de acumulación de bienes materiales, para transformarlo en un medio para vivir enriqueciéndose personalmente. Ess distanciamiento parece relacionarse con un proceso de ascenso social-aunque limitado respecto a las profesiones prestigiosas- con respecto al medio familiar, tanto en lo que se refiere a las calificaciones como al tipo de trabajo realizado.
La noción de 'sentido' - ‘trabajo con sentido'- parece declinarse en dos dimensiones: un trabajo que movilice 'el intelecto' por encima del 'cuerpo'; y un trabajo que aporte cosas 'en el ámbito personal', en oposición a un trabajo que no tiene ninguna otra finalidad que su propia ejecución. En suma, un distanciamiento propio de individuos en procesos de ascenso social de clases populares, o procedentes de segmentos de clases medias, sin estudios superiores y con pocas probabilidades de acceso a profesiones dominantes en el espacio social-abogados, empresarios-:

-S. A.: [...] Pero bueno, a mí ya me gustaba el tema, me gustaba mucho ayudar a la gente, y siempre estoy pendiente de lo que le pasa a uno y otro. Pues eso, cuando estuve en el extranjero, pensé que igual esta carrera [se refiere a Trabajo Social] me gustaría, más por interés personal que por otra cosa, no tanto para trabajar, porque yo ya tenía mi trabajo [técnica de laboratorio] y ya estaba bien, pero para enriquecerme y aprender. Entonces miré cómo iba el tema y me inscribí [...].

(S. A., 1976, trabajadora social, dos años en los servicios sociales de base).

- S. F.: Y cuando llegó a mis manos toda la información de Educación Social, sí que vi que, como formación personal, tenía mucho interés. Como la nota de corte me daba un poco baja, tuve que ir a la Pere Tarrés, y combiné trabajo y estudios.

-Ego.: ¿Tu nota de corte era baja?

- S. F.: Bueno, pinché en la Selectividad, nervios y tal, y no me daba, así que fui a Pere Tarrés, y la verdad es que todo fue muy rodado, alguna asignatura que me costó un poco más, pero me gustó mucho, la gocé mucho [...]. Había compañeros que estaban muy preocupados por si encontrarían trabajo o no, si las condiciones serían buenas o malas; yo disfruté de los tres años, saqué las mejores notas de mi toda mi escolaridad [...].

(S. F., 1976, educador social, cuatro años en los servicios sociales de base).

En síntesis, podemos caracterizar las trayectorias de los individuos que componen nuestro universo de estudio por su procedencia de familias de origen popular que invierten en la educación de sus hijos/as como modo de ascenso de éstos. En segundo lugar, cabe destacar la adhesión de los/as hijos/as a esa idea de la escuela como vía de ascenso social, aunque la mayoría realicen escolaridades que podríamos calificar de 'medias-bajas' en cuanto a las calificaciones. En tercer lugar, casi todos ellos forman parte de las generaciones en las que se produce un acceso importante de los/as hijos/as de clases populares a la Universidad. Por otro lado, la socialización en instituciones de educación no formal, de educación popular o, en menor medida, políticas o sindicales, significa oportunidades de profesionalización -un 
horizonte posible - frente al fracaso de otras vías, o como oferta real de acceso al mercado de trabajo. Posibilidades objetivas de acceso a la Universidad y al mercado de trabajo calificado se mezclan con una valorización del hecho de realizar trabajos con 'sentido', en oposición a trabajos cuya finalidad sea sólo su ejecución. Además, todos ellos dan valor a la dimensión 'intelectual' del trabajo - a los instrumentos propios de la profesión-, en oposición a un trabajo 'manual' o en 'el que no se deba pensar'. Todos estos elementos parecen combinarse, especialmente en el caso de las trabajadoras sociales, con una dimensión de género, en la que la socialización de las mujeres parece materializarse en una voluntad -'un gusto'- por 'ocuparse de los otros'.

Estas trayectorias parecen estar en la base de una adhesión a un ideal del educador o el trabajador social como alguien que establece una relación de ayuda en la que lo importante es generar un proceso 'educativo', definido como lo opuesto a un trabajo administrativo o asistencial. Administrar o asistir no tiene mucho 'sentido', ya que no implica la movilización del 'intelecto' -de lo aprendido en la Universidad-, ni ese 'ayudar' a los otros que permite dar al trabajo un elemento distintivo -valor simbólico, a falta de valor material y social- del resto de profesiones propias de los espacios populares -identificadas como manuales y repetitivas- y dominantes -identificadas como profesiones basadas en la acumulación de dinero-:

-M. C.: Tramitar prestaciones, pa' eso no hace falta estudiar una carrera. Sólo hacemos eso: la gente viene aquí para que tramites ayudas, y cuando tienes un tema educativo que podrías trabajar, te das cuenta que no tienes ni tiempo, ni nada.

(M. C., 1967, trabajadora social, veinte años en los servicios sociales de base).

Esta identidad profesional permite a los componentes de nuestro universo de estudio 'convertirse' en profesionales adquiriendo unas herramientas -conocimientos- a las que atribuyen gran valor, justamente porque les permiten pasar al estadio de 'profesionales', es decir, les ofrece el derecho de entrada a un mercado de trabajo calificado, a la vez que a una profesión con 'sentido'.

Cabe pensar que esta necesidad de encontrar 'sentido' al trabajo realizado quede reforzada por el bajo prestigio social y la poca visibilidad de las que goza la profesión, las pocas posibilidades de promoción existentes, $y$, para una parte de nuestro universo de estudio, la inestabilidad laboral persistente. Así, de todas las entrevistadas, sólo una persona ha sido promovida una vez dentro de los servicios sociales municipales, pero esas promociones sólo llevan hacia tareas de gestión, de forma que esta persona ha vuelto a los servicios sociales de base, con el argumento de que no encontraba 'sentido' en la gestión. En esta misma línea, a la pregunta sobre cómo se ven en el futuro profesionalmente, la totalidad de nuestros entrevistados no se ven en otro sitio que donde están, no por falta de ganas de hacer otras cosas - muchos manifiestan interés por ocupar posiciones de planificación de proyectos educativos-, sino por la ausencia de posibilidades 0 de condiciones materiales adecuadas:

-Ego: ¿Hacia dónde te gustaría evolucionar profesionalmente?

-S. N.: No sé, tal vez me gustaría hacer otras cosas.

-Ego.: ¿Qué tipo de cosas?

-S. N.: A ver, a mí me gusta el trabajo con las familias, pero es un trabajo que quema mucho. Creo que necesitamos épocas de descanso de la atención directa, y creo que iría bien que los profesionales que hacemos atención directa pudieran tener un tiempo en la retaguardia, aunque fuera haciendo tareas de gestión, y bueno, otro tipo de tarea, no sé exactamente cuál. A mí me gustaría hacer cosas de mediación, pero lo que se está haciendo aquí son cosas de mediación comunitaria, que están bien, pero son contratos con la Diputación, con lo cual, la contratación es muy precaria, de manera que no lo voy a hacer.

-Ego.: ¿Tienes contrato fijo aquí?

-S. N.: Desde hace 21 años.

-Ego: 0 sea, que, por el momento, no hay proyectos profesionales.

-S. N.: ¿Sabes qué pasa? Que muchas veces no es tanto lo que tú quieras como lo que haya; y es que también ves cómo está la organización y las posibilidades que hay dentro de ésta.

-Ego: ¿Cuáles son éstas en la ciudad?

-S. N.: Pues la verdad es que no hay [risas] [...].

(S. N., 1960, psicóloga, 21 años en los servicios sociales de base).

\section{La tramitación del acceso al Programa Interdepartamental de la Renta Mínima de Inserción como forma de validación de la identidad profesional}

Los profesionales de los servicios sociales de base, debido a la posición de privilegio que la arquitectura del dispositivo les otorga en el proceso de tramitación de la demanda de acceso al Programa Interdepartamental de la Renta Mínima de Inserción (PIRMI), pueden apropiarse de dicho dispositivo y dotarlo de significado en función de su identidad profesional. De esta forma, la decisión de tramitar o suspen- 
der, aparte de a los obligados criterios objetivos marcados por la ley del PIRMI, estará vinculada a la probabilidad percibida por los trabajadores sociales de poder realizar un trabajo 'educativo'. De la misma forma, la percepción, por parte del profesional, de la imposibilidad de realizar un trabajo 'educativo' con el usuario retardará o limitará las posibilidades de tramitación o continuidad en el dispositivo:

-M. C.: [...] con él no he conseguido que haga nada.

-Ego.: ¿Pero les has mantenido el PIRMI?

-M. C.: A ver, les he hecho alguna 'suspensión terapéutica' que digo yo: un par de veces, en los períodos en los que él no hacía nada, había absentismo escolar, teníamos problemas con la escuela, porque el señor es agresivo, es muy de 'yo hago lo que quiero y tú no me digas nada'. Entonces, si el tema es que él hace lo que quiere, pues muy bien, yo le suspendo el PIRMI, pero sólo durante un período corto de tiempo, ya que con la señora sí que puedo hacer cosas [...].

(M. C., 1967, trabajadora social, dieciséis años en los servicios sociales de base).

-A.: [...] Hablo con la PIRMI y les dije: "yo no sé cuál es la situación”. Me entrevisto con él, me dice que su padre había estado en el hospital y que, por eso, había tenido que ir [a Marruecos]. "Pues tráeme un documento", "no lo tengo, porque allí [en Marruecos] no funciona de esa forma, tengo que pagar"; y dije: "pues mira, si no me traes el documento, se cortará la PIRMI”, y se le ha cortado la PIRMI hasta que no aporte el documento; y mira que la situación... Y es una lástima, porque mira que la familia podía tirar para'lante, porque cobraban 700 y pico de euros y podían tirar para'lante, pero claro, si esa gente coge y se van, claro, yo entonces, ¿qué soy?, ¡soy pura tramitadora!

(A., 1972, educadora social, nueve años en los servicios sociales de base).

Vemos en este extracto de entrevista que, a pesar que potencialmente la educadora social percibía posibilidades de trabajo ‘educativo', la ausencia prolongada del beneficiario del territorio y, por tanto, de los servicios sociales donde la educadora realiza la tarea 'educativa', hace que la profesional se perciba automáticamente como 'tramitadora', un rol que se sitúa a las antípodas de la identidad profesional que hemos descrito y que implica automáticamente la demanda de suspensión de la prestación por su parte. Cabe señalar el adjetivo usado por la educadora, "pura", que nos indica que las tareas administrativas, de trámite, son aceptadas siempre que sean el medio por el cual el trabajo educativo puede empezar, es decir, siempre que esas tareas no sean 'puras', sino 'mezcladas' con las educativas.
Esta fusión entre el derecho (la renta mínima de inserción) y la identidad profesional es tan fuerte que incluso la continuidad/suspensión del derecho puede ser percibida, por parte de los trabajadores sociales, como un instrumento educativo, más que como un derecho. Así, una educadora nos relata que, después de suspender la participación de una usuaria en el PIRMI, no piensa volver a activar la prestación hasta que no perciba los cambios que ella considera necesarios en el proceso 'educativo' emprendido con ella. Es más, cuenta con que la suspensión de la prestación sea una manera de 'hacer reaccionar' a la usuaria:

-T. T.: Tengo un caso, por ejemplo, de una familia que durante seis años ha estado cobrando el PIRMI y actualmente no le estoy activando la PIRMI/RMI [se la ha suspendido], o sea, una familia que durante seis años ha estado cobrando la PIRMI, en el momento en que no se cumplieron los acuerdos, se paró y sigo con el plan de trabajo; y ahora que no hay la PIRMI, deberían haber cambios [...] la mujer reconoce a la pareja, por lo tanto, no se quiere separar, que era uno de los elementos para volver a activar la PIRMI; pues si es así, ahora deberá organizarse con los recursos que existan a nivel de servicios sociales [fuera del PIRMI/RMI]: ayudas [económicas] puntuales, derivación a módulos de técnicas de búsqueda de empleo, recordar periodos de inscripción [de los niños a la escuela], soporte de comedor [beca de comedor] si es necesario, los recursos mínimos sin activar una PIRMI/RMI.

-Ego.: ¿Esto lo has decidido tú?

-T. T.: Sí.

-Ego.: ¿Por qué razón no quieres activar la PIRMI?

-T. T.: Porque durante seis años ha estado cobrando un dinero y su situación familiar no ha cambiado [...] se trata [de] que reconozca la situación en la que se encuentra [...]. Ella [la usuaria] no es consciente de la realidad [...], es una mujer muy pasiva en relación a sus circunstancias, se refugia en el regazo de su madre y así mantiene relaciones con su pareja como una pareja libre, como si fuese su novio, no como un hombre con sus responsabilidades, con sus valores, como un padre de familia, vaya, pum, pum, donde participa en según qué tareas, que acompañara a los niños de forma puntual, que pudieran presentarse como una familia unitaria y que quisieran luchar por una casa, entonces podríamos valorar la PIRMI [...].

(T. T., educadora social, dos años en los servicios sociales de base. [Subrayado del autor]).

Sólo en los casos en los que la situación de la familia es juzgada como muy límite por parte del profesional, se puede concebir no respetar la regla de tramitar o dar continuidad a la prestación, a pesar de que no se esté validando la identidad profesional. Es a menudo 
el caso de familias con hijos muy pequeños y sin ningún tipo de recurso económico:

-S. R.: A ver, tú das unos ingresos económicos, ¡saca estos ingresos! ¿Qué haces? ¿La quitas? ¡Se quedan sin nada! El sistema es un poco perverso: parten de la premisa que tú tienes clara, y la usuaria también, que esto es una contraprestación. Pero tú, con unidades familiares con cuatro hijos que deben cobrar 800 euros, ¿por incumplimiento retiras [el] PIRMI? ¿Qué harás ahora con esa familia, que ahora teóricamente, teóricamente, no tendrá ingresos?

(S. R., 1961, veinte años en los servicios sociales de base).

No obstante, en estos casos el PIRMI es percibido como un dispositivo disfuncional que debería ser modificado en su estructura, para que la identidad profesional pueda ser validada. Dicho en otros términos, cuando el PIRMI no sirve de instrumento de validación de la identidad profesional se considera que debe modificarse de forma que sirva justamente a este fin:

-S. R.: Yo haría que [la renta mínima de inserción] fuese una pensión universal y punto, sin contraprestación, así nosotros podemos dedicar esfuerzos para personas a quien[es] esto les es realmente necesario y no estaremos haciendo gestiones, buscando recursos, cursos, por todas partes, para personas que, al cabo de unos días, te vienen con un papel diciendo que tienen una hernia, ¿me explico? Entonces, es que un PIRMI da mucho trabajo, igual en otras partes será de otra manera, pero en los territorios donde yo he trabajado presentan muchas dificultades, tanto de gestión, búsqueda de recursos, como de perseguir a la gente, y entonces, perdemos mucho tiempo, en general. Aparte de esto, hay veces que has estado haciendo todo un trabajo y luego, cuando las cosas han avanzado, te dicen [se refiere a los órganos de gestión del PIRMI del Gobierno catalán]: "no hay cursos". Entonces, vamos a ver, si no hay salidas formativas para las personas, tú no puedes llenarte la boca metiendo presión al usuario, porque después te vienen con papeles del IMPO [Instituto Municipal de Promoción de la Ocupación ${ }^{6}$, Grameimpuls ${ }^{7}$, diciendo que no hay cursos.

(S. R., 1961, veinte años de servicio en los servicios sociales de base).
Finalmente, como habíamos empezado a indicar, la noción de trabajo 'educativo' no es uniforme entre los distintos profesionales. Para algunos, el trabajo 'educativo’ en el seno del PIRMI es entendido esencialmente como un trabajo que lleve a la participación del usuario o usuaria en dispositivos de formación que permitan llegar a encontrar un empleo o tener una mínima formación académica. Sin embargo, para otros esta noción puede ser mucha más amplia:

-S. N.: Mira, yo creo que un PIRMI, en este caso, senso strictu con la filosofía del PIRMI, no tendría que ser, ¿vale?

-Ego.: ¿Porque no habrá inserción?

-S. N.: Claro, yo me planteaba que ella tuviera una PIRMI, y él, una PNC [pensión no contributiva], pero claro, yo dudo que esta señora pueda tener una inserción, porque además la familia tampoco le va a dejar y... Pero supongo que, al menos, podremos romper un poco el nivel de poder. Nosotros no podemos romper el nivel de poder en la pareja, pero si el equilibrio, con pequeños empujones; lo podemos modificar un poco para que la señora tenga una vida más... Y es que cada vez está peor físicamente, cada vez más triste, y además cada vez tiene más problemas con el señor... Bueno y es que ¡está cansada! Está cansada y no la tratan bien [...].

(S. N., 1960, trabadora social, veinte años en los servicios sociales de base).

-V. R.: Un segundo perfil sería la gente que ha tenido una trayectoria -ahora me estoy acordando- que serían laborales con una trayectoria bohemia. Nosotros aquí, en el barrio, que es un barrio obrero, hay muchas casas antiguas y tal, y hay mucha ocupación, hay muchos okupas, ¿no? Aquí hay varias casas, aquí, en la montañita que se ve, varias casas tapiadas, hay okupas, ¿vale? Un día llegó aquí una pareja punki, panki, ¡dígale como sea! [...] pues vivían de vender en mercadillos y tal [tono de descalificación], venta ambulante sin cotizar, [ya] sabes, aquello [de]: "yo estoy en contra del sistema totalmente", [tono descalificante], "a mí todo lo que tenga que ver con el trabajo, todo esto de cotizar, ¡no!”; iba contra su ideología [tono descalificante]. Entonces, ¿qué pasa? 0 sea, por un lado, quiero estar fuera del sistema, y por el otro, tengo derecho y jno tengo obligación! Entonces esta familia cumplen los requisitos y, en un momento determinado, ella se ha quedado embarazada, se les tramita [la prestación], pero para que ellos puedan hacer otro replanteamiento de vida, ¿no?

(V. R., 1980, trabajadora social, cuatro años en los servicios sociales de base).

En el primer caso, vemos que el trabajo 'educativo' tiene mucho que ver con una transformación de la situación matrimonial de una mujer a partir de la

\footnotetext{
${ }^{6}$ El Instituto Municipal de Promoción de la Ocupación (IMPO) es un organismo autónomo municipal que tiene como objetivo mejorar la ocupabilidad de la población del municipio. Para ello, esta entidad oferta cursos y recursos para las personas que buscan trabajo.

7 Grameimpuls es una empresa municipal que busca promover la ocupación y la actividad empresarial. En este sentido, oferta cursos de formación ocupacional a los que son enviados las personas sin trabajo del municipio o de la comarca.
} 
movilización de instrumentos de la psicología -las relaciones de poder en el seno de una pareja-. En este último caso, las competencias profesionales particulares de la profesional determinan el contenido y sentido dado al acceso al PIRMI. En el segundo caso, el trabajo ‘educativo’ y la decisión de tramitación van unidos, por el contrario, a un cambio de estilo de vida vinculado a posiciones ideológicas de la profesional. Así, ésta defiende un modelo de estar en sociedad -tener un trabajo estable, cotizar a la Seguridad Social- que quiere que sus usuarios compartan.

\section{Conclusión}

A lo largo de este trabajo, hemos visto que la magistratura concedida a los profesionales de lo social en el acceso a un derecho social -la renta mínima de inserción- se confunde con una identidad profesional. Esta identidad profesional está socialmente situada. Es decir, la manera de concebir la tarea en los servicios sociales de base está vinculada a ciertas trayectorias sociales que corresponden a la interrelación entre biografías individuales y contextos sociopolíticos en España. Además, esta identidad profesional -hacer un trabajo 'educativo'-, si bien coincide, en términos generales, entre profesionales, presenta múltiples variantes en lo que concierne a sus concreciones. Para algunos, este trabajo educativo pasa por una inserción profesional esencialmente; para otros, por intervenir en dinámicas relacionales a partir del uso de conocimientos en el campo de la psicología; y, finalmente, para otros pasa por conseguir un cambio de posicionamiento ideológico del beneficiario.

En este sentido, podemos decir que la magistratura social que las rentas mínimas conllevan, al menos en el caso catalán, vincula derechos sociales a variables socialmente situadas, sometidas a transformaciones potenciales. Se puede, por ello, establecer que la magistratura de lo social implica que el sentido y contenido de los derechos sociales quede muy vinculado a la posición social de los magistrados, que se tornan productores de derecho en relaciones localizadas e interpersonales. 
AGUILAR, M. et al. (1995): La caña y el pez. El salario social en las comunidades autónomas, 1989-1994, Madrid, Fundación FOESSA.

ARRIBA, A. (1999): Rentas mínimas de inserción en España: procesos de implantación y dinámicas sociales [tesis doctoral], Madrid, Universidad Autónoma de Madrid.

BOURDIEU, P. (1979): La distinction. Critique sociale du jugement, París, Éditions de Minuit.

CASTEL, R. (1995): Les métamorphoses de la question sociale, París, Fayard.

CORTINAS, J. (2010): La renta mínima de inserción y la lucha contra la pobreza en Cataluña. Sociología de una reforma de los modelos de protección social [tesis doctoral], Barcelona, Universidad Autónoma de Barcelona; París, École des Hautes Études en Sciences Sociales.

DUBOIS, V. (2003a): “La sociologie de l’action publique. De la socio-histoire à l'observation des pratiques (et vice-versa)", en LABORIER, P.; y TROM, D., Historicités de l'action Publique, París, PUF, págs. 347-364 [<http://halshs. archives-ouvertes.fr/docs/00/46/43/22/PDF/ sociologiedelalactionpbliq.pdf $>$.

- (2003b): La vie au guichet. Relation administrative et traitement de la misère, París, Economica.

PRESIDÈNCIA DE LA GENERALITAT (2001a): “Decret 118/2001, de 2 de maig, pel qual es modifica el Decret 306/1998, d'1 de desembre, de desplegament de la Llei 10/1997, de 3 de juliol, de la Renda Mínima d'Inserció", Oficial de la Generalitat de Catalunya, nํㅜ 3.390, 17-5-2001, págs. 7.169 [khttp://tinyurl.com/7v5f6uos]. (2001b): “Decret 316/2001, de 20 de novembre, pel qual es modifica el Decret 306/1998, d'1 de desembre, de desplegament de la Llei 10/1997, de 3 de juliol, de la Renda Mínima d'Inserció”, Diari Oficial de la Generalitat de Catalunya, n- 3.531, 11-12-2001, pág. 18.994 [<http:// tinyurl.com/7bgb6xa〉].

- (1998): “Decret 306/1998, d'1 de desembre, de desplegament de la Llei 10/1997, de 3 de juliol, de la Renda Mínima d'Inserció", Diari Oficial de la Generalitat de Catalunya, n- 2.787, 1112-1998, págs. 15.286-15.290 [<http://tinyurl. com/7r2fh9g'].

- (1997): “Llei 10/1997, de 3 de juliol, de la Renda Mínima d'Inserció", Diari Oficial de la Generalitat de Catalunya, no 2.435, 17-7-1997, págs. 8.1828.187 [khttp://tinyurl.com/78hzdbc)].

- (1990): “Decret 144/1990, de 28 de maig, regulador del Programa Interdepartamental de la Renda Mínima d'Inserció (PIRMI)", Diari Oficial de la Generalitat de Catalunya, $\mathrm{n}-1.309,25-$ 6-1990, págs. 2.891-2.894 [khttp://tinyurl. com/85zo4gb〉].

LIPSKY, M. (1980): Street-level Bureaucracy. Dilemmas of the Individual in Public Services, Nueva York, Russell Sage Foundation.

SERRE, D. (2009): Les coulisses de l'État Social. Enquête sur les signalements d'enfant en danger, París, Raisons d'Agir.

SPIRE, A. (2008): Accueillir ou reconduire. Enquête sur les guichets de l'immigration, París, Raisons d'Agir.

TISSOT, S. (2007): L'État et les quartiers. Genèse d'une catégorie de l'action publique, París, Seuil. 



\section{Revisión de estudios de coste- efectividad en servicios de atención comunitaria y atención centrada en la persona}

\section{Madalen Saizarbitoria}

SIIS Centro de Documentación y Estudios Fundación Eguía-Careaga

<estudios@siis.net>

SIIS Dokumentazio eta Ikerketa Zentroak Matia Fundazioarentzat eginiko berrikusketa honetan, pertsonan zentratutako eta arreta komunitarioko esku-hartze eta programen eraginkortasuna eta kostuaren arteko lotura aztertzen da.

\section{HITZ-GAKOAK:}

kostua, eraginkortasuna, berrikusketa, zientzialiteratura, arreta soziosanitarioa.
En esta revisión elaborada por el SIIS Centro de Documentación y Estudios para la Fundación Matia, se analiza la relación coste-efectividad de las intervenciones y programas comunitarios y centrados en la persona.

\section{Palabras Clave:}

coste, efectividad, revisión, literatura científica, atención sociosanitaria. 


\section{Introducción}

La Fundación Matia ha puesto en práctica un proceso de investigación para el diseño de nuevas formas de cuidado a personas dependientes o con discapacidad, con el objeto de desarrollar un nuevo modelo de atención comunitaria, individualizada e integral, en el ámbito del espacio sociosanitario. En el marco de ese proceso, se ha considerado necesario valorar los resultados que, en términos de coste-efectividad, supondría la adopción de un modelo de esas características, a partir de la literatura científica existente al respecto en los países de nuestro entorno.

Para ello, se ha solicitado al SIIS Centro de Documentación y Estudios de la Fundación Eguía-Careaga que elabore un estudio de revisión de la literatura científica que analiza el impacto económico y la relación coste-efectividad de las intervenciones, los programas o las políticas basadas en enfoques coincidentes con los del modelo que la Fundación Matia propone desarrollar. El objetivo final de este análisis es el de conocer la evidencia científica disponible en cuanto a la relación coste-efectividad de intervenciones y políticas de atención que puedan asociarse al paradigma de intervención planteado por la Fundación Matia, de forma que, a la hora de plantear el contenido de ese modelo, puedan incorporarse a él todas aquellas intervenciones, prácticas o enfoques que hayan demostrado ya, mediante estudios de evaluación rigurosos y de contrastada calidad, una relación positiva de coste-efectividad.

La revisión que se describe en este informe es una revisión sistemática cuyo objetivo consiste en sintetizar el conocimiento científico actualmente existente sobre las intervenciones que mejores resultados obtienen en el ámbito de la atención a personas mayores, tanto en términos de la calidad de la atención dispensada, como de su coste. Esto permitirá a las personas responsables de los proyectos de la Fundación Matia adoptar sus decisiones basándose en la mejor evidencia disponible y, por lo tanto, avanzar por el camino de la práctica basada en la evidencia.

De acuerdo con los objetivos del trabajo, se ha procedido a realizar una búsqueda sistemática de estudios científicos publicados sobre la relación coste-efectividad de intervenciones sociales o sociosanitarias para personas mayores o personas con discapacidad. Las búsquedas se han realizado siguiendo un protocolo que implica la progresión desde bases de datos más especializadas a aquellas de corte más general. En concreto, la búsqueda se ha realizado en cinco bases de datos: la base de datos bibliográfica del SIIS Centro de Documentación y Estudios, las bases de datos de revisiones sistemáticas y de evaluaciones económicas del Centre for Reviews and Dissemination (CRD) del Sistema Nacional de Salud (NHS) británico, la Biblioteca Cochrane, Pubmed y la base de datos científica Web of Knowledge (WOK).

Los criterios de búsqueda utilizados han sido los siguientes:
- Personas mayores o personas con discapacidad o personas con enfermedades crónicas o personas con enfermedades terminales o personas con dependencia o demencia o Alzheimer o personas con enfermedad mental; $y$

- atención social o servicios sociales o servicios sociosanitarios; y

- coordinación sociosanitaria o espacio sociosanitario o atención integrada o intervención comunitaria o servicios comunitarios o atención comunitaria o planificación centrada en la persona 0 atención centrada en la persona 0 individualización de la atención o personalización de la atención; y

- coste-eficacia o coste-utilidad o coste-efectividad o coste-beneficio.

Tras aplicar estos criterios, se han excluido 142 estudios, reduciéndose la selección final a 84 documentos, que constituyen la muestra finalmente analizada. Hay que tener en cuenta, no obstante, que 28 de los 84 documentos revisados son, en realidad, revisiones de la literatura que, por lo tanto, son, a su vez, una síntesis de cientos de estudios de investigación. Aunque algunos de los estudios individuales incluidos en esta revisión ya habían sido considerados en alguna de las revisiones utilizadas, esto amplía considerablemente el alcance de este trabajo ${ }^{1}$.

Los estudios incluidos se han clasificado en siete tipos, de acuerdo con su diseño metodológico. Por orden descendiente de calidad en relación con la fiabilidad de los datos que pueden aportar, se distinguen: las revisiones de la literatura científica, los ensayos aleatorios o estudios controlados aleatorios, los estudios controlados no aleatorios, los estudios pre-post sin grupo de control, los estudios exploratorios, los estudios de casos y los estudios teóricos.

\section{Resultados de la revisión de los estudios}

\subsection{Descripción}

\subsubsection{Tipo de estudio y calidad metodológica}

Se han encontrado y revisado 84 artículos e informes en los que se analiza la eficiencia de servicios e intervenciones coincidentes con el modelo de atención objeto de estudio en términos de su coste y efectividad. Prácticamente una cuarta parte de esos estudios (20 de los 84) son revisiones de la literatura que sintetizan los resultados de evaluaciones económicas anteriores; la tercera parte (28 de los 84 ) son ensayos aleatorios que, en principio, pueden poseer una buena validez interna y, por lo tanto, ofrecen mayor certeza de que existe una relación causal entre la intervención realizada y el efecto observado; y algo más de una quinta parte son estudios con grupo de

${ }^{1}$ De hecho, constituye una buena práctica en la realización de revisiones de la literatura considerar en primer lugar revisiones realizadas con anterioridad. 
control. Tal y como se ha explicado anteriormente, también se han incluido algunos estudios con metodologías menos robustas, como estudios pre-post sin grupo de control (cinco documentos), estudios exploratorios (siete documentos) o estudios de casos (dos documentos). Finalmente, cuatro documentos estiman el impacto de las intervenciones que evalúan de forma teórica.

Tabla 1. Estudios revisados, por tipo de diseño utilizado

\begin{tabular}{l|c|c}
\hline Tipo de diseño & $\begin{array}{c}\text { № de } \\
\text { documentos }\end{array}$ & $\%$ \\
\hline Revisión de la literatura & 20 & 23,8 \\
\hline Ensayo aleatorio & 28 & 33,3 \\
\hline Estudio controlado no aleatorio & 18 & 21,4 \\
\hline Estudio pre-post sin grupo control & 5 & 6,0 \\
\hline Estudio de casos & 2 & 2,4 \\
\hline Estudio exploratorio & 7 & 8,3 \\
\hline Modelo teórico & 4 & 4,8 \\
\hline Total & $\mathbf{8 4}$ & $\mathbf{1 0 0 , 0}$ \\
\hline
\end{tabular}

Fuente: Elaboración propia.

Atendiendo al tipo de evaluación económica realizada, 50 de los 84 analizan la relación coste-efectividad de la intervención, doce son estudios de costeutilidad (traducen todos los beneficios a un mismo indicador), y cuatro son estudios de coste-beneficio (traducen los beneficios a términos económicos).

Tabla 2. Estudios revisados, por tipo de evaluación económica de que se trate

\begin{tabular}{l|c|c}
\hline Tipo de evaluación económica & $\begin{array}{c}\text { No de } \\
\text { documentos }\end{array}$ & $\%$ \\
\hline Estudio de coste-eficacia & 51 & 60,7 \\
\hline Estudio de coste-utilidad & 9 & 10,7 \\
\hline Estudio de coste-beneficio & 4 & 4,8 \\
\hline Estudio de minimización de costes & 2 & 2,4 \\
\hline Estudio de costes & 7 & 8,3 \\
\hline No es una evaluación económica completa & 4 & 4,8 \\
\hline No se puede determinar & 7 & 8,3 \\
\hline Total & $\mathbf{8 4}$ & $\mathbf{1 0 0 , 0}$ \\
\hline
\end{tabular}

Fuente: Elaboración propia.

De los 60 estudios revisados que evalúan una intervención de forma experimental (excluyendo, por tanto, las revisiones de la literatura y los modelos teóricos), una tercera parte provienen del Reino Unido y prácticamente otros tantos de los Estados Unidos. El resto provienen de países como Canadá, Suecia, España, Países Bajos, Irlanda, Italia, Australia, China, Francia, Noruega y Nueva Zelanda. Estas cifras no sólo reflejan la mayor tradición investigadora en el ámbito de la intervención social en los países anglosajones, sino también, y de forma significativa, la mayor preocupación que existe en esos países por la eficiencia y la productividad de las intervenciones sociosanitarias.

Por lo que se refiere al año de publicación de los estudios, dado que a la hora de realizar la búsqueda de documentos la selección no se ha restringido a los publicados con posterioridad a una fecha, existe una gran variedad, desde los más antiguos, que se remontan a finales de la década de los ochenta, hasta los más recientes, publicados en 2011. En cualquier caso, la mayoría de los estudios incluidos ( 44 de los 84 revisados) son posteriores a 2005 y una tercera parte (26 de los 84) se publicaron entre 2000 y 2005. Esta distribución refleja probablemente un creciente interés por la relación coste-efectividad de las intervenciones sociales en el ámbito internacional, así como un progresivo desarrollo de las técnicas y las metodologías necesarias para la aplicación práctica de este tipo de enfoques.

En general, y teniendo presente que, tal y como se ha mencionado, la escala utilizada para la selección de los documentos es muy rigurosa, dadas las condiciones en las que frecuentemente tiene que llevarse a cabo la investigación en el ámbito sociosanitario, la validez interna de los estudios incluidos en la revisión puede calificarse de media-baja. De los 56 estudios que se han podido valorar (19 estudios eran revisiones sistemáticas y 9 documentos no daban información suficiente para aplicar el instrumento de valoración); 7 tienen una buena validez interna, es decir, se trata de ensayos aleatorios con un buen diseño; y 26 tienen una calidad aceptable, es decir, son ensayos aleatorios de calidad media o estudios controlados no aleatorios con un adecuado control de los posibles factores de confusión. Los 22 estudios restantes son pobres en cuanto a su validez interna, es decir, no controlan adecuadamente los posibles factores de confusión, lo que, si bien no invalida sus conclusiones, sí introduce un cierto factor de incertidumbre en ellas.

Tabla 3. Estudios revisados, según su validez interna

\begin{tabular}{l|c|c|c}
\hline Validez interna del estudio & $\begin{array}{c}\text { № de } \\
\text { documentos }\end{array}$ & $\%$ & \% válido \\
\hline Excelente & 1 & 1,2 & 1,8 \\
\hline Buena & 7 & 8,3 & 12,5 \\
\hline Satisfactoria & 26 & 31,0 & 46,4 \\
\hline Pobre & 22 & 26,2 & 39,3 \\
\hline $\begin{array}{l}\text { No aplicable (revisiones } \\
\text { sistemáticas/información } \\
\text { insuficiente) }\end{array}$ & 28 & 33,3 & 100,0 \\
\hline \begin{tabular}{l} 
Total \\
\hline
\end{tabular} & $\mathbf{8 4}$ & $\mathbf{1 0 0 , 0}$ & - \\
\hline
\end{tabular}

Fuente: Elaboración propia.

Por el contrario, puede decirse que, en general, la validez externa de los estudios analizados es mucho mejor, pudiéndose considerar los resultados adecuadamente extrapolables a toda la población objeto de estudio en 
28 de los 57 estudios valorados, y de generalizabilidad limitada solamente en 8 casos. En 28 de los casos, en la medida en que se trata de revisiones de otros estudios, el criterio de validez externa no se aplica.

Tabla 4. Estudios revisados, según su validez externa

\begin{tabular}{l|c|c|c}
\hline Validez externa del estudio & $\begin{array}{c}\text { № de } \\
\text { documentos }\end{array}$ & $\%$ & \% válido \\
\hline Buena & 47 & 56,0 & 83,9 \\
\hline Limitada & 7 & 8,3 & 12,5 \\
\hline Pobre & 2 & 2,4 & 3,6 \\
\hline No aplicable & 28 & 33,3 & 100,0 \\
\hline Total & $\mathbf{8 4}$ & $\mathbf{1 0 0 , 0}$ & - \\
\hline
\end{tabular}

Fuente: Elaboración propia.

Finalmente, por lo que se refiere a la calidad de la evaluación económica, la mayoría de los estudios revisados tienen una calidad buena (43,6\%) o aceptable (43,6\%), de acuerdo con los criterios señalados anteriormente.

Tabla 5. Estudios revisados, por calidad de la evaluación económica

\begin{tabular}{l|c|c|c}
\hline $\begin{array}{l}\text { Calidad de la evaluación } \\
\text { económica }\end{array}$ & $\begin{array}{c}\text { № de } \\
\text { documentos }\end{array}$ & $\%$ & \% válido \\
\hline Buena & 24 & 28,6 & 43,6 \\
\hline Aceptable & 24 & 28,6 & 43,6 \\
\hline Pobre & 7 & 8,3 & 12,7 \\
\hline No se puede determinar & 1 & 1,2 & 100,0 \\
\hline $\begin{array}{l}\text { No aplicable (revisiones } \\
\text { sistemáticas/información } \\
\text { insuficiente) }\end{array}$ & 28 & 33,3 & - \\
\hline \begin{tabular}{l} 
Total \\
\hline
\end{tabular} & $\mathbf{8 4}$ & $\mathbf{1 0 0 , 0}$ & - \\
\hline
\end{tabular}

Fuente: Elaboración propia.

\subsubsection{Tipo de intervenciones evaluadas}

Los 84 documentos revisados analizan un total de 92 intervenciones distintas, que se han agrupado en 18 grandes grupos. En la mayoría de los casos, se trata de fórmulas de alojamiento en la comunidad (15 documentos), fórmulas de coordinación de servicios sociosanitarios (11 documentos), intervenciones de promoción del autocuidado (10 documentos), intervenciones de gestión de casos (8 documentos), servicios de día, ayudas tecnológicas y programas de prevención de caídas (6 documentos), o fórmulas de individualización de la atención (5 documentos). Para otras intervenciones que pueden ser de especial interés en el marco de este trabajo, como la planificación centrada en la persona, se han encontrado muy pocos estudios que incorporen una evaluación económica.

Casi la mitad de los documentos que se han incluido en la revisión se centran en cuatro tipos de intervenciones específicas: las fórmulas de alojamiento en la comunidad, la coordinación entre los servicios sociales y sanitarios en el ámbito del espacio sociosa- nitario, el autocuidado y la gestión de casos. La propia relevancia de estos tipos de intervención en el contexto de la literatura analizada pone ya de manifiesto, al margen de los resultados obtenidos en términos de coste-efectividad, que son éstas las intervenciones que en mayor medida se han puesto en práctica, y se han evaluado, en los países de nuestro entorno.

Por lo que se refiere a los colectivos destinatarios de las intervenciones evaluadas, 59 de las 92 se refieren a personas mayores, ya sean personas mayores dependientes o en riesgo de dependencia. También se han incluido 18 intervenciones dirigidas a personas con discapacidad, 3 a personas con enfermedades crónicas y 12 dirigidas a personas que se encargan del cuidado informal de personas mayores o con discapacidad.

Las 92 intervenciones evaluadas refieren un total de 185 objetivos diferentes, que han sido agrupados en trece objetivos básicos. El propio listado resulta de interés, en la medida en que pone de manifiesto los objetivos fundamentales que se buscan mediante la puesta en práctica de las intervenciones analizadas. De acuerdo con la Tabla 6, cuatro objetivos concentran algo más de la mitad de todas las intervenciones analizadas: la mejora de la calidad de vida de las personas usuarias, señalado en 31 ocasiones; la reducción en el uso de servicios sanitarios, en 25 ocasiones; el retraso o la evitación de la institucionalización, en 23 ocasiones; y la mejora del estado de salud de las personas objeto de la intervención, en 18 ocasiones. Además, 19 intervenciones tienen el objetivo añadido de reducir el coste de la atención prestada.

Tabla 6. Intervenciones evaluadas, por tipos de objetivos perseguidos

\begin{tabular}{|c|c|c|}
\hline Objetivo de la intervención & $\begin{array}{c}\text { № de } \\
\text { intervenciones }\end{array}$ & $\%$ \\
\hline Mejorar la calidad de vida & 31 & 16,8 \\
\hline Reducir el uso de servicios sanitarios & 25 & 13,5 \\
\hline Retrasar o evitar la institucionalización & 23 & 12,4 \\
\hline Reducir el coste & 19 & 10,3 \\
\hline $\begin{array}{l}\text { Mejorar el estado de salud de las personas } \\
\text { usuarias }\end{array}$ & 18 & 9,7 \\
\hline $\begin{array}{l}\text { Incrementar el grado de satisfacción de las } \\
\text { personas usuarias }\end{array}$ & 16 & 8,6 \\
\hline Mejorar o mantener la capacidad funcional & 14 & 7,6 \\
\hline $\begin{array}{l}\text { Reducir la carga de trabajo de las personas } \\
\text { cuidadoras }\end{array}$ & 11 & 5,9 \\
\hline Reducir el uso de servicios formales & 11 & 5,9 \\
\hline $\begin{array}{l}\text { Incrementar la autodeterminación o el } \\
\text { autocontrol de las personas usuarias }\end{array}$ & 7 & 3,8 \\
\hline Prevención de caídas & 6 & 3,2 \\
\hline $\begin{array}{l}\text { Empoderamiento / incrementar la } \\
\text { autoeficacia }\end{array}$ & 3 & 1,6 \\
\hline $\begin{array}{l}\text { Incrementar el acceso a servicios } \\
\text { comunitarios preventivos }\end{array}$ & 1 & 0,5 \\
\hline Total & 185 & 100,0 \\
\hline
\end{tabular}

Fuente: Elaboración propia. 


\subsection{Resultados sobre coste-efectividad}

Cincuenta y ocho de las noventa y dos intervenciones evaluadas pueden considerarse coste-efectivas, mientras que cuatro no pueden ser consideradas como tales. En catorce de los casos analizados se obtienen mejores resultados a un mayor coste, o peores resultados a un menor coste, con lo que habría que valorar si el incremento o la reducción del coste compensan la mejora o la reducción de la efectividad. Finalmente, para dieciséis de las intervenciones evaluadas no existe información suficiente para afirmar si la intervención resulta o no coste-efectiva, o los resultados son contradictorios.

Si el porcentaje de intervenciones consideradas coste-efectivas se analiza desde el punto de vista de los colectivos destinatarios de la atención, se observa -dejando al margen a las personas con enfermedades crónicas, a quienes se dirigen solamente tres de las intervenciones analizadasque es en el caso de las intervenciones dirigidas a personas con discapacidad donde se registra un mayor porcentaje de intervenciones coste-efectivas, puesto que prácticamente dos de cada tres intervenciones analizadas se han considerado como tales. En el caso de las personas mayores, se consideraron coste-efectivas el 63,9\% de las intervenciones, y en el caso de las intervenciones destinadas a las personas cuidadoras informales, únicamente el $40 \%$. En este caso, cuatro de cada diez estudios se consideraron no concluyentes.

Tabla 7. Intervenciones evaluadas, por valoración sobre coste-efectividad y colectivo destinatario de la atención

\begin{tabular}{l|c|c|c}
\hline \multirow{2}{*}{ Colectivo } & Resultados & $\begin{array}{c}\text { № de } \\
\text { intervenciones }\end{array}$ & $\%$ \\
\hline \multirow{4}{*}{$\begin{array}{l}\text { Personas } \\
\text { mayores }\end{array}$} & Coste-efectivo & 39 & 63,9 \\
\cline { 2 - 4 } & No coste-efectivo & 2 & 3,3 \\
\cline { 2 - 4 } & No dominante & 9 & 14,8 \\
\cline { 2 - 4 } & No concluyente & 9 & 3,3 \\
\hline \multirow{3}{*}{$\begin{array}{l}\text { Personas con } \\
\text { discapacidad }\end{array}$} & No dominante & 3 & 14,8 \\
\cline { 2 - 4 } & No concluyente & 3 & 16,7 \\
\hline \multirow{3}{*}{$\begin{array}{l}\text { Cuidadores } \\
\text { informales }\end{array}$} & Coste-efectivo & 4 & 40,0 \\
\cline { 2 - 4 } & No coste-efectivo & 2 & 20,0 \\
\cline { 2 - 4 } & No concluyente & 4 & 40,0 \\
\hline $\begin{array}{l}\text { Personas con } \\
\text { enfermedades } \\
\text { crónicas }\end{array}$ & Coste-efectivo & 3 & 100,0 \\
\hline
\end{tabular}

Fuente: Elaboración propia.

No puede decirse, por otra parte, que el tipo de metodología utilizada en la revisión se relacione con el porcentaje de intervenciones consideradas costeefectivas, y menos aún que las intervenciones realizadas con los métodos a priori más exigentes, los estudios controlados aleatorios, registren un porcentaje de intervenciones coste-efectivas más bajo. Al contrario, los estudios controlados aleatorios resultan coste-efectivos en el $67,9 \%$ de los casos, y los estudios controlados no aleatorios, en el 66,7\%. Ambos tipos de estudios se encuentran, de hecho, entre los que registran un porcentaje más elevado de resultados coste-efectivos.

Tabla 8. Intervenciones evaluadas, por valoración sobre coste-efectividad y metodología utilizada

\begin{tabular}{|c|c|c|c|}
\hline Tipo de estudio & Resultado & $\mathbf{N}$ & $\%$ \\
\hline \multirow{5}{*}{$\begin{array}{l}\text { Estudio controlado } \\
\text { aleatorio }\end{array}$} & Coste-efectivo & 19 & 67,9 \\
\hline & No coste-efectivo & 2 & 7,1 \\
\hline & No dominante & 3 & 10,7 \\
\hline & Neutro & 2 & 7,1 \\
\hline & No concluyente & 2 & 7,1 \\
\hline \multirow{3}{*}{$\begin{array}{l}\text { Estudio controlado no } \\
\text { aleatorio }\end{array}$} & Coste-efectivo & 12 & 66,7 \\
\hline & No dominante & 3 & 16,7 \\
\hline & No concluyente & 3 & 16,7 \\
\hline \multirow{3}{*}{$\begin{array}{l}\text { Estudio pre-post sin } \\
\text { grupo control }\end{array}$} & Coste-efectivo & 1 & 20,0 \\
\hline & No dominante & 3 & 60,0 \\
\hline & No concluyente & 1 & 20,0 \\
\hline \multirow{3}{*}{ Estudio exploratorio } & Coste-efectivo & 5 & 71,4 \\
\hline & No dominante & 1 & 14,3 \\
\hline & No concluyente & 1 & 14,3 \\
\hline \multirow{2}{*}{ Estudio de casos } & Coste-efectivo & 1 & 50,0 \\
\hline & No concluyente & 1 & 50,0 \\
\hline Estudio teórico & Coste-efectivo & 4 & 100,0 \\
\hline \multirow{4}{*}{ Revisión de la literatura } & Coste-efectivo & 16 & 57,1 \\
\hline & No coste-efectivo & 2 & 7,1 \\
\hline & No dominante & 2 & 7,1 \\
\hline & No concluyente & 8 & 28,6 \\
\hline
\end{tabular}

Fuente: Elaboración propia.

Desde el punto de vista del tipo de intervención, las que en mayor medida se han considerado costeefectivas son las relacionadas con la coordinación de servicios sociosanitarios, ya sea a través de la integración (100\% de intervenciones coste-efectivas), o a través de la gestión de casos $(87,5 \%$ de costeefectividad). Le siguen los programas orientados a la prestación de ayudas tecnológicas ( $83 \%$ de intervenciones consideradas coste-efectivas), los programas de promoción del autocuidado (80\%, con diez intervenciones analizadas), las visitas domiciliarias preventivas $(75 \%)$ y las fórmulas de alojamiento en la comunidad ( $73 \%$, con quince intervenciones analizadas). También registran un porcentaje elevado de intervenciones consideradas coste-efectivas los servicios de atención domiciliaria (67\%), si bien en estos casos el número de intervenciones evaluadas es más reducido. 
En general, las intervenciones menos evaluadas son las que en mayor medida muestran resultados no concluyentes, no dominantes o no coste-efectivos. Así por ejemplo, ninguna de las dos intervenciones orientadas a los servicios de rehabilitación se ha mostrado coste-efectiva, y sólo una de las tres intervenciones centradas en los servicios de respiro o en los programas de asignación económica individual.

Tabla 9. Intervenciones coste-efectivas por tipo de intervención

\begin{tabular}{|c|c|c|}
\hline Tipo de intervención & $\begin{array}{c}\text { № de } \\
\text { intervenciones } \\
\text { coste-efectivas }\end{array}$ & $\begin{array}{c}\% \text { sobre el } \\
\text { total de cada } \\
\text { tipo }\end{array}$ \\
\hline Servicios sociosanitarios integrados & 4 & 100,0 \\
\hline Gestión de casos & 7 & 87,5 \\
\hline Ayudas tecnológicas & 5 & 83,3 \\
\hline Autocuidado & 8 & 80,0 \\
\hline Visitas domiciliarias preventivas & 3 & 75,0 \\
\hline $\begin{array}{l}\text { Fórmulas de alojamiento en la } \\
\text { comunidad }\end{array}$ & 11 & 73,3 \\
\hline Ayuda a domicilio & 2 & 66,7 \\
\hline $\begin{array}{l}\text { Otras fórmulas de individualización } \\
\text { de la atención }\end{array}$ & 3 & 60,0 \\
\hline $\begin{array}{l}\text { Otras fórmulas de coordinación de } \\
\text { servicios sociosanitarios }\end{array}$ & 6 & 54,5 \\
\hline Servicios comunitarios en general & 1 & 50,0 \\
\hline Servicios de día & 3 & 50,0 \\
\hline Prevención de caídas & 3 & 50,0 \\
\hline Servicios de respiro & 1 & 33,3 \\
\hline Asignación económica individual & 1 & 33,3 \\
\hline Servicios de rehabilitación & 0 & 0,0 \\
\hline Re-capacitación a domicilio & 0 & 0,0 \\
\hline Servicios de acompañamiento & 0 & 0,0 \\
\hline Planificación centrada en la persona & 0 & 0,0 \\
\hline
\end{tabular}

Fuente: Elaboración propia.

Hay también determinados tipos de intervención que no parecen mostrarse en ningún caso costeefectivos: se trata de los servicios de rehabilitación, los de re-capacitación a domicilio, los servicios de acompañamiento y los de planificación centrada en la persona. Se trata, en cualquier caso, de intervenciones sometidas a muy escasas evaluaciones (en general, una sola) que tienden a mostrar resultados no concluyentes o no dominantes, es decir, a obtener resultados positivos en términos de efectividad, si bien a un coste más elevado que las intervenciones alternativas con las que se comparan.

Los resultados de la Tabla 9 han de ser interpretados con precaución: no puede derivarse de ellos, por ejemplo, que los programas de gestión de casos sean en todo momento coste-efectivos, o que cualquier programa de gestión de casos que se desarrolle lo vaya a ser. En ese sentido, hay que tener en cuenta al menos tres cuestiones:

- Por una parte, no debe olvidarse que el carácter coste-efectivo de una intervención se establece comparándola con una intervención alternativa. Cabría la posibilidad de que, de aplicarse en otro contexto, y al compararse con otra intervención, un mismo programa dejara de considerarse coste-efectiva.

- Por otra parte, el carácter coste-efectivo de un programa no implica que, incluso aunque se aplicara de la misma forma, fuera a resultar igualmente coste-efectivo en otro contexto o circunstancia.

- Por último, el hecho de que una serie de intervenciones determinadas -por ejemplo, las relacionadas con la gestión de casos- hayan sido consideradas mayoritariamente coste-efectivas no implica que todas las intervenciones realizadas en esa misma línea lo vayan a ser. Ello dependerá, lógicamente, de la forma concreta en la que se materialice esa intervención, del perfil de las personas atenidas o de los recursos invertidos.

Los datos de la tabla sí indican, sin embargo, que existen una serie de ámbitos de intervención fundamentalmente, la gestión de casos, las ayudas tecnológicas, los programas de autocuidado, los servicios sociosanitarios integrados, las fórmulas de alojamiento en la comunidad y los servicios de ayuda a domicilio- que se han evaluado en un número considerable de ocasiones y que han resultado coste-efectivas en un porcentaje muy elevado de esas ocasiones. Puede decirse, por tanto, que se trata de líneas de intervención con un elevado potencial en términos de coste-efectividad, en la medida en que, en la mayoría de los casos en los que se han desarrollado y se han evaluado con criterios metodológicos rigurosos y contrastados, se ha hallado una relación de coste-efectividad positiva.

\section{Principales conclusiones}

Las conclusiones de este informe constituyen una base sólida sobre la que ir construyendo un modelo de atención a personas mayores que no sólo sea más efectivo en términos de mejora de su grado de autonomía, su participación y empoderamiento, su grado de satisfacción con los servicios recibidos 0 , en definitiva, su calidad de vida, sino que, además, alcance esos objetivos de la manera más eficiente posible desde el punto de vista económico, permitiendo utilizar los recursos allí donde más útiles pueden resultar.

La solidez de las conclusiones se deriva fundamentalmente del elevado número de investigaciones analizadas y del cumplimiento de una serie de criterios temáticos y metodológicos estrictos para su inclusión en este estudio. Aun teniendo en cuenta las limitaciones señaladas en el punto anterior, la revisión 
de la literatura realizada ofrece unas conclusiones generales que establecen, con claridad, el carácter coste-efectivo de la mayor parte de las intervenciones analizadas. Una extrapolación lógica de estos datos permite afirmar que la puesta en práctica de un modelo de atención basado en este tipo de intervenciones en la CAPV sería potencialmente costeefectiva. En ese sentido, cabe pensar que el desarrollo de este tipo de intervenciones permitiría no sólo mantener o mejorar la situación de las personas atendidas en términos de calidad de vida, mejora del estatus funcional y de salud, autodeterminación, integración o satisfacción con los servicios prestados, sino, además, hacerlo destinando a esos programas un nivel de recursos económicos igual o inferior.

Junto a esta conclusión general, los resultados más significativos de la revisión realizada son los siguientes:

- Se han detectado cinco tipos de intervenciones - la gestión de casos, las ayudas tecnológicas y para la adaptación de la vivienda, los programas de autocuidado, las fórmulas de alojamiento en la comunidad y la atención intermedia- que: a) han sido sometidas a un número elevado de evaluaciones, y b) resultan mayoritariamente costeefectivas. Desde ese punto de vista, y aun teniendo en cuanta las limitaciones señaladas en el epígrafe anterior, cabe pensar que cualquier modelo de atención comunitaria e individualización de los cuidados que quiera desarrollarse en nuestro entorno deberá incorporar, en la mayor medida posible, este tipo de intervenciones.

- Existe otro grupo de intervenciones -los servicios sociosanitarios integrados, la ayuda a domicilio y los programas de individualización de la atención-que también resultan mayoritariamente coste-efectivos, si bien el número de evaluaciones revisadas es sustancialmente menor, y la base para sostener su coste-efectividad es, por tanto, más limitada.

- Por último, hay un número relativamente elevado de intervenciones -los programas de prevención de caídas, los servicios de día, las visitas domiciliarias preventivas, los servicios de respiro, las asignaciones económicas individuales, los servicios de rehabilitación, los servicios de recapacitación a domicilio o los servicios de acompañamiento- que no han podido demostrar su coste-efectividad.

- En la mayor parte de estos casos, sin embargo, el número de evaluaciones revisadas es reducido, por lo que su carácter no coste-efectivo no puede establecerse con rotundidad. Además, cabe señalar que en pocos casos los programas se consideran no coste-efectivos (es decir, no consiguen resultados mejores al mismo o inferior coste); por lo general, estos estudios arrojan resultados no concluyentes o muestran una relación coste-efectividad no dominante (en la que, generalmente, se obtienen mejores resultados a costes superiores, o el gasto realizado es mayor que el ahorro inducido).
- No puede decirse, por otra parte, que la metodología empleada implique un sesgo importante en los resultados. Los estudios que han utilizado una metodología a priori más exigente, los estudios controlados aleatorios, resultan coste-efectivos en el $67 \%$ de los casos, y los estudios controlados no aleatorios, en el $66 \%$. Ambos tipos de estudios se encuentran, de hecho, entre los que registran un porcentaje más elevado de resultados coste-efectivos.

- El relativamente elevado número de investigaciones no concluyentes pone de manifiesto la necesidad de intensificar los esfuerzos dirigidos a analizar la relación coste-efectividad de los programas, sobre todo en aquellos casos en los que los resultados parecen menos claros (servicios de respiro, de atención diurna, prestaciones económicas). En ese sentido, la revisión realizada en este informe puede contribuir al diseño, en la CAPV, de un modelo de evaluación económica que permita establecer, con el necesario rigor, la relación coste-efectividad de los diversos servicios y prestaciones.

Con esta base, los elementos que cabe subrayar para la definición de un modelo de atención en la CAPV son los siguientes:

- La coordinación de los servicios sociales y sanitarios se ha mostrado altamente coste-efectiva, especialmente cuando se consigue la integración total de la atención para determinado colectivo. Aún en los casos en los que la completa integración no resulta posible por limitaciones organizativas, uno de sus elementos clave, la gestión de casos, sí resulta coste-efectiva incluso cuando se aplica de forma aislada. Esta forma de trabajo supone crear equipos multidisciplinares y designar a un gestor de casos, que adoptará la responsabilidad de coordinar y hacer un adecuado seguimiento de toda la atención que requiere la persona mayor. Este enfoque coincide, precisamente, con el adoptado en la iniciativa experimental Etxean Ondo (〈http://www.ingema. es/es/projects/etxean-ondo/>), desarrollada por la Fundación Matia.

- La promoción de la salud de las personas mayores por medio de programas de autocuidado también resulta una intervención preventiva altamente coste-efectiva que se podría implantar en el modelo que la Fundación Matia está desarrollando. Estas intervenciones, cuando están bien insertadas en la rutina de la persona mayor e implican la realización de actividades significativas relacionadas con la vida diaria, pueden mejorar el estado de salud de los mayores y suponer un importante ahorro para los servicios sanitarios y sociales.

- Las fórmulas de alojamiento residencial para personas mayores deben estar bien insertadas en su comunidad, permitiendo la participación de las personas en la mayor medida posible. Aunque 
no puede garantizar la calidad de la atención, ésta se ve favorecida en entornos pequeños con un ambiente hogareño. La investigación llevada a cabo en el ámbito de la discapacidad pone de manifiesto, en cualquier caso, que las 'deseconomías de escala' sólo se producen a partir de tamaños muy reducidos, inferiores a tres plazas.

- La adecuada prestación de ayudas técnicas y pequeñas adaptaciones en la vivienda puede suponer un importante ahorro de recursos, en la medida en que previene la utilización de servicios más costosos, tal y como han puesto de manifiesto los estudios revisados. En este sentido, un programa de adaptaciones mínimas complementario al servicio de ayuda a domicilio -ayudas técnicas para facilitar la entrada y salida de la bañera (alfombra, asideros y tabla de transferencia), sentarse y levantarse del retrete (elevador de retrete y asideros) y de la butaca (alzas), el desplazamiento en el interior de la casa (bastón) y entrada y salida de la cama (alzacamas y barandilla)- podría suponer un importantísimo ahorro para la Administración si se proveyera de forma sistemática a todas las personas usuarias del servicio de ayuda a domicilio.

- Los servicios de respuesta rápida y de intervención en crisis, dirigidos a personas mayores y con discapacidad en riesgo de ser admitidas en un hospital o un centro residencial (por un accidente o emergencia) pueden liberar camas hospitalarias y prevenir ingresos residenciales definitivos, lo que supone un importante ahorro para la Administración.

- De acuerdo con los resultados de esta revisión, los servicios de respiro deberían limitarse, de momento, al respiro residencial, el único que ha demostrado algún grado de coste-efectividad. Por otra parte, hay que tener en cuenta que, en el caso de personas mayores cuidadas por sus cónyuges, los servicios de respiro residencial, más que prevenir el ingreso definitivo, pueden provocarlo o precipitarlo. Sí se consideran una intervención coste-efectiva y de carácter preventivo en el caso de personas mayores que son cuidadas por sus hijos/as.

- La recapacitación a domicilio, a pesar de que su coste-efectividad todavía no se ha podido demostrar de forma concluyente, tiene muchas posibilidades de resultarlo, por su capacidad de reducir las necesidades de ayuda formal de las personas que pasan por el servicio, por lo que se recomienda su adopción en la CAPV, al menos de forma experimental. 
AH-SOUNE, M. F.; y DE VIGNERTE, B. (2000): "Intérêts et couts d'une réinsertion gériatrique après séjour en soins de suite et réadaptation", La Revue de Geriatrie, vol. 25, no 7 , págs. 471-476.

ANDRICH, R.; y CARACCIOLO, A. (2007): "Analysing the cost of individual assistive technology programmes", Disability and Rehabilitation: Assistive Technology, vol. 2, nํㅜ 4, págs. 207-234.

ARKSEY, H. et al. (2004): Review of Respite Services and Short-Term Breaks for Carers for People with Dementia, Londres, NHS Service Delivery and Organisation R\&D Program.

ARTASO, B. et al. (2002): "Análisis coste-consecuencia de un centro de día psicogeriátrico", Revista Española de Geriatría y Gerontología, vol. 37, nำ6, págs. 291-297.

ASHTON, T.; HEMPENSTALL, C. (2009): Research into the Financial Benefits of the Supporting People Programme, 2009, Londres, Department for Communities and Local Government.

BAUMKER, T. et al. (2008): Costs and Outcomes of an ExtraCare Housing Scheme in Bradford, York, Joseph Rowntree Foundation.

BÈLAND, F. et al. (2006): “A system of integrated care for older persons with disabilities in Canada: Results from a randomized controlled trial", The Journals of Gerontology, vol. 61A, no 4 , págs. 367-373.

BENDIXEN, R. M. et al. (2009): “Cost effectiveness of a telerehabilitation program to support chronically ill and disabled elders in their homes", Telemedicine Journal and E-Health, vol. 15, nํㅜ 1, págs. 31-38.

BOUMAN, A. et al. (2008): "Effects on health care use and associated cost of a home visiting program for older people with poor health status: A randomized clinical trial in the Netherlands", The Journals of Gerontology, vol. 63A, $n \div 3$, págs. 291-297.

CHALLIS, D. et al. (2004): “The value of specialist clinical assessment of older people prior to entry to care homes", Age and Ageing, vol. 33, no 1 , págs. 25-34.

CHAPPELL, N. L. et al. (2004): “Comparative costs of home care and residential care", The Gerontologist, vol. $44, n^{0} 3$, págs. 389-400.

CHARLESWORTH, G. et al. (2008): Does Befriending by Trained Lay Workers Improve Psychological Well-Being and Quality of Life for Carers of People with Dementia, and at What Cost? A Randomised Controlled Trial, serie Health Technology Assessment Report, no 4, Southampton, NIHR Coordinating Centre for Health Technology Assessment.

CLARKSON, P. et al. (2010): “Targeting, care management and preventative services for older people: The cost effectiveness of a pilot self-assessment approach in one local authority", British Journal of Social Work, vol. 40, nํ- 7, págs. 2.255-2.273.

COLEMAN, E. A. et al. (2006): "The care transitions intervention. Results of a randomized controlled trial", Archives of Internal Medicine, vol. 166, págs. 1.822-1.828.

COUNSELL, S. R. et al. (2009): "Cost analysis of the geriatric resources for assessment and care of elders care management intervention", Journal of the American Geriatrics Society, vol. 57, nํㅛ 8, págs. 1.420-1.426.

CUNLIFFE, A. L. et al. (2004): "Sooner and healthier: A randomised controlled trial and interview study of an early discharge rehabilitation service for 
older people", Age and Ageing, vol. 33, n- 3 , págs. 246-252.

CURRY, N. (2006): Preventive Social Care. Is It Cost Effective?, Londres, King's Fund.

DALE, S. B.; y BROWN, R. (2006): “Reducing nursing home use through consumer-directed personal care services", Medical Care, vol. 44, no 8, págs. 760-767.

DAVIS, J. C. et al. (2010): "Does a home-based strength and balance programme in people aged $=$ 80 years provide the best value for money to prevent falls? A systematic review of economic evaluations of falls prevention interventions", British Journal of Sports Medicine, vol. 44, $\mathrm{n}-2$, págs. 80-89.

ELLIS, A. et al. (2006): "Buying time II: An economic evaluation of a joint $\mathrm{NHS} /$ social services residential rehabilitation unit for older people on discharge from hospital", Health and Social Care in the Community, vol. $14, \mathrm{n}-2$, págs. 95-106.

EMERSON, E. et al. (2005): "Costs and outcomes of community residential supports in England", en STANCLIFFE, R. J.; y LAKIN, K. C. (eds.), Costs and Outcomes of Community Services for People with Intellectual Disabilities, Baltimore, Paul H. Brookes, págs. 151-174.

FELCE, D.; y EMERSON, E. (2005): “Community living. Costs, outcomes, and economies of scale: Findings from U.K. research", en STANCLIFFE, R. J.; y LAKIN, K. C. (eds.), Costs and Outcomes of Community Services for People with Intellectual Disabilities, Baltimore, Paul H. Brookes, págs. 45-62.

FELCE, D. et al. (2008): "Outcomes and costs of community living: Semi independent living and fully staffed group homes", American Journal on Mental Retardation, vol. 113, nํㅜ 2, págs. 87-101.

FRICK, K. D. et al. (2010): "Evaluating the cost effectiveness of fall prevention programs that reduce fall related hip fractures in older adults", Journal of the American Geriatrics Society, vol. 58, $\mathrm{n}^{0}$ 1, págs. 136-141.

GAUGLER, J. E. et al. (2003): “Evaluating community-based programs for dementia caregivers: The cost implications of adult day services", Journal of Applied Gerontology, vol. 22, № 1, págs. 118-133.

GRABOWSKI, D. C. (2006): "The cost-effectiveness of noninstitutional long-term care services: Review and synthesis of the most recent evidence", Medical Care Research and Review, vol. $63, \mathrm{n}-1$, págs. 3-28.

HAY, J. et al. (2002): "Cost-effectiveness of preventive occupational therapy for independent-living older adults", Journal of the American Geriatrics Society, vol. 50, no 8 , págs. 1.381-1.388.

HEAD, M. J.; y CONROY, J. W. (2005): "Outcomes of selfdetermination in Michigan. Quality and costs", en STANCLIFFE, R. J.; y LAKIN, K. C. (eds.), Costs and Outcomes of Community Services for People with Intellectual Disabilities, Baltimore, Paul H. Brookes, págs. 219-240.

HEBERT, R. et al. (2008): "Les impacts du réseau intégré de services Prisma”, Gérontologie et Société, no 124 , págs. 15-47.
HEKTOEN, L. F. et al. (2009): "Cost-effectiveness in fall prevention for older women”, Scandinavian Journal of Public Health, vol. 37, n으, págs. 584-589.

HEYWOOD, F.; y TURNER L. (2007): Better Outcomes, Lower Cost. Implications for Health and Social Care Budgets of Investment in Housing Adaptations, Improvements and Equipment: A Review of the Evidence, Londres, HM Government.

HURSTFIELD, J. et al. (2007): The Costs and Benefits of Independent Living, Londres, HM Government.

IRVINE, L. et al. (2010): “Cost effectiveness of a day hospital falls prevention programme for screened community dwelling older people at high risk of falls", Age and Ageing, vol. 39, no 6, págs. 710-716.

JOHRI, M. et al. (2003): "International experiments in integrated care for the elderly: A synthesis of the evidence", International Journal of Geriatric Psychiatry, vol. 18, no 3, págs. 222-235.

KAAMBWA, B. et al. (2008): "Costs and health outcomes of intermediate care: Results from five UK case study sites", Health and Social Care in the Community, vol. 16, no 6, págs. 573-581.

KENNEDY, A. et al. (2007): "The effectiveness and cost effectiveness of a national lay-led self care support programme for patients with long-term conditions: A pragmatic randomised controlled trial", Journal of Epidemiology and Community Health, vol. 61, nํㅜ 3, págs. 254-261.

LAKIN, K. C. et al. (2005): "Home and community-based services. Costs, utilization, and outcomes", en STANCLIFFE, R. J.; y LAKIN, K. C. (eds.), Costs and Outcomes of Community Services for People with Intellectual Disabilities, Baltimore, Paul H. Brookes, págs. 91-127.

LANSLEY, P. et al. (2004): “Can adapting the homes of older people and providing assistive technology pay its way?", Age and Ageing, vol. $33, \mathrm{n} \div$ 6, págs. 571-576.

LEUNT, A. C. et al. (2004): "Cost-benefit analysis of a case management project for the communitydwelling frail elderly in Hong Kong", Journal of Applied Gerontology, vol. 23, $\mathrm{n}^{0}{ }_{1}$, págs. 170-185.

MANSELL, J.; y BEADLE-BROWN, J. (2008): Dispersed or Clustered. Housing for Disabled Adults: $A$ Systematic Review, serie Disability Research Series, no 12, Dublín, National Disability Authority.

MANSELL, J. et al. (2007): Deinstitutionalisation and Community Living. Outcomes and Costs: Report of a European Study. Volume 2: Main Report, Canterbury, Tizard Centre.

MARKLE-REID, M. et al. (2006): "Health promotion for frail older home care clients", Journal of Advanced Nursing, vol. 54, nº 3, págs. 381-395.

MARKLE-REID, M. et al. (2006): "The effectiveness and efficiency of home-based nursing health promotion for older people: A review of the literature", Medical Care Research and Review, vol. 63, nº 5, págs. 531-569.

MASON, A. et al. (2007): A Systematic Review of the Effectiveness and Cost-Effectiveness of Different 
Models of Community-Based Respite Care for Frail Older People and Their Carers, serie Health Technology Assessment Report, $\mathrm{n} 0 \mathbf{1 5}$, Southampton, NIHR Coordinating Centre for Health Technology Assessment.

MCLEOD, B.; y MAIR, M. (2009): Evaluation of City of Edinburgh Council Home Care Re-ablement Service, Edimburgo, Scottish Government Social Research.

MELIS, R. J. F. et al. (2008): “Cost-effectiveness of a multidisciplinary intervention model for community-dwelling frail older people", The Journals of Gerontology, vol. 63A, nํㅜ 3 , págs. $275-282$

MEYER, H. (2011): "A new care paradigm slashes hospital use and nursing home stays for the elderly and the physically and mentally disabled", Health Affairs, vol. 30, noํ 3, págs. 412-415.

MILLER, P. et al. (2005): “Economic analysis of an early discharge rehabilitation service for older people", Age and Ageing, vol. 34, n으 3, págs. 274-280.

NICHOLS, L. O. et al. (2008): "The cost-effectiveness of a behavior intervention with caregivers of patients with Alzheimer's disease", Journal of the American Geriatrics Society, vol. 56, no 3 , págs. 413-420.

O’REILLY, J. et al. (2008): “Post-acute care for older people in community hospitals. A cost-effectiveness analysis within a multi-centre randomised controlled trial", Age and Ageing, vol. 37, $\mathrm{n}^{\circ}$ 5, págs. 513-520.

PICKARD, L. (2003): The Effectiveness and Cost-Effectiveness of Support and Services to Informal Carers of Older People. A Review of the Literature Prepared for the Audit Commission, Londres, Audit Commission.

POVEDA, R. et al. (2009): Análisis de costes y beneficios de la incorporación de productos de apoyo como extensión de los servicios de atención a domicilio en población mayor con dependencia. Ponencia presentada en el I Congreso de la Red Española de Política Social, Oviedo, noviembre 2009.

RICHARDS, K. C. et al. (2005): "Effect of individualized social activity on sleep in nursing home residents with dementia", Journal of the American Geriatrics Society, vol. 53, no 9, págs. 1.510-1.517.

RICHARDSON, G. et al. (2008): “Cost effectiveness of the Expert Patients Programme (EPP) for patients with chronic conditions", Journal of Epidemiology and Community Health, vol. 62, n- 4, págs. 361-367.

ROBERTSON, J. et al. (2008): “Análisis longitudinal del impacto y coste de la planificación centrada en la persona para personas con discapacidad intelectual en Inglaterra", Siglo Cero, vol. 39, $\mathrm{n} 01,225$, págs. 5-30.

ROBERTSON, J. et al. (2004): "Quality and costs of community-based residential supports for people with mental retardation and challenging behavior", American Journal on Mental Retardation, vol. 109, nํㅜ 4, págs. 332-344.

ROBERTSON, M. C. et al. (2001): "Economic evaluation of a community based exercise programme to prevent falls", Journal of Epidemiology and

Community Health, vol. 55, no 8, págs. 600-606.

SAHLEN, K. G. et al. (2008): "Preventive home visits to older people are cost-effective", Scandinavian Journal of Public Health, vol. 36, no 3 , págs. 265-271.

SCHWAB, T. C. et al. (2003): "Home- and community-based alternatives to nursing homes: Services and costs to maintain nursing home eligible individuals at home", Journal of Aging and Health, vol. 15, nํㅡ 2, págs. 353-370.

SPREAT, S. et al. (2005): "A cost-benefit analysis of community and institutional placements for persons with mental retardation in Oklahoma", Research in Developmental Disabilities, vol. 26, no 1 , págs. 17-31.

STAINTON, T. et al. (2009): “Independence pays: A cost and resource analysis of direct payments in two local authorities", Disability and Society, vol. 24, no 2 , págs. 161-172.

STANCLIFFE, R. J.; y KEANE, S. (2000): "Outcomes and costs of community living: A matched comparison of group homes and semi-independent living", Journal of Intellectual and Developmental Disability, vol. 25, nํ4, págs. 281-305.

STANCLIFFE, R. J.; y LAKIN, C. (2004): "Costs and outcomes of community services for persons with intellectual and developmental disabilities", Policy Research Brief, vol. 15, nํㅜ 1 .

TIMONEN, V. (2004): Evaluation of Homecare Grant Schemes in the NAHB and ECAHB, Dublín, Eastern Regional Health Authority.

TOSELAND, R. W.; y SMITH, T. L. (2006): “The impact of a caregiver health education program on health care costs", Research on Social Work Practice, vol. 16, nํㅜ 1, págs. 9-19.

TOUSIGNANT, M. et al. (2003): "Economic evaluation of a geriatric day hospital: Cost-benefit analysis based on functional autonomy changes", Age and Ageing, vol. 32, nํㅜ 1, págs. 53-59.

TURNING POINT (2010): Benefits Realisation: Assessing the Evidence for the Cost Benefit and Cost Effectiveness of Integrated Health and Social Care, Londres, Turning Point.

VV.AA. (2000): The Way to Go Home: Rehabilitation and Remedial Services for Older People, serie Promoting Independence, $\mathrm{n}-\mathbf{4}$, Londres, Audit Commission.

WAGNER, L. M. et al. (2007): “Description of an advanced practice nursing consultative model to reduce restrictive side-rail use in nursing homes", Research in Nursing and Health, vol. 30, $\mathrm{n}^{\circ} \mathbf{2}$, págs. 131-140.

WATT, S. et al. (1999): “Community care for people with chronic conditions: An analysis of nine studies of health and social service utilization in Ontario", The Milbank Quarterly, vol. 77, nํㅜ 3, págs. 363-392.

WINDLE, K. et al. (2009): National Evaluation of Partnerships for Older People Projects. Final Report, Kent, Personal Social Services Research Unit. 



\section{Envejecimiento y deterioro de las personas con discapacidad intelectual de Lantegi Batuak en el ámbito ocupacional y del empleo en Bizkaia.}

\section{Lantegi Batuak \\ <info@lantegi.com>}

Edurne Elorriaga Zugazaga

\section{William Restrepo}

Lantegi Batuak

\section{Víctor Bayarri}

Lantegi Batuak

\section{Yolanda Fillat}

Alter Civites
Artikulu honetan biltzen dira Lantegi Batuak erakundeak Bizkaiko lanbide terapia eta enpleguaren arloan ikasteko urritasunak dituzten pertsonen zahartze eta andeatzeren inguruan egindako ikerketa eta gogoetarako proiektu baten ondorioak. Proiektu horren helbururako xedea izan da ikasteko urritasuna izan eta laneko ingurunean zahartzen diren pertsona horien partaidetza eta autonomia errazteko ekimenak prestatzea. Horren bidez prebenitu nahi da lanpostuen galera, berauen bizimailaren okertzea eta diskriminatzeak gertatzeko arriskua. Horretaz gain, sustatu nahi dira pertsona horiek lan egiten duten enplegu berezietarako zentroak eta lanbidearen terapiaren arloko zerbitzuak.

\section{HITZ-GAKOAK:}

zahartzea, andeatzea, enplegua, ikasteko ezintasuna, lanbide terapia.
Este artículo sintetiza los resultados de un proyecto de investigación y reflexión de Lantegi Batuak en torno al envejecimiento y el deterioro de las personas con discapacidad intelectual en el ámbito ocupacional y de empleo de Bizkaia. La finalidad de dicho proyecto era diseñar nuevas acciones que facilitaran una mayor participación y autonomía de las personas con discapacidad intelectual que envejecen en el ámbito laboral. Con ello se buscaba prevenir la pérdida de puestos de trabajo, el deterioro de su calidad de vida y el riesgo de discriminación, asi como promover una mayor viabilidad de los centros especiales de empleo y los servicios ocupacionales donde estas personas trabajan o desarrollan su actividad.

\section{Palabras clave:}

envejecimiento, deterioro, empleo, discapacidad intelectual, trabajo ocupacional.

\footnotetext{
${ }^{1}$ Este artículo sintetiza el estudio de Edurne Elorriaga et al. (dirs.), Investigación sobre el envejecimiento y deterioro de las personas con discapacidad intelectual en el ámbito ocupacional y del empleo en Bizkaia, Loiu, Lantegi Batuak, 2011.
} 


\section{Introducción}

En el marco del proyecto "Envejecimiento y deterioro de las personas con discapacidad intelectual de Lantegi Batuak en el ámbito ocupacional y del empleo en Bizkaia", se han llevado a cabo varias actuaciones de investigación, así como reuniones internas de un grupo de reflexión experto -en el que ha tomado parte la dirección de Lantegi Batuak-y un seminario de participación con personas expertas del movimiento asociativo, para el análisis y diagnóstico de la situación, y el planteamiento de líneas de actuación. Todo ello se ha llevado a cabo desde el convencimiento de que el abordaje de las situaciones de deterioro/envejecimiento debe realizarse desde la perspectiva de las necesidades suplementarias de apoyo.

Los objetivos del proyecto en el ámbito específico de las modalidades de la ocupación y el empleo han sido los siguientes:

- Evitar la pérdida de puestos de trabajo entre el colectivo de personas con discapacidad intelectual que envejecen o sufren algún deterioro.

- Promover nuevas soluciones y dispositivos de apoyo que permitan mejorar la calidad de vida de las personas con discapacidad intelectual que envejecen, así como prevenir situaciones de deterioro.

- Mejorar las condiciones de ajuste sociolaboral, la formación, la adaptación de los puestos de trabajo y las medidas complementarias que permitan una mayor y mejor calidad de vida para el colectivo de personas con discapacidad intelectual que envejecen o sufren algún deterioro.

- Prevenir la discriminación laboral de las personas con discapacidad intelectual que envejecen y promover una plena igualdad de oportunidades en el ámbito del empleo.

- Prevenir las dificultades de viabilidad de los centros especiales de empleo y servicios ocupacionales a los que acuden las personas con discapacidad intelectual que envejecen o sufren algún deterioro.

En la Figura 1, se recoge el esquema de actuaciones realizadas. A partir de los resultados obtenidos en todas ellas, se ha elaborado el documento definitivo de conclusiones, retos, necesidades y propuesta de soluciones y dispositivos, que culmina la investigación realizada, para su posterior presentación y transferencia de resultados.

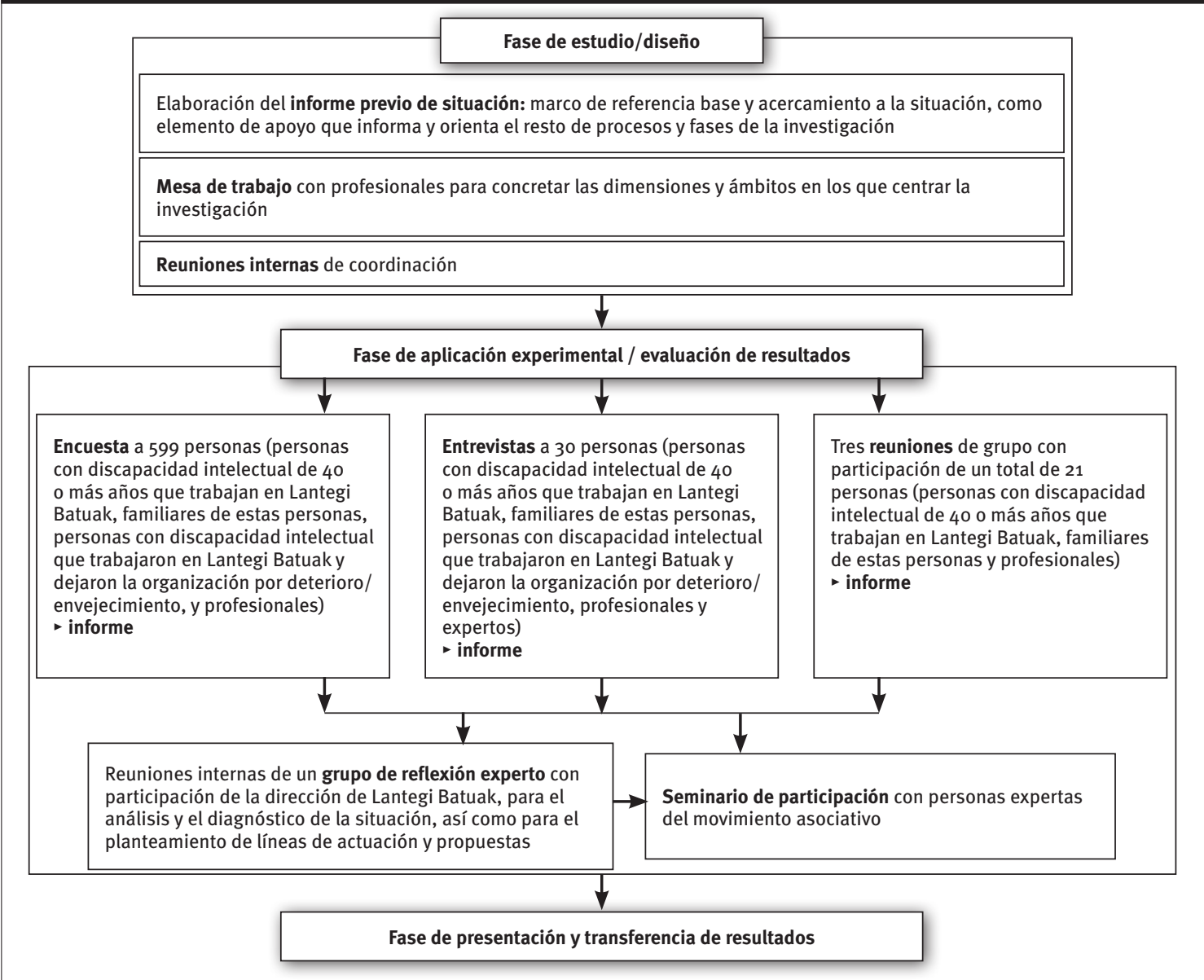

Fuente: Elaboración propia. 
En el citado marco, este artículo recoge los resultados de la investigación realizada, las conclusiones y las propuestas, elementos todos ellos fruto de dos procesos:

- Sesiones de trabajo del grupo de reflexión experto con participación de la dirección de Lantegi Batuak, obtenidos a partir de la valoración de los resultados de las actuaciones de investigación realizadas. Recogen el análisis, el diagnóstico de la situación, las líneas de actuación y las propuestas en relación con las situaciones de necesidades suplementarias de apoyo de las personas con discapacidad de Lantegi Batuak (entre ellas, por motivo de deterioro/envejecimiento).

- Seminario de participación con personas expertas del movimiento asociativo, para el contraste de las valoraciones, conclusiones y propuestas del grupo de reflexión.

El artículo tiene en cuenta, además, estas fuentes:

- Resultados obtenidos en los procesos de encuesta, entrevistas y reuniones de grupo, desarrollados entre los meses de junio y octubre de 2010.

- Diversos datos y referencias recogidas en el informe previo: bases conceptuales y referencias diversas con respecto a otros estudios de envejecimiento, marco jurídico, situación, y marco interno de Lantegi Batuak -datos generales, modelo de calidad de vida, Estudio de la incidencia de problemáticas asociadas en personas con discapacidad intelectual en Lantegi Batuak (Montero et al., 2006), Método de perfiles de adecuación de la tarea a la persona (Badiola et al., 2011)-, así como las conclusiones del seminario inicial de trabajo, en el que se concretaron dimensiones y ámbitos del estudio.

- Reflexiones del grupo interno de trabajo (dirigido por Lantegi Batuak) y otras personas expertas en este ámbito (seminario de participación).

\section{Antecedentes}

Diversas investigaciones ponen de relieve que el envejecimiento o deterioro se produce de manera prematura entre el colectivo de las personas con discapacidad intelectual, siendo, además, un motivo de necesidad suplementaria de apoyo. Así, el Estudio de la incidencia de problemáticas asociadas en personas con discapacidad intelectual en Lantegi Batuak (Montero et al., 2006), destaca que el 40,17\% de ellas tienen trastornos mentales, de conducta, pluridiscapacidades, o trastornos generalizados del desarrollo. Si se tiene en cuenta el porcentaje de personas con discapacidad intelectual con 50 o más años de la organización, casi la mitad (49,09\%) tienen problemáticas asociadas, y presentan, en consecuencia, necesidades suplementarias de apoyo. Destaca asimismo entre sus conclusiones la existencia de diferencias significativas en la intensidad de apoyos de las personas con discapacidad intelectual con 56 años o más, en relación a las de 55 años o menos, en especial, en cuanto se refiere a sus habilidades motoras. Además, alerta sobre el hecho de que, en los próximos cinco años, el número de personas dentro de este grupo en la organización casi va a duplicarse.

Es decir, Lantegi Batuak ha detectado el envejecimiento como uno de los motivos de doble diagnóstico y, en consecuencia, de necesidad suplementaria de apoyo, para las personas con discapacidad intelectual de la organización.

En relación con el deterioro o envejecimiento, también se han de considerar otros estudios y referencias. La Cartera de servicios sociales del movimiento FEAPS (2005) propone que el envejecimiento en estas personas se considere a partir de los 50 años, y lo planea como uno de los motivos que suponen necesidades específicas de apoyo y comportan intensidades de apoyo profesional más elevadas. El estudio Envejecimiento y deterioro de las personas con discapacidad intelectual en el ámbito del empleo en la Comunidad Foral de Navarra (FEAPS Navarra, 2005) también pone de relieve el envejecimiento prematuro del colectivo. Además, este deterioro/ envejecimiento, entre otros factores, incide en la pérdida o el deterioro de capacidades y competencias en el ámbito laboral. En concreto, a partir de los 50 años las personas con discapacidad intelectual presentan síntomas importantes de deterioro en los centros especiales de empleo, en aspectos que miden su capacidad de trabajo: la actitud, la perseverancia, la polivalencia, la disciplina, la perseverancia y la calidad de trabajo. La capacidad más afectada con la edad es la polivalencia.

Por su parte, el Informe Séneca. Envejecimiento y discapacidad intelectual en Cataluña 2000-2008 (Novell et al., 2008) concluye que las personas con discapacidad intelectual envejecen prematuramente: a excepción de las personas con síndrome de Down u otros síndromes, el envejecimiento prematuro de las personas con discapacidad intelectual leve y moderada es el resultado de la falta de programas de promoción de la salud, del reducido acceso a los servicios sanitarios, y de la baja calidad de la atención sanitaria y social recibida. Asimismo, entre sus resultados es destacable que tres de cada diez personas con discapacidad intelectual ligera y moderada mayores de 40 años o con grave deterioro de salud que están ocupadas en los diferentes servicios (tanto centros especiales de empleo como modalidades de servicio ocupacional) tienen un probable trastorno mental. En los diferentes ámbitos laborales/ ocupacionales, se constata una falta de detección de los problemas de salud mental y de las condiciones asociadas al envejecimiento que permitan ajustes personales y apoyos para evitar el desarraigo del entorno en que la persona se encuentra.

El estudio sobre las Necesidades de las personas con discapacidad intelectual en proceso de envejecimiento en Bizkaia (Aguado et al., 2007) pone de relieve que 
existen elementos diferenciales en el proceso de envejecimiento de este grupo frente al proceso de envejecimiento de la población general. Entre las conclusiones que plantea en el entorno laboral, destaca las consecuencias que el envejecimiento puede tener en un porcentaje importante de personas que realizan su actividad diaria en un contexto laboral (centro especial de empleo), por lo que parece necesario mencionar las posibles líneas de actuación que contribuyen a minimizar dichos efectos.

En el marco de la atención personalizada y de itinerarios individualizados que responden a cada una de las personas, se debe establecer la opción que más se adecue al/a la trabajador/a: cambio de actividad laboral, modificaciones en la actividad laboral actual, jubilación anticipada o paso a una actividad ocupacional. Para ello es necesario implementar, por un lado, mecanismos de tránsito como la flexibilidad en las jornadas laborales, facilitar jornadas reducidas o dedicaciones parciales; $y$, por otro, facilitar el acceso a servicios especializados de apoyo que contemplen reforzar aquellas áreas especialmente afectadas en la persona (prevención del deterioro, promoción de las habilidades comunicativas, etc.). Si la opción es la movilidad de los/as trabajadores/as a otras áreas o departamentos de la empresa, ello puede requerir dispositivos de reciclaje y/o capacitación, instrucción en el nuevo puesto y una monitorización más cercana hasta la adaptación al nuevo puesto. En caso de no ser posible el mantenimiento en una actividad laboral remunerada, procedería establecer itinerarios flexibles hacia la actividad en un Centro Ocupacional. En el fondo estamos hablando de desarrollar o actualizar las tareas y funciones de los SAP-Servicios de Ajuste Personal, ya contemplados desde los inicios del marco legislativo que regula el empleo protegido, de tal forma que contemplen las necesidades de estos/as trabajadores/as en su proceso de hacerse mayor. Por otro lado, la puesta en marcha de estas medidas puede implicar costes adicionales para la empresa y [que] requieran financiación por parte de las instituciones competentes en dicha materia (ibídem: 70).

Por último, el Plan para la Participación y Calidad de Vida de las Personas con Discapacidad en Bizkaia 2010-2013 (Diputación Foral de Bizkaia, 2010), entre las necesidades de las personas con discapacidad subraya que se aprecia un incremento de las necesidades complejas derivadas de las situaciones de pluridiscapacidad o multideficiencia, asociadas entre otros factores, al envejecimiento de la población.

\section{La realidad del deterioro/envejecimiento entre las personas con discapacidad intelectual que trabajan en Lantegi Batuak}

En el País Vasco, se registran unas 251.600 personas con discapacidad de 450 más años, de las cuales 133.900 viven en Bizkaia (Encuesta de Discapacidad,
Autonomía Personal y Situaciones de Dependencia 2008, Instituto Nacional de Estadística) ${ }^{2}$ : Dentro de las personas con discapacidad en Euskadi, 18.900 presentan dificultades de aprendizaje, aplicación de conocimientos y de desarrollo de tareas.

Los resultados de las actuaciones de investigación realizadas durante 2010 en el marco de este estudio ponen de relieve que el deterioro/envejecimiento es uno de los motivos por los que se producen necesidades suplementarias de apoyo entre las personas con discapacidad intelectual de Lantegi Batuak. También aparecen tales necesidades de apoyo por otras causas, como los trastornos de salud mental asociados, o los trastornos de conducta o de comportamiento.

En el momento en el que se inició el estudio, en Lantegi Batuak había 727 personas con discapacidad intelectual con edad igual o superior a 40 años: 366 en centro especial de empleo, de las cuales 249 eran hombres y 117 mujeres; y 361 en servicio ocupacional, de las cuales 227 eran hombres y 134 mujeres. La encuesta realizada revela que las personas con discapacidad intelectual de Lantegi Batuak comienzan a percibir síntomas de envejecimiento a partir de los 50 años. Sin embargo, también hay que tener en cuenta que muchas otras personas más jóvenes presentan síntomas de deterioro que requieren actuaciones transversales previas. Este fenómeno está dando lugar en Lantegi Batuak a problemáticas puntuales, que son objeto de una respuesta e intervención sistemática por parte de la organización. Se advierte una lógica tendencia incremental de estas situaciones a medio y largo plazo, de acuerdo con el propio avance de la edad de las personas.

El envejecimiento o deterioro incide en Lantegi Batuak con intensidad diversa, en función de distintos aspectos:

- Los efectos que esa situación tiene en función de que se trate de personas en centro especial de empleo o en servicio ocupacional.

- La propia realidad de la población actual de los centros: en los centros más antiguos hay personas más mayores que en otros más recientes.

- La diversidad existente dentro de la discapacidad intelectual, como elemento que influye directamente en la evolución y el envejecimiento de las personas y que genera grandes diferencias.

Seguidamente se recoge la caracterización de los efectos del deterioro/envejecimiento con respecto a cada una de las dimensiones de la calidad de vida, en coherencia con el Modelo de apoyos individuales... de Lantegi Batuak (Elorriaga et al., 2010) y a partir de los resultados obtenidos en el trabajo de campo desarrollado en este estudio (más detalles en Elorriaga et al.,2011: anexo 1).

${ }^{2}$ Se trata de una encuesta dirigida a hogares. Los datos sobre población con discapacidad según grupo de discapacidad no están desagregados por provincias. 


\subsection{Bienestar físico y material}

En la dimensión de bienestar físico y material, se percibe un progresivo deterioro de la salud y mayores dificultades físicas. Los síntomas más frecuentes que se manifiestan con el paso de la edad y que dificultan el desarrollo de la actividad laboral son: cansancio, dolores de espalda y piernas, pérdida de la vista y oído, dificultades para coger pesos, dificultades de movimiento y desplazamiento, problemas motores, menor motricidad, desorientación y déficits de atención. Otros síntomas del deterioro se manifiestan en la existencia de déficits en el autocuidado, el aseo, el vestido, la alimentación, los hábitos de vida saludable o el seguimiento de la salud.

Pero sobretodo son importantes las dificultades cognitivas - pérdida de memoria, mayores dificultades para el aprendizaje- y los trastornos asociados - problemas de salud mental, trastornos de conducta y de comportamiento-. De hecho, es en este ámbito donde más se observa el deterioro de estas personas con respecto a quienes no tienen discapacidad intelectual ${ }^{3}$.

Como consecuencia de este deterioro, se producen mayores niveles de dependencia, así como la necesidad de ajustes y adaptaciones en los puestos de trabajo, ayudas técnicas y productos de apoyo. También se manifiestan mayores dificultades para la autonomía en el traslado a los centros de trabajo.

La situación de deterioro/envejecimiento de las personas está unida al envejecimiento/deterioro de sus familias. En muchos casos, los síntomas de deterioro en la persona, o sus mayores demandas de apoyo, están directamente relacionadas con el deterioro de sus familias (familias que ya no pueden atenderles como hasta ahora, que requieren apoyos y cuidados por parte de la propia persona con discapacidad). Esto puede dar origen a situaciones de déficits en la higiene o el vestido, ausencias en el trabajo para atender situaciones de hospitalización o cuidado de familiares, situaciones de tristeza o duelo por enfermedad o fallecimiento, o falta de concentración, entre otras.

\subsection{Bienestar emocional}

En la dimensión de bienestar emocional también se observan síntomas de deterioro, por ejemplo, irritabilidad o cambios de humor. En algunos casos, se manifiesta aburrimiento y desmotivación con respecto a la actividad laboral. Son destacables también los sentimientos de incertidumbre ante el futuro, o de tristeza y duelo ante las situaciones de envejecimiento/deterioro de las familias.

Fomentar sentimientos de autoestima, autova-

${ }^{3}$ Es interesante citar que el Informe Séneca... (Novell et al., 2008), entre sus conclusiones, destaca que tres de cada diez personas con discapacidad intelectual ligera y moderada mayores de 40 años que están ocupadas en los diferentes servicios de empleo u ocupacionales tienen un probable trastorno mental. loración, aceptación e inclusión en el centro de trabajo resulta clave en esta etapa. Merece la pena destacar la satisfacción de las personas con discapacidad intelectual con la actividad que desarrollan, su sentimiento de superación y sus ganas de realizar bien su trabajo, porque esa actividad y sus resultados les hace sentirse realizados, porque perciben su contribución en el resultado obtenido con su trabajo.

\subsection{Desarrollo laboral}

Es fundamental la valoración y el efecto positivo que el trabajo tiene para estas personas: constituye una fuente de apoyo inestimable para su autoestima, autonomía y participación, y el desarrollo de una vida social y relacional. A este respecto, se percibe una incidencia directa del deterioro y los déficits en el nivel y ritmo de productividad, el rendimiento laboral, la capacidad de trabajo y aprendizaje y, en consecuencia, en menores posibilidades de reciclaje o reubicación. Se producen tiempos de inactividad cada vez más largos, con actividades menos significativas y valiosas, no adecuadas a las necesidades de desarrollo de estas personas. El deterioro provoca una mayor inadecuación de las personas a los contenidos actuales de los centros y la pérdida de capacidad asociada al tipo de actividad laboral que actualmente se desarrolla en ellos.

Se advierte la necesidad de mantener a estas personas con el mayor nivel de actividad posible, como la mejor forma de evitar y prevenir la aparición o el agravamiento de los efectos de deterioro. Además, se ha de mantener su actividad con un mínimo de trabajo real, incluso aunque la mayor parte del tiempo se desarrollen actividades no laborales y el taller, como centro de trabajo, pase a ser un recurso o una fuente más de apoyo.

\subsection{Relaciones interpersonales}

En muchos casos, las relaciones sociales que desarrollan estas personas se circunscriben a sus compañeras/os de trabajo y su familia. En principio, los resultados del estudio no reflejan una influencia del deterioro en el ámbito de las relaciones interpersonales, pero es apreciable un riesgo de soledad y aislamiento que se puede intensificar cuando la persona ya no está en Lantegi Batuak.

\subsection{Integración en la comunidad}

Existe un riesgo de aislamiento de estas personas si no se articulan apoyos suficientes y adecuados en el entorno comunitario, tanto en paralelo a su actividad laboral u ocupacional, como al finalizar ésta. Se han de permitir ajustes personales y apoyos para evitar el desarraigo del entorno en el que la persona vive. 


\subsection{Autodeterminación}

Existe un claro riesgo de pérdida de autodeterminación como consecuencia de la pérdida de capacidades asociada al deterioro/envejecimiento. Lo mismo cabe decir sobre las habilidades de autoprotección ante situaciones de vulneración de sus derechos y activación de mecanismos de defensa. También se observa una incidencia en la capacidad de participación en los diversos ámbitos del entorno comunitario.

\subsection{Derechos}

No existe un nivel suficiente de garantía de derechos en lo que respecta a su situación económica, tanto en caso de jubilación como de movilidad entre recursos distintos (centro especial de empleo, servicio ocupacional, centro de actividades diurnas/centro de día). No existe flexibilidad en el acceso, ni facilidad para pasar de un recurso a otro, o para compatibilizar servicios y prestaciones. Por último, tampoco se garantiza un sistema de valoración de la discapacidad al servicio de las personas.

\section{Deterioro/envejecimiento: efectos, necesidades y retos}

El Cuadro 1 sintetiza los efectos que la situación de deterioro/envejecimiento está suponiendo en Lantegi Batuak, así como sobre las necesidades y los retos que plantea.

De las conclusiones del estudio explicitadas en estos retos y necesidades con respecto a los diversos agentes, el diagnóstico de la situación que se obtiene es el siguiente: si bien las situaciones de deterioro 0 envejecimiento entre las personas de Lantegi Batuak $-\mathrm{y}$, con carácter general, del conjunto de personas con discapacidad en Bizkaia- es un fenómeno que, de manera generalizada, y a corto plazo, no se percibe como una situación de inminente necesidad, a medio/largo plazo la evolución apunta a una situación de deterioro más generalizada. Esta realidad comporta un importante reto, tanto para Lantegi Batuak como para el conjunto de la sociedad, las administraciones públicas y el movimiento asociativo, que exige anticipar respuestas y soluciones desde ahora.

Cuadro 1. Efectos del envejecimiento/deterioro en Lantegi Batuak, por agentes o grupos de interés

\begin{tabular}{|c|c|c|}
\hline $\begin{array}{l}\text { Agentes o } \\
\text { grupos de } \\
\text { interés }\end{array}$ & Efectos & Necesidades y retos, resultados que se han de conseguir \\
\hline $\begin{array}{l}\text { Personas con } \\
\text { discapacidad } \\
\text { de } 40 \text { o más } \\
\text { años }\end{array}$ & $\begin{array}{l}\text { - Progresiva inadecuación de sus capacidades, habilidades } \\
\text { y competencias a la oferta laboral actual. } \\
\text { - Insuficiente diversificación o adecuación de los conteni- } \\
\text { dos de la actividad laboral a sus necesidades específicas } \\
\text { de apoyo. } \\
\text { - Mayores dificultades para adaptarse a la oferta laboral } \\
\text { en servicios o enclaves laborales: los perfiles con } \\
\text { mayores dificultades requieren y demandan un marco de } \\
\text { actividades estable, con ubicación en centros especiales } \\
\text { de empleo -no en servicios ocupacionales-, con conte- } \\
\text { nidos pautados de manipulación dentro de una cadena } \\
\text { productiva. } \\
\text { - Demanda de nuevas alternativas y combinación de activi- } \\
\text { dades, laborales y no laborales, orientadas a favorecer el } \\
\text { mantenimiento de capacidades y a evitar los efectos del } \\
\text { envejecimiento/deterioro. } \\
\text { - Necesidad de adaptaciones y mayor flexibilidad de las } \\
\text { condiciones laborales, por motivos de conciliación o } \\
\text { por sus propias dificultades asociadas al deterioro/ } \\
\text { envejecimiento. } \\
\text { - Incremento de la demanda de atención con respecto a los } \\
\text { profesionales de apoyo. } \\
\text { - Situaciones de desigualdad e insuficiencia de garantía de } \\
\text { derechos en caso de jubilación. Desincentivación o impo- } \\
\text { sibilidad de cumplimiento de requisitos para el acceso } \\
\text { efectivo a los recursos existentes, o para la movilidad } \\
\text { entre ellos. } \\
\text { - Situaciones de desigualdad en las declaraciones o los } \\
\text { reconocimientos de incapacidad permanente de la Segu- } \\
\text { ridad Social. No existe un sistema con carácter institu- } \\
\text { cional y garantías suficientes de igualdad que determine } \\
\text { cuándo una persona ha de acceder a los diversos recur- } \\
\text { sos (centros especiales de día, servicios ocupacionales, } \\
\text { centros de día), ni con respecto a los itinerarios óptimos } \\
\text { para atender las necesidades específicas de apoyo en el } \\
\text { ámbito laboral y ocupacional. }\end{array}$ & $\begin{array}{l}\text { Reto: que las personas con discapacidad intelectual, } \\
\text { en proceso de deterioro/envejecimiento tengan cabida } \\
\text { en Lantegi Batuak, desarrollen una actividad laboral u } \\
\text { ocupacional valiosa y significativa, en el marco de la misión } \\
\text { y valores de Lantegi Batuak, y tengan asegurados todos los } \\
\text { apoyos y recursos necesarios para su desarrollo y calidad } \\
\text { de vida. } \\
\text { Esto supone que las personas con discapacidad intelectual } \\
\text { en proceso de deterioro/envejecimiento puedan: } \\
\text { - En el ámbito interno (Lantegi Batuak): } \\
\text { - Disponer de una oferta diversa y suficiente de apoyos } \\
\text { y contenidos de actividad, laboral y no laboral, } \\
\text { adecuados a sus necesidades específicas. } \\
\text { - Contar con mecanismos adecuados para la } \\
\text { prevención y detección tempranas de situaciones de } \\
\text { envejecimiento/deterioro. } \\
\text { - Seguir disponiendo de una oferta laboral, en centros } \\
\text { especiales de empleo, adaptada a sus necesidades. } \\
\text { - En el ámbito externo (sociedad, entorno): } \\
\text { - Tener garantizado en cualquier situación laboral u } \\
\text { ocupacional el nivel de ingresos de, como mínimo, la } \\
\text { renta de garantía de ingresos. } \\
\text { - Disponer de una oferta adecuada y suficiente de } \\
\text { apoyos, servicios y recursos, tanto especializados } \\
\text { como generales de ámbito comunitario. } \\
\text { - Disponer de garantías efectivas de acceso y movilidad } \\
\text { entre recursos existentes, sin que ello comporte } \\
\text { penalización en sus ingresos. } \\
\text { - Tener garantizado su derecho a unos recursos } \\
\text { económicos adecuados y suficientes en el momento } \\
\text { de su jubilación. } \\
\text { - Tener garantizado un sistema homogéneo de } \\
\text { valoración de la incapacidad: homogeneización de las } \\
\text { características de las personas con discapacidad para } \\
\text { de sus necesidades específicas de apoyo, pueden } \\
\text { acceder a los diversos recursos de empleo o a } \\
\text { diferentes tipo de actividad ocupacional. }\end{array}$ \\
\hline
\end{tabular}




\begin{tabular}{|c|c|c|}
\hline $\begin{array}{l}\text { Agentes o } \\
\text { grupos de } \\
\text { interés }\end{array}$ & Efectos & Necesidades y retos, resultados que se han de conseguir \\
\hline Familiares & $\begin{array}{l}\text { - Inseguridad y desconocimiento con respecto a la forma } \\
\text { de actuar ante estas nuevas situaciones. } \\
\text { - Preocupación y miedo ante el futuro, por ejemplo, en } \\
\text { temas como el relevo en el cuidado de sus familiares con } \\
\text { discapacidad. } \\
\text { - Situaciones coincidentes de deterioro/envejecimiento } \\
\text { tanto de la persona con discapacidad como de las } \\
\text { propias familias. } \\
\text { - Necesidad de recursos de apoyo a las familias (servicios } \\
\text { de ocio, respiro, apoyo a domicilio). }\end{array}$ & $\begin{array}{l}\text { Reto: que las familias obtengan apoyo adecuado y } \\
\text { suficiente ante las situaciones de envejecimiento/deterioro } \\
\text { de sus familiares con discapacidad. } \\
\text { Esto supone que las que las familias puedan: } \\
\text { - En el ámbito interno (Lantegi Batuak): } \\
\text { - Disponer de una comunicación continua con la entidad } \\
\text { acerca de la evolución de las necesidades de su } \\
\text { familiar con discapacidad. } \\
\text { - Disponer de la orientación y el apoyo suficientes para } \\
\text { acceder a las prestaciones y recursos existentes. } \\
\text { - En el ámbito externo (sociedad, entorno): } \\
\text { - Disponer de una respuesta especializada de } \\
\text { orientación y asesoramiento, con la máxima } \\
\text { antelación posible. } \\
\text { - Disponer de una oferta suficiente y adecuada de } \\
\text { servicios y recursos de apoyo (apoyo a familias, } \\
\text { respiro, apoyo a domicilio). } \\
\text { - Disponer de apoyos suficientes para facilitar la } \\
\text { tramitación y el acceso a los diversos recursos. }\end{array}$ \\
\hline Profesionales & $\begin{array}{l}\text { - Exigencia de una mayor dedicación, desarrollo de funcio- } \\
\text { nes para las cuales no disponen de tiempo suficiente, no } \\
\text { están preparados o que requieren la respuesta de otros } \\
\text { perfiles profesionales más adecuados. } \\
\text { - Actitudes diversas ante la situación: } \\
\text { - Preocupación/desazón ante las situaciones de } \\
\text { deterioro/envejecimiento. } \\
\text { - Actitud de implicación activa en la activación de } \\
\text { soluciones. } \\
\text { - Rechazo a la permanencia en los centros de personas } \\
\text { que ya no son productivas, y a la priorización de la } \\
\text { actividad productiva frente a las necesidades de la } \\
\text { persona. } \\
\text { - Conformismo ante las dificultades que esta situación } \\
\text { puede plantear. Se tiende a mantener a la persona } \\
\text { en la tarea en la que está, aunque esté sin producir o } \\
\text { aburrida, antes que intentar realizar cualquier cambio } \\
\text { dirigido a activarla o estimularla, ya que esto requiere } \\
\text { más tiempo y dedicación. }\end{array}$ & $\begin{array}{l}\text { Reto: alinear y unificar la respuesta de las/los } \\
\text { profesionales hacia la consecución de la mayor calidad de } \\
\text { vida posible para las personas con discapacidad intelectual } \\
\text { en situación de deterioro/envejecimiento de Lantegi } \\
\text { Batuak. } \\
\text { Esto supone que las/los profesionales puedan: } \\
\text { - Conocer la estrategia y las actuaciones de la organización } \\
\text { respecto a las personas con discapacidad intelectual en } \\
\text { proceso de deterioro/envejecimiento, y participar en su } \\
\text { despliegue y desarrollo. } \\
\text { - Disponer de las competencias y condiciones necesarias } \\
\text { para el adecuado desarrollo de las funciones de apoyo a } \\
\text { estas personas. } \\
\text { - Disponer de formación y competencias para mejorar la } \\
\text { detección, prevención e intervención ante síntomas y } \\
\text { situaciones de deterioro/envejecimiento de las personas } \\
\text { con discapacidad. }\end{array}$ \\
\hline $\begin{array}{l}\text { Centros } \\
\text { especiales } \\
\text { de empleo, } \\
\text { servicios } \\
\text { ocupacionales } \\
\text { y otros } \\
\text { dispositivos }\end{array}$ & $\begin{array}{l}\text { - Periodos largos de inactividad por parte de algunas } \\
\text { personas en los centros. } \\
\text { - Inadecuación de los puestos de trabajo como conse- } \\
\text { cuencia de la pérdida de capacidad asociada al tipo de } \\
\text { actividad laboral que actualmente se desarrolla. } \\
\text { - Desigual distribución de cargas de trabajo. } \\
\text { - Número de profesionales de apoyo insuficiente o con } \\
\text { perfil de atención inadecuado. } \\
\text { - Necesidad de nuevos contenidos de actividad, más ade- } \\
\text { cuados a las capacidades de estas personas, orientados } \\
\text { a su mantenimiento y a la prevención de los efectos del } \\
\text { deterioro/envejecimiento. }\end{array}$ & $\begin{array}{l}\text { Reto: conseguir unas condiciones y una oferta de } \\
\text { actividades en los centros y servicios que permitan a } \\
\text { las personas con discapacidad intelectual en proceso } \\
\text { de deterioro/envejecimiento tener cabida en aquéllos y } \\
\text { desarrollar una actividad laboral u ocupacional valiosa y } \\
\text { significativa. } \\
\text { Esto supone: } \\
\text { - Desplegar una oferta de actividad diversificada, de } \\
\text { contenido laboral y no laboral, orientada a conseguir el } \\
\text { máximo estímulo y desarrollo de las capacidades y poten- } \\
\text { cialidades, evitando y retrasando al máximo la aparición } \\
\text { de síntomas de deterioro/envejecimiento. } \\
\text { - Implementar espacios diversificados para el desarrollo } \\
\text { de actividades de contenido no laboral. } \\
\text { - Organizar los equipos profesionales, en número y de } \\
\text { perfiles adecuados, teniendo en cuenta los apoyos } \\
\text { suplementarios requeridos por las trabajadoras/es con } \\
\text { discapacidad, por deterioro/envejecimiento o por otros } \\
\text { motivos. }\end{array}$ \\
\hline $\begin{array}{l}\text { Lantegi } \\
\text { Batuak (como } \\
\text { organización) }\end{array}$ & $\begin{array}{l}\text { - Insuficiencia/inadecuación de la oferta actual de los } \\
\text { centros especiales de empleo y servicios ocupacionales } \\
\text { laboral para atender las necesidades suplementarias de } \\
\text { apoyo de estas personas. } \\
\text { - Necesidad de equilibrar la respuesta a nuevas nece- } \\
\text { sidades y la viabilidad/sostenibilidad de las diversas } \\
\text { medidas, en un escenario a medio/largo plazo. }\end{array}$ & $\begin{array}{l}\text { Reto: continuar incluyendo a las personas con } \\
\text { discapacidad con necesidades específicas de apoyo, } \\
\text { entre ellas, las personas con discapacidad intelectual } \\
\text { en deterioro/envejecimiento, en el conjunto de la } \\
\text { organización. } \\
\text { Esto supone: } \\
\text { - Innovar en soluciones y respuestas. } \\
\text { - Visibilizar la actividad que las personas con discapacidad } \\
\text { desarrollan en Lantegi Batuak, sus resultados y valor } \\
\text { añadido. } \\
\text { - Contribuir a la reivindicación de actuaciones precisas, } \\
\text { por parte de las administraciones públicas, dirigidas } \\
\text { hacia una respuesta global que haga efectivos todos los } \\
\text { derechos de las personas con discapacidad intelectual y } \\
\text { sus familias. } \\
\text { - Incluir los resultados de este trabajo como un elemento } \\
\text { de análisis, diagnóstico y formulación de estrategias } \\
\text { y actuaciones, en relación con el reto del deterioro/ } \\
\text { envejecimiento, en el proceso de elaboración del plan } \\
\text { estratégico que lleve a cabo Lantegi Batuak. }\end{array}$ \\
\hline
\end{tabular}




\begin{tabular}{|c|c|c|}
\hline $\begin{array}{l}\text { Agentes o } \\
\text { grupos de } \\
\text { interés }\end{array}$ & Efectos & Necesidades y retos, resultados que se han de conseguir \\
\hline $\begin{array}{l}\text { Sociedad, } \\
\text { entorno }\end{array}$ & $\begin{array}{l}\text { - Insuficiencia/inadecuación de la oferta actual de } \\
\text { recursos y apoyos a las personas con discapacidad } \\
\text { intelectual en situación de deterioro/envejecimiento y a } \\
\text { sus familias. } \\
\text { - Insuficiencia/inadecuación de los recursos comunitarios } \\
\text { del entorno como oferta actual válida o suficiente ante } \\
\text { estas necesidades. } \\
\text { - Insuficiencia de condiciones que permitan de forma } \\
\text { efectiva a todas las personas que los requieran acceder } \\
\text { a los recursos existentes por parte de todas las personas } \\
\text { que los requieran. } \\
\text { - Insuficiencia de garantías con respecto al derecho a } \\
\text { estas personas a unos recursos económicos adecuados y } \\
\text { suficientes en el momento de su jubilación. }\end{array}$ & $\begin{array}{l}\text { Reto: avanzar hacia un nuevo sistema de organización de } \\
\text { los apoyos con respecto a las personas con discapacidad } \\
\text { intelectual que presentan necesidades especiales, por } \\
\text { motivo de deterioro/envejecimiento o por otras causas, } \\
\text { con un sistema donde la oferta de apoyos se gestione en } \\
\text { función de la demanda. } \\
\text { Esto supone: } \\
\text { - Contar con una oferta adecuada, diversa y suficiente de } \\
\text { servicios, recursos y apoyos, que garantice condiciones } \\
\text { de acceso a los recursos y movilidad entre ellos, de } \\
\text { acuerdo con las necesidades de las personas. } \\
\text { - Contar con una oferta adecuada y suficiente de apoyo } \\
\text { para las familias. } \\
\text { - Asegurar el derecho de estas personas a unos recursos } \\
\text { económicos adecuados y suficientes en el momento de } \\
\text { su jubilación. }\end{array}$ \\
\hline
\end{tabular}

Fuente: Elaboración propia.

La solución práctica a estas nuevas situaciones de necesidad que se vienen produciendo como consecuencia del deterioro o envejecimiento las personas con discapacidad se ha de articular desde la perspectiva de las necesidades suplementarias de apoyo, que han de incluir actuaciones con respecto a las personas con discapacidad intelectual en situación de deterioro/envejecimiento, trastornos de salud mental asociados, y trastornos de conducta o de comportamiento, entre otras circunstancias.

En este marco, Lantegi Batuak, en coherencia con su visión, misión y valores, afronta la problemática del deterioro/envejecimiento desde la apuesta estratégica por que las personas que se deterioran o envejecen, o que, por cualquier otro motivo, presentan necesidades suplementarias de apoyo, puedan seguir trabajando en Lantegi Batuak, si así lo escogen, con las condiciones y la diversidad de apoyos necesarios para hacerlo posible.

Desde esta perspectiva global, el diagnóstico permite observar la necesidad de disponer de un nuevo sistema de empleo, ocupación y apoyos capaz de dar una respuesta efectiva y no discriminatoria a las necesidades evolutivas de las personas con discapacidad intelectual que envejecen o sufren deterioros significativos de salud, o tienen necesidad de apoyo suplementario por otras causas. Asimismo, en el plano interno se pone de manifiesto la necesidad de Lantegi Batuak de adecuar la oferta y la diversidad de apoyos de carácter suplementario que puedan necesitar estas personas, atendiendo a la diversidad de estas necesidades.

En concreto, Lantegi Batuak, como organización que genera en Bizkaia el mayor número de oportunidades de empleo para las personas con discapacidad, con una importante solvencia técnica, una metodología de trabajo innovadora, con herramientas para la adaptación de los apoyos y trayectoria comprometida con la calidad de vida de sus trabajadoras/es, en línea con las actuaciones que ya viene desarrollando e impulsando, debe seguir asumiendo un papel proactivo, participando activamente en impulsar condiciones, tanto en el entorno como en el ámbito interno de su organización, para ofrecer una adecuada respuesta a la evolución de las necesidades de estas personas, en la construcción de este nuevo sistema.

El escenario ofrece importantes oportunidades que Lantegi Batuak debe aprovechar para impulsar adaptaciones normativas y del entorno, así como para adecuar sus condiciones y dispositivos internos al modelo de empleo protegido, la asunción de políticas activas de empleo por parte de Gobierno Vasco, o a la sensibilidad de la Diputación Foral de Bizkaia y sus políticas alineadas con la apuesta estratégica de Lantegi Batuak por las personas.

En concreto, el Plan para la Participación y Calidad de Vida de las Personas con Discapacidad en Bizkaia 2010-2013 (Diputación Foral de Bizkaia, 2010), entre sus conclusiones de diagnóstico, observa una necesidad creciente y diversificada de adaptar las prestaciones y servicios a las necesidades específicas de apoyo propias de cada etapa del itinerario vital de las personas con discapacidad (infancia y adolescencia, edad adulta y deterioro/envejecimiento), y ve preciso adaptar o buscar nuevas respuestas a estas necesidades emergentes. Además, entre sus objetivos prevé adecuar los servicios a la evolución de las necesidades de las personas con discapacidad, orientando su desarrollo hacia la progresiva incorporación del modelo de participación y calidad de vida en la comunidad, lo que supone, entre otras, actuaciones en clave de flexibilización y combinación de recursos.

\section{Visión: propuesta-marco de un nuevo sistema de organización de los apoyos para personas con discapacidad que presentan necesidades suplementarias de apoyo}

A la vista de los efectos que la situación de deterioro o envejecimiento está suponiendo en Lantegi Batuak, y teniendo en cuenta la diversidad de planteamientos 
y propuestas expresadas por las personas que han participado en este estudio, este apartado recoge la visión de la entidad para orientar las propuestas, las líneas de actuación, las soluciones y los dispositivos dirigidos a ofrecer una respuesta global a este fenómeno, con requerimientos de condiciones y actualizaciones, tanto en el ámbito interno de Lantegi Batuak como en el externo (administraciones públicas en su diversos niveles, movimiento asociativo y sociedad en su conjunto).

Con carácter previo a la formulación de esta visión, se recogen varias consideraciones y premisas con respecto al sistema de apoyos en el ámbito laboral y ocupacional de las personas con discapacidad. Tales consideraciones y premisas se tienen en cuenta en la construcción de la visión, la estrategia y las actuaciones de Lantegi Batuak frente a las situaciones de deterioro/envejecimiento de sus trabajadores/as con discapacidad intelectual, así como a la de otras personas con necesidades suplementarias de apoyo.

\subsection{Consideraciones previas}

- Nos hallamos en un escenario de necesidad de actualización del vigente modelo de empleo protegido y, por extensión, del sistema de organización de los apoyos para las personas con discapacidad en el ámbito de empleo y de la actividad ocupacional.

- El marco para afrontar la problemática del envejecimiento es la propia apuesta estratégica de la organización por las personas.

- El hecho de analizar y plantear mejoras en relación con el envejecimiento/deterioro no supone que se esté juzgando o poniendo en entredicho la sostenibilidad del modelo de Lantegi Batuak.

- Se trata de una problemática que no está demandando soluciones o respuestas urgentes, pero que sí requiere una progresiva incorporación de medidas y soluciones (internas y externas) a medio/largo plazo, en orden a una estrategia decidida, asumida y comunicada.

- El abordaje de las situaciones de deterioro/envejecimiento debe realizarse desde la perspectiva de las necesidades suplementarias de apoyo, incluyendo la intervención y las actuaciones con respecto a las personas con discapacidad intelectual en situación de deterioro/envejecimiento, trastornos de salud mental asociados, trastorno de conducta o de comportamiento, entre otras.

- Hay que tener en cuenta que la presencia de otro tipo de trastornos: de conducta o de comportamiento, o la enfermedad mental asociada, están generando situaciones de mayor dificultad en la intervención de los profesionales.

\subsection{Premisas de la visión de Lantegi Batuak}

\subsubsection{Derecho al trabajo, la autonomía personal, la libertad de elección y a una contraprestación justa}

Cualquier planteamiento en relación con el empleo de las personas con discapacidad y, en particular, de aquellas que presentan necesidades suplementarias de apoyo, se debe realizar:

- Con plena garantía de su derecho al trabajo, la autonomía personal y la libertad de elección.

- Con plena garantía de su derecho a una contraprestación justa que compense, en su caso, su déficit de productividad o rendimiento.

Ambas premisas se basan en la Convención de las Naciones Unidas sobre los Derechos de las Personas con Discapacidad (arts. 1.1, 3, 19, 26 y 27) y en la Ley $51 / 2003$, de 2 de diciembre, de Igualdad de Oportunidades, no Discriminación y Accesibilidad Universal de las Personas con Discapacidad (LIONDAU, arts. 8.1. y 8.2).

\subsubsection{Condiciones que se deben asegurar en todo caso}

Cualquier persona con discapacidad intelectual que sufra un proceso de deterioro o envejecimiento prematuro, según la valoración de Lantegi Batuak, tiene que poder:

- Continuar trabajando, todo el tiempo que sea posible, si así lo decide, disponiendo, en su caso, de los dispositivos adecuados para ofrecerle la oportunidad de seguir realizando actividades productivas significativas.

- Escoger entre una diversidad de alternativas adecuadas a sus necesidades de apoyo suplementarias.

- Optar, si así lo decide, por combinar distintas opciones de protección social (incapacidad laboral, jubilación anticipada, apoyos sociales).

- Tener siempre garantizado, como mínimo, un nivel de ingresos equivalente al $100 \%$ de la renta de garantía de ingresos, cualquiera que sea su situación laboral o actividad.

A este último respecto, es preciso decir que la Ley de Servicios Sociales de Euskadi propone nuevos derechos subjetivos para las personas, de manera que los servicios sociales se configuran como un elemento adicional de garantía para el bienestar de la ciudadanía. La ley viene a completar un sistema de servicios sociales que ha ido configurando, en Euskadi, un nuevo pilar para la protección social de los más desfavorecidos. En este mismo sentido, se aprobaron la Ley 12/1998 contra la Exclusión Social y la Ley 10/2000 de Carta de Derechos Sociales. Esta última consagró el derecho a una renta básica, garantizando, por un lado, la existencia misma de dicha 
prestación y, por otro, el derecho de todas las personas a percibir unos ingresos en cuantía suficiente para ejercer sus derechos de ciudadanía, o derechos sociales básicos, y evitar así la exclusión social por motivos económicos, eliminando situaciones de pobreza. Luego tuvo una modificación, que dio lugar a la actual renta de garantía de ingresos.

Creemos que el desarrollo normativo posterior a la Ley de Servicios Sociales deberá tener en cuenta situaciones de injusticia social que pueden producirse, por lo que pensamos que se debería asegurar que la suma del valor de las prestaciones públicas percibidas por las personas usuarias del servicio ocupacional, junto con las gratificaciones percibidas como prestación propia, superen en todo caso el valor de la renta de garantía de ingresos, de manera que se garantice a la persona con discapacidad, individualmente considerada, los mismos derechos ciudadanos establecidos para el resto de las personas.

\subsubsection{Condiciones que permitan el desarrollo de una actividad laboral u ocupacional, productiva, significativa, reconocida y valorada}

Hemos de avanzar para conseguir oportunidades laborales y condiciones, internas y externas, que permitan que todas las personas con discapacidad intelectual puedan desarrollar una actividad laboral u ocupacional, productiva, significativa, reconocida y valorada. Esto supone, entre otros cambios, construir un nuevo sistema de organización de los apoyos dirigido a las personas con discapacidad intelectual que presentan necesidades especiales, por motivo de deterioro/envejecimiento o por otras causas; un sistema donde la oferta de apoyos se gestione en función de las necesidades y la demanda de dichos apoyos.

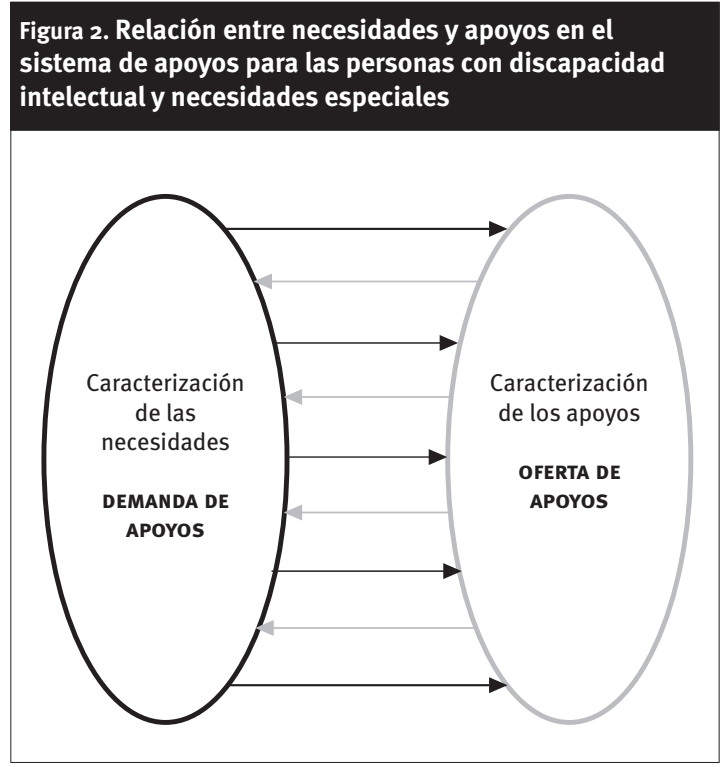

Fuente: Elaboración propia.
Se trata de ofertar un mayor abanico de posibilidades de empleo, ocupación, actividades diurnas y respuestas intermedias, con elementos de apoyo diverso y complementario. Estas vías han de permitir la promoción y el acceso a fórmulas con mayores posibilidades de desarrollo laboral, y, en el caso de personas en situación de deterioro o envejecimiento, fórmulas de adecuación a esas necesidades específicas de apoyo. En este sentido, Lantegi Batuak apuesta por lograr modelos y metodologías innovadoras a partir de la experiencia práctica y la investigación aplicada.

\subsection{Propuesta de un nuevo sistema de organización de los apoyos para las personas con discapacidad que presentan necesidades suplementarias de apoyo}

De acuerdo con las consideraciones y premisas expresadas, la visión de Lantegi Batuak es la de disponer de un nuevo sistema de organización de los apoyos para las personas con discapacidad de Lantegi Batuak que presentan necesidades suplementarias de apoyo, con un diseño de itinerarios circulares y compatibilidad de medidas de apoyo. Esta visión informa el planteamiento de estrategias y líneas de actuación, tanto en el plano interno como en relación con agentes externos: es el caso de las reivindicaciones de cambios normativos o iniciativas que han de adoptar las administraciones públicas de ámbito competencial diverso.

Se trata de diseñar y desarrollar un sistema de organización de apoyos a la actividad laboral y ocupacional que permita combinarlos y compatibilizarlos, y concretar itinerarios y dispositivos de la oferta, en función de los perfiles de necesidad, bien sea por deterioro/envejecimiento o por otros motivos, comprendiendo, a partir de los recursos actuales, la posibilidad de combinaciones diversas entre:

- Empleo ordinario.

- Empleo con apoyo.

- Empleo especial (centros especiales de empleo).

- Servicio ocupacional (programas con diferentes intensidades de apoyo).

- Centros de día y centros de actividades de día.

- Recursos económicos complementarios.

- Otras prestaciones y recursos, tanto de carácter sociolaboral como de otro tipo.

La consecución de un sistema de estas características requiere adaptaciones internas, como organización, y, sobretodo, cambios externos: adaptaciones y conciliación de normativa, y cambios estructurales, con implicación de distintos niveles competenciales (Ministerio de Empleo y Seguridad Social, Departamento de Empleo y Asuntos Sociales del Gobierno Vasco, Departamento de Acción Social de la Diputación Foral de Bizkaia).

El sistema habría de respetar, en cualquier caso, la voluntad y la libertad de elección de las personas. 
Cuadro 2. Posibles combinaciones de recursos de apoyo, según la situación de la personas con discapacidad intelectual con necesidades especiales

\begin{tabular}{|c|c|c|c|}
\hline \multirow{3}{*}{$\begin{array}{l}\text { Sistemas de } \\
\text { respuesta }\end{array}$} & \multicolumn{3}{|c|}{ Posibles situaciones de la persona con discapacidad intelectual que presenta necesidades suplementarias de apoyo } \\
\hline & \multicolumn{2}{|l|}{ En centros especiales de empleo } & \multirow{2}{*}{ En servicio ocupacional } \\
\hline & Jornada completa & Jornada parcial (25\%-75\%) & \\
\hline Seguridad Social & & $\begin{array}{l}\text { Acceso, en su caso, a los regímenes } \\
\text { de incapacidad permanente total o } \\
\text { incapacidad permanente parcial en la } \\
\text { parte de jornada laboral no cubierta. }\end{array}$ & $\begin{array}{l}\text { Percepción, en su caso, de } \\
\text { la pensión por incapacidad } \\
\text { permanente que corresponda (de } \\
\text { acuerdo con lo que hubiera podido } \\
\text { cotizar previamente en centro } \\
\text { especial de empleo o en empleo } \\
\text { ordinario). }\end{array}$ \\
\hline $\begin{array}{l}\text { Políticas activas de } \\
\text { empleo }\end{array}$ & $\begin{array}{l}\text { Garantía de, como mínimo, la renta } \\
\text { de garantía de ingresos. }\end{array}$ & $\begin{array}{l}\text { Salario correspondiente según la } \\
\text { jornada laboral desarrollada (de } \\
\text { forma que se garantice, junto con la } \\
\text { Seguridad Social, como mínimo, la } \\
\text { renta de garantía de ingresos). }\end{array}$ & \\
\hline Servicios sociales & $\begin{array}{l}\text { Apoyos con intensidad gradual, } \\
\text { según necesidad. }\end{array}$ & $\begin{array}{l}\text { Apoyos con intensidad gradual, según } \\
\text { necesidad. }\end{array}$ & $\begin{array}{l}\text { Apoyos con intensidad gradual, } \\
\text { según necesidad, y renta de garantía } \\
\text { de ingresos garantizada. }\end{array}$ \\
\hline
\end{tabular}

Fuente: Elaboración propia.

Además, deberá permitir el acceso de las personas en centros especiales de empleo que se encuentren en una situación de deterioro o envejecimiento a las prestaciones de incapacidad permanente de la Seguridad Social. De esta forma, habría de ser posible que, cuando una persona así lo requiera como consecuencia de deterioro o envejecimiento, pudiera seguir trabajando en un centro especial de empleo con una jornada parcial (del $25 \%, 50 \% 075 \%$ ) y, al mismo tiempo, en la parte de jornada no cubierta, percibiera la correspondiente pensión por incapacidad permanente -total o parcial- (del 75\%, 50\% o $25 \%$ ). En el caso de personas en servicio ocupacional, tal combinación también debería ser posible siempre que la persona hubiera generado previamente su derecho a percibir pensión por incapacidad permanente de la Seguridad Social, por haber cotizado el tiempo requerido en centro especial de empleo o en empleo ordinario. Todo ello, además, debería poder combinarse con los apoyos precisos del sistema de servicios sociales, con intensidad gradual, según la necesidad que la persona presenta.

El Cuadro 3 resume este sistema de apoyo a las actividades laborales desde la perspectiva de los diversos sistemas de respuesta -Seguridad Social, políticas activas de empleo y servicios sociales-, y según la diversidad de situaciones de la persona -centro especial de empleo o servicio ocupacional-.

Según el perfil de necesidad de apoyo que presente (alto, medio o bajo), la persona con discapacidad habría de tener la oportunidad de recibir apoyos diversos de los distintos sistemas de respuesta, con posibilidad de combinarlos. En especial, y cuando así proceda, sería deseable compatibilizar las prestaciones de incapacidad permanente -total o parcialcon la continuidad en un centro especial de empleo en jornada parcial. Todo ello sin perjuicio de que pudiera proceder, si la persona cumple los requisitos establecidos, el reconocimiento de situación de gran invalidez, incapacidad permanente absoluta para todo el trabajo o jubilación anticipada.

La identificación de los diversos escenarios y combinaciones de apoyo a las actividades laborales u ocupacionales habrá de venir determinada por:

- El perfil de necesidad de apoyo de las personas, lo que requiere caracterizarlas en función del deterioro de sus capacidades, como consecuencia de envejecimiento o por cualquier otro motivo.

- La aplicación de una herramienta y un protocolo para detectar el deterioro/envejecimiento, la articulación de perfiles de necesidad de apoyo y el establecimiento de programas de apoyo.

\section{Perfil de necesidad de apoyo: caracterización de las personas en función del deterioro de sus capacidades como consecuencia de envejecimiento o por cualquier otro motivo}

Seguidamente se propone una caracterización de los perfiles de necesidad de las personas de Lantegi Batuak, basada en su Método de perfiles de adecuación de la persona a la tarea (Badiola et al., 2011), que diferencia tres niveles según la intensidad de apoyo requerida: alto, medio y bajo. Cada uno de estos perfiles se define, según las consecuencias del deterioro/envejecimiento $u$ otras situaciones que suponen la necesidad de apoyos suplementarios, en relación con:

- Las variables que recoge el citado método en los siguientes aspectos del perfil de la persona: autonomía personal, procesado de la información, aptitudes físicas y actitudes ante el trabajo. 
- Variables tomadas de los resultados de este estudio con la finalidad de completar la caracterización en los casos de deterioro/envejecimiento en los ámbitos físico, cognitivo, relacional y emocional. En concreto, se hace referencia a: cansancio, memoria, irritabilidad y cambios de humor, tristeza y apatía, y aislamiento.
- Los apoyos que se ofertan en Lantegi Batuak a las personas con discapacidad intelectual, que constituyen una parte central de su Modelo de apoyos individuales... (Elorriaga et al., 2010) y se articulan sobre las siete dimensiones de calidad de vida que se explican más detenidamente en dicha publicación. En el Cuadro 3 se detallan esos apoyos.

Cuadro 3. Apoyos ofrecidos, agrupados por dimensiones de la calidad de vida

\begin{tabular}{|c|c|}
\hline Dimensiones & Apoyos \\
\hline Bienestar físico y material & $\begin{array}{l}\text { - Control de comida y alimentación. } \\
\text { - Ayuda para el traslado y la movilidad. } \\
\text { - Ayuda en el aseo y vestido. } \\
\text { - Acciones de seguimiento de la salud. } \\
\text { - Acciones para el manejo del dinero y las propias finanzas. } \\
\text { - Acciones de lectura y escritura funcional, y conocimiento numérico. } \\
\text { medio ambiente. } \\
\text { - Examen de salud. } \\
\text { - Apoyo a la toma de medicación. } \\
\text { - Adaptación de jornada y horario. } \\
\text { - Transpones físicas y arquitectónicas. } \\
\text { - Entidades de previsión social voluntaria. }\end{array}$ \\
\hline Bienestar emocional & $\begin{array}{l}\text { - Acciones para el fomento de la autoestima y la autovaloración, aceptación e inclusión en el } \\
\text { centro. } \\
\text { - Charlas de desarrollo (usuarios y usuarias, y sus familias/tutores). } \\
\text { - Intervenciones de ajuste psicosocial. } \\
\text { - Intervenciones conductuales. } \\
\text { - Medición del grado de satisfacción. }\end{array}$ \\
\hline Desarrollo laboral & $\begin{array}{l}\text { - Acciones de orientación laboral. } \\
\text { - Realización de la actividad laboral. } \\
\text { - Evaluación del desempeño de puestos y tareas. } \\
\text { - Formación en competencias básicas laborales. } \\
\text { - Formación en seguridad laboral. } \\
\text { - Promoción. } \\
\text { - Paso al empleo. } \\
\text { - Acciones de formación y adiestramiento en tareas específicas. } \\
\text { - Acciones de adaptación del puesto de trabajo: } \\
\text { - Productos de apoyo. } \\
\text { - Programa Ergohobe Banaka. } \\
\text { - Pcciones para el conocimiento y la integración en la organización: } \\
\text { - Visitas a otros centros. } \\
\text { - Visitas a clientes. }\end{array}$ \\
\hline
\end{tabular}

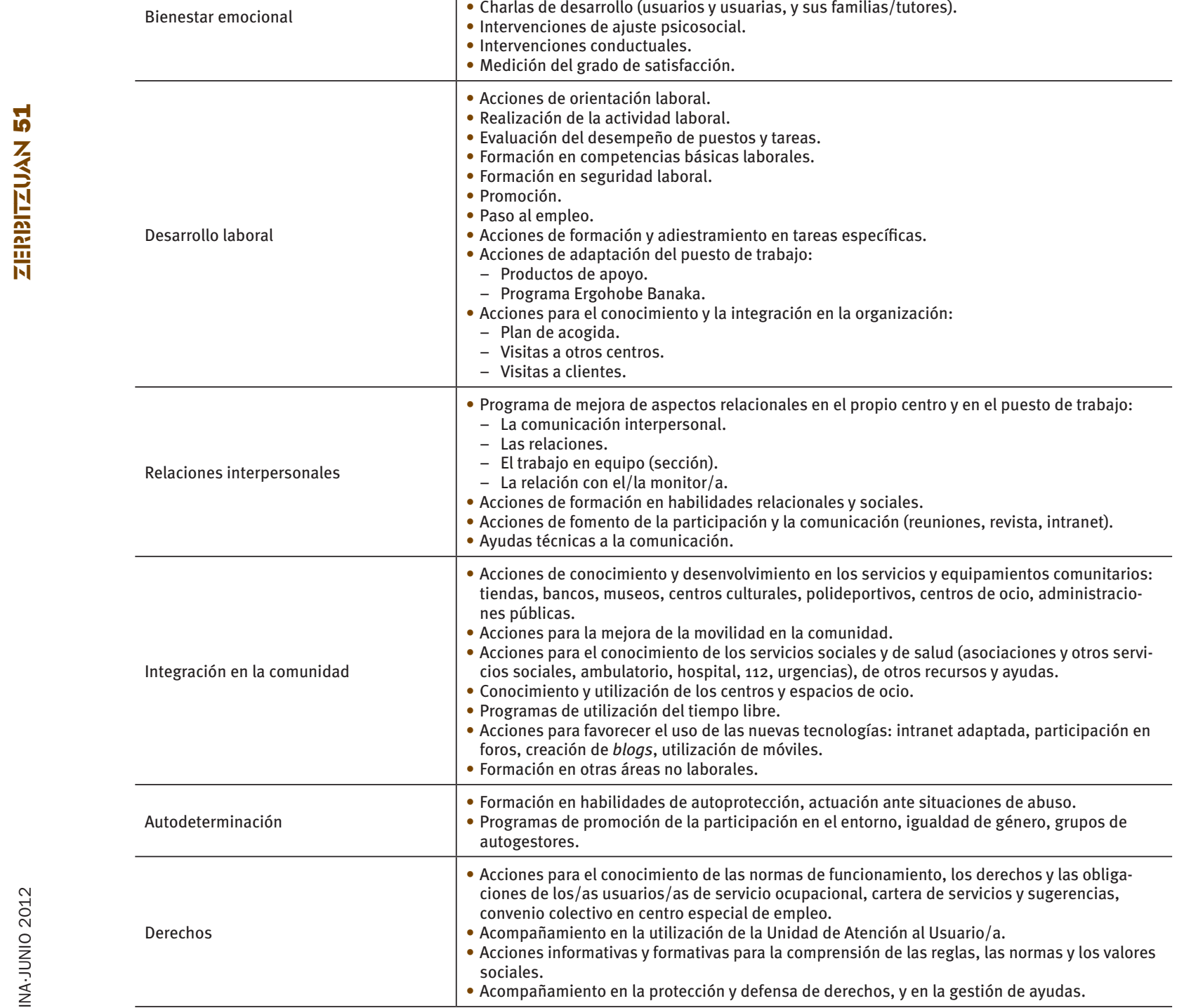

Fuente: Elaboración propia, a partir de American Association on Mental Retardation (1997: 131). 
7. Herramienta y protocolo para la detección del deterioro/envejecimiento, la articulación de perfiles de necesidad de apoyo y el establecimiento de programas de apoyo

Este apartado recoge una primera propuesta para desarrollar una herramienta y un protocolo adaptados para la detección del deterioro/envejecimiento, la articulación de perfiles de necesidad de apoyo y el establecimiento de programas de apoyo, según el Método de perfiles de adecuación de la tarea a la persona (Badiola et al., 2011) y el Modelo de apoyos individuales... (Elorriaga et al., 2010) de Lantegi Batuak. Su validación definitiva requiere un proceso de pilotaje, de acuerdo al esquema que aquí se expone. La aplicación de la herramienta/protocolo, así como la de los programas de apoyo para perfiles con necesidades suplementarias de apoyo, estará supeditada al futuro desarrollo de este apartado.

En ese proceso se contemplan las siguientes fases:

1. Articulación de un protocolo que facilite la detección del deterioro/envejecimiento, de acuerdo con el siguiente planteamiento:

- Se han analizado las variables del perfil (Badiola et al., 2011) y se han clasificado en tres tipos, según su importancia en la detección del deterioro/envejecimiento.

- Se han definido otras variables, obtenidas en el curso de este estudio: cansancio, memoria, irritabilidad y cambios de humor, tristeza y apatía, y aislamiento. Estas variables, que se relacionan con determinadas variables del perfil, serán tenidas en cuenta más adelante.

- Para validar la propuesta, se plantea llevar a cabo un pilotaje utilizando las variables críticas y las otras variables mencionadas. La muestra que se seleccionará deberá contemplar personas con discapacidad intelectual con deterioro por envejecimiento, o por otros motivos, y se hará un contraste con personas que no presenten deterioro.

- Una vez obtenidos los resultados, se validará la selección de estas variables críticas y se establecerá la puntuación que se considerará necesaria para que se active el protocolo o la 'señal de alarma' por deterioro/ envejecimiento.

2. Articulación de perfiles de necesidades de apoyo para toda la población con necesidades suplementarias de apoyo (discapacidad intelectual, trastorno mental y trastorno del comportamiento):

- Según las necesidades, se distinguen tres perfiles de apoyo: alto, medio y bajo (cfr. Cuadro 4).

- Estos nuevos perfiles se definirían a partir de:

- Las valoraciones del método de perfiles (variables críticas, de media y de baja intensidad).
- Las valoraciones de las otras variables citadas anteriormente.

- Otros aspectos que ya se conocen: ayuda de terceras personas, adaptación de horarios, doble diagnóstico, presencia de problemas de conducta o intervenciones en el ámbito de la de salud (u otros), examen de salud.

3. Establecimiento de programas de apoyo para estos perfiles:

- Se establecerían actividades, espacios, recursos y ratios de atención, entre otros elementos.

- Los programas de apoyo intensivo podrían ser de intensidad alta, media y básica (cfr. Cuadro 4).

Cuadro 4. Articulación entre perfiles de necesidades de apoyo y programas de apoyo

\begin{tabular}{l|l|l}
\hline $\begin{array}{l}\text { Perfil de } \\
\text { necesidad } \\
\text { de apoyo }\end{array}$ & $\begin{array}{l}\text { Niveles de dedicación a actividades } \\
\text { laborales y no laborales }\end{array}$ & $\begin{array}{l}\text { Programas } \\
\text { de apoyo }\end{array}$ \\
\hline Alto & $\begin{array}{l}\text { Dedicación del } 50 \% \text { o menos a } \\
\text { actividades laborales, y del 50\% 0 } \\
\text { más a actividades no laborales }\end{array}$ & $\begin{array}{l}\text { Intensidad } \\
\text { alta }\end{array}$ \\
\hline Medio & $\begin{array}{l}\text { Dedicación de entre el } 50 \% \text { y el } 75 \% \\
\text { a actividades laborales, y de entre } \\
\text { el } 25 \% \text { y el } 50 \% \text { a actividades no } \\
\text { laborales }\end{array}$ & $\begin{array}{l}\text { Intensidad } \\
\text { media }\end{array}$ \\
\hline Bajo & $\begin{array}{l}\text { Similar al modelo actual de servicio } \\
\text { ocupacional o centro especial de } \\
\text { empleo, que pivota en función del } \\
\text { plan de apoyos individuales }\end{array}$ & $\begin{array}{l}\text { Intensidad } \\
\text { baja }\end{array}$ \\
\hline
\end{tabular}

Fuente: Elaboración propia.

\section{Prioridades estratégicas y objetivos}

A la luz de las conclusiones del estudio, analizados los retos y las necesidades que la situación de deterioro/envejecimiento plantea, $y$ desde la perspectiva de construir la visión de Lantegi Batuak explicitada en el epígrafe 5 , el conjunto de propuestas de actuación, soluciones y dispositivos habrán de articularse en el marco de dos prioridades estratégicas:

1. Adecuar, en el seno de Lantegi Batuak, y en función de la diversidad de las necesidades de las personas con discapacidad intelectual que envejecen o sufren deterioros significativos, la oferta y diversidad de apoyos de carácter suplementario que puedan necesitar, con la asignación de medios y recursos adecuados.

2. Proponer a las administraciones públicas competentes, de manera directa o a través de las organizaciones representativas en las que Lantegi Batuak participa, un nuevo sistema de empleo, ocupación y apoyos capaz de dar una respuesta efectiva y no discriminatoria a las necesidades evolutivas de las personas con discapacidad intelectual que envejecen o sufren deterioros significativos. 


\section{Propuestas de actuación, soluciones, dispositivos}

Con el objeto de responder a las prioridades estratégicas y objetivos recogidos en el epígrafe anterior, se plantean las siguientes propuestas de actuación, soluciones y dispositivos, relacionados con la organización de Lantegi Batuak, con las administraciones públicas y con el movimiento asociativo.

Cuadro 5. Propuestas dirigidas a los grupos de interés de Lantegi Batuak

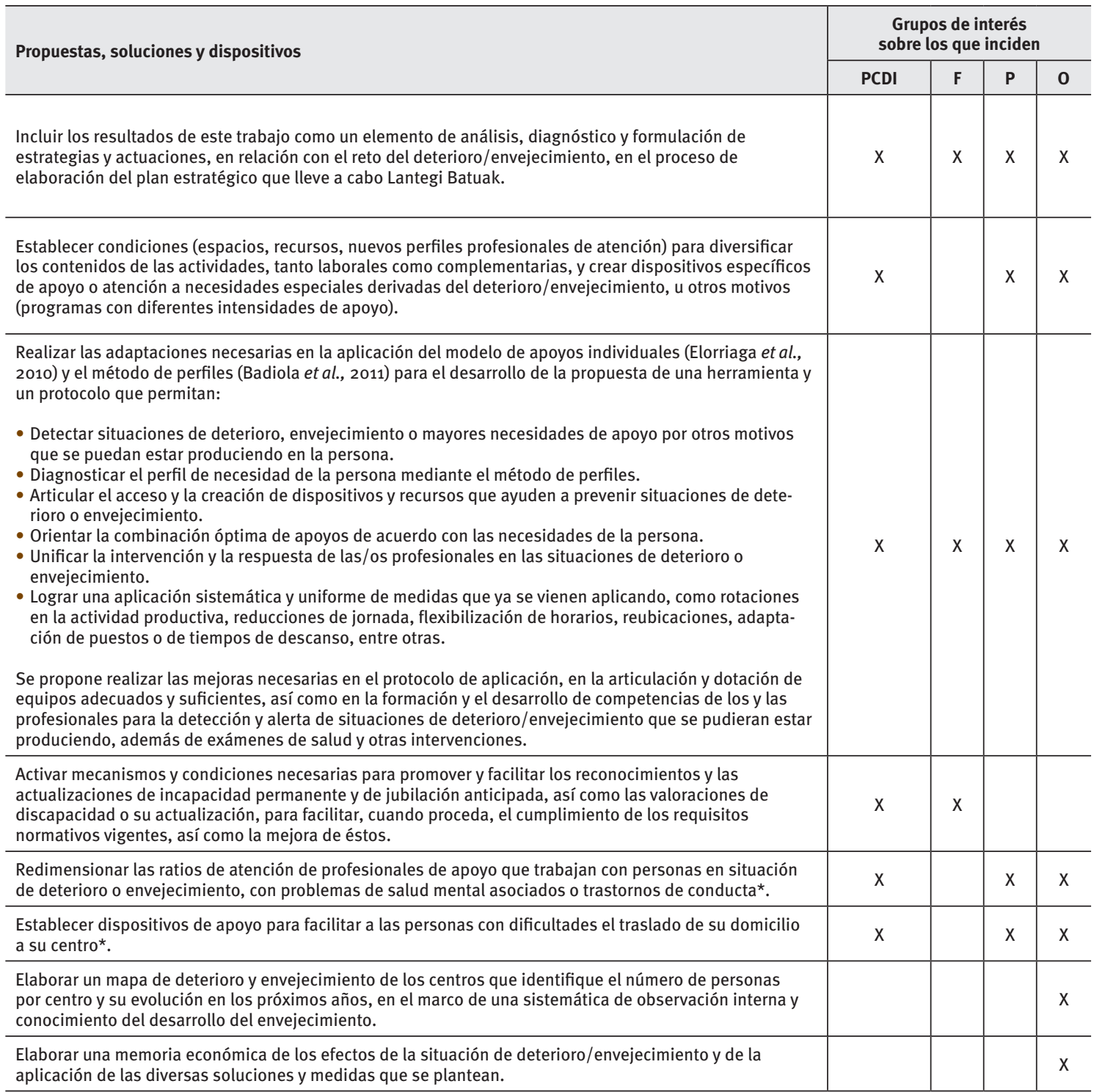

PCDI: personas con discapacidad intelectual. F: familiares. P: profesionales de apoyo de Lantegi Batuak. O: Lantegi Batuak como organización. * Propuesta condicionada a la obtención de financiación suficiente.

Fuente: Elaboración propia. 


\begin{tabular}{|c|c|c|c|c|}
\hline \multirow{2}{*}{ Propuestas, soluciones y dispositivos } & \multicolumn{4}{|c|}{ Administraciones públicas destinatarias } \\
\hline & AGE & GV & DFB & EE.LL. \\
\hline $\begin{array}{l}\text { Reivindicar que se lleven a cabo las modificaciones normativas que permitan los escenarios y } \\
\text { las combinaciones de alternativas de apoyo a la actividad laboral y ocupacional, flexibilizando } \\
\text { las condiciones de acceso y la movilidad entre recursos y ayudas, garantizando siempre que } \\
\text { la persona mantenga el nivel de ingresos de, como mínimo, la renta de garantía de ingresos. } \\
\text { Esta reclamación se refiere, en particular, a compatibilizar un régimen de incapacidad } \\
\text { permanente, total o parcial, con una actividad laboral en centro especial de empleo o con una } \\
\text { actividad en servicio ocupacional, en un régimen de mayor intensidad de apoyos para las } \\
\text { personas con discapacidad intelectual. }\end{array}$ & $x$ & $x$ & $x$ & \\
\hline $\begin{array}{l}\text { Proponer la articulación de dispositivos de valoración técnica para dictaminar capacidades y } \\
\text { la posibilidad de acceso a los diversos recursos, escenarios y combinaciones, en condiciones } \\
\text { de igualdad para todas las personas. }\end{array}$ & $x$ & $x$ & $x$ & \\
\hline $\begin{array}{l}\text { Contribuir a reivindicar el desarrollo de un sistema unificado de valoración y reconocimiento } \\
\text { de la discapacidad y la dependencia que esté al servicio de las personas y contemple, entre } \\
\text { otras, las especificidades de las necesidades de apoyo de las personas con discapacidad } \\
\text { intelectual, y que, entre otras cuestiones: } \\
\text { - Permita la toma en consideración de dictámenes de los servicios médicos y psicológicos de } \\
\text { los centros especiales de empleo y servicios ocupacionales. } \\
\text { - Elimine trabas burocráticas innecesarias. } \\
\text { - Permita contar con herramientas comunes y validadas de valoración y diagnóstico. }\end{array}$ & $\mathrm{x}$ & $x$ & $x$ & \\
\hline $\begin{array}{l}\text { Instar a la aplicación de los convenios para la gestión de servicios prevista en el art. } 69 \text { de } \\
\text { la Ley } 12 / 2008 \text { de Servicios Sociales, cómo fórmula jurídica de apoyo de la Administración } \\
\text { a los programas con diferentes intensidades de apoyo en servicio ocupacional, de acuerdo } \\
\text { con lo que se plantea en la propuesta que recoge este documento, en cuanto supuesto de } \\
\text { singularidad de la actividad y carácter innovador y experimental. }\end{array}$ & & & $\mathrm{X}$ & \\
\hline $\begin{array}{l}\text { Reivindicar la financiación estable y suficiente para redimensionar los ratios de atención } \\
\text { de profesionales de apoyo en los casos en que trabajen con personas con necesidades } \\
\text { suplementarias. }\end{array}$ & & $x$ & $\mathrm{x}$ & \\
\hline $\begin{array}{l}\text { Reivindicar que se garantice la financiación estable y suficiente para contar con equipos } \\
\text { multidisciplinares (unidades de apoyo) en centro especial de empleo, en número suficiente, } \\
\text { para atender las necesidades específicas de apoyo de sus trabajadoras/es. }\end{array}$ & $x$ & $x$ & & \\
\hline $\begin{array}{l}\text { Reivindicar que se garantice la financiación estable y suficiente para contar con preparadores } \\
\text { laborales y equipos profesionales adecuados y suficientes en la modalidad de empleo } \\
\text { con apoyo, para evitar y prevenir el deterioro/envejecimiento entre trabajadores de esta } \\
\text { modalidad. }\end{array}$ & $x$ & $x$ & & \\
\hline $\begin{array}{l}\text { Reivindicar la financiación estable y suficiente para desarrollar el pilotaje de las herramientas } \\
\text { y el protocolo para la detección del deterioro/envejecimiento; la articulación de perfiles de } \\
\text { necesidad de apoyo y el establecimiento de programas de apoyo, así como para el diseño y } \\
\text { aplicación de programas con diferentes intensidades de apoyo. }\end{array}$ & & $x$ & $\mathrm{x}$ & \\
\hline $\begin{array}{l}\text { Instar el apoyo al transporte (individual o grupal) para el traslado de las personas que lo } \\
\text { requieran de su domicilio al centro especial de empleo o servicio ocupacional. }\end{array}$ & & $\mathrm{x}$ & $\mathrm{x}$ & \\
\hline $\begin{array}{l}\text { Contribuir a la reivindicación del movimiento asociativo de que se intensifiquen los servicios } \\
\text { de apoyo a las familias (servicios de apoyo a familias, residenciales, de ocio, respiro) y } \\
\text { conseguir una mayor intensidad de los servicios de apoyo y promoción de la autonomía } \\
\text { personal. }\end{array}$ & & $x$ & $X$ & $x$ \\
\hline $\begin{array}{l}\text { Apoyar la reivindicación de cambios normativos en materia de jubilación, para favorecer una } \\
\text { respuesta global y adecuada, que contemple en su conjunto la realidad y las necesidades } \\
\text { de las personas con discapacidad, dirigida a asegurar una pensión digna, suficiente y justa } \\
\text { (reducción razonable de los tiempos y tipos de cotización, condiciones y requisitos de } \\
\text { diagnóstico y grado de discapacidad). }\end{array}$ & $x$ & & & \\
\hline $\begin{array}{l}\text { Instar la mejora de bases, criterios y fuentes de información sobre datos cuantitativos de } \\
\text { la población con discapacidad, en particular, la población con discapacidad intelectual en } \\
\text { situación de envejecimiento o deterioro. }\end{array}$ & & $x$ & $x$ & \\
\hline
\end{tabular}

AGE: Administración General del Estado. GV: Gobierno Vasco. DFB: Diputación Foral de Bizkaia. EE.LL.: entidades locales. Fuente: Elaboración propia.

\section{Cuadro 7. Propuestas que Lantegi Batuak plantea desarrollar en cooperación con el conjunto del movimiento asociativo de la discapacidad}

Fomentar la colaboración con el conjunto del movimiento asociativo para reivindicar las propuestas expuestas dirigidas a las administraciones públicas.

Promover que el movimiento asociativo intensifique los servicios de apoyo para las personas y familias en la información y la formación sobre cómo afrontar el deterioro/envejecimiento, la preparación para la etapa de jubilación, el relevo, la pérdida de familiares u otras situaciones en las que la persona con discapacidad pasa a ejercer nuevas funciones de cuidador/a de sus familiares.

Desarrollar una planificación de los recursos necesarios (centros de día, residencias, viviendas, tutela) que la evolución de las necesidades de las personas con discapacidad intelectual va a requerir en los próximos años, para exigir a las administraciones públicas una dotación de plazas y recursos adecuados y suficientes.

Fuente: Elaboración propia. 
AMERICAN ASSOCIATION ON MENTAL RETARDATION (1997): Retraso mental: definición, clasificación y sistemas de apoyo, Madrid, Alianza.

AGUADO, A. L. et al. (2007) Necesidades de las personas con discapacidad intelectual en proceso de envejecimiento, Bilbao, Diputación Foral de Bizkaia [khttp://www.bizkaia.net/Homez/ Archivos/DPTO3/Temas/Pdf/topaketa16/ Publicacion $\% 20$ Discapacidad\%20y\%20 Envejecimiento.pdf〉]

BADIOLA, V. et al. (2011): Método de perfiles de adecuación de la tarea a la persona, Loiu, Lantegi Batuak, $3^{\underline{a}}$ ed. revisada [<http://www.lantegi. com/wp-content/uploads/downloads/oo_ Publicaciones/manuales/Metodo\%20 perfiles_3ed.pdf $>$.

DIPUTACIÓN FORAL DE BIZKAIA (2010): Plan para la Participación y Calidad de Vida de las Personas con Discapacidad en Bizkaia 2010-2013, Bilbao, Diputación Foral de Bizkaia [<http://www. bizkaia.net/home2/Archivos/DPTO3/Noticias/ Adjuntos/Plan\%20Discapacidad_cas\%202010. pdf>].

ELORRIAGA, E. et al. (dirs.) [2011]: Investigación sobre el envejecimiento y deterioro de las personas con discapacidad intelectual en el ámbito ocupacional y del empleo en Bizkaia, Loiu, Lantegi Batuak [<http://www.lantegi.com/ wp-content/uploads/downloads/2012/04/ LANTEGIBATUAK_Estudio-Envejecimiento.pdf)].
FEAPS (2005): Cartera de servicios sociales del movimiento FEAPS, Madrid, FEAPS [resumen ejecutivo disponible en <http://www.feaps.org/ profesionales/documentos/servicios_resumen. pdf)].

FEAPS NAVARRA (2005): Envejecimiento y deterioro de las personas con discapacidad intelectual en el ámbito del empleo en la Comunidad Foral de Navarra, Pamplona, Fundación Koine-Aequalitas [<http://www.navarra.es/ NR/rdonlyres/DDC9A5A5-32Ao-4C2E-BF7C6C7EAE4DD329/63795/EnvejecimientoEmpleo. pdf $>$.

INSTITUTO NACIONAL DE ESTADÍSTICA (2008): Encuesta de Discapacidad, Autonomía Personal y Situaciones de Dependencia 2008, Madrid, Instituto Nacional de Estadística [<http://www.ine.es/jaxi/ menu.do?type $=$ pcaxis $\&$ path $=\% 2 \mathrm{Ft}_{15} /$ p418\&file $=$ inebase $\& L=0$ > $]$.

JEFATURA DEL ESTADO (2003): “Ley 51/2003, de 2 de diciembre, de Igualdad de Oportunidades, No Discriminación y Accesibilidad Universal de las Personas con Discapacidad", Boletín Oficial del Estado, no 289, 3-12-2003, sección I, págs. 43.187-43.195 [<http://www.boe.es/diario_ boe/txt.php?id=BOE-A-2003-22066)].

MONTERO, D. et al. (2006): Estudio de la incidencia de problemáticas asociadas en personas con discapacidad intelectual en Lantegi Batuak, Lantegi Batuak [<http://www.lantegi.com/ wp-content/uploads/downloads/oo_ Publicaciones/estudios/Estudio_discapacidad_ intelectual_LB.pdf`].

NACIONES UNIDAS (2006): Convención sobre los Derechos de las Personas con Discapacidad y Protocolo Facultativo, Nueva York, Naciones Unidas 
[<http://www.un.org/disabilities/documents/ convention/convoptprot-s.pdf〉].

NOVELL. R. et al. (2008): Informe Séneca. Envejecimiento y discapacidad intelectual en Cataluña 20002008, Federación Catalana Pro-personas con Discapacidad Intelectual [disponible resumen ejecutivo en 〈http://www.dincat.cat/ fichero-21051_21051〉].

PRESIDENCIA DEL GOBIERNO VASCO (2000): “Ley 10/2000, de 27 de diciembre, de Carta de Derechos
Sociales", Boletín Oficial del País Vasco, no 249, 30-12-2000, págs. 23.377-23.379 [ http://www.euskadi.net/cgi-bin_k54/ bopv_20?c\&f=20001230\&a=200005881)].

- (1998): “Ley 12/1998, de 22 de mayo, contra la Exclusión Social”, Boletín Oficial del País Vasco, n- 105, 8-6-1998, págs. 10.46710.506 [ [http://www.euskadi.net/cgibin_k54/bopv_20?c\&f=19980608 $\& a=199802519>$ ]. 



\section{Tendencias, innovaciones y buenas prácticas internacionales en el ámbito del voluntariado:}

\section{SIIS Centro de Documentación y Estudios}

Fundación Eguía-Careaga

<estudios@siis.net>

Artikulu honetan, gure inguruko herrialde batzuetako administrazio publikoek antolatutako boluntariotzaren sustapenerako politika eta jarduera egokiak ezagutu, deskribatu eta balioztatzen dira, eta nazioarteko panoraman ematen ari diren joerak jasotzen dira bertan. Hori egiteko oraintsu argitaratutako dokumentazioaren arabera eginiko hautaketa burutu da, bai estatuko bai nazioarteko ehundik gora azterlan, ebaluazio eta plangintza estrategikoak aztertuz.

\section{HITZ-GAKOAK:}

boluntariotza, joerak, esperientziak, jarduera egokiak, nazioarteko ikuspegia.
Este artículo identifica, describe y valora las políticas y las buenas prácticas desarrolladas en los países de nuestro entorno, por parte de las administraciones públicas, en relación a la promoción del voluntariado organizado, y recoge algunas tendencias que se están produciendo en el panorama internacional. Lo hace mediante la revisión de una selección documental reciente de ámbito estatal e internacional que recopila más un centenar de estudios, evaluaciones y planes estratégicos que tratan la cuestión del voluntariado.

\section{Palabras ClaVe:}

voluntariado, tendencias, experiencias, buenas prácticas, panorama internacional. 


\section{Introducción}

La declaración de 2011 como Año Europeo del Voluntariado pretende sensibilizar y concienciar a la población sobre el valor de este tipo de participación solidaria, así como establecer canales que permitan fomentar el desarrollo de la acción voluntaria y fortalecer la labor de las entidades de voluntariado. La Comisión Europea calcula que, en los 27 Estados miembros, más de 100 millones de personas dedican en la actualidad parte de su tiempo en alguna tarea relacionada con el voluntariado. La campaña promovida por la Unión Europea ‘¡Hazte voluntario! Marca la diferencia' (2011) tiene por objetivo convertir la acción voluntaria en un eje para fomentar la participación ciudadana y ofrecer medios para mejorar la gestión de las entidades que trabajan con personas voluntarias, así como reconocer el papel esencial que juegan las personas voluntarias y las entidades de voluntariado. A partir del reconocimiento de la importancia de la labor voluntaria para alcanzar una ciudadanía más activa y democrática, la UE quiere impulsar una mayor diversidad entre las personas que participan en el voluntariado y eliminar las barreras que puedan existir para la incorporación de toda la ciudadanía a este tipo de entidades.

El marco desarrollado para el Año Internacional del Voluntariado de 2001 señalaba cuatro objetivos, que resumen adecuadamente las posibilidades de intervención de las administraciones en relación a este tema:

- Reconocimiento de la labor realizada y del papel que juegan en la sociedad las entidades de voluntariado, así como desarrollo de medidas que contribuyan a reforzar el estatus social de las personas voluntarias.

- Promoción de las ventajas que el voluntariado tiene tanto para la sociedad como para las propias personas voluntarias, de forma que se establezca un clima social favorable a la acción voluntaria.

- Apoyo, a través del desarrollo de infraestructuras y organismos que faciliten la acción voluntaria, así como de un marco normativo adecuado.

- Establecimiento de redes que faciliten una mejor conexión entre las entidades de voluntariado y el resto del tejido social.

Desde esa perspectiva y en el marco de las actuaciones del II Plan Vasco del Voluntariado², el Departamento de Empleo y Asuntos Sociales del Gobierno Vasco, en colaboración con las tres agencias de voluntariado y el Consejo Vasco del Voluntariado,

2 El II Plan Vasco del Voluntariado, inicialmente concebido para el periodo 2008-2010, fue prorrogado en diciembre de 2011, considerando que la coyuntura socioeconómica invitaba a aunar esfuerzos en torno a compromisos firmes más que a diseñar grandes planes, y tras constatar que las líneas estratégicas del documento conservaban plenamente su sentido (Departamento de Empleo y Asuntos Sociales, 2011). encargó al SIIS Centro de Documentación y Estudios la realización de un informe con el objetivo de identificar, describir y valorar las políticas y las buenas prácticas desarrolladas en los países de nuestro entorno, por parte de las administraciones públicas, en relación a la promoción del voluntariado organizado, así como recoger algunas tendencias que se están produciendo en esos países en torno al fenómeno del voluntariado. El estudio también pretendía detectar las líneas estratégicas básicas aplicadas en esos países para promover un desarrollo adecuado de las entidades de voluntariado, así como las buenas prácticas mediante las cuales se desarrollan esas estrategias y los cambios que se están produciendo en la forma de entender el voluntariado. El presente artículo es una síntesis de dicho informe (SIIS Centro de Documentación y Estudios, 2011).

En el curso del estudio, se revisó una selección documental reciente -de ámbito estatal e internacional- que recopilaba más un centenar de estudios, evaluaciones y planes estratégicos 3 . Para localizar la documentación consultada, se realizó en primer lugar una búsqueda documental mediante la base de datos bibliográfica del SIIS Centro de Documentación y Estudios, que cuenta con cerca de dos mil referencias bibliográficas relacionadas con la acción voluntaria, fundamentalmente en el ámbito de los servicios sociales y la intervención social. Esa primera búsqueda se complementó con la realizada en otras bases de datos especializadas en el ámbito del tercer sector o de las políticas sociales, así como con la consulta a las sedes electrónicas de las principales instituciones, de carácter público o privado, que trabajan en los países de nuestro entorno en el ámbito del voluntariado. La mayoría de informes, manuales, buenas prácticas o campañas para la promoción del voluntariado que se recogen en el informe tienen origen en el Reino Unido, Canadá y Francia, así como en el Estado español. Ello se debe tanto a la mayor disponibilidad de documentación referente a esos países como, probablemente, al énfasis que en ellos se ha dado a la promoción de la acción voluntaria.

Es importante señalar que el informe no recoge todas las acciones que se desarrollan en el ámbito de la promoción del voluntariado, sino únicamente aquellas que el equipo redactor consideró más innovadoras, interesantes o prometedoras, y que, por tanto, cabe destacar como tendencias novedosas y de interés en el ámbito de la promoción del voluntariado en Euskadi.

\section{Líneas estratégicas en el ámbito del voluntariado}

Las líneas de estrategia que marcan los diferentes documentos consultados son muy variadas. Las directrices del Consejo de Europa para este Año Euro-

3 Para una nómina detallada de la bibliografía y las fuentes utilizadas, consúltese el informe original (SIIS Centro de Documentación y Estudios, 2011). 
peo del Voluntariado 2011 se centran, por ejemplo, en impulsar el voluntariado entre las personas más jóvenes y las de mayor edad. Además de estos dos colectivos específicos, la atención de esta segunda campaña comunitaria se centra en la transversalidad de la acción voluntaria en las diversas políticas europeas y subraya el carácter inclusivo de esta forma de participación. A su vez, el Manifiesto a favor del voluntariado en Europa (Centro Europeo del Voluntariado, 2006: 1) propone acciones concretas para reconocer, promover y facilitar el voluntariado en la Unión para asegurar una "sociedad voluntaria".

Las estrategias presentadas en el II Plan Vasco del Voluntariado 2008-2010 se dirigen a sensibilizar a la ciudadanía y a mejorar el dinamismo de las asociaciones que emplean a personas voluntarias. A su vez, la Estrategia Estatal del Voluntariado para los años 2010-2014 (Gobierno de España, 2010) está centrada en el estudio, la difusión, la formación y la búsqueda de nuevas formas de financiación de las organizaciones de acción voluntaria. El análisis de los planes de voluntariado existentes en el Estado español hace referencia a muy diversas funciones y ámbitos de intervención: sensibilización, apoyo, coordinación, cooperación, captación, fidelización, gestión, rendición de cuentas, investigación y formación, entre otras. Todas ellas tienen, de una u otra forma, reflejo en el repaso bibliográfico que se recoge en este artículo.

Las directrices detectadas en la literatura consultada han sido divididas en nueve grandes ejes o tendencias:

- Nuevas formas de implicación en la acción voluntaria.

- Voluntariado y diversidad.

- Voluntariado como herramienta de inclusión sociolaboral.

- Voluntariado corporativo.

- Desarrollo de infraestructuras y medidas de apoyo.

- Gestión del voluntariado e introducción de sistemas de calidad.

- Trabajo en red y refuerzo de la dimensión local.

- Mejora del conocimiento científico relativo a la acción voluntaria.

- Voluntariado y nuevas tecnologías.

\subsection{Nuevas formas de implicación en la acción voluntaria}

Con el paso de los años, las entidades tienen que adaptarse a la mayor diversidad en cuanto a disponibilidades de tiempo, capacidades de intervención, expectativas y motivaciones de las personas que quieren (o querrían) ejercer el voluntariado. Esa mayor diversidad ha traído consigo nuevas formas de ejercer el voluntariado, tanto en lo que se refiere al tipo de actividad realizada, como a la intensidad y la naturaleza de la vinculación existente entre la persona voluntaria y la entidad con la que colabora.
De la literatura consultada para realizar el informe, se deriva la creciente importancia de nuevos tipos de voluntariado, o de formas de ejercer la labor voluntaria, que están, en cierta manera, modificando el panorama tradicional de la acción voluntaria. Todos ellos tienen en común una vinculación más débil o discontinua con las entidades de voluntariado y la emergencia de un tipo de acción voluntaria más individualizada, diversificada e informal, aunque no necesariamente de menor intensidad.

En ese sentido, algunos estudios han puesto de manifiesto la tendencia hacia un voluntariado menos dispuesto que antes a consagrarse durante mucho tiempo a la misma organización y a asumir responsabilidades en la toma de decisiones. Estos cambios en la disponibilidad ciudadana para implicarse en las labores de voluntariado suponen, por una parte, un reto para las entidades voluntarias, en la medida en que obligan a trabajar mediante fórmulas menos convencionales, pero traen también consigo la posibilidad de extender el voluntariado a ámbitos en los que no estaba anteriormente presente, así como de plantear fórmulas de intervención más adaptadas a las necesidades de las personas voluntarias y, a menudo, de las personas que reciben sus servicios.

\subsubsection{Voluntariado 'de persona a persona'}

Aunque sus contornos son todavía difusos, puede pensarse que se están consolidando -o al menos están adquiriendo mayor importancia-fórmulas de voluntariado que, por definirlas de alguna forma, podrían llamarse 'de persona a persona', en el sentido de que implican una relación más directa entre la persona voluntaria y la persona usuaria, y una menor intervención de las estructuras de la entidad. Este tipo de intervenciones incluyen los grupos de autoayuda, las intervenciones de pares, las fórmulas de tutoría o padrinazgo, y los modelos -más conocidos- de acogimiento familiar voluntario. Su denominador común es que la acción voluntaria tiene una base fundamentalmente individual, con relaciones personales de mayor intensidad y mayor autonomía de acción por parte de la persona voluntaria, y que la dependencia respecto a la organización es menor.

\subsubsection{Voluntariado de la experiencia o de las competencias}

En algunos países, como Francia, este tipo de voluntariado consiste en poner al alcance de una entidad un saber hacer específico y especializado para llevar a cabo una actividad o misión determinada. Estas fórmulas, por lo tanto, consisten en la realización por parte de personas voluntarias -general, aunque no necesariamente, de forma puntual- de tareas más o menos especializadas que requieren una capacitación profesional media o alta, y que responden a necesidades concretas de las entidades. Difieren de las fórmulas clásicas de voluntariado en la medida 
en que trascienden las actividades genéricas o poco cualificadas que a menudo se encomiendan a las personas voluntarias; se orientan especialmente a personas de cierta edad -de entre 30 y 50 años-con escasa disponibilidad de tiempo y conocimientos avanzados en disciplinas específicas; y se realizan a menudo, aunque no siempre, a distancia (Bazin y Malet, 2010).

\subsubsection{Voluntariado no encuadrado en organizaciones e intercambio de actividades de voluntariado}

El intercambio de actividades de voluntariado toma a menudo la forma de bancos del tiempo. Los bancos del tiempo, como fórmulas de voluntariado recíproco que se desarrollan en el seno de una comunidad, están estrechamente ligados a otras tendencias, como la co-producción o la implicación del voluntariado en actividades de desarrollo comunitario. Es cierto que no se trata de actividades completamente altruistas o carentes de compensación (en la medida en que existe una compensación recíproca por las actividades realizadas), lo que implica una cierta desarticulación de la relación tradicional de voluntariado, pero, al mismo tiempo, también representan una extensión de la acción voluntaria hacia fórmulas más diversas y flexibles. La filosofía de los bancos del tiempo es la de ofrecer la posibilidad de realizar un intercambio de servicios entre las personas que se asocian a ellos, no necesariamente de forma directa o inmediata, sino cuando éstas lo necesiten (Recio, Méndez y Altés, 2009). Según estos autores, se trata de iniciativas estrechamente vinculadas a las ideas de solidaridad, cooperación, comunicación, inclusión e intercambio.

\subsubsection{Fórmulas de voluntariado episódico o puntual}

Se trata de las actividades de voluntariado que se realizan en torno a una campaña o un evento concreto (de hecho, se ha solido hacer referencia a este tipo de fórmulas como voluntariado de eventos). $\mathrm{Si}$ bien es cierto que a menudo estas fórmulas de colaboración están excesivamente ligadas a operaciones de marketing de empresas privadas, a acontecimientos deportivos de carácter masivo y similares, resulta una fórmula interesante para las entidades tradicionales de voluntariado, que pueden tener necesidades extraordinarias en momentos puntuales, y que sólo mediante el recurso a este voluntariado episódico podrían desarrollar determinadas actividades.

\subsection{Voluntariado y diversidad}

Franco y Guilló (2011), alertan sobre la escasa pluralidad del voluntariado y sobre las barreras culturales para la participación de otros grupos sociales más allá de la clase media, de la etnia y la nacionalidad mayoritarias. Las entidades de voluntariado tienen pendiente establecer protocolos de no discriminación que se apliquen activamente en la captación y selección de su voluntariado, en relación a la edad, el sexo, la discapacidad, y la diversidad cultural y de nacionalidad.

Una de las tendencias más notables y evidentes es el creciente interés de las entidades de voluntariado, y de las entidades públicas que las apoyan, por adaptarse a la diversidad social y por ampliar su base de personas voluntarias a colectivos que hasta ahora habían participado en escasa medida en tareas de voluntariado, 0 que habían encontrado obstáculos para participar en ellas. También son numerosas las iniciativas desarrolladas para integrar a otros colectivos en el mundo del voluntariado, como las personas con discapacidad, las minorías étnicas o las personas inmigrantes. Se trata de estrategias con un claro enfoque antidiscriminatorio, en la medida en que se basan en la idea de extender el principio de igualdad de oportunidades al ejercicio de la acción voluntaria, evitando las barreras de acceso al voluntariado que pueden derivarse de determinadas características personales.

\subsubsection{Desarrollo del voluntariado entre personas mayores}

Uno de los ámbitos en los que se ha querido ampliar la base social del voluntariado es, claramente, el de las personas mayores. Esta iniciativa se ha dado a partir de dos consideraciones: por una parte, su creciente peso poblacional y social; y por otra, el creciente interés por el paradigma del envejecimiento activo, en el que el ejercicio de tareas de voluntariado resulta un elemento fundamental. En cualquier caso, este tipo de voluntariado se enfrenta a cierto dilema: desde determinados sectores se apuesta por el desarrollo de entidades y movimientos específicamente formados por personas mayores o dirigidos a prestar servicios a las personas mayores. Por otra parte, sin embargo, se busca una mayor integración -de corte transversal- de las personas mayores en entidades generales de voluntariado, no necesariamente formadas por mayores, y una mayor participación de estas personas en el conjunto de las actividades de voluntariado.

La segunda de las opciones supone un mayor potencial de integración, en la medida en que se basa en una concepción intergeneracional del voluntariado y en que busca implicar a las personas mayores en el abordaje de todo tipo de problemáticas, y no sólo las que les atañen directamente. En este sentido, el papel de las agencias de voluntariado es clave, igual que lo es el desarrollo de nuevas fórmulas de implicación que permitan que las tareas de voluntariado se adapten a las disponibilidades y capacidades de las generaciones de voluntarios de mayor edad.

\subsubsection{Voluntariado joven}

Diversas encuestas apuntan a que la tasa de participación en actividades de voluntariado entre las personas jóvenes no es especialmente alta, a pesar de 
que las iniciativas que se han llevado a cabo en ese sentido han sido muy numerosas. También se han desarrollado de forma particularmente intensa los modelos de voluntariado transnacional, que permiten la realización de actividades de voluntariado -generalmente durante periodos puntuales de tiempo- en países extranjeros, lo que permite combinar el ejercicio del voluntariado con la práctica de idiomas o el conocimiento de otras sociedades, por ejemplo.

\subsubsection{Otros colectivos: inmigrantes, exusuarios/as de servicios, personas con discapacidad}

Numerosas investigaciones ponen de manifiesto que, entre los colectivos más desfavorecidos (personas con discapacidad, en riesgo de exclusión, inmigrantes, personas sin hogar), el ejercicio de tareas de voluntariado es menos infrecuente que en los que pueden considerarse más favorecidos. Así, se han puesto en marcha numerosos programas para integrar a estas personas en el ámbito del voluntariado, a partir de la idea de que el ejercicio del voluntariado puede tener efectos positivos en sus procesos de inclusión social (Commision on the Future of Volunteering, 2008).

En el caso específico de las personas inmigrantes, la Asamblea Parlamentaria del Consejo de Europa (Volontè, 2010) pone de manifiesto el papel que el voluntariado puede jugar como "vehículo para la integración social, cultural y ocupacional” de las personas inmigrantes. "El voluntariado -señala el informe - facilita a las personas recién llegadas un mejor conocimiento de la sociedad de acogida, promueve su participación social mediante la educación formal e informal y refuerza su empleabilidad en el mercado de trabajo. Además, hace más visible la contribución de las personas inmigrantes a la sociedad de acogida". Como en el caso de las personas mayores, existen dos formas de promover el voluntariado entre las personas inmigrantes: el desarrollo de fórmulas de asociacionismo exclusivamente formadas por inmigrantes $u$ orientadas a prestarles servicios 0 a defender los intereses de estas personas; o la búsqueda de una mayor participación de estas personas en el tejido asociativo general.

\subsubsection{La creciente importancia de la co-producción}

En algunos países, como el Reino Unido, se ha dado un creciente desarrollo de la idea de la coproducción. De acuerdo con Prestoff (2009), la co-producción equivale a la implicación ciudadana en la provisión de servicios públicos, y se relaciona estrechamente con los modelos de autodesarrollo comunitario. Según Prestoff, este modelo resulta de la combinación de actividades de los agentes de servicios públicos y los ciudadanos participantes en la provisión de tales servicios. Needham (2009), a su vez, la define como la colaboración entre la persona que utiliza los servicios y el proveedor formal de éstos. Ciertamente, el concepto de co-producción es muy amplio y se pueden distinguir al menos tres acepciones diferentes:

- Un proceso mediante el cual los usuarios de los servicios colaboran con los profesionales en la consecución de los fines de la intervención.

- El desarrollo de programas autogestionados, basados en la ayuda mutua, y en la implicación personal en el desarrollo comunitario, de los cuales pueden ser buen ejemplo las cooperativas de vida independiente o los bancos de tiempo (Boyle, Clark y Burns, 2006).

- La realización de actividades de voluntariado por parte de personas que son, o han sido, usuarias de los servicios de esas mismas entidades de voluntariado.

La co-producción, entendida como el acceso de las personas usuarias o exusuarias a la realización de tareas de voluntariado no es, por tanto, un elemento nuevo en la CAPV y, de hecho, el 70\% de las organizaciones vascas señalan conocer experiencias de procesos por los que las personas usuarias de una organización se convierten en voluntarias (Fundación EDE, 2010).

\subsection{El voluntariado como mecanismo para la inclusión laboral}

El creciente énfasis en las políticas activas de empleo y el amplio desarrollo del paradigma de la activación han tenido como consecuencia una equiparación casi absoluta entre integración laboral e inclusión social, y el empleo -incluso en las épocas en las que las tasas de desempleo eran bajas- se ha considerado el objetivo principal de las políticas sociales. En los últimos años, han sido muy numerosas las estrategias que han intentado establecer un vínculo entre voluntariado e integración laboral.

Por una parte, la realización de tareas de voluntariado se presenta como una herramienta de capacitación y cualificación, de prevención del desempleo, de adquisición de experiencia y, por tanto de generación de capital social, considerado como factor de protección frente al desempleo 4 . Por otra, la participación en actividades de voluntariado se plantea como una solución a las personas que ya están en situación de desempleo o exclusión, en la medida en que se considera que la participación en estas tareas puede ser de utilidad de cara a la inclusión laboral (mediante la mejora de la autoestima, la (re)adquisición de ciertas capacidades laborales, la generación de redes de apoyo social más amplias, la propia adquisición de capacidades y destrezas laborales, entre otras).

${ }_{4}$ El Parlamento Europeo se ha pronunciado recientemente en esta línea, admitiendo que "las capacidades adquiridas con el trabajo voluntario también tienen una importancia considerable en la vida laboral y proporcionan un valor añadido al currículum" y subrayando que "es esencial el reconocimiento de competencias y capacidades obtenidas mediante el voluntariado como experiencia laboral y formativa no formal e informal" (Parlamento Europeo, 2012). 
Según afirman Hardill et al. (2007), el voluntariado se asocia de forma cada vez más clara, al menos en algunos países, con la cualificación y la recualificación para el empleo, despojándosele de su carácter altruista y desinteresado para centrarse más en los elementos instrumentales, es decir, en los beneficios personales que se derivan para la persona voluntaria de la práctica del voluntariado. Esta tendencia a la utilización del voluntariado como herramienta para la inclusión laboral se plantea en ocasiones en términos de contraprestación u obligatoriedad, especialmente en el caso de las personas que perciben prestaciones económicas de garantía de ingresos ${ }^{5}$.

Otra de las estrategias que vinculan el empleo y el voluntariado, aunque de forma más indirecta, es la que pasa por asociar las tareas de voluntariado con cotizaciones a la Seguridad Social, de forma que, si bien no se remuneran como un puesto de trabajo, sí generan ciertos derechos contributivos de cara a la jubilación.

Sin duda, la vinculación entre el voluntariado y la inclusión laboral tiene elementos positivos, pero no está exenta de riesgos, por lo que se ha visto sometida a numerosas críticas. Simonet (2010), por ejemplo, hace referencia al riesgo de "instrumentalización del compromiso” y de precarización que implica vincular voluntariado e inserción laboral, lo que supone, a su juicio, un paso adelante en el desarrollo de lo que denomina "infra-empleo"6.

\subsection{Nuevas relaciones con las administraciones públicas y con la empresa}

\subsubsection{Voluntariado promovido desde las entidades públicas}

En algunos países, se está experimentando con la participación de personal voluntario en actividades realizadas y promovidas desde centros o entidades de

5 En el ámbito de la activación de las políticas de garantía de ingresos, son numerosas las experiencias que establecen contrapartidas o contraprestaciones orientadas a la participación en actividades de voluntariado (que, de esa forma, pierden su carácter voluntario para convertirse en actividades obligadas o semiobligadas). A esta lógica responde, aparentemente, algunas de las líneas de reforma de la normativa vasca en materia de rentas de inserción, en la medida en que se plantea la participación de las personas útiles para el trabajo en actividades de interés comunitario. Al mismo espíritu obedecen los cambios que se vienen realizando en el sistema de prestaciones económicas británico, que establece la obligatoriedad de que determinados perceptores de las prestaciones de garantía de ingresos participen durante un periodo determinado de tiempo en actividades de voluntariado.

${ }^{6}$ Para esta autora, las actividades de voluntariado, entendidas como un trabajo, pueden contribuir a reforzar la precarización de los grupos de población más vulnerables, privándoles del estatus de persona asalariada en el marco de una relación laboral convencional. En este sentido, la autora alerta de la progresiva incorporación del voluntariado en el contexto de los programas de workfare dirigidos a las personas menos cualificadas y a la función que estas actividades voluntarias cumplen para aliviar algunos de los efectos del desmantelamiento de los servicios públicos, mediante la sustitución de empleados públicos, bien pagados y con una fuerte representación sindical, por personal voluntario 0 , incluso, participantes en programas de empleo que no han elegido voluntariamente participar en este tipo de actividades, sino que han sido obligados a ello so pena de perder las prestaciones económicas que perciben. titularidad pública7, especialmente de ámbito local. Este tipo de 'voluntariado público' se enmarca muy a menudo en fórmulas de voluntariado puntual o de eventos, si bien en algunos casos se realiza también con mayor continuidad. En ocasiones, también se relaciona con el concepto de co-producción. En el Reino Unido, la utilización de personas voluntarias por parte de las administraciones públicas está especialmente extendida en ámbitos como las emergencias y la protección civil. Otro ejemplo puede ser el de las agencias conservacionistas del medio ambiente, que cuentan con más de dos mil participantes voluntarios reclutados directamente por las administraciones públicas. El sistema de justicia británico es el ámbito donde más personas colaboran voluntariamente con el Gobierno: 30.000 se sientan voluntariamente en magistraturas similares a la de los jueces de paz, y otras 14.000 colaboran en servicios de apoyo a la Policía. Además, miles de personas voluntarias cumplen un rol muy importante en defensa de los derechos de las personas detenidas por la Policía, o como voluntarias para visitar a los presos en las cárceles.

\subsubsection{Voluntariado corporativo o de empresa}

El voluntariado de empresas es quizá una de las tendencias o innovaciones más analizadas, publicitadas y debatidas en este ámbito, si bien cabe señalar que a menudo se percibe con escepticismo por parte de las entidades de voluntariado. El voluntariado corporativo se entiende como la posibilidad que las empresas ofrecen a sus trabajadores de realizar actividades voluntarias en entidades del tercer sector. Los promotores de este tipo de fórmulas afirman que producen beneficios para todas las partes implicadas -las empresas, sus trabajadores/as, las entidades de voluntariado y el conjunto de la sociedad-. Pero también hay referencias a los riesgos que provoca este tipo de iniciativas: al margen del más evidente -el de utilizar la acción voluntaria como mero reclamo promocional-, también existe el peligro de distorsionar la misión de la entidad sin fin de lucro, y el de convertir la acción voluntaria en un apéndice de la actividad comercial de las empresas. En la literatura consultada también se apunta el riesgo de no casar adecuadamente las capacidades, expectativas y necesidades de todas las partes, así como el carácter puntual de muchas de estas iniciativas, que pocas veces se consolidan como proyectos a largo plazo.

¿Cuáles son los criterios y condiciones que cabe aplicar para el desarrollo de fórmulas de voluntariado corporativo enriquecedoras tanto para las empresas como para las entidades de voluntariado y la comunidad? El informe monográfico editado por el Centro

Esta tendencia no es del todo desconocida en la CAPV. Según la Estadística de Servicios Sociales de Eustat, en 2008 las entidades públicas de la CAPV contaban con un total de 134 personas voluntarias a dedicación plena equivalente. Lo cierto es, en cualquier caso, que el peso de este voluntariado público nunca ha sido importante y que, además, no ha dejado de caer. Si en 1994 suponían el 3,4\% de todo el voluntariado de acción social, en 2008 el porcentaje apenas alcanzaba el $0,7 \%$. 
Europeo del Voluntariado tras su conferencia de 2009 (Storme, 2009), dedicada precisamente a esta cuestión, pone de manifiesto una serie aspectos básicos, que pasan fundamentalmente por establecer un marco de relaciones equilibrado entre la empresa y la entidad sin fin de lucro, y por ajustar, en la medida de lo posible, el lenguaje de las entidades de voluntariado al lenguaje empresarial, para poder asociarse a las empresas que cumplan con sus expectativas.

\subsection{Desarrollo de infraestructuras y medidas de apoyo}

\subsubsection{Desarrollo de agencias y centros de apoyo al voluntariado}

La revisión documental realizada pone también de manifiesto la importancia concedida en los países de nuestro entorno, y por parte de la UE, al desarrollo de agencias y centros de apoyo al voluntariado, ya sea a escala estatal, regional o local. Si bien se trata de iniciativas ya adoptadas a escala territorial en la CAPV -mediante la creación de Bolunta en Bizkaia, Gizalde en Gipuzkoa y Erdu en Álava-, es conveniente hacer aquí una referencia a este elemento, vista, entre otras razones, la importancia que se le da por parte en las entidades que representan al voluntariado a escala europea y estatal.

El desarrollo de una infraestructura de apoyo al voluntariado fue precisamente el objeto de debate del Asamblea General del Centro Europeo del Voluntariado realizada en 2009, en Suecia (Storme, 2009). De acuerdo con el documento marco elaborado, las funciones de las agencias de voluntariado se centran fundamentalmente en los siguientes aspectos:

- Intermediación para conectar a voluntarios potenciales con entidades que requieran de personal voluntario.

- Marketing mediante campañas, eventos y otras actividades de promoción.

- Desarrollo e intercambio de buenas prácticas.

- Actividades de lobby e intercesión ante los agentes políticos para mejorar el apoyo que se presta a las entidades de voluntariado.

- Dinamización de redes de colaboración y coordinación entre las entidades de voluntariado, y entre éstas y las administraciones públicas.

El papel de las agencias del voluntariado se completa con la tendencia a la creación, en diversos países, de unidades especializadas para el apoyo a las entidades del voluntariado dentro de las administraciones públicas.

\subsubsection{El servicio cívico como mecanismo de provisión de voluntarios gratificados}

Dentro de la Unión Europea, en esta tendencia de implantar servicios civiles nacionales para la acción voluntaria destaca la situación italiana, por la avanzada implantación de un sistema que gestiona el servicio civil de todo el país. Italia ha sido un país pionero en poner en marcha un servicio de estas características para las personas voluntarias, dotando de un acceso directo a nuevas personas interesadas en la acción voluntaria, y mejorando el acceso a su formación y su acreditación.

En Francia, los servicios civiles nacionales son de reciente implantación -concretamente, de 2010-, y según afirma Ferry (2008), las diversas iniciativas desarrolladas en este ámbito -incluyendo diversas proposiciones de ley presentadas en el Parlamento por el Partido Socialista- se relacionan claramente con las dificultades de integración social de una parte de la población juvenil francesa y aspiran a cumplir las funciones del antiguo servicio militar obligatorio.

El hecho de que las personas que participan en este sistema -tanto en Francia como en Italiaperciban una gratificación económica, y su vinculación, al menos en Francia, con las políticas de empleo, impide en cualquier caso considerar este tipo de iniciativas, estrictamente hablando, pertenecientes al ámbito del voluntariado. Por otra parte, son obvios los riesgos que se derivan de este tipo de esquemas desde el punto de vista de la confusión entre voluntariado y puestos de trabajo precarios en el tercer sector.

\subsubsection{Otras medidas de incentivación de la acción voluntaria desde las administraciones públicas: incentivos y desgravaciones fiscales}

En los países analizados, se han identificado diversas fórmulas para incentivar o compensar la realización de actividades de voluntariado, si bien no puede decirse que existan en ese ámbito tendencias claras en un sentido concreto. El último informe sobre la situación del voluntariado en Europa (Dirección General de Educación y Cultura, 2010) pone de manifiesto la existencia de diversas fórmulas, como las desgravaciones fiscales por los gastos realizados por las personas voluntarias en el ejercicio de sus actividades (de forma que el rembolso de sus gastos queda exento de tributación, así como, hasta ciertos límites, las remuneraciones o gratificaciones que puedan ser recibidas por las personas voluntarias).

\subsection{Mejoras en la gestión del voluntariado e introducción de sistemas de calidad}

\subsubsection{Mejoras en la gestión del voluntariado: el ciclo} de voluntariado

Folia et al. (2010) explican que hay aún muchas entidades de voluntariado que carecen de una gestión sistematizada de sus procedimientos, lo cierto es que resulta cada vez más habitual introducir mecanismos de gestión de la labor voluntaria basados en 
el denominado 'ciclo de voluntariado'. Trabajar con base en este ciclo implica desarrollar estrategias en, al menos, cinco fases diferentes de la vida o el ciclo que realiza la persona voluntaria:

- Estrategias de captación (y selección) de voluntariado: líneas de actuación que utilizan las organizaciones para captar y seleccionar a personas para que sean voluntarias.

- Estrategias de acogida del voluntariado: líneas de actuación que utilizan las organizaciones para recibir al voluntariado, explicar el funcionamiento de la organización y acompañarlo en sus primeros momentos.

- Estrategias de acompañamiento: líneas de actuación que utilizan las organizaciones para atender las personas voluntarias en la organización.

- Estrategias de seguimiento y promoción del voluntariado: líneas de actuación que utilizan las organizaciones para supervisar el trabajo que realiza el personal voluntario, y para decidir sobre la intervención en tareas de mayor responsabilidad.

- Estrategias de formación continua: líneas de actuación que utilizan las organizaciones para formar a las personas voluntarias en la organización.

- Estrategias de salida: líneas de actuación que utilizan las organizaciones para facilitar que el voluntariado encuentre espacios alternativos para realizar otra acción voluntaria, con el objeto de evitar el abandono.

- Estrategias de vinculación: líneas de actuación para seguir en contacto, y mantener la relación, al menos informativa, con la persona que ha sido voluntaria en la entidad.

El ciclo de gestión del voluntariado proporciona un marco teórico que permite una aproximación gráfica y esquemática al funcionamiento del voluntariado, $y$ aporta una visión global de todo el proceso que debe plantearse una organización a este respecto desde el momento previo a la entrada de una persona en la entidad hasta después de que deje de participar en ella activamente.

\subsubsection{Planificación estratégica, cultura de la evaluación y calidad}

De acuerdo con el Diagnóstico de la situación del voluntariado de acción social en España (Plataforma del Voluntariado de España, 2011: 186), "la planificación estratégica es una herramienta que se va incorporando de forma cada vez más habitual en las entidades sociales y de voluntariado, en especial en las de mayor tamaño. Se trata de una planificación que permite modular el trabajo de la organización para avanzar en sus objetivos estratégicos sin perder de vista sus principios, involucrando a la mayor parte de personas y grupos que la componen".

Son pocas, en cualquier caso, las experiencias relacionadas con la introducción de mecanismos de calidad específicamente destinados a la gestión del voluntariado, o de organizaciones de voluntariado, y habitualmente las entidades de voluntariado recurren a mecanismos orientados a las entidades del tercer sector en general. Desde ese punto de vista, cabe pensar que una de las carencias básicas en este campo es, por una parte, el desarrollo de herramientas de calidad verdaderamente adaptadas a las necesidades específicas de las entidades del tercer sector que trabajan en el ámbito de la intervención social y, por otro, una consideración más específica de los aspectos relacionados con el voluntariado en el diseño de estos sistemas de aseguramiento de la calidad.

\subsection{Trabajo en red y refuerzo de la dimensión local}

En los últimos años, desde las entidades de voluntariado y las instituciones públicas se ha tendido a potenciar el trabajo en el ámbito local, a partir de estructuras de base territorial, basadas muy a menudo en modelos de autoayuda comunitaria que buscan implicar directamente a la ciudadanía en el abordaje de los problemas sociales que afectan a sus comunidades.

\subsubsection{Refuerzo de la dimensión local, autogestión comunitaria y voluntariado de proximidad}

La idea central de la apuesta por la participación ciudadana es que tanto las administraciones como los ciudadanos deben implicarse conjuntamente en la resolución de los problemas que afectan a los barrios, especialmente a los más desfavorecidos. Se trata de una respuesta cívica a los problemas sociales más cercanos que, partiendo de unos pocos, beneficia a toda la comunidad, mejorando los servicios, renovando los barrios y reavivando la democracia.

Son muchas las experiencias que se han desarrollado en ese sentido en el Reino Unido, como consecuencia de la apuesta del anterior Gobierno laborista por el desarrollo de este tipo de redes de autogestión comunitaria a partir de la idea del 'nuevo localismo', que implica no sólo una descentralización de las competencias hacia los ayuntamientos, sino también de éstos a la propia ciudadanía. La idea central de esta apuesta por la participación ciudadana es la de que administraciones y ciudadanos deben implicarse conjuntamente en la resolución de los problemas que afectan a los barrios, especialmente a los más desfavorecidos. Si bien es cierto que esta clase de estrategias han estado sujetas a numerosas críticas, los estudios realizados sobre el desarrollo de este tipo de actividades ponen de manifiesto la conveniencia de este tipo de iniciativas que, adecuadamente diseñadas y desarrolladas, empoderan a las propias comunidades y llevan a la práctica la idea de una ciudadanía activa. El voluntariado constituye un elemento crucial de estos enfoques, en la medida en que se basan en la implicación voluntaria de la ciudadanía en las tareas de desarrollo comunitario. 


\subsubsection{Trabajo en red}

Según el Diagnóstico sobre la situación del voluntariado social en España (Plataforma del Voluntariado de España, 2011: 209), por trabajo en red "se entiende el uso de estructuras, formales o no, que permitan la articulación complementaria de recursos (coordinación), incluyendo el intercambio de información para aumentar su eficacia como entidades". Para De la Riva y Moreno (2002), trabajar en red "es otra manera de trabajar dentro de las asociaciones y en las relaciones en ellas; es una manera de organizarse, de actuar, de compartir la información, de trabajar como un solo equipo cohesionado... No es un cambio superficial, sino una transformación profunda de la cultura asociativa". Para estos autores, el trabajo en red tiene que basarse en los siguientes principios:

- Horizontalidad: la relación entre los colectivos que trabajan en red son 'entre iguales', no vienen determinadas por una jerarquía piramidal. Eso no quiere decir que todas las partes hagan de todo, que las tareas y funciones no estén organizadas.

- Sinergia, trabajo en equipo: cada componente de la red se ve a sí mismo como un nudo, como una parte de un entramado mucho más amplio. Un principio fundamental es la complementariedad de las partes, que permite multiplicar las capacidades.

- Autonomía y relación entre las partes: cada colectivo debe tener plena autonomía en el desarrollo de sus funciones y tareas. El trabajo en red es una forma de trabajo muy descentralizada, con la mayor autonomía posible de cada cual.

- Pertenencia participativa: la ligazón con la red se sustenta en la participación, no sirve simplemente enviar 'representantes' para que informen. La participación activa ha de ser el nexo de unión.

- Compromiso: entendido como asumir responsabilidades y solidarizarse con el proyecto.

- Objetivos comunes: claros y precisos, asumidos por la totalidad de los colectivos que participen.

- Comunicación bidireccional entre todas las partes (multidireccional).

- Construcción y gestión colectiva del conocimiento: el problema no es la falta de información (que frecuentemente es, incluso, excesiva), sino saber elegir la importante y saber gestionarla. Todos sabemos cosas y todos tenemos necesidades, por tanto, el proceso debe ser colectivo. No tenemos que esperar al experto que venga a decirnos lo que hemos de hacer.

- Acción común: el trabajo en red es comunicación y cooperación para la acción, para hacer cosas.

- Simplicidad y flexibilidad organizativa: la organización de la red no es una finalidad; debe ser un medio al servicio de los objetivos.

- Evaluación y aprendizaje: aprendiendo de la propia experiencia, y de la de otros. La evaluación no es un trámite; es una herramienta fundamental para mejorar nuestra tarea.
2.7.3. Atención específica a las entidades de menor tamaño

Las instituciones responsables de la regulación de estas entidades han optado -además de por potenciar el trabajo en red-por apoyar de forma especialmente intensa a las entidades de menor tamaño y, especialmente, a las que trabajan en el ámbito local.

\subsection{Mejora del conocimiento científico relativo a la acción voluntaria}

Uno de los ejes básicos que articulan muchas de las estrategias de promoción del voluntariado es la mejora del conocimiento científico relativo a la acción voluntaria. Si bien es cierto que la literatura y la labor investigadora al respecto es amplia, a menudo se destaca la ausencia de investigaciones rigurosas que permitan dimensionar las características del voluntariado y su impacto económico y social. El Centro Europeo del Voluntariado, en su Manifiesto a favor del voluntariado en Europa (2006: 7), ha puesto de relieve la necesidad de "una mejor comprensión del voluntariado dentro de la UE y la necesidad de estudios comparativos europeos con el fin de obtener datos al respecto". Para Franco y Guilló (2011), el conocimiento científico sobre el voluntariado en nuestro país es escaso, pese a los avances académicos significativos sobre aspectos particulares y los esfuerzos del propio sector en la búsqueda de buenas prácticas.

\subsubsection{Valorar el impacto económico del voluntariado}

Después de un largo periodo en el que el centro del interés investigador se centraba en el número de personas voluntarias y sus características, los esfuerzos se centran ahora en valorar -especialmente desde el punto de vista económico- el impacto del voluntariado, al objeto de alcanzar un mayor reconocimiento político y social. Medir y presentar el impacto económico del voluntariado puede ser una forma eficaz de alcanzar un mayor reconocimiento para el sector, fundamentalmente de cara a las decisores políticos. Tales estimaciones deben ser, en cualquier caso, manejadas con cuidado, y junto a otras herramientas de medición que permitan valorar los impactos intangibles del voluntariado en aspectos tales como la cohesión social, el capital social, el desarrollo personal o el empoderamiento.

En el mismo sentido, desde el Centro Europeo del Voluntariado (2006) se ha hecho un llamamiento a las instituciones europeas y a los Gobiernos nacionales para poner en práctica el Manual sobre las instituciones sin fines de lucro en el sistema de cuentas nacionales (Naciones Unidas, 2007) en sus respectivos sistemas de cuentas nacionales, estableciendo cuentas satélite -como empieza a ocurrir también en lo que se refiere al trabajo doméstico y la atención informal-que proporcionen datos sobre el voluntariado y su valor económico, y que hagan visible la 
contribución del sector sin fin de lucro, y especialmente del voluntariado, a las economías nacionales. En la actualidad, según el Consejo de Europa, al menos nueves países han desarrollado este tipo de cuentas satélites -Australia, Bélgica, Canadá, República Checa, Francia, Japón, Nueva Zelanda, México y Estados Unidos- y otros veinte los están poniendo en marcha en este momento.

\subsubsection{Otros enfoques}

En los últimos años también se ha avanzado de forma notable en el uso de otras herramientas, como las encuestas de uso del tiempo, para un mejor conocimiento de la dedicación de la ciudadanía a las labores de voluntariado. Sin embargo, diversos estudios y planes estratégicos han puesto de manifiesto la ausencia de estudios de tipo cualitativo, que midan las motivaciones y los beneficios que las personas voluntarias obtienen de la práctica del voluntariado, así como el impacto positivo que éste pueda tener en términos de la eficacia y la eficiencia de los programas en los que estas personas toman parte.

\subsection{Voluntariado y nuevas tecnologías: cibervoluntariado}

De acuerdo con Franco y Guilló (2011), lo que se ha denominado 'voluntariado on-line', 'e-voluntariado', 'voluntariado en línea' o ‘voluntariado virtual', puede asumir numerosas tareas, pero requiere de una excelente definición de los objetivos de la acción y del uso del resultado que se va obtener: es decir, enfatizar la tecnología como un medio para un fin, y no como un fin en sí misma. En general, las actividades voluntarias 'a distancia' suponen un reto para la gestión de las entidades de voluntariado de acción social, porque las organizaciones no tienen un programa formal de voluntariado en línea.

El desarrollo de las nuevas tecnologías de la información ha permitido, por otra parte, desarrollar nuevas formas de implicación en la acción voluntaria, basadas fundamentalmente en la realización de trabajos específicos que no siempre se han de desarrollar en la sede de la entidad o en contacto directo con las personas usuarias. Se trataría, en este caso, de una forma de 'teletrabajo' voluntario en el que las personas voluntarias no tienen la misma vinculación con la entidad que las personas voluntarias presenciales.

Junto a este tipo de voluntariado a distancia, se ha hablado también del denominado ciberactivismo. Según varios autores, el ciberactivismo es una herramienta complementaria del voluntariado, que se refiere a las acciones dirigidas a la sensibilización, que utilizan Internet y las redes sociales como forma de divulgar campañas, de sensibilizar a la ciudanía o de mantener el contacto entre los diferentes agentes implicados en una asociación.

\section{Reflexiones y recomendaciones finales}

A tenor de lo leído en la revisión de la literatura científica, se pueden extraer algunas conclusiones con respecto a las tendencias en la promoción del voluntariado. La principal es que no se puede hablar de cambios radicales o de innovaciones determinantes, y que en ocasiones algunos de los cambios que se apuntan están relacionados con el conjunto del tercer sector y no exclusivamente con el mundo del voluntariado.

Cuatro son los aspectos que cabe subrayar, en la medida en que son los que mayor influencia tendrán o están teniendo en la evolución del fenómeno del voluntariado:

- La aparición de nuevas fórmulas de voluntariado, de carácter en general más informal o difuso, si bien en ocasiones se caracterizan, precisamente, por una vinculación personal más intensa (como por ejemplo, en el caso del mentoring o del acogimiento familiar). Sin duda, frente al voluntariado tradicional están emergiendo, y se están fomentando en varios países, nuevas fórmulas de implicación cívica, que suponen una forma alternativa de practicar el voluntariado (bancos del tiempo, redes cooperativas o grupos de autoayuda, entre otras). Todas ellas están muy relacionadas con la búsqueda de fórmulas de autorganización ciudadana, y suponen un cambio respecto a las fórmulas clásicas del voluntariado.

- La aparición del voluntariado cualificado o de la experiencia, el desarrollo de fórmulas de voluntariado de persona a persona, la coproducción, los grupos de autoayuda, y el denominado voluntariado de proximidad, estrechamente relacionado con la tendencia a reforzar las redes de autorganización ciudadana.

- La búsqueda de una mayor diversidad en el seno de las entidades de voluntariado, la eliminación de las barreras de acceso para determinados colectivos y la aplicación de políticas de no discriminación constituyen otras tendencias evidentes, que apuntan en una misma dirección.

- Los riesgos de utilizar el voluntariado como mecanismo para promover la inclusión social y laboral de las personas en situación de desempleo o de exclusión social también resultan evidentes.

De todo lo apuntado, cabe extraer algunas recomendaciones útiles para el desarrollo de las políticas de voluntariado en la CAPV:

- Seguir promoviendo la adopción de planes de calidad y herramientas de planificación basadas en el ciclo del voluntariado, especialmente entre las entidades de menor tamaño.

- Promover la creación de redes de coordinación, especialmente a escala local, que permitan mayores sinergias entre las entidades que trabajan en un mismo territorio. 
- Puesta en marcha de medidas de fomento del voluntariado de proximidad y de las redes de autorganización comunitaria.

- Promover la puesta en marcha de un programa específico para el acceso de personas mayores y de personas inmigrantes a las entidades de voluntariado.

- Puesta en marcha de medidas de apoyo a la implicación como voluntarias de las personas usuarias y exusuarias de esas mismas entidades, $y$ refuerzo de los programas basados en la intervención de pares y en el mentoring, especialmente de carácter intergeneracional.

- Valorar la posibilidad de crear, en colaboración con Eustat, un sistema de cuentas satélite que permitan valorar la aportación económica realizada por el voluntariado en Euskadi.
- Promover el establecimiento de un foro de reflexión sobre el voluntariado corporativo.

- Promover la creación de una bolsa de voluntariado cualificado que permita responder a las necesidades de colaboración especializada que puedan tener las entidades de voluntariado.

- Evaluar la posibilidad de crear, en colaboración con Lanbide, un programa que facilite el acceso de las personas en situación de desempleo o en riesgo de exclusión social a las entidades de voluntariado.

- Puesta en marcha de un proyecto piloto que permita evaluar los efectos de un servicio civil en el País Vasco, mediante el cual pueda ofrecerse a las personas jóvenes la posibilidad de colaborar durante un periodo determinado con entidades sin fin de lucro, a cambio de una gratificación inferior al SMI. 


\section{Referencias bibliográficas}

BAZIN, C.; y MALET, J. (2010): La France bénévole, $7^{\text {a }}$ ed., París, France Bénévolat [«http://www. recherches-solidarites.org/media/uploads/ lafrancebenevole2010.pdf)].

BOYLE, D.; CLARK, S; y BURNS, S. (2006): Hidden Work. Co-production by People Outside Paid Employment, York, Joseph Rowntree Foundation [<http://www.jrf.org.uk/sites/files/ jrf/9781859354674.pdf $)$.

CENTRO EUROPEO DEL VOLUNTARIADO (2006): Manifesto for Volunteering in Europe, Bruselas, Centro Europeo del Voluntariado [<http://www. eyv2011.eu/funding-opportunities/item/ download/30〉].

COMMISSION ON THE FUTURE OF VOLUNTEERING (2008): Report of the Commission on the Future of Volunteering and Manifesto for Change, Londres, Commission on the Future of Volunteering.

DE LA RIVA, F.; y MORENO, A. (2010): Redes asociativas. Sumar fuerzas para multiplicar resultados, serie Cuadernos Prácticos para Asociaciones, Barcelona, Fundación Esplai.

DEPARTAMENTO DE EMPLEO Y ASUNTOS SOCIALES (2011): II Plan Vasco del Voluntariado. Prórroga 2011-2012, Vitoria-Gasteiz, Eusko JaurlaritzaGobierno Vasco [〈http://tinyurl.com/77v6as5〉].

- (2009): II Plan Vasco del Voluntariado 2008-2010, Vitoria-Gasteiz, Eusko Jaurlaritza-Gobierno Vasco [<http://www.euskadi.net/r33-2288/es/ contenidos/informacion/ii_plan_voluntariado/ es_iipvv/adjuntos/II_PVV.pdf〉].

DIRECCIÓN GENERAL DE EDUCACIÓN Y CULTURA (2010): Volunteering in the European Union. Final Report, Londres, GHK [rhttp://ec.europa.eu/ citizenship/pdf/doc1018_en.pdfı].
EUSTAT (2010): Estadística de Servicios Sociales y Acción Social 2008 / Gizarte-zerbitzuen eta Gizarteekintzaren Estatistika 2008, Vitoria-Gasteiz, Eustat.

FERRY, L. (2008): Pour un service civique. Rapport au Président de la République, serie Penser la Société, París, Odile Jacob [<http://www.cas. gouv.fr/IMG/pdf/132825SKV_Civique.pdf〉].

FRANCO, P.; y GUILLÓ, C. (2011): "Situación y tendencias actuales del voluntariado de acción social en España", Documentación Social, $\mathrm{n}-160$, págs. 15-41.

FUNDACIÓN EDE (2010): Informe anual de la situación de las organizaciones de voluntariado en la CAPV 2009, Vitoria-Gasteiz, Eusko JaurlaritzaGobierno Vasco [/http://tinyurl.com/7xhsku8〉].

GOBIERNO DE ESPAÑA (2010): Estrategia Estatal del Voluntariado 2010-2014, Madrid, Gobierno de España [rhttp://www.msc. es/politicaSocial/ongVoluntariado/docs/ estrategiaEstatalVoluntariad02010_2014.pdf>].

HARDILL, I. et al. (2007): “Volunteering for all? Explaining patterns of volunteering and identifying strategies to promote it", Policy and Politics, vol. 35, nํㅜ 3, págs. 395-412.

NACIONES UNIDAS (2007): Manual sobre las instituciones sin fines de lucro en el sistema de cuentas nacionales, serie Manual de Contabilidad Nacional, no 91, Nueva York, Naciones Unidas.

NEEDHAM, C. (2009): Co-production: An Emerging Evidence Base for Adult Social Care Transformation, serie $\mathrm{SCIE}$ Research Briefing, $\mathrm{n}^{0}$ 31, Londres, Social Care Institute for Excellence [<http://www. scie.org.uk/publications/briefings/briefing31/ index.asp >]. 
PARLAMENTO EUROPEO (2012): Resolución del Parlamento Europeo, de 12 de junio de 2012, sobre el reconocimiento y el fomento de las actividades voluntarias transfronterizas en la UE, 2011/2293(INI), Bruselas, Parlamento Europeo, puntos 35 y 36 .

PLATAFORMA DEL VOLUNTARIADO DE ESPAÑA (2011): Diagnóstico de la situación del voluntariado de acción social en España, serie Informes, Estudios e Investigación, Madrid, Ministerio de Sanidad, Política Social e Igualdad [<http:// www.msc.es/politicaSocial/ongVoluntariado/ docs/diagnosticoSituacionVoluntariado.pdf>].

PRESTOFF, V. (2009): “Gobernanza democrática, coproducción y tercer sector en la provisión de servicios sociales en Suecia”, Panorama Social, no 9, págs. 147-158.

RECIO, C. et al. (2009): Los bancos de tiempo. Experiencias de intercambio no monetario, serie Acción Comunitaria, nํㅜ 10, Barcelona, Editorial Graó.

SIIS CENTRO DE DOCUMENTACIÓN Y ESTUDIOS (2011): Tendencias, innovaciones y buenas prácticas internacionales en el ámbito del voluntariado, Donostia-San Sebastián, Fundación EguíaCareaga [<http://www.siis.net/documentos/ ficha/197485.pdf〉].

SIMONET, M. (2010): Le travail bénévole: engagement citoyen ou travail gratuit?, serie Travail et Salariat, París, La Dispute.

STORME, A. (2009): An Enabling Volunteering Infrastructure in Europe: Situation, Trends, Outlook. Final Report. Conference Conclusions. Malmö, Sweden, CEV General Assembly Conference, 15-16 October 2009, Bruselas, Centro Europeo del Voluntariado [<http://issuu.com/ european_volunteer_centre/docs/101027_ gareportmalmoe_internet>].

UNIÓN EUROPEA (2011): Año Europeo del Voluntariado 2011. ‘Hazte voluntario! Marca la diferencia' [<http:// europa.eu/volunteering/〉].

VOLONTÈ, L. (2010): Promoting Volunteering in Europe, Estrasburgo, Consejo de Europa, 2010 [<http:// assembly.coe.int/Documents/WorkingDocs/ Doc10/EDOC12430.pdf>]. 



\section{Normas de presentación de originales para Zerbitzuan}

- Zerbitzuan está abierta a la publicación de artículos sobre servicios y políticas sociales por parte de profesionales, investigadores, representantes institucionales y de todas aquellas personas interesadas en las políticas de bienestar social.

- Todos los artículos deberán ser inéditos y girar en torno a los ejes temáticos básicos de la revista (servicios sociales y políticas de bienestar social, participación social, inmigración, pobreza y exclusión social, discapacidad, atención a las personas mayores, infancia y menores en situación de desprotección, drogodependencias e intervención social en general). Una vez recibidos, los artículos serán sometidos a la consideración de los miembros del Consejo de Redacción, que decidirán sobre su publicación de acuerdo a criterios de calidad científica y oportunidad editorial.

- Una vez aceptados los artículos para su publicación, la dirección de la revista se reserva el derecho de modificar el título y epígrafes de los textos, así como de realizar las correcciones de estilo que se estimen convenientes, de acuerdo con las normas de estilo de la revista.

- Los artículos se enviarán en un documento de Word y por correo electrónico.

- Los artículos pueden redactarse tanto en euskera como en castellano, y serán publicados en el idioma en el que se reciba el original.

- Desde el punto de vista formal, se ruega atenerse a las siguientes pautas:

- La extensión del contenido de cada artículo será de entre 6.000 y 15.000 palabras, contando las posibles tablas, cuadros, gráficos y bibliografía. Se ruega adjuntar sólo las tablas y gráficos que se consideren imprescindibles.

- En la primera página, se hará constar el título del artículo, el nombre del autor o autores, su dirección y teléfono de contacto, así como su adscripción institucional. Se añadirá también un breve resumen o sumario del artículo (máximo 150 palabras) y cinco palabras clave que describan el contenido del texto. El resumen y las palabras clave irán en castellano y euskera.

- Las citas o notas irán a pie de página.

- Las referencias bibliográficas de los artículos seguirán las Normas ISO 690/1987.

La dirección y teléfono de contacto de la revista son los siguientes:

Zerbitzuan

SIIS Centro de Documentación y Estudios

SIIS Dokumentazio eta Ikerketa Zentrua

General Etxague 10 bajo

20003 Donostia-San Sebastián

Tel. 943423656

Fax 943293007

publicaciones@siis.net 


\section{피타|ㅣㅡㅁAN}
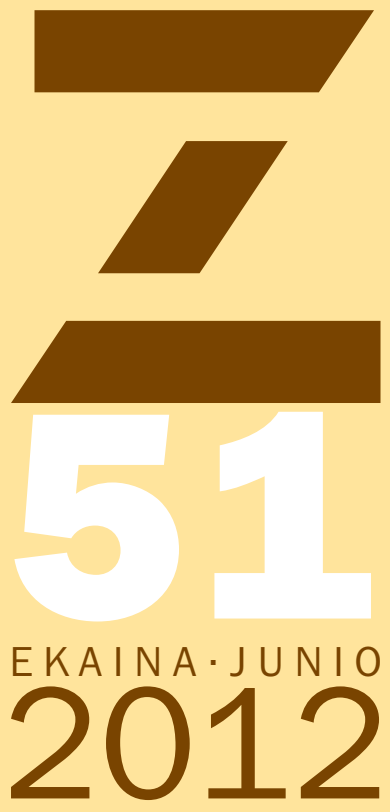

Los servicios sociales frente a la exclusión

Estrategia Europa 2020 e inclusión social: distanciamiento creciente entre objetivos, políticas e instrumentos

Aktibazioa eta gizarteratzeko eskubidea, EAE-ko enpleguko eta diru-sarrerak bermatzeko politiken esparruan

Las empresas de inserción social en un contexto de cambios sociolaborales. Un análisis crítico de su regulación desde la normativa vasca y estatal

La medida de la empleabilidad en las empresas de inserción en el País Vasco: de la exclusión a la inserción sociolaboral

La identidad profesional de los trabajadores sociales como elemento clave en el acceso a los programas de rentas mínimas: el caso de Catalunya

Revisión de estudios de costeefectividad en servicios de atención comunitaria y atención centrada en la persona

Envejecimiento y deterioro de las personas con discapacidad intelectual de Lantegi Batuak en el ámbito ocupacional y del empleo en Bizkaia

Tendencias, innovaciones y buenas prácticas internacionales en el ámbito del voluntariado

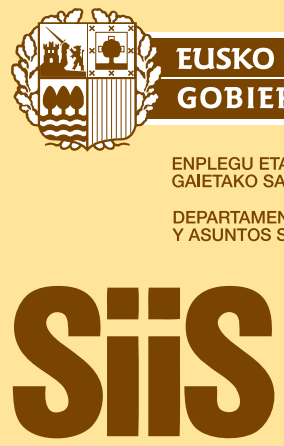
JAURLARITZA GOBIERNO VASCO

NPLEGU ETA GIZARTE TEPARTAMENTO DE EMPLEO ASUNTOS SOCIALES 